Music/ology: A Baradian Account 


\title{
Music/ology: A Baradian Account
}

\author{
Proefschrift \\ ter verkrijging van de graad van doctor aan de \\ Universiteit van Utrecht \\ op gezag van de \\ rector magnificus, prof. Dr. H.R.B.M. Kummeling, \\ ingevolge het besluit van het college voor promoties \\ in het openbaar te verdedigen op
}

vrijdag 24 januari des middags te 16.15 uur

door

Jantje Pranger

geboren op 15 mei 1956

te Beilen 


\section{Promotoren:}

Prof. dr. Karl Kügle

Prof. dr. Iris van der Tuin 


\section{Contents}

$\begin{array}{ll}\text { Acknowledgements } & 6\end{array}$

$\begin{array}{ll}\text { Introduction } & 7\end{array}$

1. Music-Drastic or Gnostic? Traversing the Question 20

1.1. Abbate's Plea: A Close Reading 23

1.2. Flight of Meaning, Wishing for Grounds 33

1.3. Drastic and Gnostic: An intimate Relationship 47

1.4. The Abbatean Drastic: Initial Condition 58

2. Music, Musicology, and Their Relationship: Problems of Connectivity 62

2.1. Metaphysical Mania and Different Metaphysics 66

2.1.1. Gnostic and Drastic: Reading Music $\quad 68$

2.2. Christopher Hasty: Musicking and Experiencing 70

2.2.1. Musicking: The Concept and a Metaphysical Problem 73

2.2.2. The Use of Metaphysical Insights 77

2.2.3. Experiencing the Drastic 81

2.3. Georgina Born: Relational Musicology 86

2.3.1. The Shackles of Two Conceptual Boundaries 88

2.3.2. Differences: Preconditions for a Relational Musicology 91

2.4. Benjamin Piekut: Gathering Together 96

2.4.1. Latourian Thinking and Piekut's Argument 98

2.4.2. Piekut's Argument: Two Readings 101

2.4.3. Method and Metaphysics 103

2.4.4. Importing Dualisms 106

2.4.5. Reconceptualising Concepts: The Abbatean Plea 107

$\begin{array}{ll}\text { 2.5. Conclusion } & 110\end{array}$

3. Agential Realism: The Ethicality of "Spacetimemattering" 114

3.1. Abbate and Barad: Shared Insights 117

3.2. Agential Realism: The Bohrian Fold 123

3.3. Agential Realist Reconfigurings: Objectivity and Subjectivity 134

3.4. Diffraction: Method and Methodology 138

3.4.1. Diffraction: Implicated in Practices of Research and Theorising 141

3.4.2. Diffraction Supersedes Reflection 145

3.5. Studying Entangled Being Diffractively 151

3.5.1. Diffraction: The Intricacies of Studying Phenomenal Being 155 
3.6. The Metaphysics of an Agential Real 159

3.7. Material-discursive Practices: Traversing Disciplinary Thresholds 163

3.8. Onto-epistemology: The Ethical Call 172

3.8.1. The Intra-active Relationality of Barad's Ethics of Mattering 176

3.9. The Inhuman: The Ethics of Entangled Being 183

$\begin{array}{ll}\text { 3.10. Conclusion } & 188\end{array}$

4. Musicality: An Intra-active Musico-material Encounter 191

4.1. Abbate's and Barad's Arguments: The Limits of Diffractive Reading 192

4.2. Questions that Permeate Barad's and Abbate's Insights 202

4.2.1. Causality: Causal Intra-actions 211

4.2.2. The Silence of the Cabinet 218

4.2.3. Intra-actions: Ghostly Causality 225

4.3. Musicality and the Drastic: Musico-material Agency 233

4.3.1. Musical Agency: An Enacted Doing of Intra-active Responsivity 236

4.4. Musicality: The Ethics at the Heart of Musico-mattering 240

4.4.1. Musicality: Responsivity, the Speculative, and Material Aliveness 247

$\begin{array}{ll}\text { Conclusion } & 253\end{array}$

$\begin{array}{ll}\text { Bibliography } & 259\end{array}$

Summary $\quad 277$

Samenvatting (Summary in Dutch) 279

$\begin{array}{ll}\text { Curriculum vitae } & 281\end{array}$ 


\section{Acknowledgements}

Throughout my research and the writing of this dissertation I have received a great deal of support and assistance. I would first like to thank my supervisors, Prof. Dr. Karl Kügle and Prof. Dr. Iris van der Tuin, for the freedom they gave me to explore my ideas. Their expertise and trust in me were invaluable in the formulating of my research topic and in the fusing of my musicological research with my intuited knowledge of music-making as a singer.

I would like to acknowledge Dr. Paul van Emmerik, who introduced me to Carolyn Abbate's work. I also want to thank my friend, physicist Dr. Rainer Gruber, for our discussions, which deepened my insights into Karen Barad's approach to physics. I also acknowledge and thank Dr. Rick Dolphijn for the Contemporary Cultural Theory seminar series (with Prof. Van der Tuin), which constituted my entrance into the intricacies of new materialisms. Further gratitude goes to the inspiring reading group, the "Barad Bond," with Alex Hebing, Freya de Mink, and Peta Hinton. The planning and outline of my research benefitted from our fine conversations and the exploration of challenging texts from our individual research areas.

I also want to thank the various employees of Utrecht University, the Faculty of Humanities and the Department of Media and Culture, whom I met during my research and who made me feel very much at home. I wish to thank Sophie Chapple and Nina Bresser for supporting me in the final production of this dissertation, editing my text and providing crucial comments. I thank Tomoko Mukaiyama, Arda Risselada, Florine Wiebenga, and Peter van Bergen for staying with me, listening to my new materialist reports, whilst continuing to pose their artist's questions. Finally, I wish to thank Rom Gaastra, my artist, my love, for his everlasting support. 


\section{Introduction}

The impetus for this dissertation grew from my interest in the complexity inherent in the dynamic "doings" involved in making music and in musicological research and theorisingdoings that seemed more attuned to the provisional and the speculative, than to the presumptive representational stability of musicality, its language and ideas. The concepts "provisional" and "speculative" here are meant to express the intrinsically exploratory nature of making music, of "doing" and theorising musicological research. Both engaged me as physically sensed actions, albeit that seemed to me only partially determined, anticipating a not fully determined purpose. In short, I encountered the dynamics of musical and musicological "life," the aliveness of actions, and of the material presence of making music and doing musicology; an aliveness indifferent to, or left unaccounted for, both by musicians' performance routines and by musicological representations. (In the present context, I understand routines as functional actions based on a belief in what is perceived to be, musically and physically, the right course of action; representations share with routines the assumption that music is a pre-existing phenomenon that can be accessed via symbolic means). These may seem bold statements, driven largely by a local and personal experience. However, as this dissertation engages precisely with questions of material aliveness and relationality in the context of the "ordinary life" of routines and representations, I propose that we do not move on too quickly. Let us instead pause for a moment, and reflect.

I have spent many years of my life on stage, as a classically trained, professional singer specialising in twentieth-century and twenty-first-century music. As a singer I trained my voice, I learnt to improvise, to read scores, to "read" an acoustic space, to collaborate with composers and other musicians, and to perform for the public-all situations (usually) characterised by complex yet obvious difficulties that one must learn to overcome. I say "obvious," because of an assumed clarity, not only of the goals to be reached, but also of how I was supposed to act-how to fulfil (and invent, and reconfirm) aesthetic norms as well as

other norms, for example, how to sing well to ensure the body's well-being. Herewith I mean the processual, step-by-step nature of a performer's craft, which is built on skills, intuitive knowledge (that is, the residual memories as embodiments of the musical, lived, and acted), 
and felt cause-and-effect patterns-in short, a craft from which I can tell how music is made and how music works. At the same time, as a musicologist, I learnt to aim for practical clarity based on consistent reasoning and a reliance on representations, in which music's temporal and dynamic reality is captured and represented by symbols and graphics, via which music can be analysed as a social and cultural artefact. However, such a clarity of process and goal does not conceal an uneasy discrepancy between the speculative dynamics of musical reality (the material aliveness and my "being there") and how I, as both a musician and a musicologist, learnt to capture "that" reality—not only in routines that make music doable, but also in representations that make music thinkable.

Admittedly, most musicians and musicologists are familiar with the above discrepancy between the stability of representations on the one hand, and the unstable material activity involved in making and thinking music in performance on the other, trusting their respective skills and scholarly discipline whilst accepting it as an inconvenient truth. Notwithstanding this tacit acceptance, I consider musical and musicological practices to be potentially haunted by the danger that routines (representing accepted musical values and facts) and representations (representing accepted musicological values and facts) take precedence over the provisional and speculative aspects of both practices. The more so when recognising that routines and representations are social and historical constructions framed as musical and musicological expressions of the past. A few simple questions related to my experiences as both a musicologist and a singer may illustrate the difficulty involved: What is excluded from research and theorising when provisional and speculative aspects (involved in material and musical "doing") of composing are not considered in studying a composition? Is a composition not more than just a "work," but rather, an inseparable part of a compositional, material, and musical practice, with all the material and musical uncertainties and coincidences that entails? What becomes excluded or, for that matter, included when practices of singing in tune are considered as nothing more than a technical matter, oriented towards the simple goal of producing a predefined frequency? Are not 
singing a pitch and the notion of singing "correctly" inseparable aspects of a performance as a material and musical practice? ${ }^{1}$

Although this introduction starts from my personal musical and musicological interests and experiences, the philosopher and writer Henri Bergson ([1889] 1910) defined the accepted discrepancy between dynamic reality (denoted in his work as "time" and "the unextended") and its representations (denoted as "space" and "the extended") as a real problem that might present us with serious difficulties. As Bergson ([1889] 1910) cautions: "When an illegitimate translation of the unextended into the extended, of quality into quantity, has introduced contradiction into the very heart of the question, contradiction must, of course, recur in the answer" (xix). Pointing to the necessity of intuitive knowledge"knowledge which establishes itself within the moving reality and adopts the life itself of things" (Bergson [1934] 1946, 227)—Bergson argues for philosophical and scientific precision, which takes account of the dynamics of material and temporal being.

More than a hundred years later, the question "Music-Drastic or Gnostic?" posed by the musicologist Carolyn Abbate (2004) articulates a similar Bergsonian problem, this time with regard to musicological scholarship. Abbate (2004) addresses the relationship between musical and musicological knowing and being, expressing her anxiety that attempting to capture the drastic (the unextended, time, and dynamic musical reality) through the gnostic (the extended, space, thinking, and symbolic representations) constitutes a serious problem at the heart of musicological scholarship. For Bergson ([1912] 2004), when failing to start from intuitive knowledge, the danger resides in "many lame answers to badly stated questions" (45). Whilst for Abbate (2004), it is clear that we must explore the dynamics of making music—referred to as "music-as-performed" (532)—although this might exhaust musicology's scholarly possibilities. ${ }^{2}$ For Abbate, there is no other option, since not turning to music-as-performed would undermine musicology's very existence. Simultaneously,

\footnotetext{
${ }^{1}$ The notion of practice, throughout this dissertation, entails a going together of specific material and meaningful actions, producing specific music or specific musicological knowledge. Practice in the form of repeated exercises, used in musical training, will be discussed in chapter 3.

${ }^{2}$ When referring to Abbate's (2004) conception of music's dynamic reality, I will use her term "music-asperformed" (532).
} 
however, she questions whether musicology is even capable of representing music-asperformed (Abbate 2004, 505). In short, with the question “Music—Drastic or Gnostic?” Abbate draws attention to a seemingly incompatible relationship: If music-making is a drastic occurrence, where does this leave musicologists with their ambitions to think, know, and thus stabilise a dynamic musical world? Conversely, if music is gnostic, where does this leave the speculative and unforeseeable nature of a particular event? For Abbate, music is drastic - generated by doings, such as playing, singing, listening, and by the doing of the experiencing body affected by music. In contrast, the musical gnostic concerns the knowledge of music and the cognitive aspects involved in gaining such knowledge. Thus, creating a divide in which the gnostic and the drastic are incompatible, Abbate first queries, then reaffirms a stalemate that, she suggests, is in the nature of things: The musical drastic is out of reach of the musical gnostic. Therewith, in its final consequences, Abbate announces the death of musicology.

Taking account of the close relationship between Abbate's question-a plea for a serious musicological attention to music-as-performed-and the insights of Bergson, I take Abbate's (2004) musicological and philosophical intervention as an apt starting point for a musicological exploration of the musical drastic in its relation to the assumed gap between knowing and being. This exploration is based on my experiences as a singer and a belief in the necessity of a musicological, scholarly account of today's rapidly changing musical practices of listening, producing, and performing, against the background of this age-old dichotomy. The overall effort of this dissertation is to traverse the Abbatean stalemate, theorising a music/ology as gnostic in drastic. Traversing suggests movement, which in this context implies traversing musicology, portrayed by Abbate as a transcendental illusion. It entails examining responses of the musicological field to her article, which suggest new lines of thought by considering a positive relationship between the drastic and the gnostic. This demands a turn towards practices of musicological research and a theorising that pays due attention to the material generativity of (musical and musicological) reality. Thereby, we necessarily also take notice of the ontological, epistemological, ethical, and aesthetic implications of both musical and musicological practices. 
Further deepening my exploration of the relationality of musical and musicological being and knowing, I subsequently turn to the work of the physicist and feminist theorist Karen Barad, who emphasises (and here I adhere to Abbate's terms) how knowing and being are both drastic, and that representational stabilisation is profoundly drastic as well-that is, material and temporal. Barad (2007) explicates this through her metaphysics of an agential real—a performative account of how matter comes to matter (in its double meaning)—in which matter is considered an active, relational, and generative doing. Barad's thoughts on relationality and inseparability, involving the inseparability of being, knowing, and valuing, are inspired by the physicist Niels Bohr's (1958) question of how to give an unambiguous account of quantum experiments. Bohr observes how measurements of atomic and subatomic behaviour demonstrate that concept and material setup are entangled: To measure the position of a particle, the concept position is materialised in the apparatus with stable parts. Whilst measuring momentum, however, one finds that an apparatus with moving parts is needed. Starting from Bohr's materialised concept, defined thus by the material and discursive circumstances of taking measurements, Barad (2007) elaborates the inseparability of the material and the discursive in the object of research, the agencies of observation, and their relationship. Thereby she succeeds in traversing classical notions of transparent measurement (or, in general, observational) conditions, which are based on a nature-culture binary, with the assumption that "observation-independent objects have well-defined intrinsic properties that are representable as abstract universal concepts" (Barad 1998, 95).

These issues will be pursued at greater length. For now, they point to a fundamental feature of Barad's thinking (enabling us to traverse the Abbatean drastic-gnostic dichotomy). In Barad's (2007) often quoted terms: “Matter and meaning are not separate elements. They are inextricably fused together, and no event, no matter how energetic, can tear them asunder" (3). Asserting the inseparability of the material and the discursive, Barad shifts the representationalism—-musical reality considered independent of its representationsinherent in Abbate's (2004) oppositional stance. Barad's notion of the inseparability of matter and meaning does not recognise the individual and isolated entity, but rather starts its inquiry from their relationality. This also shifts my study into Abbate's eventual stalemate 
position, which is caught in a representationalist frame. Rather than focussing on a collision between arguments, which suggests commencing from predefined domains, Barad's insights invite us to question these very boundaries and properties, searching for concepts that structure insights (of both Abbate and Barad) and their relationship. My Baradian approach to Abbate's plea for a serious musicological study of musical performance softens the stalemate position of Abbate's argument, emphasising how something lingers in her musicological struggle with drastic musical being that rather announces, in Barad's (2007) terms, how we (musicologists and our thinking) are of a musical world.

Barad's thinking might be considered as falling into the (very broad) field of new materialism, given her focus on the nature of matter and materialisation. Similarly, both Abbate's more recent arguments (reiterated in a modified form in Abbate 2016, 2017) and the reactions from the musical field to her initial question demonstrate their embeddedness in a general urge to take material practices, and the physical, serious (again). Such a renewed attention to the material and the dynamic we also encounter in the new materialist focus on matter-and the humanist neglect thereof-necessitating a reconsideration of the position of the human observer. This has resulted in many fine publications that build on feminist research and theorise the relationship between nature and culture (Alaimo and Hekman 2008; Barrett and Bolt 2013; Coole and Frost 2010; Dolphijn and Van der Tuin 2012; Kirby 2017). ${ }^{3}$ Coming from very different backgrounds (the humanities, the natural sciences, and the social sciences), new materialist approaches cannot be gathered under a single denominator-hence the plural form of the noun in the title of Diana Coole and Samantha Frost's (2010) edited volume New Materialisms: Ontology, Agency, and Politics. In the same vein, Rick Dolphijn and Iris van der Tuin's (2012) demonstrate in New Materialism: Interviews and Cartographies that very different voices are gathered together under the name of new

\footnotetext{
${ }^{3}$ For feminist research and theorising, the materiality of bodies and nature has long been a productive site, interrupted by a turn towards the role of language in the constitution of reality, emphasising how "discursive practices constitute the social position of women" (Alaimo and Hekman 2008, 1). New materialism, as a general term, indicates a renewed attention to ontology and the relationship between nature and culture in feminist research and theorising. This (specific) feminist materialism challenges the anthropocentric practice of humanism, which suggests that knowledge, being, and value are predicated upon the "human [observer] in its Renaissance iteration" - that is, taking the human as the measure of knowing, being, and valuing to the exclusion of all Others (Panurgiá 2018, 44).
} 
materialism. What these voices share is an ontological and epistemological concern with rethinking and re-searching the relationship between the human, the nonhuman, and the (material) Other. In my own research, I similarly hope to contribute to a new materialist take on music and musicology.

However, more so than other new materialist voices, Barad nullifies any thinking that starts from the ability to isolate object and subject. In other words, she challenges precisely the Abbatean gap between the drastic object and the gnostic subject, arguing for the inseparability of matter-meaning, based on the thesis that we are of the world that we attempt to understand and help to create. Barad thus shifts the notion of human engagement with the world-implicating a predefined difference between the human and the world-to the notion of knowing as an inseparable part of the world's (re)configurings. Barad's (2007) inseparability thesis suggests that, when knowing is a practice that matters (again, in its duplicity), the relationality between knowing and being becomes inherently ethical, as research and theorising involve that which is included and excluded from mattering. Knowing, being, and valuing are inseparably bound together; an entanglement that Barad (2007) articulates via the concept of ethico-onto-epistemology.

Structured by the insights of Abbate and Barad, this dissertation explores ontological immanence (traversing the Abbatean binary) and its consequences for musicological research and theorising. Barad's metaphysics of an agential real shifts a metaphysics of things and ideas, theorised and researched as entities in predefined time and space-a metaphysics that, as I will argue, underlies Abbate's argument. In contrast, Barad's agential real proposes an ontology of radical immanence, taking seriously the nature of ongoing material differentiation in which "things" and "thoughts" emerge through and within relationsrelations that include "us." In other words, Barad does not recognise the existence of individual entities with inherent properties, ready to be observed and analysed by (detached) humans. Barad's notion of radical immanence therefore implies a real, indeed radical epistemological and ontological shift. Consequentially, this dissertation's attention turns, amongst other things, towards the necessary reconceptualisation of relationality as implicated in scholarly notions of objectivity, subjectivity, and causality. 
When it comes to epistemological matters, a Baradian metaphysics of radical immanence necessitates a different methodology and different methods to think musical dynamic being from within. This suggests an undoing of the illusory transcendental stability (as questioned by Abbate) from which we think music. Barad elaborates Donna Haraway's (1997) concept of diffraction as a methodology (that is, a theory of how "we" engage with the world as an inseparable part of the world) and as a method (pointing towards the actions involved in theory and research). Barad's diffractive approach, respecting the prerequisite of radical immanence, does not start research and theorising from a fixation on binaries and boundaries. Agencies of observation and objects of observation, subjects and objects, are not fixed terms in which one is a referent for understanding the other. Rather, this dissertation's diffractive methodology and method, following Barad (2007), "involves reading insights through one another in ways that help illuminate differences as they emerge" (30). Diffraction is both a physical phenomenon, referring to the behaviour of waves when they combine and overlap, and a method of reading insights together. It shifts emphasis from questions of comparing the one to the other, to questions of how differences (identities) get made, paying attention to "what gets excluded, and how those exclusions matter" (Barad $2007,30)$. Barad $(2010,255)$ gives the example of two stones that drop into a pond simultaneously. Through the disturbance, waves overlap or are cancelled out when meeting, resulting in the formation of a new pattern of crests and troughs. In this example, diffraction involves the meeting of waves. The diffraction apparatus are the stones dropping into the water, causing the disturbance; the resulting wave form is the diffraction pattern and sum of the effect of waves meeting. The effect is inseparably entangled with the diffraction apparatus. Therefore, diffraction as both method and methodology is a material doing (and metaphorically, too, it (re)configures the world). It brings into focus relationality as generated by, and generative of, matter and meaning formations, reformulating the ontology of knowing and "the ethics of mattering" $(2007,36)$.

The example of waves meeting might be used to demonstrate how notions of meaning and intelligibility are not exclusively used in terms of human consciousness. From Barad's (2007) perspective the material and the discursive are fused together. This suggests 
that human subjectivity and human culture become decentred, not as predefined entities, but as emergent matter-meaning components that are an inextricable part of nature and its diffraction apparatuses. It is in the nature of the disturbance resulting from two stones dropping into a pond (the diffraction apparatus) and in the nature of waves that meet (diffraction) that wave components are considered responsive, both materially and meaningfully-how they are generative of mattering or not-mattering (resulting in a diffraction pattern). Therefore, this dissertation is orientated towards the performative aspects of diffraction and the intricacies of "the doing" of knowing and valuing in being.

Traversing Abbate's stalemate through the encounter with Barad's metaphysics of an agential real, I propose a music/ology as knowing in being, which necessitates a transdisciplinary exploration. My diffractive approach of reading together the insights of Abbate and Barad emphasises in musicology, philosophy, feminist scholarship, and in my experiences as a performer those issues that resonate with the relationality between the drastic and the gnostic (Abbate's terms), or matter and meaning (Barad's terms)—all within the dynamics of, respectively, music-as-performed and an agential real.

To evidence the impact of the shift in research and theorising as proposed by Barad's ethico-onto-epistemology for musicology, I elaborate upon Abbate's oppositional difference and the field's responses to it. This will bring into focus the epistemological, philosophical, and musicological underpinnings of Abbate's argument. The selected responses to Abbate's drastic versus gnostic opposition offer various strategies for overturning the devaluation of music's material and temporal dynamics. These responses and arguments also serve to expose the difficulty that, when attempting to escape a binary logic by starting from a divide, a backdoor for such logic to return is created. Further, reading Abbate and Barad diffractively, I attempt a music/ology. Although elements of disclosure, exposure, and demystification feature in this dissertation, emphasis is placed on diffractive reading as an affirmative engagement that is productive for my exploration of musicological knowing and valuing in being. This exploration issues how (musical) ethics is at the heart of musical, material, and dynamic production. Theorising ethics as valuing that lies at the heart of musico-mattering, I re-evaluate the concept of musicality as an enactment from within 
heterogeneous musico-materiality. The reworked concept of musicality is a "valuing" (involved in performing, producing, and listening to music) that is responsive and enabling responsivity to the music-material exploration of the indeterminacies of an (materially and socially) enfolded musico-material practice.

Musicality is commonly considered an added value (an acquired quality), based on a conventional and stable concept of music: A thing or person is considered to have a particular quality or a felt worth. Reworked, however, value becomes inseparable from material-discursive Baradian intra-activity through and within which value emerges as temporal stability; as the effect of valuing. Barad's (2007) term intra-action points towards an action from within a relationality through which entities emerge, rather than an action between predefined, independent entities, as suggested by interactivity. Valuing is thus not a calculation (added value) or a recognition of predefined values, but is inseparable from touching as relationality to the Other, who is "always already integral to the world's ongoing intra-active becoming and not-becoming" (Barad 2010, 265). Hence valuing is inseparable from ethics, as it operates on the brink of (musical) mattering or not-mattering. This reworked concept of musicality implicates a concept of music as a temporal thickening; a holding together of sonorous matter as the effect of specific musico-material responsiveness.

\section{Overview of the Dissertation}

The first two chapters expand on Abbate's (2004) question "Music—Drastic or Gnostic?" as an oppositional difference and the field's responses to it. The discussion is based on responses that react to Abbate's article directly (Berger 2005), and responses that affirm the drastic-gnostic dichotomy as elaborated by Abbate, yet suggest other consequences and solutions (Born 2010a; Hasty 2010a; Piekut 2014).

Before turning to the reaction of Karol Berger (2005), chapter 1 starts by stating the phenomenological, philosophical, and musicological underpinnings of Abbate's argument. Abbate follows the philosopher Vladimir Jankélévitch's (2003) notions of the drastic and the gnostic as a relation between the ineffable and the thinkable. However, I argue that Jankélévitch's insights are suffused with a phenomenologically inclined Bergsonism that 
positions the human as the standard for experiencing the musical world, thus affirming a fundamental gap between the human and the world. The chapter continues with Berger's (2005) reaction to Abbate's article. Berger takes the famous argument of Carl Dahlhaus (2000) on the foundations of musicology-i.e., the aesthetics of the musical composition-as a touchstone to mark Abbate's plea for a serious musicological account of music-as-performed as diverging from this Dahlhausian scheme. Reading Berger's argument on Dahlhaus and Abbate together, I nuance Berger's notion of divergence in terms of placing composition and performance in opposition, arguing that Dahlhaus and Abbate share a search for musicological ground in changing times. Dahlhaus seeks to counter the "socialist" approach of German universities between the 1960s and the 1980s, and proposes to ground musicology in the work itself, considered here as the unified aesthetic outcome of a composer's hand. Conversely, Abbate seeks to counter new musicology's linguistic turn of the 1980s and the 1990s by arguing for musical performance as musicology's "natural" setting.

In chapter 2, I present three reactions to Abbate's article by the musicologists Christopher Hasty (2010a), Georgina Born (2010a), and Benjamin Piekut (2014). These scholars all affirm Abbate's critique of musicology's inability to capture the dynamic and temporal reality of musical performance. In a positive way, affirming the urgency of Abbate's plea, these musicologists present alternatives for musicological research and theorising into the dynamics of musical performance and the expanded setting of music as a global and technological phenomenon. However, I will argue that, although the epistemological and ontological positions of these scholars are varied and sophisticated, they all miss a crucial point regarding the real traversal of the drastic-gnostic dualism. That is, their arguments do not meet the musicological challenge to engage with-in either theory or research—music's dynamic, material, and temporal nature. Hasty (2010a) combines process philosophy with phenomenology, which issues a break-as does Abbate, via her Jankélévitchian phenomenological take-between human perception and the musical world perceived, whilst Born (2010a) widens the methodological apparatus in tandem with a similarly widened musicological domain. However, Born embarks on her research and theorising from within bounded fields, definitions, and categories, thus putting herself in the 
Abbatian gnostic position of the human who stabilises the world, creating a point of view at a distance. Piekut (2014) follows Latour's actor-network theory (ANT), but does not consider Abbate's (and Barad's) key questions of identity and relationality, remaining instead with the Latourian suggestion of a human observer who is entitled to arrange matter and meaning.

Chapter 3 engages with Barad's (2007) metaphysics of an agential real, complicating Abbate's assumed oppositional difference between the drastic and the gnostic. As Barad's metaphysics is detailed and complex, the entire chapter engages with her insights, providing an introduction to her thinking in the context of musicological scholarship. Moreover, the chapter serves to further illuminate Barad's notion of diffraction, both as a methodology and as a generative method of reading insights together. After discussing Barad's metaphysics and methodology, chapter 3 concludes with her elaboration of ethics. Barad's ethics relates to her notion of intra-active mattering, which states how entities and their abilities to act emerge from within their relationships. In an agential realist sense, intra-active mattering is unstable, suggesting new connectivities, inclusions, and exclusions of things that come to matter (or not). That is, a politics of valuing is introduced according to which things are not predefined and bound to "natural" processes of unfolding. Rather, Barad's elaboration of ethics concerns a valuing from within that literally matters; ethics and justice become an inseparable part of the indeterminacy of material differentiation. Its exploration here is important, even more so as in the next chapter, I elaborate on the aspect of (musical) value as a politics of musicality. I suggest this is also a matter of musico-ethics, in which the question of music or not-music is inextricably linked with the question of musical specificity as an emergent factor within and through musico-material intra-activity (music-as-performed).

Finally, chapter 4 is devoted to a diffractive reading of Abbate's and Barad's insights. Taking into account Abbate's more recent articles (Abbate 2016, 2017), I argue that a material turn (as suggested by Abbate) in which the intimacy of musical matter is acknowledged, does not resolve the dichotomy between the drastic and the gnostic. Reading Abbate and Barad together, I propose a music/ological approach to music-as-performed. I rework the notion of musicality, not as a natural "given" or a talent possessed, but rather, as musico- 
material responsivity, allowing for a musicological leap into the dynamics of music-asperformed. Whilst the Abbatean concept of the drastic emphasises "doing" as perceived from a defined (phenomenological) standpoint, musicality concerns a generative relationality: A musico-material "differencing" in motion without a predefined foundation. I suggest that touch (the musical toucher and toccare) and care (the durational effort of staying with the tone) involve temporal stabilisations, as effects of valuing and ethics (that which matters or that which does not-matter), and of which one is an inseparable part. This concept of musicality is implied by a music/ology as thinking from within musico-material dynamics, suggesting that music-making and music/ology are diffracted, musico-materialdiscursive practices. 


\section{Chapter 1}

\section{Music-Drastic or Gnostic? Traversing the Question}

It is a question posed in a moment of quiet restlessness, at midnight, when there is no longer anything to ask. It was asked before; it was always being asked, but too indirectly or obliquely; the question was too artificial, too abstract. Instead of being seized by it, those who asked the question set it out and controlled it in passing.

-Gilles Deleuze and Félix Guattari, What is Philosophy? (1994, 1)

This chapter introduces the main problem of my dissertation, namely, the musicological challenge to come to terms, via theory and research, with music's dynamic, material, and temporal nature. Framed as Carolyn Abbate's (2004) statement "Music—Drastic or Gnostic?," it connotes a classic musicological problem—one that may at first seem to be an epistemological question of how to know music beyond the familiar objects of its cultural and social sedimentations. In a few tests that underline her argument, Abbate seeks the intimacy of the musical encounter as performer and listener; she closes in on the epistemological question of where we touch on music in the flesh, either through bodily experience or intellectual reasoning. In a broader sense, considering the material aspects of sound and how music is threaded through the lives of people, animals, and the things that surround us, the question's ontological aspects must be considered (Deleuze and Guattari 
[1980] 2004, 330). ${ }^{4}$ Another important aspect is the sheer scope of the question: You only have to replace the word "music" with "reality," and immediately we enter into the scholarly and scientific quandary concerning the dynamics of worlding, representation, and their complex relationships. ${ }^{5}$ This qualification reveals how I consider the musicological challenge to be part of a broader philosophical concern, thus leading my inquiry into other disciplinary fields in due course.

In chapters 1 and 2, I introduce the difficulty of conveying music's dynamic ontology, and how musicologists have engaged with this difficulty. I am guided here by the work of Abbate (2004), who passionately articulated the problem faced by musicology, phrased as "Music-Drastic or Gnostic?" Abbate does not explicate these concepts in terms of their etymological and historical traces. Rather, she uses "drastic" to express how both making and listening to music involves an intense and intimate dynamic with immediate bodily effects. For listeners, this concerns the emotions felt, and for performers, the labour and perseverance that is needed to make music. For Abbate, these bodily effects connote an essential aspect that cannot be accounted for by the academic "gnostic," which she defines as the human intellect that operates from a distance. This aspect of music is most apparent when attending a live performance in the togetherness of listeners and performers, which Abbate terms "music-as-performed." Similarly, I will use the term "drastic" with a leaning towards feeling, effort, and intimacy when confronted with music, and "gnostic" as representing human reasoning about music from a distance. When Abbate thus speaks of performance, she points towards the coming together of music, listeners, and performers. In general, I will follow Abbate's concept of performance in the first two chapters-that is, as the liveliness of doing within an event considered fixed in time and space.

\footnotetext{
${ }^{4}$ Following Deleuze and Guattari ([1980] 2004), music-making is not an exclusively human affair. We cannot claim sole ownership of a concept of music: Birds sing, animals listen and, moreover, animal parts are used to make musical instruments that "sing." In short, Deleuze and Guattari's interest in the musicality of animals is not an anthropomorphic error, but rather invites us to reconsider the question of music in terms of all Others. As Barad (2012d) puts it, we can use "the anthropomorphic moment ... not to reiterate the habits of projection, but rather, in fracturing the presumptions of the 'anthropos' of anthropocentrism ... opening up a space for response" (27).

${ }^{5}$ The verb "worlding" articulates how the world is not a passive stage for actions to occur, but rather, is an ongoing materialisation of which humans, their actions, thoughts, and languages are an inseparable part (Barad 2007, $180 \mathrm{ff}$.).
} 
Presented as a question of binarity, Abbate poses the musical drastic as a problem of implication; there is no way of detaching oneself from the musical drastic, whereas academic standards dictate a distancing, scholarly gnostic. Abbate $(2004,511,543)$ illustrates this by two simple tests in which she tries to answer her question "Music-Drastic or Gnostic?" whilst playing the piano, and whilst attending a live performance. I consider these two tests to be nodes where Abbate's and my own arguments meet. As a singer, I value the importance of Abbate's turn towards the practice of making music and listening to music herself, however simple and informal, as they are tests that inform her argument. The particular thoroughness and commitment of Abbate's argument enable me to take up the leads that she offers and, in doing so, to complicate the relationship between the drastic and the gnostic. In other words, I use Abbate's article as a starting point and guide to set the stage for the main issues addressed in this dissertation. I closely follow the ambiguous twists of Abbate's argument-how it engages with the pleasure of musical experience, and how it gets caught up by it whilst simultaneously acknowledging the scholarly pressure to cut that cord. Furthermore, I seek tendencies that might allow for a "going beyond" any implied stalemate. In chapters 3 and 4, I will turn to the feminist materialism of Karen Barad in order to rethink the drastic and the gnostic as intimately entangled.

Therefore, the aim of my intervention throughout this first chapter is not to formulate a critique that might overrule Abbate's argument, nor do I locate Abbate's approach as a particular perspective and part of general musicological performance research and theorising. For now, though critical on many occasions, my overall analysis of the Abbatean question seeks the junctures and the disconnections present in her argument that point to, or obstruct, an altogether different understanding of the dynamics of music and the difference between the (so-called) unstable drastic and (so-called) stable gnostic. As such, I relate Abbate's argument to the following issues:

(1) The references to the work of the philosopher and musicologist Vladimir Jankélévitch, introducing, though unacknowledged by Abbate, the work of the philosopher Henri Bergson; 
(2) the response of the musicologist Karol Berger to Abbate's article and that response's centrality to musicological discourse;

(3) a discussion, adducing Bergson's dualisms and Niels Bohr's concept of complementarity (an inspiration for Barad), of how Abbate's strict dualism also harbours a different understanding of the relationship between the drastic and the gnostic;

(4) a consideration of how staging the gnostic and the drastic, considered as oppositional, opens the door to the two-world logic of representationalism (Barad $2007,194){ }^{6}$

\subsection{Abbate's Plea: A Close Reading}

Well over a decade ago, Abbate (2004) confronted musicological scholarship with a ringing question: "Music—Drastic or Gnostic?" Questions about the nature of music have been, and will continue to be, asked. Not only scholars and scientists, but all of those for whom music plays an important role in their lives may puzzle over its ontological status: What is music? However, I will not ask the ontological question per se.? Although Abbate's question seems to be straightforward, she does not refer to any absolute, definable phenomenon. Rather, her question concerns the relational being of music, in which music is "drastic" in its relation to listeners and performers, and "gnostic" in its relation to musicologists. Crucially, her question and its implied answer do not achieve the stillness of something settled, but rather

\footnotetext{
${ }^{6}$ Representationalism is based on the notion of a separation between a world of language (the symbolic), and a world of things, with the assumption of transmitting a homologous picture of reality (based on correspondence) to the knowing mind (Barad 2007, 194).

${ }^{7}$ For an elaborate bibliography on the philosophy and ontology of music, see the work of Andrew Kania (2014). Strictly speaking, the notion of ontology as referred to in the lemma authored by Kania entails the difficulty of defining music as an ontological, propertied entity. This dissertation, however, issues a relational ontology that considers (music's) being within and through relationality, building on feminist materialisms and in particular Barad's (2007) notion of onto-epistemology (see chapter 4).
} 
concern the stating of a problem. At first sight, this problem may be considered to represent the Cartesian dualism of body and mind: the body being caught up in music via the senses, whilst the mind is considered the means by which to know music. This understanding implies that eventually, the mind is the faculty that gives proof of the existence of a musical world. As such, Cartesian doubt is introduced as an overwhelming faith in the reasoning mind as the quintessential means to arrive at a true knowledge claim about musical reality. Doubt as a method of reasoning thus functions to produce the Cartesian cogito (ergo sum), whilst the unruly senses may easily deceive the mind as to the true nature of, in our case, music (Cimini 2012, 353).

Following Jankélévitch, Abbate (2004) depicts the drastic as "physicality, but also desperation and peril," as it is open to the experiences of performers and listeners (510). Simultaneously, she describes the musicological gnostic as "not just knowledge per se but making the opaque transparent" (510). From this it follows that Abbate's question foremost involves an epistemological difficulty pertaining to the relationship between experiencing and knowing (live performed) music, in which the nature of music seems a stable object. She explicates that knowledge can be obtained through bodily experience (drastic), but that this-once translated into words-only allows for a subjective knowledge that hardly seems to be of any value according to the "universalizing endemic in academic discourse" (536). As such, Abbate confronts her readers with the inconvenient situation in which "real" music, deemed musicology's very raison d'être, is actually out of reach for serious gnostic exploration.

Considering its primarily epistemological basis, Abbate's (2004) question regarding the nature of music seems to be rhetorical, rather than an exclamation calling musicologists to account for musical performance-a rhetoric that lives "in its material form as real music, the social event that has carnal effects" (534). As such, her article also expresses a moral idea-“shouldn't we write about performed music and not about a 'work'?" (505). She also presents a passionate love for "music-as-performed" (532), in which morality and love are 
articulated as the dilemma of the impossible choice: "Drastic or Gnostic?"8 This seemingly straightforward question thus entails a real doubt as to whether music can be truly known by academic means, whilst at the same time advocating calm towards the envisaged loss of "music-as-performed" as an object of scholarly research and theorising (521). However, referencing Deleuze and Guattari's epigraph, things remain far from settled. Abbate's ambiguity as to the consequences of affirming the proposed binary between the drastic and the gnostic supposes that she does not "control the question in passing," but rather passes on to her readers an open struggle (one familiar to musicologists) that articulates a friction between music and musicology.

The rhetorical nature of Abbate's question generates a persuasive power to convince musicologists of her justified critique of Joseph Kerman's 1985 call “for a disciplinary revolution in musicology," with the promise to "divert musicology towards criticism and hermeneutics and away from composer biography, archival history, and strict formalism" (Abbate 2004, 506). Kerman's book Contemplating Music (1985), referred to by Abbate, might be considered one of the earliest challenges to open up musicology (of the post-World War II years, in particular as practiced in the United States and Canada) to the new discourses of poststructuralism that were burgeoning in the wider domain of academic scholarship. ${ }^{9}$ Musicologist Susan McClary ([1991] 2002) nuances the effect and purpose of Kerman's book by stating that it was not so much a call to revolutionary action, but instead "designated a provisional space [for those] within the profession [who] already started working in these

\footnotetext{
${ }^{8}$ See Lydia Goehr (1992) on the work concept: "[M]ost of us tend . . to see works as objectified expressions of composers that prior to compositional activity did not exist. We ... treat works as ... original, unique products of special, creative activity. We assume ... that the tonal, rhythmic, and instrumental properties of works are constitutive of structurally integrated wholes that are symbolically represented by composers in scores. Once created, we treat works as existing after their creators have died, whether or not they are performed or listened to at any given time" (2).

${ }^{9}$ Poststructuralism and structuralism are concepts too comprehensive to fully cover here. For my argument it will suffice to note how structuralism concerns a worldview that considers language and meaning as based on and controlled by an overarching, fixed, system, whilst poststructuralism is a worldview that considers the constructed nature of language and meaning. Poststructuralists accept difference between meanings, however not in the structuralist sense as different against a foundational system, but as effect of hierarchical and power structures, introducing mobile, social and cultural factors of meaning formation. See also Sally Macarthur's (2010) work on the 1980 change, in which musicology became "new" musicology. Macarthur especially discusses musicology's opening up to a feminist politics of music (99 ff.).
} 
areas" (xiv). Even so, Kerman's promise of a new musicology entails a preference for the mind's volatility as an inexhaustible resource for the production of opinion and hermeneutic interpretation. The main address of Abbate's (2004) article is the musicological shortfall, in which performances—-in terms of music-as-performed-“were to remain in large part as marginal to criticism or hermeneutics as they had been to formalism, biography, history, or theory" (506). ${ }^{10}$

However, Abbate (2004) does not dismiss hermeneutics (a musicological approach centred on interpretation as part of musicological research and theorising), nor formalism (a musicological approach centred on analysing the inner structures of individual compositions). Rather, her critique concerns new (hermeneutic) approaches that pursue musical meaning by venturing beyond materiality and musical embodiment, or that attempt to research performance whilst relying on interpretations within a social and cultural framework with the score as the main point of entry. According to Abbate, these approaches bypass music's temporal reality and the drastic (performative) aspects of making and listening to music: "[T]here is something about the objective mode that seems to protest too much, bypassing the uncanny qualities that are always waiting nearby in trying to domesticate what remains nonetheless wild" (508). Regarding these new hermeneutics, her conclusion is that performance remains to be considered as simply "another object awaiting decipherment, a recordable text subject to some analytical method yet to come" (513).

The loud call for a musico-logical engagement with live performance, together with the smothering effect of the insuperable difficulties- “[ $t$ ]here is no a priori theoretical armor" (Abbate 2004, 510)—to represent, through thinking (and writing), the non-representative determination of musical becoming, forms the tenor of Abbate's argument. She casts the inconvenient question into the musicological arena whilst re-staging the drama of

\footnotetext{
${ }^{10}$ Abbate refers, amongst others, to Suzanne Cusick, who is committed to an "embodied criticism," but is criticised by Abbate (2004) for not writing "about an actual performance" (506). Abbate points here to the increased musicological attention to performance, however analysed within the frame of the written composition (see Godlovitch 1998; Rink 1995; Taruskin 1995). Similarly, Nicholas Cook and his research into recordings is criticized, by Abbate, for considering performance (as recorded) in the name of "works" and interpretations (Abbate 2004, 507). Abbate points to how, despite musicology's attention to performance, nothing was really changed, as analyses were still based on composer and performer biographies, documents and scores.
} 
musicology's "ungraspable" — that is, the dynamic reality of music-as-performed. We see this in her counter suggestion in which she proposes that we consider the question of "why the academic discourse devoted to music . . is comfortable with the metaphysical and abstract and uninterested in the delivery systems that bring music into ephemeral phenomenal being" (513, emphasis added). I consider this question as pointing to the "why" of the Cartesian gap, its pragmatic and humanist framework of thought, and the resultant exclusion of music-as-performed from research and theorising-a subject I will explore further in chapter 4. Furthermore, Abbate urges us to scrutinise "the clandestine mysticism involved in musical hermeneutics" (513), in which her use of the term "clandestine mysticism" suggests how musical forces active during performance are relocated through a "passionate metaphysics" in writing, whether acknowledged or unacknowledged (514). In addition, Abbate suggests exploring new audio technologies, questioning how, through inscription devices, the labour and carnality of performance is relocated "in the physical motion and material products of machines" (514). I take up this suggestion in the final chapter, too, discussing Abbate's later articles, "Sound Object Lessons" (2016) and “Overlooking the Ephemeral” (2017). Abbate's (2004) last proposal for a musicological account of the reality of music-as-performed affirms her acknowledged scholarly interest in "vanished live performances" and "perpetually absent objects" (514). ${ }^{11}$ These proposals attempt to inquire into a musical reality that is not reduced to meaning, and form the heart of her argument. However, they also hint at how the absence of music's reality constitutes the object of musicological scrutiny, thus assuming a difference between an ungraspable real musical world on the one hand, and its cultural traces on the other. As I will argue, this opposition obstructs further inquiry into the nature of the drastic-gnostic dichotomy and the exclusions it effects.

\footnotetext{
${ }^{11}$ Music in its absence - that is, studying the traces of a music that once was there-plays an important role in Abbate's musicological work. For example, in Unsung Voices, she seeks "something extra in music" that cannot easily be defined, and consists of voices that are not sounds in themselves, but which she considers to be bodies "vibrating with musical sound" (Abbate 1991, 13, emphasis in original). Additionally, in "Debussy's Phantom Sounds," Abbate (2001, 145-184) demonstrates her fascination with how music speaks through silence. In "Overlooking the Ephemeral" (Abbate 2017), the efficacy of music is central when studying silent film and how bodies move on music that was there during recording, but cannot be heard by the audience.
} 
Abbate's (2004) loud and clear plea, and especially its conclusion, with a timid acceptance of the "mortality [of any musical performance], refusing to look away" in order to recognize the temporality of all being, is for her the maximum attainable for musicological research and theory (536). Accepting the musicological discourse of the 1980s, as well as Abbate's concern for live performance-specifically her critique of (new) hermeneutics-I will now focus on some of the other levels on which her analysis operates: The philosophical question of the relationship between the drastic and the gnostic, and her connection with Jankélévitch and Bergson. It is to this latter connection that I shortly turn, as it involves an inclusive relationship and theoretical commitment palpable throughout Abbate's "MusicDrastic or Gnostic?" article, as well as throughout her later work (see Abbate 2016, 2017), which will be discussed in chapter 4 .

Music and the Ineffable (Jankélévitch 2003) is Abbate's translation of Jankélévitch's La Musique et l'Ineffable, originally published in 1961. Her 2004 article might best be considered as a further exploration of Jankélévitch's thinking. Indeed, the question of the drastic and the gnostic, the exceptionality of music as a temporal art, and the difficulty of speaking of music are all themes explored by Jankélévitch (see also Gallope and Kane 2012, 217). However, more is happening here. Although Abbate does not refer directly to Bergson, his thinking has a strong resonance in Jankélévitch's work and consequentially, his influence can be seen in Abbate's work. ${ }^{12}$ However, the dualist aspect of Jankélévitch's Bergsonism is not unproblematic in relation to my project and its search for an onto-epistemology of musical performance. ${ }^{13}$

\footnotetext{
12 Jankélévitch's commentary on Bergson in Henri Bergson (2008), the revised edition of Bergson (1931), shows his admiration for Bergson's work on time and its relation to music-for instance, how the evolution of Bergson's thoughts throughout his oeuvre attest to his work on duration (durée). As Jankélévitch (2008) suggests, the way in which Bergson's oeuvre evolves, constitutes a condition for reading it, analogous to the notion that "[I]'ordre temporel n'est pas un accident de la sonate, mais son essence elle-même" [the temporal order is not an accident of the sonata, but its very essence] ( 3 , translation mine). This is to say that the temporal order of Bergson's thoughts evolves, like music, through a retroaction of the present through the past and into the future. Furthermore, as Bergson ([1889] 1910, 100) states in Time and Free Will: An Essay on the Immediate Data of Consciousness, both "past and present" are melted into one another, as is the case when we recall the notes of a tune.

${ }^{13}$ The neologism onto-epistemology concerns an early announcement of Karen Barad's metaphysics of an agential real, which marks the inseparability of ontology and epistemology as the study of entangled practices of (musical) knowing and being.
} 
The philosopher and film theorist John Mullarkey (1999) suggests that Bergson's work operates on numerous levels and is thus open to several interpretations, amongst which we might distinguish two main directions. The first direction outlined by Mullarkey follows the requirements of a "naturalistic process philosophy" (11) as one that considers nature processually, of which the human is an inseparable part, following an inner, nonteleological, generative dynamic. The second orientation in Bergson's thinking-upon which Jankélévitch's Bergsonism is built—aligns itself with a phenomenological perspective (11), considering the human as the first-person perspective for exploring reality. In ontological and epistemological terms, the first orientation tends to imply a knowing from within reality, where knowledge is intuited. The second orientation understands the human knower as detached from reality through the operation of perception. ${ }^{14}$ In other words, importing Jankélévitchian Bergsonism into her argument emphasises the dualist tension within Abbate's "drastic or gnostic" question. I will pause here for a moment to examine in more depth the phenomenological leaning of Jankélévitch's interpretation of Bergson's thinking, as it is precisely this that prevents Abbate from traversing the drastic-gnostic dichotomy. Despite not being able at this point to give a detailed account of Jankélévitch's rich phenomenological discourse, I address that which is of greatest importance for understanding his Bergsonism, namely, the phenomenological perspective as the starting point for observing a (musical) world.

Written in the period 1900-1901, Logische Untersuchungen [Logical Investigations] by Edmund Husserl—commonly considered as the "founder" of phenomenology as a distinct philosophical discipline-addresses conscious experience as consisting of different types of experiences, such as seeing, hearing, imagining, thinking, emotional feeling or desiring, but also embodied intentions, such as the playing of music (Woodruff Smith 2013b). The

\footnotetext{
${ }^{14}$ Van der Tuin (2011) illuminates Bergson's work on the concept of intuition. She argues that Bergson distinguishes between intelligence and intuition as oppositions. However, read together with Barad's notion of the inseparability of matter and meaning, Van der Tuin (2011) suggests that the Bergsonian concept of intuition might be read as how "matter envelops meaning, and meaning matter" (32). Thinking further along this line, we might think of how the Abbatean drastic and gnostic are inseparably threaded through one another. However, Abbate as well as Jankélévitch draw on Bergson's dualist tendency, differentiating between the one who perceives, and that which is being perceived, thus rehearsing the opposition between the gnostic (perception) and the drastic (the musical world to be perceived).
} 
experience of first-person observation (the "I" who listens to music) and the intention towards the object (e.g., music) are prominent assumptions in phenomenological research and theorising, suggesting that the way in which " $\mathrm{I}$ " (the individual) experiences-by seeing, hearing, conceptualising, or understanding—defines the object's meaning. In Husserl's Logische Untersuchungen, musical meaning is always more than can be articulated through language, because meaning is also constituted through environmental and other, implicit conditions of experience (Woodruff Smith 2013a, 260).

However, this does not downplay the fact that the phenomenological project is primarily founded on how the world appears by virtue of the gnostic effort of my thinking, imagining, interpreting, and intending. Consider how Abbate (2004) interprets the gnostic as how music is perceived by the thinking " $\mathrm{I}$ " as a musicologist, and the drastic as how music is perceived by the feeling "I" as a listener or performer. Both of these perspectives are addressed in Maurice Merleau-Ponty's ([1962] 2005) Phénoménologie de la perception, in which the phenomenologist discusses the important role of the body in human experiences, considering the senses as indivisible parts of the body. Whilst there remains the norm of a predefined (human) perceiver "standing before," and distinct from, the object of observation, this perspective does not overlook the supposed connection between body and world. In Merleau-Ponty's ([1962] 2005) own words, he considers how "[o]ur own body is in the world as the heart is in the organism: It keeps the visible spectacle constantly alive, it breathes life into it and sustains it inwardly, and with it it forms a system" (235). We also see this idea expressed in the work of Michel Serres ([1985] 2008), who adds movement and connection with the world, stating that "[t]he mind sees, language sees, the body visits" (304). However, although in both Merleau-Ponty's and Serres's work the phenomenological project thus widens, it does not escape the necessity of an observer as the norm for (human) experience. Serres's phrase implies a mobile, embodied, sensitive being, inseparably fused with a mind, language, and sight. His widened frame of perception introduces the complexity of experience, which cannot be reduced to a singular sense of listening when experiencing music. This is because, whilst listening, the musical body "quivers beneath waves of sound" at the same time as it smells a perfume; touches a fabric; sees the complex landscape of an 
orchestra, a band, an audience, a dancing public, a film; sees the familiar circumstances of a home; or—if moving — sees a landscape in motion; or tastes a sweet or a drink, whilst all the time past occurrences and feelings enter through the action of memory (Serres [1985] 2008, 306). Yet this perspective still serves the dualist phenomenological idea of a predefined subject and (human) norm of experience, leaving the (musical) object of perception bleak.

This aspect of "lived through" experience (Merleau-Ponty [1962] 2005, xxi), performed by the "I" who experiences by thinking, feeling, and listening, is brought into focus in Jankélévitch's (and Abbate's) idea of the drastic and the gnostic, albeit with a peculiar reversal. ${ }^{15}$ As Jankélévitch (2003) states, “[m]usic acts upon human beings, on their nervous systems and their vital processes .... This power ... is in the case of music particularly immediate, drastic, and indiscreet" (1). Here, the phenomenological, experiencing subject is affected by the musical object of experience in a way that does not "tap the logistical or governing aspects of the mind but rather engages the mind's entire psychosomatic element" (Jankélévitch 2003, 2). Following Jankélévitch, this would bring the phenomenological "I" to the edge of being able to "live through" — that is, to cope with the musical force that affects a listening body. However, it also mystifies the object of experience as that which can be felt, but not known. Nevertheless, the phenomenological subject—in other words, the normative "I" who observes-is present at the scene of performed music. Abbate's (2004) conclusion is that "[r]eal music, the event itself . .., is what damps down the gnostic" (532). Thus, according to Abbate, music is drastic for listeners and performers who do not have to (or who cannot) give an account of their actions, and gnostic for musicologists, who are obliged to passive attendance at a distance. The consequence is that for both, music remains a mystery.

Concluding, the phenomenological inclination of Jankélévitch's Bergsonism sketches a musical world that is observed from a predefined, normative standpoint that leaves the

\footnotetext{
${ }^{15}$ It is the experience of "[w]hen an event is considered at close quarters, at the moment when it is lived through, [that] everything seems subject to chance" (Merleau-Ponty [1962] 2005, xxi). In Abbate's (2004) terms (and those of Jankélévitch), this would be the drastic experience, which connotes "physicality, but also desperation and peril, involving a category of knowledge that flows from drastic actions or experiences and not from verbally mediated reasoning" (510), which would imply a gnostic perspective, starting from symbolic means.
} 
observer with an overwhelming, yet unsayable experience. Normativity supposes here that the human observer is the absolute reason for a musical world, albeit one that simultaneously remains unknown to that observer. To unravel this puzzle woven into Abbate's (2004) article, we need to turn to the "other" Bergson—the one who, through his method of intuition, enables a situation in which the drastic and the gnostic can meet. Moreover, this Bergson—that of intuitive knowledge-opens up the possibility to relate the debate Abbate initiates concerning musicology and its problem of including music-asperformed in academic research models, to Barad's insights concerning a non-dualist ontoepistemology. Following Jankélévitch's phenomenological interpretation of Bergson's thinking, which assumes a predefined observer before a musical unknowable world, Abbate does not buy into intuition as a serious musicological method for meeting a musical world. ${ }^{16}$ Thus, at this level also, Abbate's argument repeats the dualism.

Since its publication in 2004, the focus of responses to her article has changed. Initial reactions first and foremost engage with Abbate's argument, considering it an attack on failed musicological scholarship. Lawrence Kramer (2004) refutes Abbate's stalemate position by pointing to how metaphor and metaphysics "can never be avoided ... [and] are deeply interrelated" (10). Ian Quin (2006), a self-proclaimed formalist, rejects Abbate's argument on how the drastic damps down the gnostic, arguing that the "two attitudes are not complementary but orthogonal and intersecting" (286). However, a turn to representational flexibility, serving interpretative mobility, and to pragmatic and common sense, fails to address the serious emphasis that the Abbatean question places on the

\footnotetext{
${ }^{16}$ Jankélévitch (1996) states: "All Bergsonianism is a rejection of distant idols, which divide the actor and the spectator. ... [I]s not intuition, which is both gnostic and drastic, defined as sympathy and commitment? That's it - to be committed, and nothing else. Not to give lectures on commitment, nor to conjugate the verb, nor commit oneself to commit oneself, as men of letters do, but really to commit oneself by an immediate and primary act, by an effective and drastic act, by a serious act of the whole person; not to adhere halfheartedly but to convert passionately to the truth, that is to say, with one's entire soul .... It is hardly the case, however, that the vicious and frivolous, superficial and mean person constantly realizes this natural vocation of life" (550, emphasis in original). We see here how Jankélévitch affirms Bergson's intuition, although it is not in the nature of the human and involves sustained effort, and is unlikely to be successful. Whilst Jankélévitch's translator, Ann Hobart, speaks here of "Bergsonianism," I will remain here with the now more common term "Bergsonism" as a general reference to Bergson's theories in the English language.
} 
representational, material, and performative nature of musical and musicological practices and their relationship. To my knowledge, Berger (2005) is the only one who takes up the challenge of a serious response in this context, considering Abbate's plea as part of a broader musicological impetus to study musical performance. Other reactions to Abbate's plea take the form of short references in sections addressing a wide range of topics. This is not particularly surprising, considering, as I have and will demonstrate, that her article can be read in various different contexts, such as, in case of this dissertation, phenomenology, Jankélévitchian Bergsonism, or as a plea for serious musicological attention to music-asperformed. In the years that followed, responses to the issues Abbate raises are more concerned with questions about performance and with research that addresses the relationship between human and nonhuman elements engaged in the dynamics of musical creation. Amongst these responses are texts by Benjamin Piekut, Christopher Hasty, and Georgina Born, to which I turn in chapter 2. In the following section, however, I shall turn to Berger's response to Abbate's plea.

\subsection{Flight of Meaning, Wishing for Grounds}

Berger's elaborate response to Abbate's article is grounded in his introduction of the work of the German musicologist Carl Dahlhaus. In the article "Musicology According to Don Giovanni, or: Should We Get Drastic?," Berger (2005) opens his response to Abbate by situating her musicological interest in live performance as a divergence from the hermeneutic tradition of music history, taking the work of Dahlhaus as a touchstone. Berger criticises Abbate for overemphasising "the opposition between the real performance and the imaginary work" (497). For Berger, hermeneutics and formalism are "an indispensable component of any such [drastic] experience" (497). He further argues that "the hermeneutic element cannot be wholly banished from the arena of performance," stating that "we are hermeneutic creatures through and through" (497). With this statement, Berger is probably referring to a general understanding of the nature of human beings—-to always seek 
meanings, connecting them to the environment. In his reading, Berger fully endorses Abbate's insistence "that we do not bypass the immediate, sensuous experience and sacrifice its carnal and spiritual effects in our professionally motivated eagerness to move on to interpreted, intellectual meaning" (496). Yet simultaneously, he weakens the significance of Abbate's argument by considering it one of the many new "trends" (493) in musicological research. He further weakens the musicological challenge involved in Abbate's drastic versus gnostic opposition by only considering its epistemological aspects and not its concomitant ontological aspects, and the problem of relating the two. Both issues (affirmation and critique) addressed by Berger require further nuancing. Exploring this, I now turn to the proposed connection between Dahlhaus and Abbate as introduced by Berger.

Berger (2005) recalls Dahlhaus's Foundations of Music History (1983), which discusses the double historiographical problem of how to create a history of art, which is simultaneously a history of $a r t .{ }^{17}$ In short, Dahlhaus suggests that historiography does not involve an account of events, creating an order set against a general structure of progress. Rather, Dahlhaus argues that facts should be enriched by (aesthetic) values, expressed by questions of "how" and "why" through interpretation (Berger 2005, 491). Dahlhaus's remark further refers to how writing a history of an art-in this case, music-necessarily assumes a distinction between musical and extra-musical elements (Dahlhaus 2000, 203). This latter point is taken up by Berger (2005) as the Dahlhausian problem able to save musical aesthetics from a growing political (cultural and social) interest. Dahlhaus's (2000, 206) concern is that understanding music history as music history entails the idea that music cannot serve to illustrate cultural or social history. To paraphrase Dahlhaus (2000) when music serves cultural or social arguments, an aesthetic selection on which a music history could be predicated, cannot be accounted for, because every sonic event would then have an

\footnotetext{
${ }^{17}$ Dahlhaus (2000) refers to René Wellek's (1973) critique of the history of literature, in which Wellek brings forward a historiographical and methodological dilemma inherent in writing literary history. Wellek suggests that histories of literature concern either a collection of critical essays, or a history of culture, in which "die eine Art ist keine Geschichte der Kunst, die andere keine Geschichte der Kunst" [the former is not a history of art, and the latter is not a history of art] (cited in Dahlhaus 2000, 203, emphasis in original, translation mine).
} 
equal claim to being understood in its social and cultural context (206). ${ }^{18}$ In response to this music-historiographical dilemma, Dahlhaus turns to the "work" as the aesthetic foundation for a music history (and not to the musical event). ${ }^{19}$ Music historiography must thus negotiate between the discontinuity of musical "works" on the one hand, and the continuity (with inevitable gaps) of history on the other. Paraphrasing Dahlhaus (2000, 208), a music historiography that reconciles historical continuity with a history of music does not exhaust itself in general compositional topoi, but rather constitutes a stable relation of traditionsthat is, a relation between practices of aesthetic-compositional configurations. ${ }^{20}$ The idea is that compositional elements enter into a meaningful relationship that exceeds time and location, traversing the significance of details belonging to a specific composition. Dahlhaus thus cordons off an (autonomous) space where musical aesthetics and historical continuity go together through the relationship within, and between, musical "works" (208).

Berger (2005) takes the Dahlhausian argument for a musicology exploring the historical relationship between the aesthetics of musical "works" as his point of departure, marking the specific tendencies of new musicological scholarship as diverging from this Dahlhausian, musicological scheme (490). Berger refers to Dahlhaus's concern by considering how new musicologists use musical facts to illuminate cultural and social ones (thus losing the aesthetic claim), instead of following Dahlhaus's dictum to start analysis from the musical work as an aesthetic object, which in turn might be illuminated by its social and cultural embeddedness (493). For Berger, the deviation from the Dahlhausian dictum is

\footnotetext{
${ }^{18}$ In his own words: "dass eine ästhetische Selektion, auf die sich eine Musikgeschichtsschreibung stützen könnte, nicht mehr begründbar wäre: Jeder tönende Vorgang hätte von sich aus gleichen Anspruch darauf, in seinem sozialen Kontext begriffen zu werden" (Dahlhaus 2000, 206).

${ }^{19}$ Music history, for Dahlhaus (2000), is based on the study of musical compositions from which one distinguishes "die Entwicklung der musikalischen Emanzipation von Gattungsnormen und satz-technischen Regeln" [the development of music as liberation from norms and compositional rules] (203, translation mine). He thus suggests that music history describes the formation of compositional means, supporting music as autonomous art.

${ }^{20}$ This text is a paraphrase of the following quotation: "Die geschichtliche Kontinuität, die beschrieben werden muß, wenn sich die als Historie der Musik als Kunstwissenschaft und umgekehrt die Kunstwissenschaft als Historie bewähren soll, erschöpft sich also nicht in der Überlieferung und Modifikation satztechnischer Topoi oder Gattungsnormen und formaler Schemata, sondern ist als rekonstruierbarer Traditionszusammenhang zwischen den ästhetisch-kompositionstechnischen Konfigurationen zu begreifen..." (Dahlhaus 2000, 208).
} 
a "useful tool for spotting trends in recent musicology" (493). Berger further argues how contemporary musicological research topics are seen as part of the larger field of cultural studies: "[I]nspired by the ethnomusicological example, [musicologists] do not hesitate to use musical facts to illuminate a culture they study" (493). ${ }^{21}$ Berger thus suggests that research and theoretical concerns regarding musicology display a shift in perspective, namely, from the poietics and aesthetics of composing, to musical performance and cultural and social contexts. According to Berger, this represents another trend that demonstrates a divergence from Dahlhaus's historiographical argument. For Berger, Abbate's article is “a recent proposal in this area" (494), as it turns to performance and does not centre itself upon the analysis of canonical works, in the way Dahlhaus would have it.

However, although Abbate urges for an engagement with musical performance, her perspective differs considerably from other proposals in this area-as referred to by Berger $(2005,494)$. Abbate (2004) clearly articulates how her plea differs from the attention paid to "the relationship (or lack of one) between musicological dicta and musical praxis" (507). ${ }^{22}$ Regarding the rich subject matter of Abbate's article, her plea entails a critique rather than an affirmation of the familiar musicological discourse on performance. In this sense, Berger too easily jumps to conclusions when putting Abbate in the "trendy" category of performance research as deviating from the 'work' as Dahlhaus's musicological foundation. Hers is a critique in which she disputes contemporary musicological scholarship in general—and performance research in particular — that, although preaching performance, does not include

\footnotetext{
${ }^{21}$ In Contemplating Music: Challenges to Musicology, Kerman (1985) also points to the trend to "learn" from ethnomusicological (contextual) methods, evolving contextuality into a "cultural musicology" (180). However, resonating with Dahlhaus, Kerman expresses his hesitations about contextual studies, "founded on the impression that they are usually tilted much too far towards the consideration of contexts. They usually deal too little with music as music" (180).

${ }^{22}$ Abbate points here to the historical performance movement. For a critique of historically informed performance (HIP), see Richard Taruskin's Text and Act: Essays on Music and Performance (1995). Abbate $(2004,507)$ adds to this a list of scholars who write on the subject of performers and performance art. I would add performance approaches that take the interpretation of a "work" as their subject, in which case the process of performance seems to be confused with the product of performance. Examples are Edward Cone's Musical Form and Performance (1968); Jonathan Dunsby's Performing Music: Shared Concerns (1995); and John Rink's The Practice of Performance: Studies in Musical Interpretation (1995). See also Nicholas Cook's (2007) work on comparing interpretations in his CHARM project (2004-2009), which belongs to those performance research approaches focusing on interpretation and its relation to a compositional "work" (see http://www.charm.rhul.ac.uk, last accessed September 10, 2019).
} 
the dynamic reality of musical performance. As she argues, what counts is not the abstraction of a work, but "a material, present event" that "entails seeking a practice" (Abbate 2004, 506). Therefore, Abbate's attention to musical performance might be considered first and foremost as an endeavour to ground analysis in the circumstances within which music (and musicology) occurs in practice. Nevertheless, Berger's idea to connect Abbate to Dahlhaus is interesting, albeit for other reasons, as I will discuss now.

Although Abbate and Dahlhaus diverge in many ways-in style, approach, background, and modes of argumentation—crucially they also share interests, such as the music of Richard Wagner, and nineteenth- and early twentieth-century music more generally. ${ }^{23}$ Reading the relationship between Dahlhaus and Abbate in this way, I consider their connection, contrary to Berger, as involving a shared, enduring debate concerning musicology's grounding and disciplinary stability-one to which they both respond, albeit differently. However, I do not suggest any analogy, as problems and their responses grow out of material, social, and cultural circumstances that of course differ considerably between them. Nor does this dissertation allow for an exhaustive discussion of this otherwise interesting issue. Rather, the discussion serves here to situate the Abbatean argument in both musicological and wider discussions across the humanities.

When reading Abbate and Dahlhaus together, what becomes apparent is how they both attempt to intervene in a musicological shift in which cultural and social aspects take precedence over musicological research into "composer biography, archival history, and strict formalism" (Abbate 2004, 506). Although working with documents, sources, and (discovered) facts, both scholars emphasise music as a component of a particular social and cultural environment. In Abbate's article, this is problematised through the statements of Kerman (1985), who, according to Abbate (2004), proposes a "focus on musical works and their meaning" (506), "saluted in prose descriptions" (509). Borrowing from Jankélévitch, Abbate undermines efforts to articulate musical meaning, stating that, indeed, (instrumental) music has "broad shoulders," bearing "whatever specific meaning we ascribe to it" (516). For

\footnotetext{
${ }^{23}$ See Abbate's (1996, 156-205) publication Unsung Voices, especially the chapter “Wotan's Monologue," in which she references Dahlhaus's work on Wagner.
} 
Abbate, it is clear that "music [is] shaped by social and cultural forces" (514). Her point is that musical meaning gets all the attention, whilst music's materiality and dynamic being are ignored (514). As Abbate suggests, it is plausible that the strong focus on the articulation of musical meaning - the cultural and social embeddedness of music - together with the "embrace of codes and mechanisms" also provided the base for the entry of musicology into the "linguistic turn" of the humanities during the 1970s and 1980s (527).

Professor of sociology Vicki Kirby (2011), who is famous for her studies of the linguistic turn in the life sciences, mentions how this shift has changed the ways in which "we conceive and communicate our various concerns" (68). Kirby cites words "such as 'text,' 'writing,' 'inscription,' 'language,' and 'code'" (68). These words are familiar in musicological inquiry into written listeners' reactions to absolute music, here understood as European instrumental music that is considered untouched by extra-musical elements. Absolute music considers the musical event as exclusively using its "own" factors of expression (often conceptualised as the musical parameters of melody, harmony, rhythm, timbre, and so forth), which enter "in a relational field, so that upon entering that field they become musical forces" (Massumi 2011, 145, emphasis in original). However, as listening is not a purely auditory event, but a fusional occurrence within "changing circumstances" (Serres [1985] 2008, 303), images and feelings will emerge from this relational field, giving the impression that music "speaks," or has a "clue." Returning to the linguistic turn as mentioned by Kirby (2011), Abbate (2004) cautions us not to confuse such listeners' experiences, in which music seems to convey "the best truth," with new musicological hermeneutic research that makes music speak, dealing with it either as a "sign" that has to be "deciphered" (Abbate 2004, 522), or as something that "articulates" (Cook 2001, 177).24 This suggests new musicological hermeneutics to be musicology's entrance into the linguistic turn, demonstrated in the famous debates between Lawrence Kramer and Gary Tomlinson,

\footnotetext{
${ }^{24}$ Cook (2001) cites Stephen Miles, who refers to Susan McClary, stating: "McClary 'treats music as if it were almost linguistic in nature: witness the liberal use of verbs such as 'articulated'" (177). Cook also mentions Lawrence Kramer's literary background as a cause, stating that "he [Kramer] identifies meaning with language and thinks in terms of the mutual permeability of text and commentary" (177). For Cook, "the premise of Kramer's criticism is ... that [music] can be made to talk" (177, note 56).
} 
in which "contextualisation" is discussed as a method by which to define musical meaning (see Kramer 1993; Tomlinson 1993).. ${ }^{25}$ In the same way as stated by Kirby (2011), these developments have generated "new disciplinary formations across the academy and transformed the content, approach, and even the justifications for research" (68)- -hence the explosion of research topics in the 1980s and 1990s. Whilst these interventions are considered by Berger (2005) as deviations from the historiographical Dahlhausian touchstone, the general effect of this process of linguistification has been the positing of the human as an even more absolute attractor of all musical concerns-a problem to which I will return in subsequent chapters.

Dahlhaus (2000) reacts to the growing instability of the aesthetic hegemony of Western classical music and seeks a review of disciplinary boundaries by reaffirming the idea that the basic category of musicology, in the sense of music history, is the work concept and not the musical event as a social and cultural phenomenon. ${ }^{26}$ Crucially, what Dahlhaus and Abbate share (but also what divides them) is a concern to ground musicology in the concept of "work" (Dahlhaus), and in live performance (Abbate). Both try to escape the volatility of meaning and with it, the dominant focus on cultural and social circumstances, as negotiated within language and not bounded by the "work" as a predefined body of

\footnotetext{
${ }^{25}$ The famous debate about a new musicology between Charles Rosen, Gary Tomlinson, and Lawrence Kramer draws on two main issues. First, in the new musicologists' critique of the inward focus of musicology - articulated by Tomlinson's wish to dethrone "close reading" (cited in Rosen 1994, 2)musicology is considered far too invested in formal and structural analysis. The second issue considers how contextualisation would enable us to relate musical aesthetics with its "cultural, social, historical, and political dimensions" (Kramer 2003, 6-12). Both Kramer and Tomlinson try to escape modernist orthodoxy through contextualisation (considering Rosen as orthodoxy's protagonist). Kramer does this by discovering, through close reading and listening, the contexts that assumedly appear in music, in which music has the function of mediator. Tomlinson, widening the scene considerably, sees a means in music to open doors to other knowledge practices. With a critical response to new musicology's contextualisation, Rosen joins the debate. His concern is that both forms of contextualisation must fail, because they do not acknowledge "the inherent instability of musical meaning" (Rosen 1994, 10). See also Cook's (1998, 113-114) Music: A Very Short Introduction for a concise description of the aims and claims of new musicologists.

26 "Musikhistorie ist-da sie eine Auswahl der Werke voraussetzt, deren Entstehungs- und Wirkungsgeschichte zu schreiben lohnt-durch Ästhetik, und zwar durch die klassisch-romantische Ästhetik des autonomen Werkes, fundiert. Der Begriff des Werkes und nicht der des Ereignisses bildet ihre tragende Kategorie" [Music history-as based on a selection of compositions that have proven, by their influence and reception, to be worthwhile writing about-is founded on aesthetics, that is, on the classical-romantic aesthetics of the autonomous composition. The concept of the work and not of [its] performance constitutes the foundational category] (Dahlhaus 2000, 197, translation mine).
} 
musicological research (Dahlhaus), or by the real, dynamic being of music-as-performed (Abbate).

James Hepokoski (1991) demonstrates that Dahlhaus's project to re-ground musicology can be read as a response to the controversies that arose within West German universities between the 1960s and the 1980s. He formulates this as "the attack on objectivity" and the fact that "[t]he actual results and claims made by established literary criticism (or, pari passu, by history, science-or musicology) receded in importance, indeed, seemed almost irrelevant, before the new, sociological interrogation" (223-224). "Sociological interrogation" concerns the call to subject the National Socialist past to critical examination, which affected scholarly debates, as Hepokoski suggests: They "were no longer to center on overt content; rather, the topic was the concealed motivation of the researcher, or better, of the literary-critical or historical institution as a whole" (224).

In Anne C. Shreffler's (2003) work, the (musicological) problematic of including the social and the cultural is considered from another perspective by situating Dahlhaus, not as a representative of the "West," but rather as a musicologist who lives in a divided city. Shreffler does this by comparing Dahlhaus's work with that of his Marxist colleague from East Berlin, Georg Knepler. ${ }^{27}$ I will not follow Shreffler's lead and include a discussion of the relationship between the "sociological interrogation" and the Marxist inspired Gesellschaftswissenschaft [science of society]. ${ }^{28}$ However, of interest here is that Shreffler and Hepokoski both support the idea put forward here, namely, to situate Abbate via a shared

\footnotetext{
${ }^{27}$ In West Germany, since World War II, the question of "social interrogation" did not so much concern social structures, but the socio-political "concrete praxis" of "the confrontation with, and assimilation of, its National Socialist past (and the history that had let up to that past)" (Hepokoski 1991, 224). Hepokoski (1991) discusses Dahlhaus's ideas from the 1970s and 1980s within their West German context of social upheaval and "Western influences" (499). Conversely, Shreffler (2003) takes as her focus how Dahlhaus writes "against ... the prolific and increasingly Marxist musicology emanating from the other side" (500, emphasis in original) of divided Berlin. She introduces the Austrian musicologist Georg Knepler, living in East Berlin after 1949, to confront Dahlhaus's take on music historiography, based on the idea of Geisteswissenschaft [humanities], with Knepler's Marxist take, based on the idea that Gesellschaftswissenschaft [sociology] shifts emphasis from the individual subject to the collective (503). ${ }^{28}$ In (post-war) East Germany, Gesellschaftswissenschaft reflects the social basis of all human activity, emphasising the collective, and involves the Marxist rejection of the traditional German Geisteswissenschaften as "rooted in the Kantian distinction between the disembodied Geist and the tangible material aspects of life," with emphasis on the individual human being (Shreffler 2003, 503).
} 
critique and not, as Berger suggests, via a view of Dahlhaus as a datum point from which Abbate's approach to musical performance can be identified as a deviation.

According to Hepokoski (1991)—and regardless of a fading, yet still present faithfulness to the traditional mix of "positivistic empiricism and Geistesgeschichte" - the rise of new epistemological and hermeneutic models and the disruptive effect of "sociological interrogation" was a fact (224). Therefore, Abbate faced the effects of the linguistic or cultural turn with its new hermeneutics, as announced by Kerman (1985). Similarly, Dahlhaus faced political and social upheaval, which also contributed to a destabilisation of previously stable musicological reference points that in turn had allowed for stable methodologies concerning recognised musicological research topics. Another (related) point was that Dahlhaus (2000, 198,209 ) acknowledged a general decrease of interest in (music) history and the fact that musicological research was not at all popular outside the academy.

Abbate (2004) also reacts to the receding importance of (classical) music, speaking of "classical music's slow-motion death in the twentieth century" outside the academy (515). She too is part of the turmoil of changing values concerning objectivity and the increase of sociological and cultural concepts embodied in the publication of Kerman's Contemplating Music: Challenges to Musicology. Kerman's (1985) critique is an inclusive approach to music through a "fusion" of musicologists' "musical insights and passions" with "their scholarly" work (18-19). Through the upgraded status of insights and passions, rather than documents or biographical facts, Kerman suggests taking Verdi operas as an example of a fundamentally new, highly negotiable disciplinarity. This disciplinarity consists of multiple perspectives that

add up to a confused, variable, exciting beneficial sum which contributes to the understanding and appreciation of Verdi's operas as scores, as sound, as spectacle, as drama, as social commentary, and as personal testament. (Kerman 1985, 149-150).

However, according to Abbate (2004), musicologists committed to Kerman's ideas have instead dealt with "musical works as abstractions to be scrutinized for supra-audible 
meanings, or saluted in prose descriptions" (509). Her rationale is that, in spite of the multiple perspectives, musicology's first raison d'être, (live) performance, remains neglected. Precisely because of the multiple perspectives, a serious scholarly engagement with performance becomes frustrated (508).

Dahlhaus and Abbate do not deny the fact that music is a social phenomenon. Abbate (2004) states "[t]hat high classical music was shaped by social and cultural forces, by national ethoses, and that musical works were molded by their maker's psychic individuality are all truisms" (514). Dahlhaus states, for example, "[t]hat there are social implications in the works themselves ... and in the idea of absolute music embodied in the string quartet, [that] cannot seriously be denied" (cited in Hepokoski 1991, 228). ${ }^{29}$ Both seem to be embroiled in a critique against grounding musicology in a confusing linkage between music and meaning. Nicholas Cook $(2001,176)$ tries to unravel this linkage in terms of the neo-Hanslickian search for musical meaning as inherent in music, allowing for critical interpretation on the one hand, and the neo-Adornian search for musical meaning as a social construction, on the other, assuming a relationship between social and musical structures. ${ }^{30}$ Abbate's and Dahlhaus's critiques of new hermeneutic and epistemological models clearly show what Abbate (2004) considers as two forms of hermeneutics, "low" and "soft," displaying a similarity to Cook's neo-Hanslickian emphasis on interpretation (soft) and the neo-Adornian emphasis on deciphering the social in musical structures (low; Abbate 2004, 516). According

\footnotetext{
${ }^{29}$ The string quartet as purely instrumental music, emphasising musical structures for attentive listening in a private and serious domestic sphere, might be considered the model for absolute music. However, even the string quartet was not excluded from social and extra-musical influences. Hence Op. 59 of Ludwig van Beethoven, in which a "change in social character [from private to public] is part of the composition" (Dahlhaus 1991, 14).

${ }^{30}$ Here, Cook (2001) nuances the legacy of Eduard Hanslick's Vom Musikalisch-Schönen [On the Musically Beautiful], arguing that, contrary to orthodox notions that understand Hanslick's approach to music exclusively in structural terms, for Hanslick, musical expression and meaning were not mutually exclusive (174). Cook argues that new musicological hermeneutics affirms a neo-Hanslickian engagement in which meaning and music are inherently intertwined, allowing for critical interpretation. In contrast, the neoAdornian approach (in Cook's argument espoused by McClary) considers music a social construction, starting from Adorno's claim that music "presents social problems through its own material and according to its own formal laws" (cited in Cook 2001, 172). However, in both cases-critical interpretation or social construction-it is hard to determine how exactly the relation between music and meaning (via interpretation or structure) is made to work. This spurs the reluctance of Abbate and Dahlhaus to ground musicology in such an unstable relationship.
} 
to Abbate (2004), low hermeneutics concerns the decipherment of "trace[s] or mark[s]," testifying to "supra-audible content ... from the past," as inscribed into the score (516), whilst soft hermeneutics concerns the search for musical meaning, considered to be a "product born in the messy collisions between interpreting subject and musical object" (516). Dahlhaus's critique considers a flaw in academic seriousness, when, in the end, there remains the unsolvable scholarly problem of "deciphering [the social implications]" (Hepokoski 1991, 228). This affirms Abbate's notion of low hermeneutics, decoding the extra-musical marks that are apparent in the score. Abbate's notion of soft hermeneutics as the construction of musical meaning by the interpreting subject we find in the by Dahlhaus considered difficulty of accounting for the detached and constructed analogies that "rest exclusively on words and not on the matters that they are supposed to represent" (Hepokoski 1991, 228). Both foresee a lack of scholarly seriousness as a result of disciplinary destabilisation, effected by the impossibility of an unequivocal deciphering of structural codes and the arbitrariness of musical meaning as a result of critical interpretation.

Referring to "the aesthetic and technical terms of reference," Dahlhaus points to the music-analytical tools of, for example, formal analysis, which account for "the matters that they are supposed to represent" (cited in Hepokoski 1991, 228, emphasis added). By themselves, analytical tools "are inadequate in their exclusiveness," yet "equally essential, as a first stage that must on no account be skipped over" (Dahlhaus cited in Hepokoski 1991, 228). Here again we see in Dahlhaus the priority given to the "work" in relation to formal analysis and musical aesthetics (in chapter 3, I will discuss the crucial inseparability of an analytical tool and a "work" or object of research). However, Dahlhaus does not problematise how the tools may represent the "matters," as Abbate does; stability in this case also concerns the (assumed) stability of the "work" as "work-concept" (Goehr 1992) against the instability of the musical event. Instead, Dahlhaus reformulates disciplinary foundations primarily as aesthetic boundaries (the "canon") inhibiting the undermining power of "sociological interrogation," and against the deficit of scholarly seriousness. Conversely, Abbate's priority lies with musicology's missing link-live performance-as the dynamic matter that must be accounted for. I therefore re-position the relationship between Dahlhaus 
and Abbate through their shared problems and different answers, in which Dahlhaus does not figure as an absolute to measure divergence, as suggested by Berger, but rather as one of several demonstrations of musicological debates concerning epistemological and hermeneutic models, set against the backdrop of the dynamic reality of musical creation. In this sense, Dahlhaus's realism considers a match between the analytical tools for analysing "works," and the dynamic matter that they are "supposed" to represent. His concern is the foundational boundary built on Western canonical "works," which are to be considered by their inner structures and the interpreted characteristics set up between "works." This signals a kind of structuralism, as a method allowing for serious scholarly research, starting with musical analysis from given elements.

Abbate's $(2004,510,529)$ realism concerns the realism of phenomenological "physicality" affected by musical impact—an impact that resists capture by words or other symbolical means. Hence her "Drastic or Gnostic?" question, presented as an oppositional dyad separating two worlds-albeit one that simultaneously opens doors for an (unwanted) idealism of a felt yet unknowable world. Hence also the ambiguity of her critique of that (unwanted) idealist frame, which builds on a "revelatory force" (518) ascribed to an a priori backdrop of musical sounds that supports complex meaning formations, subjugated to "the professional deformations proper to hermeneutics" (513). Crucial is how Abbate changes the debate, in the sense that she attempts (unlike Dahlhaus's focus on the aesthetics of the musical "work" as the final purpose of musicological research and theorising) to implicate the dynamic, material, and social formation of music as a ground for musicological research and theory.

We see, then, that Dahlhaus's structuralist approach does not seriously consider a problematic relationship between musicology and music's dynamic being; a refusal based on the belief that musical structures, written in a score, correspond to a musical reality. For Abbate, new hermeneutics as proposed by new musicology—which, from an idealist viewpoint, uses the "revelatory force" (Abbate 2004, 518) of music—neither seriously problematises music's dynamic reality, nor the relationship between musicology and musicas-performed. Abbate, in fact, does problematise this relationship on the level of material 
substance. As she affirms, "[r]eal music is a temporal event with material presence that can be held by no hand" (Abbate 2004, 531). However, as we will see, her inference that music's temporality escapes any representation — my reading of "can be held by no hand" — brings her to accept the reality of music's absence. That is to say, music is absent for the "gnostic" mind, and thus only knowable through silent witnesses, evidencing that music was there.

Abbate's (2004) answer concerns a hermeneutics that "considers the exclusions and stratagems" left as traces of the "forces in play during musical performance" in written texts (513). She refers to this, borrowing from Jankélévich, as "clandestine mysticism" (Abbate 2004, 513). Jankélévitch (2003) defines clandestine mysticism as

[a] metaphysics of music that claims to transmit messages from the other world [and] retraces the incantatory action of enchantment upon the enchanted in a form of an illicit relocation of the here-and-now [of performance] to the [scholarly] Beyond. (15)

Abbate (2004) expands "clandestine mysticism" into hermeneutics, searching for silent witnesses of "the incantatory action" (the musical drastic) in musicological writings through which social ideas and truths "are being made monumental and given aura by music" of the once here and now (520). Whilst, according to Abbate, music-as-performed is rather indifferent to hermeneutic decisions, it nonetheless relies thoroughly on the aura of musical impact, and thus on the material and social reality of music-as-performed.

However-and this is Abbate's central critique-music's drastic being is referred to, voluntarily or involuntarily, to gain an effect without accounting for it. To demonstrate this, she cites Jacques Attali's “techno-mysticism” (Abbate 2004, 527-528), metaphorically deciphering music as an "audible waveband" that provides a record of the "vibrations and signs that make up society" (Attali 2006, 4). ${ }^{31}$ In a similar sense, Theodor Adorno ([1928] 2005) refers to a seismograph, used to metaphorically decipher the musical code in which the

\footnotetext{
${ }^{31}$ Attali (2006) considers "[m] usic, the organization of noise," from a social constructivist perspective that "reflects the manufacture of society; [which] constitutes the audible waveband of the vibrations and signs that make up society" (4).
} 
structures of society are considered manifest. In this case, it is Schubert's music that is encountered as a seismograph to register "man's qualitative change" (Adorno ([1928] 2005, 14). ${ }^{32}$ According to Abbate (2004), the idea is that these references to technical apparatuses invoke for hermeneutics and philosophy an unassailable objectivity of research: "[M]usic qua machine traces what is there without subjective bias" (529). However, according to Abbate (2004), they do so clandestinely, as the metaphors used rely "on false Eros and synthetic carnality for persuasive impact," bypassing the material presence and carnality of live performance through which music comes into existence in the first place (529).

Abbate's (2004) attention to "clandestine mysticism" might be considered an attempt to find a different starting point for musicological hermeneutics, asking how and why accounting for the "supra-audible others" is "hermeneutics' involuntary response to music as performed" (521). The point here is that hermeneutics—of which clandestine mysticism might be considered one form — relies on hermeneutic faith: the belief that human intention and social formation leave marks and traces on music that are specific and open to be read and deciphered. It is the conviction that "musical artifacts at later points can be read for exact localizable traces ... and that reading such traces for the facts they reflect accesses the proper meaning that one should attach to musical sounds" (515). Abbate points to circumstances in which hermeneutic faith comes into being, and she thereby turns to the nature of the musicological practice of doing hermeneutics, bypassing the discussion of whether the musicological question supports a social constructivist stance (i.e., music as defined by a collective of humans), or a representationalist stance (i.e., a musical real represented by symbolical means). Whilst I consider Abbate's move as an attempt to locate a different starting point—one that I will expand upon by reading the insights of Abbate and Barad together in due course-Abbate's plea points to the key question of whether and how music's dynamic, material, and social being can be reconciled with a musicological practice of representing.

\footnotetext{
${ }^{32}$ Adorno ([1928] 2005) writes here: “In jagged lines, like a seismograph, Schubert's music has recorded the tidings of man's qualitative change" (14).
} 
I have shifted the connection between Abbate and Dahlhaus-proposed by Berger as a matter of divergence against a standard-into a divergent reading of a set of similar, shared problems, albeit one to which they formulate different answers. Both Dahlhaus and Abbate seek to re-ground musicology as a reaction to the social and cultural challenges that have come into being through linguistic (e.g., Kirby), social (e.g., Knepler), and cultural (e.g., new musicology) turns in the humanities. For Dahlhaus, a turn to social constructivism undermines music's history as a history of (absolute, and autonomous) music, whereas Abbate critiques hermeneutics based on linguistics because it bypasses music's "drastic" occurrence. Dahlhaus seeks safe musicological ground in canonical "works," and Abbate (albeit unsuccessfully) in the practice of music-as-performed, that is, in the material presence and carnality of live performance.

\subsection{Drastic and Gnostic: An Intimate Relationship}

As the stable forms have been obtained by extracting from change everything that is definite, there is nothing left, to characterize the instability on which the forms are laid, but a negative attribute, which must be indetermination itself.

—Henri Bergson, Creative Evolution ([1911] 1998, 326)

In the following, final section of this chapter, I engage with one more aspect of Berger's critique, in which he considers the oppositional difference between the drastic and the gnostic to be overdrawn. Through the introduction of the Bohrian concept of "complementarity" and the work of Bergson, I hope to demonstrate why both Abbate's and Berger's statements concerning the oppositional relationship between the drastic and the gnostic warrant reconsideration. The concept of "complementarity" —an early announcement of Barad's insights-permits a modified exploration of Abbate's drastic- 
gnostic dualism, now considering the qualitative relationship between respective terms and music, operating from different yet complementary circumstances. A concept that enables a shift in Abbate's strong distinction between knowing (gnostic) and being (drastic) to a relationality of knowing in being, is Bergson's notion of intuition, which I herewith introduce into the discussion. I will demonstrate how the aspects of complementarity and intuition are latently present in Abbate's argument. It is clear that Abbate holds on to a drastic-gnostic relationship that is based on a sharp distinction in the form of an oppositional difference, in which the gnostic is defined against the drastic and vice versa. This results in a status quo whereby one term functions as a reference for the other, leaving music as the third term-a vague background. ${ }^{33}$ In view of this, let us first consider how Abbate advocates such a sharp division.

The oppositional difference proposed by Abbate $(2004,510)$ concerns drastic action involving the music-affected body and its experience as opposed to gnostic reasoning involving music's intellectual, or linguistic representation. As the social theorist Patricia Hill Collins (2002) states, an oppositional difference suggests that "[o]ne part is not simply different from its counterpart; it is inherently opposed to its 'other'" (70). This suggests that in Abbate's question "Music-Drastic or Gnostic?" the gnostic and the drastic are "fundamentally different entities related only through their definition as opposites" (Hill Collins 2002, 70). This entails an ontological difference expressed by different properties, in which case the drastic is further defined as the psycho-somatic being of a body, involving its “physicality, but also [its] desperation and peril" (Abbate 2004, 510). ${ }^{34}$ Meanwhile, the

\footnotetext{
${ }^{33}$ Oppositional difference as a form of analysis builds on a logic of stable identities and negation: "drastic" is "drastic," and thus not "gnostic." This form of binary analysis has recently become the subject of intense critique, as underpinning a system of thought in which concepts "imply relationships of superiority and inferiority, hierarchical bounds that mesh with political economies of race, gender, and class oppression" (Hill Collins 2002, 71). To be able to think beyond the enclosure of interlocking components, the term "difference" has been taken up by poststructuralist philosophers, amongst others, Jacques Derrida (1982) and Gilles Deleuze (2004). I will come back to the problem of difference in detail in chapter 3, discussing the Baradian contribution to the debate through her concept of "diffraction."

${ }^{34}$ In Abbate's description of "drastic," it is not very clear whether it concerns human action in general, or specifically music's impact on bodies. I consider both possibilities: music that has an impact on a human body ("physicality, desperation and peril;" Abbate 2004, 510), and the actions a human undertakes to make, think, and listen to music ("the labor of performance"[531]; "[musicologists'] own labor" [536]).
} 
gnostic, as reasoning capacity, brings things and thoughts to light and is concerned with "not just knowledge per se but making the opaque transparent" (Abbate 2004, 510). A point of concern in this framework is that the material "doing" of musical and sounding gestures is in danger of becoming a neutralised third term, remaining as a vague backdrop and serving only as a passive support to delineate the drastic and the gnostic as opposed categories.

Nevertheless, borrowing from the literary theorist Hans Ulrich Gumbrecht, Abbate explicates the drastic and the gnostic as different categories of human involvement into music. She uses Gumbrecht's understanding of "meaning culture" as opposed to "presence culture" (Gumbrecht 2004, 19). ${ }^{35}$ In this case, she understands meaning culture to be predicated on a new hermeneutic emphasis on interpretation: a musical object of research comes into being through interpretation. Yet it remains "inadequate to deal with certain aesthetic phenomena, events like performed music" (Abbate 2004, 531). Because gnostic reasoning is abstract and emptied out of the material and dynamic reality of a presence culture, for Abbate (2004), this culture-music-as-performed-is "perpetually in danger of appearing illegitimate in the academy" (531). This oppositional difference as explicated by Abbate implies an unacknowledged difference between being and knowing as hierarchical oppositions, in which the gnostic-as the location for the negotiation between intellectual attention and music — is considered as the standard point of view.

Abbate's question, posed as an oppositional difference, entails a critique and is therefore assumed to address a general scholarly approach to the dynamic reality of musical creation, in which "[f]eeling [drastic] cannot be incorporated into thought [gnostic] or even function in conjunction with it because in binary oppositional thinking, feeling retards thought and values obscure facts" (Hill Collins 2002, 70). The opposing terms drastic and gnostic constitute a dualism in which the knower (as mind and as phenomenological body)

\footnotetext{
${ }^{35}$ In Production of Presence: What Meaning Cannot Convey, Gumbrecht (2004) considers a dichotomy between "presence cultures" and "meaning cultures" (19), in which the former relates to a "spatial relationship" of humans to "the world and its objects" and their immediate impact on human bodies, whereas the latter refers to the concept that humans form an idea of "the thing that is present" and of what its relations might be (xiv). In the same way as Abbate, Gumbrecht urges against the "systematic bracketing of presence, and against the uncontested centrality of interpretation, in the academic disciplines that we call 'the humanities and arts'" (xv).
} 
and the known are considered separate entities for reasons of scientific and scholarly objectivity. ${ }^{36}$ Abbate, seeing herself confronted with the scholarly obligation to avoid personal knowledge obtained by the music-affected body (drastic), cannot but corrupt the reigning notion of objectivity that is considered the "eternal and collective possession of a community of thinking beings dispersed over time and space" (Daston and Galison 2010, 376). ${ }^{37}$ The drastic-gnostic dichotomy discussed by Abbate thus constructs a scholarly regime in which Abbate (2004) considers (in earnest and with frivolity) that musicology eventually "may ... find itself a wallflower at the ball" (505).

Abbate's discussion of the drastic and the gnostic as oppositional difference can also be read as a personal dilemma: Although academic mores exclude the dynamic and material reality of music-as-performed, she does not want to give up that crucial reality of felt musical affect-a testimony to music's richness. For Abbate (2004), "casting one's lot with performance and the drastic" cannot be taken up by scholarly standards of musicological research and theorising, or by models of new musicological hermeneutics (536). This dilemma, obviously raised by the dualist starting point of her argument, is threaded through her text in all keys. However, unacknowledged in Abbate's argument is how a phenomenological approach (discussed in section 1.1. of this chapter)—considered the correct model of research to encounter the drastic-postulates music as a non-specific sound

\footnotetext{
${ }^{36}$ Suzanne G. Cusick (2001) articulates how the feminine code as obstructing objectivity is an inherent part of, and haunts, musicology. She tells us how the composer Ruth Crawford (1930) was once the "woman excluded from the room" where men were gathered for a discussion of what later turned out to be the foundation of musicology in America (Cusick 2001, 472). Cusick further accounts for how musicology's legitimacy to enter the academy - that is, to be part of the other "great studies of the day"was jeopardised by music as the very object of study, which was "widely associated with the feminine" (473) and coded as analogous to the (non-intellectual) powerless position of women, characterised "by emotionality, sensuality, and frivolity" (473). For musicology, entering the academy and demanding a "scientific, objective, and serious" approach necessitates that the field differentiates itself "from its object of study," namely, music (473). In musicology, we thus find a deeply ethical concern caused by a continuous impulse to exclude the material and temporal dynamics of musical performance (as too feminine and frivolous) from serious musicological exploration. Abbate engages with this in her elaboration of the drastic as a doing, physicality and sensibility, and all that involves music-as-performed, thus in fact questioning musicology's foundation on the exclusion of both females and femininity. For Barad (2007), too, in a first instance, the feminine is the excluded differentiated-the Ruth Crawford excluded from the room-destabilising and jeopardising that which is presumably stable, patterned, and in charge of future unfolding.

${ }^{37}$ Here, the authors paraphrase Albert Einstein (Daston and Galison 2010, 376).
} 
world affecting a body. By centralising the affected body as the phenomenological firstperson, music seems to be rather accidental. Put differently, considering the drastic-gnostic relationship as an oppositional difference posits music as an unspecified, passive, and functional third term, serving a conceptual condition and enabling the making of distinctions.

We could conclude here by stating that, although Abbate's argument opens the ontological and epistemological debate concerning music, musicology, and their relationship, as a default option, she eventually reassigns it to a (phenomenological) dualist, human-centred, meaning-based musicology. It is easy to read this, like Lawrence Kramer (2004), as an insoluble position that condemns us to a barren discussion. ${ }^{38}$ However, my interest goes instead to the many leads in her argument that seem to urge a way out of a transcendent musicological gnostic. Berger's (2005) response to Abbate's article is helpful in this regard, for it allows us to see how Bergsonian intuition-generative of intuitive knowledge (knowing in being) as one answer to the drastic-gnostic oppositional differenceis latently present in Abbate's argument.

The seriousness of Abbate's sharp distinction between ontology and epistemology is both affirmed and weakened by Berger's (2005) irony, who argues that Abbate "overdraws the opposition between the real performance and the imaginary work" (497). He states that "[t]here is no such thing as pure experience, uncontaminated by interpretation," like there is no "pure unmediated musical experience" (497). For Berger, the gnostic as thinking, imagination, and interpretation can invade the experience of music at any moment.

Berger's argument helps in grasping Abbate's drastic-gnostic distinction and his response to it as a Bergsonian problem. The opposition between drastic and gnostic in Abbate's argument may seem unrelenting, but when considered in a Bergsonian context, the sharp dualism also offers a clear take on the two terms. Via the affected body, Abbate shows the drastic as the condition to perceive a musical world, and the gnostic mind as "the faculty

\footnotetext{
${ }^{38}$ As a reaction to the impasse that haunts Abbate's article, Lawrence Kramer (2004) suggests to "just call the whole thing off," for "whatever is said is said wrongly" (10).
} 
of dissociating, of distinguishing, of oppositional logic" (Bergson [1912] 2004, 236). For Bergson ([1912] 2004), an analysis that "[pushes] dualism to an extreme" brings to the fore how the proposed disconnection might entail contradictions, in turn opening up to a reworking of dualism(s) (236). ${ }^{39} \mathrm{I}$ am aware that Abbate (and Berger) rest their case and do not follow this line of argument; however, Bergson (1912] 2004) uses extreme dualisms in order to "prepare the way for a reconciliation" between the gnostic (unextended) and the drastic (extended), and between value and fact (236-237). Let us now see how Abbate's argument opens up to the Bergsonian imperative to reconcile the drastic and the gnostic.

Bergson is famous for the use of dualisms in his analysis: matter-memory; intuitiveintellectual thinking; duration-space; and recollection-perception. Intuitively, we feel that the terms of these dualisms are mixed. As expressed through Abbate's notion of the drastic, we experience a continuity that is broken up by an intellectual engagement that transforms music into structures. This is precisely what Berger (2005) refers to as an unavoidable human habit, arguing that the "immediacy of presence [is contaminated] with interpreted meaning" (497). Bergson's notion of reconciliation through intuition fruitfully complicates Abbate's oppositional dualism and Berger's unavoidable mix as conditions via which to consider the drastic-gnostic relationship.

In Bergson's ([1889] 1910) first book, Essai sur les données immédiates de la conscience [Time and Free Will: An Essay on the Immediate Data of Consciousness], duration (durée) is considered to be the ongoing flux of the human mind. Through the working of the human intellect, this flux is stratified into spatial elements (a succession of different entities or thoughts). In his second book, Matière et mémoire [Matter and Memory], via the concept of perception, the concept of duration accounts for the durational being of the material world within which "my body is a centre of action ..., [s]ituated between the matter which influences it and that on which it has influence" (Bergson [1912] 2004, 178). We see how the

\footnotetext{
${ }^{39}$ This argument is made by Dolphijn and Van der Tuin $(2012,119)$, also with reference to Deleuze's take on Bergson. Discussing new materialism, referred to in the introduction to this dissertation, Dolphijn and Van der Tuin (2012) argue that "by radically rewriting the dualisms of modernity, new materialism precisely becomes a philosophy of difference that opens up for a 'new' ontology, or rather, a 'new' ontogenesis" (119).
} 
phenomenological standpoint of observation (the body as centre) can easily be distilled from Bergson's argument. Yet, Bergson's specific concept of intuition introduces movement (the drastic) within the stratifying act of the gnostic as a difference within; you are not able to sing by reading or analysing a vocal score, without the social-material intuition of singing itself. This suggests how Berger's response, in which he weakens Abbate's severe separation, makes sense from a Bergsonian point of view: On the one hand, the gnostic engagement with music entails that musical structures are "carved out of reality" (Bergson [1912] 2004, 239, emphasis added). On the other hand, Bergson's thinking implies a crucial nuancing of Berger's notion of the unavoidability of intellectual intervention, affirming Abbate's "intuition" that musical analysis starts with the reality of making and listening.

Bergson's notion of intuition therefore provides a real method for grasping reality in its dynamic being. ${ }^{40}$ Intuition enables one to traverse and acknowledge the edge of knowing and being, in which "to think intuitively is to think in duration" (Bergson [1934] 1946, 38). In other words, the effort of starting from within the moving, generative, material nature of being, referred to as duration (durée), enables one to think from movement to abstraction, rather than simply adding movement to abstraction. Bergson ([1934] 1946) gives the example of how intuition learns that "[one cannot shorten] the length of a melody without altering its nature .... The inner life is that very melody" (19). A considerable part of Bergson's work concerns how the limitation of the human intellect (stabilising an ongoing generative flux) obstructs the articulation of duration, suggesting that to think intuitively is an effort to go beyond that point at which the intellect stabilises movement and change into stagnant concepts and things (Bergson [1934] 1946, 39). In musicology, perhaps more than anywhere else, to give an account of music's dynamic being, we necessarily end up using words and thus "think in terms of space" (Bergson [1889] 1910, xix), bypassing time. In the same way, we speak of sounds as next to or above each other, being higher, lower, or here, there, now,

\footnotetext{
${ }^{40}$ Anthony Newcomb (1984) also uses the concept of intuition, denoting feeling, instinct, and inspiration. His concept of intuition differs considerably from Bergson's notion, however, which always involves a relation to a dynamic, temporal, material reality, such as performed music.
} 
and then. ${ }^{41}$ In short, music — a performance art—cannot help but be referred to by means of spatialisation and objectification: "When we evoke time, it is space which answers our call" (Bergson [1934] 1946, 13).

The consequence (apparent in the work of Jankélévitch [2003]) would be that real music becomes musicology's "unthought;" unsayable, ineffable, unreal, absent, enigmatic, and mystified as an unknown. For Bergson ([1911] 1998), this is denoted as a "negative attribute" (see the epigraph above); as the determined "indetermination itself" (326). Bergson's "negative attribute" implies the potential of future determination, whereas for Jankélévitch and Abbate, the "negative" concerns a predetermined "not-to-be-known." The notion of absent music underlines Abbate's critique of musicologists, who encounter the musical "unthought" via a considerable gnostic (new musicological hermeneutic) investment in deciphering, decoding, and interpreting.

We can now see the double feeling that is also involved in Abbate's inclination to unravel "clandestine mysticism" as an illegal answer to the absence of music. Her answer is to transfigure the "negative attribute" — music's dynamic reality-into a "positive" by defining music's absence as the "really real" for musicologists. In her book In Search of Opera, Abbate (2001) demonstrates her specific approach, writing about music as real absent. She does so by seeking the connection between "music that escapes cages: we never hear it" and "live performance, grounded and intensely material" (vii). As a "master symbol" (5) of the book, she introduces the floating, decapitated head of Orpheus with the lyre next to it, dead with its singing mouth open, connecting unheard, ongoing singing and the horrific real. This image allows her to question, in a variety of ways, the idea of "a musical work as a transcendent object, as opposed to that object's embodiment in any given performance" (6). Emphasis is put on music that is not present, but "rather implied," in order "to see the music that is there as a pointer toward this other" (vii). Turning to the "really real" of music's

\footnotetext{
${ }^{41}$ Think of the "arcane sign-gesture-and-grunt system" (Kerman 1985, 196) by which musicians communicate during rehearsals. Kerman (1985) uses the concept to depict a difference between musicologists' articulated thoughts and those of a musician, which is "not thought of a kind that is readily articulated in words" (196). Kerman's concept is appealing, especially as a fine notion of how musicians seek to go beyond formal language in order to incorporate time and musical affect in their communication.
} 
absence seemed to be Abbate's scholarly answer at the time to the musicological difficulty of grasping the dynamic reality of music through a musicological approach of research and theorising.

It is clear, however, that ambiguity is threaded throughout her argument, and Abbate maintains a decisive stance according to the separation of the drastic and the gnostic in her study of 2001. By identifying the Bergsonian elements in her work, I therefore hope to reinforce a lingering part of her argument that attempts to find a more positive relationship between the drastic and the gnostic, grounding the musicological approach in practice. A concept that challenges the passive oppositional relation between the drastic and the gnostic even more, is complementarity—an idea that permits the affirmation of difference whilst simultaneously complicating it as relationality. In my argument, the concept of complementarity capitalises on how music and musicology become determined within specific material and social circumstances, thus affirming the Abbatean approach to ground musicology in practice and, as an early announcement of Barad, considering both as ontoepistemological.

Complementarity is a concept that has its roots in physics—one that we will again encounter in chapter 3 as one of the inspiring links between the thinking of Barad and that of the physicist Niels Bohr. Here complementarity is not complementary-as used, for example, by Anthony Newcomb (1984) in his discussion on how formal and expressive interpretation form "two modes of thought" that "go on simultaneously" and are "complementary" (636). In Newcomb's argument, formal and expressive interpretation complement each other and enable a fuller account of the "socially signifying aspects" of music (638, emphasis in original). Newcomb's statement affirms Abbate's problem that (new) musicology mainly considers music as culture. ${ }^{42}$ Rather, as used by Barad (2007, 19; and introducing Bohr's insights)

\footnotetext{
${ }^{42}$ Newcomb's as well as Abbate's arguments build, amongst others, on canonical, "classical" music. Contemporary musicological scholarship values the explication of the specific "music ontology" that underlines the argument. Thus, the researcher and the theorist make a distinction between the particular musical standpoint in the light of the diversity of musics, distinguishing "my music" and "our music" (Bohlman 2001, 19-20; emphasis removed). The aim of this practice is twofold: To underline how the "own" musical culture is intertwined with practices of research and theorising, and to avoid generalisations about the cultural and social diversity of the world's music. I will not follow this scholarly habit here, as it would immediately introduce the cultural, the social, and the political as power
} 
complementarity concerns the problem of mutual exclusion combined with mutual necessity. As a physical phenomenon complementarity means that "an entity either behaves like a wave or a particle depending on how it is measured" - to measure a "wave" another apparatus is needed than when measuring a particle (Barad 2012d, 42; emphasis in original). In Barad's elaboration, examining the ontological and epistemological implications when matter (specific material apparatus) and meaning (concept of wave or particle) are entangled, complementarity suggests "that identity is not fixed and inherent, but performative" (43). I will come back to this notion of complementarity in chapter 3. Taking my cue from Barad (and with further justification to follow), I consider complementarity here as connoting the nature of the music-musicology relationship in terms of Abbate's argument in Baradian terms.

Abbate (2004) cites two tests she performed, which, for her, prove how mutual exclusion conditions the fact that you are not able to concentrate on playing the piano and, at the same time, observe the thoughts about what you are doing, and vice versa; you are not able to think about playing the piano and, at the same time, play the piano. Mutual necessity entails that musicology needs music for its mode of existence, but for music to be a determined cultural and social practice, it needs-besides practical music-making and at least in today's Euro-American cultural environments—public affirmation through speaking, writing, and thinking, thus including the work of musicologists. As such, complementarity seems to endorse Abbate's distinction between the drastic and the gnostic.

However, whereas Abbate considers the drastic of making and listening to music as active and the gnostic of thinking, writing, and speaking as passive, complementarity considers both playing and thinking as active. It emphasises the doing of playing and listening, and of thinking and writing as embodied practices, situated in different material and social circumstances, through which particular outcomes become determinate.

\footnotetext{
apparatuses building on a negative difference (this is not that), thus starting from predetermined identities and boundaries. Whilst this dissertation is precisely concerned with such problems of musicological knowing and valuing in being, these problems involve the material-discursive dynamism and performative quality of "relating" and are not reducible to a particular musical standpoint as owned, shared, and considered as "different from" (Barad 2007).
} 
Interestingly, in Abbate's (2004) description of the gnostic, she already refers twice to the gnostic as a doing: "[M]aking the opaque transparent" (510); and again, when she brings in the "intellectual pleasure" to "disentangle some virtues from a situation" of attending a musical event (533).

It is, however, the (borrowed) argument of Jankélévitch—namely, that "Making" is “of an entirely different order from Saying" (Jankélévitch 2003, 77)—which, for Abbate (2004), throws doubt on the gnostic as a doing. Jankélévitch (2003) underlines his statement with the rhetorical question: “Composing music, playing it, and singing it; or even hearing it in recreating it-are these not three modes of doing, three attitudes that are drastic, not gnostic, not of the hermeneutic order of knowledge?" (77). Complementarity complicates this statement by stating that thinking is also a doing, including every feature of the Abbatean drastic and, as such, is no different to playing, composing, and singing. However, different material and socio-discursive circumstances are needed in order to perform these various actions. In other words, thinking and playing are both doings (drastic), merely differentiated from each other by being generated through, and within, different circumstances. This means that the gnostic does not concern a passive position, but is instead an activity.

If Bergson ([1912] 2004, 236) pushes dualism to the extreme in order to prepare the way for intuition to fulfil its task to reconcile the two terms (drastic and gnostic), complementarity puts emphasis on the material and discursive circumstances through, and within, which music and musicology come into being. That is, the determination of musical and musicological outcomes is inseparable from, and implicated in, specific material and discursive practices. Complementarity suggests that material and discursive circumstances and outcomes implicate both the drastic and the gnostic, relating (and related) to each other as an onto-epistemology of music-making and musicology. Thus, complementarity ultimately suggests that musicians and musicologists are both part of the musical world they seek to create and understand. ${ }^{43}$ Research and theorising allow for a situated-and thus

\footnotetext{
${ }^{43}$ This refers to the inseparability thesis on which Barad's insights are based, and to which I will return in chapter 3.
} 
partial—understanding of music (Haraway 1988). ${ }^{44}$ Whilst this is unpacked further in chapter 3, for now it may serve to demonstrate that the concept of complementarity has the serious potential to shine a new light on the idea of difference between musical and musicological practices. It complicates the dualism in Abbate's question "Music—Drastic or Gnostic?" as something not to refute for practical reasons, nor to heal or bridge, but rather to leave the opposing terms intact, albeit in need of a serious reworking.

Summing up the discussion thus far: Considering Abbate's definition of the drastic and the gnostic as oppositional terms, read together with Berger's response to dualisms, allowed us to push dualisms to the extreme. It also enabled a connection with Barad's understanding of the concept of complementarity, which complicates Bergsonian intuition (here considered as the reconciliation of the drastic and the gnostic) as a specific material and discursive practice with specific outcomes. This significantly amplifies Abbate's $(2004,505)$ assertion that musicologists cannot do without intuitive knowledge of music-as-performed. With the concept of complementarity, the relation between music-making and musicology is not one of opposing the drastic and the gnostic, but rather of several specific materialdiscursive practices, both supporting, in Abbate's argument, the notion of knowing via the material dynamics of musical being.

\subsection{The Abbatean Drastic: Initial Condition}

In addition to the test of combining playing the piano with musicological thinking referred to above, in a second test, Abbate (2004) again explores the reconciliation of the drastic and the gnostic by asking: "Would attending performances entirely damp down the gnostic?" (533). Her answer is a simple, "No" (533). Abbate supports this by a detailed account of what she experienced as a listener during Laurie Anderson's performance of Happiness (2002-

\footnotetext{
${ }^{44}$ For a more elaborate exploration of the work of Donna Haraway, see section 3.4.2.
} 
2003), in which a memory of an earlier event-watching a documentary about the destruction of the World Trade Center in New York-was mobilised and interwoven with her perception of an electronic sound made by Anderson. Through the clicking of Anderson's teeth, amplified by tiny microphones in her spectacles, Abbate's memory of that particular documentary ("bodies hitting the ground") came alive and "triggered real terror at that moment in her [Anderson's] performance" (534), attributing a specific, autobiographically grounded meaning to that specific sound.

As referred to in the introduction to this chapter, I affirm the way in which Abbate poses the crucial question of the relationship between the dynamics of musical creation and musicology in the sense that I recognise, support, and explore her endeavour to ground musicology in musical practice. The principle referred to in this section suggests that, through the entanglement of perception (listening to Anderson's music) and memory ("a gnostic moment [that arises] in unexpected ways;" Abbate 2004, 533), meaning is created. Whereas her first test concerns the attempt to discern (being gnostic) something from music whilst playing (being drastic), now the attempt to be gnostic, within drastic circumstances, entails the inclusive operation of synthesising memory with perception, through which the meaning of a particular sound is generated.

Although this test seems promising as to the purpose of Abbate's search for a musicological approach that includes the drastic, nevertheless, for her, it also supports her doubt. In her argument, she turns to meaning formation as the constitution of an original, personal, and local "secret knowledge-the object of hermeneutics—and its loss" (Abbate 2004, 533). The inference is that her "secret knowledge" - the identification of a specific sound in Anderson's performance as the sound of bodies that hit the ground-cannot be represented by the hermeneutic approaches of future musicologists. This reveals how the Abbatean dualism between the drastic and the gnostic is repeated in Abbate's example as a two-world logic of representationalism, without considering reconciliation as Bergsonian intuitive knowledge. Conversely, complementarity—as in the work of Barad and Bohrwould recognise in this drastic-gnostic entanglement a meeting of the drastic and the gnostic 
as inseparable parts of material and discursive circumstances, producing both music and musicology.

Abbate's $(2004,534)$ argument starts from the conditions of temporality, demanding that the (musicological) hermeneutic act comes after a musical occurrence. Obviously, the fleeting and ephemeral nature of any (musical) event has a definitive character, but the point Abbate raises here with her second test is precisely that, through the working of memory, a past occurrence and its felt affect may survive with the promise of re-entering, albeit changed, in future circumstances. Suggesting strange resonances that complicate any notion of time and space as stable unities, this immediately complicates Abbate's linear notion of time, according to which the hermeneutic act comes after the event. It indicates that her experience is a process distinct from "secret knowledge" —as an identified event that may lead to a subsequent distinct moment in which the hermeneutic act is generative of a new knowledge event. However, her argument does not concern any general question that the humanities might ask regarding how and why the past survives—of how representing and representations work.

Abbate's (2004) rationale is that the once synthesised memory and perception, which constitute meaning — in this case enabling her to identify the "sound" that induced her with a feeling of "real terror" (534) — is not shareable with, let alone understandable for, future musicologists. Through the assumed linear, temporal conditions of the hermeneutic act, musicologists are bound to craft meaning out of a correspondence between a recording or description of the "loud boom" (533) in Anderson's performance, and the sound of bodies that hit the ground as seen and heard in the documentary. Abbate thus considers her test a process of meaning formation in which the drastic and the gnostic are interwoven, although expecting the musicological follow-up to be subjected to the representationalist approach-a predefined sound to be scrutinised for correspondence with a predefined past occurrence. Thus, the musicological result is necessarily emptied of the drastic feeling of real terror, as it was felt by her at that moment. This leaves Abbate to conclude that the practice of meaning formation, in which the drastic and the gnostic are caught up with each other, concerns an 
original, a personal, and a local—in short, a unique situation that is neither transmissible nor graspable by any scholarly approach.

Concluding, we can now see that Abbate treasures the drastic as an initial condition in her 2004 article, separating the "I" from any objectification through perception (via Jankélévitch's phenomenological approach), language or, for that matter, musical notation. This necessarily makes any representation a stand-in for the absent event and summons the two-world logic of representationalism. In this light, Abbate's critique of new musicological hermeneutic approaches-an analysis based on two independent worlds; one of representations, and the other of the represented, passive background (musical) worldseems puzzling. Abbate thus critiques new musicological hermeneutics, seeking correspondences between these two worlds. Yet, holding on to a sharp distinction between the drastic and the gnostic implicates a two-world logic that "sneaks" into her argument at every instance. However, by suggesting that her argument does not escape representationalist logic, as referred to in many instances, opens it to another starting point, considering musicology, music, and their relationship as both generated and generative in nature. This different (Baradian) starting point for a scholarly approach considers how things and thoughts are generated by, and generative of, new things and thoughts. I will come back to this when introducing Barad's work in chapter 3, further exploring this approach in the reading together of Abbate and Barad in chapter 4. In the next chapter, I turn to the responses of Benjamin Piekut, Christopher Hasty, and Georgina Born to the issues that Abbate touches upon. Unlike Berger's reaction, they (in principle at least) affirm Abbate's plea, taking it as a starting point from which to explore questions of performance and the dynamism of musical creation in relation to musicological scholarship. 


\section{Chapter 2}

\section{Music, Musicology, and their Relationship: \\ Problems of Connectivity}

The recourse to metaphysics is like throwing a match into the powder magazine. It blows up the whole arena.

—Alfred North Whitehead, The Concept of Nature $(1920,36)$

This chapter follows the field's responses to the challenge set by Abbate to include the question of materiality and the dynamic reality of music in musicological theory and research. Other than Berger's response, the responses in this chapter take up Abbate's concern with musicology's ingrained drastic-gnostic dualism as a general concern of what is excluded from today's musicological research and theorising. The argument points towards the need for a more inclusive musicological focus with attention to the heterogeneity of musical and music-related expressions, suggesting a shift in the comparatively reductive scholarly scope of Western art and music as exemplified by contemporary research into scores, documents, and composer biographies.

Reactions to Abbate's plea, including those of Christopher Hasty (2010a), Georgina Born (2010a), and Benjamin Piekut (2014), were expressed via articles and chapter sections mainly as short references (Born, Piekut) or taken up as motivating questions, palpable throughout their arguments (Hasty). The responses are of interest for this dissertation, as they all address the formation of a theory of musicological knowledge questioned by Abbate as "Music-Drastic or Gnostic?" At the same time they, like Abbate, critique the way in 
which musicology has objectified music's temporal reality as "works, structures, or schemes" (Hasty 2010a, 198). In other words, like Abbate, the cited scholars consider the present-day epistemological configurations of music, musicology, and their relationship as problems that necessitate renewed attention. This new attentiveness is demonstrated through their shared-albeit differently elaborated-acknowledgement of the connection between the drastic and the gnostic (Hasty); of the connection between music, musicology, and other scholarly disciplines (Born); and between human and nonhuman entities (Piekut). Hasty has a background in music theory, whereas Born and Piekut have backgrounds in music sociology and music history respectively. However, despite their differing perspectives and methodologies, their responses express a collective agreement to conceptualise the dynamics of musical creation, the heterogeneity of musical expressions, and the materialities involved in music production and distribution through an acknowledged (or in the case of Piekut, unacknowledged) call to metaphysics.

The responses to Abbate's (2004) article selected for detailed discussion in this chapter take up her question of the inherent drastic-gnostic dualism of musicological scholarship, and like Abbate raise the question of how to incorporate the drastic in thought and other symbolic representations. After searching Google Scholar with reference to the question of the drastic-gnostic dualism, and evaluating the results returned, I deliberately do not account for the many reactions displayed as results of the query "Music-Drastic or Gnostic?" (Abbate 2004). Most of the articles and book chapters found here affirm in passing Abbate's plea for performance research or critique her notion of new musicological hermeneutics with regard to the complexity of meaning formation (e.g., Leech-Wilkinson 2012). In other cases, Abbate's emphasis on musical performance research is welcomed, but her starting point of music-as-performed is considered too narrow, as it would ignore recorded musical performances (Cook 2013).45 Taking into account the totality of responses,

\footnotetext{
${ }^{45}$ Nicholas Cook's (2012) well-known research on musical performance and his concern for developing new (empirical) methodologies must be mentioned here, even though his research does not question the formation of musicological knowledge in relation to the Abbatean plea. Similar to Born (2010a), who considers a relational musicology that enables different perspectives through the use of methodologies of different scholarly disciplines, Cook (2012) opts for a relational musicology, which he frames as an
} 
my selection of three is justified by this dissertation's interest in the relation between the drastic and the gnostic, considering the inclusion of material dynamics in scholarly research and theory. My approach therefore does not involve a defence of Abbate's argument against critique from the musicological field. Rather, what I am suggesting is that her question "Music—Drastic or Gnostic?" is both pertinent and essential—not to reiterate an established order between the drastic and the gnostic, but to open up a space for thinking the two together. I propose to traverse the (to my knowledge) preliminary social and cultural underpinnings of the responses, and to search for lines of thought amongst the responses to Abbate's plea that would open up to the possibility to incorporate the material dynamics of musical being into musicological scholarship. These lines—enabling my response-I find in the selected works of Hasty, Born, and Piekut.

Christopher Hasty (2010a) remains close to Abbate's argument, engaging with questions regarding the temporal reality of musical events as experienced by human beings and how, from those events, meaning is produced. Although his argument follows several lines of thought, the perspectives of the philosopher Alfred North Whitehead, and the philosopher and psychotherapist Eugene Gendlin, are foremost. Georgina Born (2010a) suggests a relational musicology via which to engage with heterogeneous musical forms of expression and musical practices from various disciplinary angles. She extends musicological scholarship with insights from anthropology and social theory. Benjamin Piekut (2014) considers ANT-as elaborated by the social scientist Bruno Latour-as a methodological extension of a music-historical concern that promises new ways of engaging with concepts such as influence, genre, and context.

Although the epistemological and ontological positions of the aforementioned scholars are varied and sophisticated, they miss a crucial point that concerns "knowing in

\footnotetext{
intercultural encounter. Cook argues for an approach that focuses on intercultural sense-making by understanding how texts are expressed through other texts as networks of interactions through which meaning is generated. He discusses, for instance, how Hindostannie airs of colonial Calcutta are neither Western nor Indian, demanding a relational, intercultural analysis that takes account of the Indian musicians, the colonists, and the interpreter-musicologists writing then and now. Cook therefore does not address an Abbatean drastic-gnostic or nature-culture encounter that is my primary concern in this study, but instead remains within social and cultural domains of meaning formation, in which writing and the ensuing mechanism of representation remain at the centre.
} 
being" —or, in Barad's (2007) terms, onto-epistemology. Onto-epistemology involves a traversal of the nature-culture dualism, which underlines the fact that "[k]nowing is a direct material engagement ... with the world as part of the world in its dynamic material configuring" (Barad 2007, 379). This suggests that, instead of the opposition implied by Abbate's question, the gnostic and the drastic cannot be torn apart, but are entangled. The notion of entanglement needs careful study, bearing in mind Kirby's (2011) remark on our strong commitment to dualist thinking. She cautions for simply "[replacing] binary errors with nonbinary correctives," as they will reinstate binarity "in a disavowed and subtle way" (Kirby 2011, 69). Keeping this in mind, my argument aims towards an attentive study of entanglement, as will be explored further in subsequent chapters. For now, the exploration of the responses of the aforementioned scholars serves a careful examination of precisely Kirby's problem: Entrenched dualisms are repeated when binary difficulties are addressed whilst starting research and theorising from a division (drastic and gnostic; mind and body; music and social; the human and the nonhuman). The responses demonstrate this quandary of dualist starting points. As a result, they focus on representations (experience, consciousness, language, the cultural, the social, or other "mediums") as a necessary means via which to capture a musical reality and, as such, keep the dynamics of musical reality at a distance. As a consequence, the arguments of Hasty (2010a), Born (2010a), and Piekut (2014) contain an implicit (or at times explicit) dualism based on a negative relation between terms, which obstructs a serious engagement with the Abbatean question and, in fact, tends to reinforce its implicated binarity.

My overall intention is to explore how Hasty, Born, and Piekut attempt to traverse the drastic-gnostic dualism by borrowing metaphysical and philosophical insights. ${ }^{46}$ Before

\footnotetext{
${ }^{46}$ I use the concepts of philosophy and metaphysics interchangeably, in accordance with the referenced texts. I do not refer to a history of concepts of philosophy and metaphysics. I follow Deleuze and Guattari's ([1980] 1994) description of philosophy as "[t]he art of forming, inventing, and fabricating concepts" as a situated performance, suggesting that both concepts address questions of reality; of being and beings (2). As for the concept of metaphysics, we see in Whitehead (1920, [1927-1928] 1985). Bergson ([1912] 2004), and also in Barad (2007) a discussion of scientific engagement with reality as a method by which to gain insight into the operations of being and beings, considered as a transcendence of the reality under observation; a meta-physics. They opt instead for a "different metaphysics," asking why and how reality exists, and exploring the question of immanence: "[W]e are part of that nature that
} 
discussing Hasty's article, I first recall Abbate's stance concerning metaphysics, and the relationship between music and musicology. As Whitehead's thinking plays a constitutive role in Hasty's argument (and, albeit latently, in Born's and Piekut's), I also turn to the way in which Whitehead explores a different metaphysics.

\subsection{Metaphysical Mania and a Different Metaphysics}

The reactions of the selected scholars to Abbate's plea are in favour of metaphysics and philosophy, ignoring the Abbatean "aversion" to what she refers to as "metaphysical mania" (Abbate 2004, 505). For Abbate (2004), following the work of Vladimir Jankélévitch, a turn to metaphysics equals a "retreat from real music to the abstraction of the work, furthermore, always to see ... something behind or beyond this mental object" (505). ${ }^{47}$ For her, metaphysics seems to be a form of new musicological hermeneutics (see chapter 1), in which the once drastic occurrence is "illicitly relocated to the beyond" by discursive means (514). ${ }^{48}$ This suggests that any metaphysical study into the being of the dynamic phenomenon of music is stranded by the workings of language and the human intellect that seeks to study it, and therefore, in Abbate's view at least, cannot bring back the drastic.

The epigraph at the beginning of this chapter, which cites the process philosopher Alfred North Whitehead, is simultaneously illuminating and confusing. It refers to the force

we seek to understand" (Barad 2007, 26). For new materialisms and ontologies of immanence, see Van der Tuin (2011); and Åsberg, Thiele, and Van der Tuin (2015).

47 Jankélévitch's (2003) argument against a metaphysical perspective on music is based on his belief that musical reality cannot be grasped. He states: "I am not here to find handholds in music, to have something to say about it, nor to confer a pseudo-consistency on ultimate inconsistency by means of analogies taken at face value" (118). "Simple listening, or performing per se, is far more effective than the most striking intellectual insights" (119). In other words, he strongly upholds making a distinction between the drastic and the gnostic. For further reading, see Michael Gallope and Brian Kane (2012), convenors for the special issue of the Journal of the American Musicological Society on Jankélévitch's philosophy of music.

${ }^{48}$ Abbate (2004), however, affirms the (dualist) metaphysics of Gumbrecht, which is oriented towards action, events, and presence, and considered to be in opposition to the non-action of discursivity. Thereby, Abbate upholds the unrepresentability of the musical drastic (531). 
of human reasoning, which makes us "instinctively" believe "that by due attention, more can be found in nature than that which is observed at first sight" (Whitehead 1920, 37).

Whitehead thus seems to endorse Abbate's $(2004,505)$ understanding of metaphysical mania as any discussion in which a "passed" musical reality is subjected as a "mental object" to the whims of the discursive mind, seemingly independent of, and ignoring, the singularity of musical experience.

As Whitehead is generally considered to be one of the most influential metaphysicians of our time, his statement may initially appear confusing. However, the critique that endorses Abbate's argument also underlines Whitehead's desire for a different metaphysics-not metaphysics as meta-position, but rather as a conscious human being in the world. For Whitehead (1920), a metaphysics must not remain with the epistemological question in which nature serves as cause for knowledge-that is, we must seek "not to explain knowledge, but exhibit in its utmost completeness our concept of reality" (39). Whitehead thus affirms Abbate's critique of the interpretative mode of new musicological hermeneutics.

Whitehead's ([1927-1928] 1985) different metaphysics seeks to scrutinise the relationship between the knower and the known, producing knowledge that is intelligible in the sense that "it belongs to the nature of 'being' that it is a potential for every 'becoming,', thus including knower, known, and knowledge and their relationality (22, emphasis added). As such, Whitehead proposes a concept of reality in which we can never "acquiesce in the merely given" (42). When we, instead of knower, known, and knowledge, speak of listener/musicologist, the sound perceived, and the musical knowledge created, in terms of givens, they have to be questioned as consequences of an ontological and epistemological relationality, or put forward as de facto starting points. We may actually take the concept of music as a starting point for research and theory formation (there is music), but must always acknowledge that the concept concerns an entity that implies both what is perceived and that which perceives, bringing together, for example, both the listener (or the musicologist) and music "in-the-making." This suggests an approach that also bypasses any reductive (cognitive) approach that focuses on the mechanisms of how, or what, humans know. Thus, 
paraphrasing the philosopher of science Isabelle Stengers (2011), Whitehead's different metaphysics forms a serious invitation to ask questions that seek to explore, for instance, harmony as an unstable node between becoming music and becoming listener (86). As Stengers suggests, the point will no longer be to construct (analyse) music to which givens such as "this" chord, "whose" harmony "I" recognise, may belong, but music "in which this [harmonic] enjoyment vibrates" (111) as a consequence of the coming together of musical processes of becoming - in both the listener, and their intimate relationality.

I refer to Whitehead (1920), whose thinking resonates with both Hasty's and (through Latour) Piekut's arguments, to demonstrate in their arguments the re-invention of the concept of metaphysics, and the endeavour to retrieve music's dynamic reality as a relationality between listener and sounding gesture. In short, Whitehead qualitatively shifts the new musicological construction of knowledge as the addition of meanings to assumed entities, and also qualitatively shifts Abbate's exploration of the lost affect (discussed in section 1.4.). Whitehead's metaphysics of process concerns the dynamics of being as a becoming actual, considered as a generative relationality that, in terms of the conscious human being, involves listener/musicologist, the sound perceived, and musical knowledge.

\subsubsection{Gnostic and Drastic: Reading Music}

The relationality of music and musicology suggested by the distinction Abbate (2004) makes between the drastic and the gnostic concerns a disruption between felt musical affect and the abstraction of a musicological approach. The general obstacle-the impossibility of transmitting (original) personal and local experience through language—is, according to Abbate, entangled with a specific academic habit that includes neither personal nor local knowledge (536). Although Abbate does not approach the drastic-gnostic dualism as a specific problem of transmission that is open to reconsideration, I nevertheless follow this perspective briefly in order to gain a better understanding of its potentially generative relationality. 
In one of her tests, Abbate (2004) accompanied a Mozart aria on the piano. As described earlier, she presents herself as unable to be "gnostic" whilst playing—she did not consider herself to be in a position to find the intellectual distance needed to perceive musicological issues. Interestingly, nor does she consider a generative relationality to be at work when, through notation, Mozart (supposedly absent from the scene) "resounds" in her performance. This suggests that, for Abbate at least, notation (writing) and readingconsidered as gnostic activities-incorporate both past and future, thus involving an act of re-creation (as opposed to an act of re-presentation). ${ }^{49}$ It demonstrates that the drastic and the gnostic are already entwined, even though Abbate's conflict of failed connection does not take into account this generative relationality (a going together of past and future through reading, the written, writing, and performance).

As referred to previously, Abbate (2004) considers as "clandestine mysticism" the (illicit) feasibility of re-creating music of the past when music resonates through a metaphorical use of language. We know by now that Abbate does not embrace other perspectives about the relation between the drastic and the gnostic, preferring instead to maintain a sharp separation between the terms. The dualism therefore repeats itself twice as a historical argument, involving an original event as a given starting point, and demanding a linear relationship between two otherwise stable notions of space and time: the original (Mozart) and its (true or not true) repetition through musical performance, and the original as a performance that can never be repeated through discursive means.

I have considered Abbate's aversion to "metaphysical mania" as well as Whitehead's different metaphysics. I have also pointed out how Abbate's perspective as a performer tacitly demonstrates a re-creation that traverses the drastic and the gnostic, and also gathers together past, present, and future. However, according to Abbate's (2004) argument, knowledge gained in the process of listening or playing necessarily passes under the "academic radar" or suffers the loss of its potentiality by being disciplined through "the

\footnotetext{
${ }^{49}$ From a music performer's perspective, Deleuze's (2004) understanding that "to differ" requires ongoing change is an experiential matter; playing a piece "again" cannot be reduced to a mere repetition, concerning identity, opposition, resemblance, or analogy, contrary to the impression we get when talking about a performance.
} 
universalizing endemic in academic discourse" (536). Now that I have reiterated the crucial points of Abbate's argument-also demonstrating how an affirmative reading of these points enables a different understanding that focuses on the generative processes involved in making and studying music-I will turn to Hasty's article and his response to the Abbatean plea.

\subsection{Christopher Hasty: Musicking and Experiencing}

The title of Hasty's (2010a) article, "If Music is Ongoing Experience, What Might Music Theory Be? A Suggestion from the Drastic," already provides a hint that Hasty wants to move beyond the "stalemate" of Abbate's argument. Hasty's answer to Abbate's question, "Music-Drastic or Gnostic?," shines through as a reformulation, in which he asks: If music is drastic, how does this fact open up to the gnostic? As Hasty's argument is rich with his former work, I also base my discussion on his monograph Meter as Rhythm (Hasty 1997) and the book chapter "The Image of Thought and Ideas of Music" (Hasty 2010b). Together with the article that discusses Abbate's question, they demonstrate Hasty's familiarity with philosophies that take process and becoming as starting points, rather than objects.

Counterintuitively, regarding Hasty's affinity with time and process, he too, responding to Abbate's question, seems to start his argument from the gnostic and the drastic as given, stable identities forming an oppositional difference. Hasty's (2010a) "[s]uggestion from the [d]rastic" thus assumes a drastic and a gnostic that pre-exist their relationship (197). Taking into account this dissertation's (Baradian) onto-epistemological approach (to be developed in chapters 3 and 4), suggesting an entangled drastic-gnostic that does not exist in individual, isolated terms is a problem that needs to be resolved. Recalling our ingrained commitment to binary thinking, as discussed in the introduction to this chapter, maintaining the relative positions of the drastic and the gnostic will simply reintroduce binarity. This is demonstrated throughout Hasty's argument, and thus obstructs 
the mentioned "suggestion from the drastic" from functioning as a viable ontoepistemological move.

Both teaching at Harvard University, Hasty and Abbate might have met and discussed their shared point of interest: the relationship between musicology and the musical drastic. In Abbate's (2004) terms, the drastic concerns "the irreversible experience of playing, singing, or listening [through which] any meanings summoned by music come into being" (505). This is affirmed by Hasty, who endorses her point (and Whitehead's; see the epigraph to this chapter). Taking her argument one step further, Hasty also formulates the musicological consequences of taking the drastic seriously. As stated in an interview with Beth Potier (Hasty 2003), he suggests that "it looks like meaning gets out of control when you start valuing the temporal and sensible, the actual" (n.p.). Note that, for Hasty, this does not refer to the mobility involved in Joseph Kerman's (1985) critique (in turn critiqued by Abbate and discussed in chapter 1), but entails a complication of how things and thoughts stabilise and destabilise when seen (beyond the formation of meaning) as inseparable from time, human experience, and materiality. Whereas Abbate sees herself confronted with the loss of the original affect and emotion when trying to conceptualise the full personal experience, Hasty (2010a) considers the giving of musicological attention to the drastic to be an invitation "to think about time and process in music" (197). He shifts to a metaphysics that addresses the problem of the dynamics of (musical) reality according to the experiencing, conscious human being. Both consider the artificial stability of the "work" (Abbate) and the score (Hasty) to represent a musicological conundrum. Abbate criticises new musicology's desire to exploit the infinite reservoir of musical meaning, lifted from its original grounding of music-as-performed, whilst Hasty, a music theorist, aims to apply music analysis—-the study of musical form and structure-to the analysis of unstable musical processes. For Hasty (2010a), moving beyond the primacy of structures involves "discovering new ways of thinking about music and human experience in general" (199).

In this sense, the phrase "a suggestion from the drastic" in the title of Hasty's (2010a) article thus concerns the conceptualisation of time and process in relation to (human) experiences of music. Hasty's (1997) attempt to go beyond the dominance of structure in 
music analysis is based on Whitehead's ([1927-1928] 1985, 136) discussion of the experiential nature of contrasting concepts such as "repetition," "immediacy," "endurance," and "change." Whitehead's stance is summed up in the phrase, "experience involves a becoming, . . . becoming means that something becomes and ... what becomes involves repetition transformed into a novel immediacy" (136-137, emphasis in original; cited in Hasty 1997, 65). ${ }^{50}$ Notions of time (becoming and repetition) are inherent elements when experiencing musical reality as a process. They are presented to us as contrasting elements that seem to endure in continuity, and that seem to change, presenting the new as discontinuity (as changing forms open to our analysis). The concepts of repetition, becoming, and immediacy demonstrate Hasty's interest in the concept of time. They also demonstrate how the writings of Gilles Deleuze (2004) and Henri Bergson ([1889] 1910)—although not always explicitly cited in Hasty (2010a)—are, nonetheless, employed in his argument. Both Bergson's concept of time as ongoing qualitative change and Deleuze's concept of becoming, which accentuates mutation and difference as a verb, problematise the notion of grounded, stable structures, and underline Hasty's (2010a, 205) notion of the human encounter with a musical object. Similarly, the concept of "experiencing" —not only in Whitehead's terms, but also as a more explicit human experience elaborated by the philosopher and psychotherapist Eugene Gendlin ([1962] 1997)—contributes considerably to Hasty's argument. I shall look into this more closely in what follows. My interventions address the way in which Hasty injects his argument with metaphysics, taking experience as his starting point. In his response to Abbate's question, Hasty introduces a metaphysics of process that he links to Christopher Small's ([1987] 1998) concept of "musicking" and a metaphysics of the experiencing body, linked to Gendlin's ([1962] 1997) concept of "experiencing" (see section 2.2.1.). Combining process and experience might suggest a new phenomenology that goes beyond the experiencing human body as its grounding reality. However, as I will show, Hasty's

\footnotetext{
${ }^{50}$ In the introduction to his Meter as Rhythm, Hasty (1997) acknowledged his debt to the work of Whitehead, although he does not attempt "to ground his theory of musical meter in a general theory of time or process" (ix). Instead, he adopts "some of [Whitehead's] central insights" (69), which are cited here.
} 
argument ultimately forecloses the possibility of such a new phenomenology because the insights of Gendlin frustrate a Whiteheadian metaphysics of process and generativity.

\subsubsection{Musicking: A Metaphysical Problem}

Hasty's (2010a, 198) argument adopts an initial musicological stance by referring to Small's neologism "musicking" - a concept that accounts for music as both a social and a dynamic occurrence. ${ }^{51}$ He elaborates on Small's well-known concept by considering how the verb uproots music as a stable entity. In other words, the term "musicking" immediately problematises the constitution of a musical "thing" and, consequentially, raises questions that consider time and process (and do not start from the stability of a defined "being"). It thus calls into question the relationship between the representations deployed by and for musicologists and the reality of musical creation in performance (198). Borrowing from Whitehead's conceptualisation of process, Hasty enforces Small's concept of "musicking." In doing so, he shifts musicological thinking that takes "things" (identities, meanings, essences, pre-established properties) for granted, towards an approach that instead takes into account "the creativity of music and the production of novel meaning" (197). For Hasty, addressing the dynamics of performed music through Small's concept of "musicking," furthermore infused with the Whiteheadian concept of process, destabilises the relationship between music and musicology. He considers the musicological gnostic as "inseparable from the living" and "part of 'the phenomenon that is music'" (213).

Hasty's (2010a) answer to the Abbatean problem, from an analytical perspective, concerns his account of "[m]usicking 'music' [as] a way of expanding and complicating the study of music and its theorization" (198).52 He also considers embracing "complexity" as a

\footnotetext{
${ }^{51}$ See Small $(1998,2-9)$. Already in Music of the Common Tongue, Small ([1987] 1998) discusses that in English, there is no verb that can be used to express that "music is not primarily a thing or a collection of things, but an activity in which we engage" (50, emphasis in original).

52 Note how Small's ([1987] 1998) concept of "musicking" tends to the gerund form, suggesting the "act of taking part in a musical performance" (50). The implication is one of people involved in something that happens in a limited time and space. Hasty's (2010a) conceptualisation focuses, not so much on the actthe "musicking" of people-but rather on "the multiplicity of doings," with an emphasis on change and not limited to any specific space or time (198). James Williams (2008) takes up this point when discussing
} 
necessary step in addressing both the temporal dynamics of music (for a conscious human being), and the expansion of musicological repertory via the addition of popular and nonWestern music and a diversified body of documents, including recorded sound, speech, performances, and computation-retrievable aural and visual data. As an effect, according to Hasty, traditional boundaries between musicological sub-disciplines "have become increasingly permeable" (198). This he considers to be an opportunity for music theory "to claim the speculative or 'philosophy-oriented' role in research and pedagogy" (198). Hasty hopes that

music theory does not abandon its commitment to speculating on the organization of musical sound, but ... that this commitment might be deepened and made more productive by seriously engaging the difficult questions of time and process, meaning and feeling, perception and experience rather that [sic] resting in comfortable fantasies of fixed compositional structures. (199)

Hasty thus seeks a speculative metaphysics that does not start from the identified, selfevident given, but instead explores the complex dynamics of (any) musical creation by “mobilizing experience and putting thought to a test" (Stengers 2011, 233). Hasty's (2010a) argument follows Whitehead's speculative metaphysics, in which complexity cannot be encountered merely by accommodating "comfortable fantasies" (199)—or, in Abbate's (2004) terms, "metaphysical mania" (505). Nor does a Whiteheadian speculative metaphysics allow for the kind of connectivity expressed by the concept of addition-adding one "thing" to another "thing," like adding musical movement to musical notation and like it is suggested by dynamic computer graphics adding visualisations to music recorded and replayed.

Connectivity in this sense would concern complexity added to predefined musical structures that are open to analysis, yet bypass the inherent mobility of time and process as factors of

the idea of "events-effects" in Gilles Deleuze. Transposed to our discussion, Williams indicates a difference between music as an effect of all that are gathered in the event of "musicking" on the one hand, and the effect of "musicking" as creating changes and unpredictable patterns of cause and effect on the other, which seems to be more in tune with Hasty's conceptualisation. 
change. Hasty's $(1997,2010 b)$ hope is shaped by the Whiteheadian frame, concerning a complexity of the dynamics of musical experience that traverses the so-called (stable) objectivity of musicological analytical thinking based on predefined structures. For Hasty, this means that from a music theory point of view (e.g., analysing rhythm or meter), his Whiteheadian account necessarily traverses pre-established disciplinary boundaries of music analysis, addressing communication, musical meaning, and performance-in the process of course, mobilising experience. That is, it acknowledges "pluralism in the study of music and a sense of the open, unfinished, problematic nature of such study" (Hasty 2010a, 199).

As a consequence, Hasty's commitment to speculative thinking regarding musical organisation has to consider a more intuitive encounter in which "organisation" does not linger as a predefined background structure, but rather is fully taken up by the process of experiencing music. This is similar to the unfolding of a Deleuzian perspective on representationalism in Hasty's (2010b) article “The Image of Thought and Ideas of Music," which is open to the potentiality of "real" music, and not subject to the regime of pre-existing structures of analysis. As such, more than referring to accepted forms of music analysis, Hasty considers a metaphysical approach to the processual becoming of music. Using the concept of "musicking," infused with Whiteheadian thinking, for Hasty would offer musicology a way in to the complexity of the dynamics of musical creation through experience-that is to say, "from the [d]rastic" (Hasty 2010a, 197). Simultaneously, as we will see below, Hasty's emphasis on the "experiencing" body concerns an emphasis on epistemology, in which the listening body is (like in Abbate's [2004] argument) a receptacle, mediating knowledge "from the [d]rastic" (Hasty 2010a, 197).

The way in which Hasty (2010a) takes up the Abbatean question may be understood as a poststructuralist approach that recognises the untenability of organising music into closed structures of the musical "work," "cognitivist information processes," or "rulegoverned mechanisms for manipulating internal representations" (197). Poststructuralists acknowledge that there is no such thing as a secure foundation for knowledge in the way that structuralists believe it exists in musical or linguistic "deep" structures, or in the way phenomenologists find it in human experience. Poststructuralists understand this, in the 
words of the cultural theorist Claire Colebrook (2002), "not [as] a failure or loss but a cause for celebration and liberation ... the opportunity to invent, create and experiment" (2). Hasty's (2010a) argument "lives and breathes" this poststructuralist spirit, positively embracing thinking about time and process in music, and describes Small's concept of "musicking" as a "creativity of experiencing and all the complexity that comes with it" (197). For Hasty, contrary to Abbate's argument, musicking does not "make knowing an impossibility" (201). Rather, it incorporates complexity as that which "will not rest in a finished known apart from the living, experiencing body" (201). This suggests instead a gathering together of the dynamics of musical and musicological knowledge creation in terms of a conscious, experiencing human being.

I am aware that describing Hasty (2010a) firmly as a poststructuralist would require more attention as to his use of the thinking of Deleuze (204), Bergson (205, 208, 209), and Whitehead (209). However, this is not the place to discuss in detail how the works of Deleuze, Bergson, and Whitehead intersect with Hasty's aim to "theoriz[e] musical experience" as a "creativity of experiencing;" as a "suggestion from the drastic" (197).53 Instead, and considering this dissertation's new materialist (specifically Baradian) reading of Abbate's plea, my interest lies in the pedagogical value that resides in the way in which Hasty imports metaphysical insights into a musicological argument; insights that aim to traverse the drastic-gnostic oppositional difference.

\footnotetext{
${ }^{53}$ For Hasty (2010a), creativity is a power engendered through the experiencing body that never stays the same, as "the power to make something new, something that was not there already and something that will not stay there ready to be had again as the same thing" (200). It is the experiencing body of ongoing change that opens up to the new. In his recent book Music as Creative Practice, Cook (2018) considers social and cultural interaction as a source of musical creative actions and the musical new by "making music together [and] the action and interaction of individuals ... [embracing] material agents as instruments and scores: instruments and scores 'talk back' just as human agents do" (9-10). In the context of this dissertation, the difficulty in both Hasty's and Cook's accounts of creativity is that they incorporate material doing (and change and the new) as authored by human intentionality, although they speak of, respectively, change and material substances. In chapter 4, I discuss Barad's (2007) notion of the "world's radical aliveness" (33) as a source of creativity that includes the emergence of human subjectivity and music, and that "can never 'run out"' (177). Barad's approach does not consider the "experiencing body" and "making music together" as isolated projects from which to start analysis, but rather, as effects of enfolded material-discursive practices.
} 


\subsubsection{The Use of Metaphysical Insights}

Philosophers who take up movement and change in their thinking offer a comforting "homecoming" for musicians and musicologists. Musicians and musician/musicologists, like myself recognise that to which a philosopher is (really) alluding; "we" are able to fill in the relational and situational specificities of the material and discursive dynamics involved in (musical) performance. ${ }^{54}$ However, the ease with which concepts such as "process" and "becoming" are endowed with the weight of (musical) reality may also hint to something Abbate (2004) criticises—the aforementioned "metaphysical mania" —as the meta-position of metaphysics, suggesting a (gnostic) distance from the reality of being and beings. Even when taking account of the writings of philosophers such as Whitehead, Deleuze, and Bergson, the question remains how these insights, considering reality in its entirety, work in terms of the musicological problem of coping with the dynamics of musical performance.

My concern is that Hasty (2010a) uses "musicking" in terms of "experiencing," supposedly explaining the "real" in an instrumental manner. By this I mean that these concepts do not (re)configure a musical "real," but rather simply exemplify the writings of the philosophers themselves. To demonstrate this point from the philosopher's perspective, we might consider how, for instance, Deleuze and Guattari ([1980] 2004, 527) use statements of the composer and conductor Pierre Boulez to explain the real. In particular, his concepts of "striated time" and "smooth time" are taken up in their philosophical argument. For Boulez ([1986] 1990), these concepts allude to, respectively, musical time related and not-related to musical pulsation. He remarks that striated and smooth time reciprocally interact, since “time cannot be only smooth or only striated" (Boulez [1986] 1990, 87, emphasis in original). For Boulez, the two concepts are fully intertwined with musical and compositional materiality; they do not explain music and composition as objects, but work through

\footnotetext{
${ }^{54}$ Susanne K. Langer ([1953] 1976) makes this point when criticising Bergson, as well as those musicians who consider him "the artist's philosopher" (114-115). Langer explains how musicians recognise what the philosopher is getting at, "and with the courage of innocence went straight to the solution" (115). Placing to one side the critical mood of Langer, I take this as a significant point in which philosophical writing gives words to, and seems to unravel the complexity of, what musicians do and feel when making music. Additionally, for musicians (and musicologists), writing (symbolic representations) is intuited knowing, indeed allowing them to go "straight to the solution" (Langer [1953] 1976, 115). For further reading on Langer's discussion of Bergson, see Van der Tuin (2016).
} 
performing, composing, and their relationship. However, as John Mullarkey and Anthony Paul Smith (2012) argue, these musical indications are used "in the name of . . philosophy ... with all its architectonics" of concepts (3, emphasis in original). That is to say, the problem is not that concepts change their material and discursive groundings; rather, they lose that grounding when used to exemplify a standpoint, thus re-introducing the dualism of the metaphysical as meta-position.

Hasty's (2010a) argument tunes in to an aspect of the various topics of experience. It also gives rise to the question of how Hasty takes up Small's socially and culturally confined concept of "musicking" in his philosophically inspired thinking of experience, process, and time. The same holds true for how Whiteheadian thinking infuses Hasty's concept of experience, problematising its relationship to Gendlin's concept of the "experiencing" body (Gendlin [1962] 1997, 3; Hasty 2010a, 201). Whilst it would be worthwhile to pursue these strands further, here I focus on Hasty's attempt to go beyond Abbate's (2004) drastic-gnostic stalemate position, in which he carefully unpacks the relationship between musicology and metaphysics whilst being aware of the risk of falling prey to what Whitehead ([1927-1928] 1985) terms the "fallacy of misplaced concreteness" (7). This concerns the intellectual pitfall of neglecting the degree of abstraction involved when, for instance, musical form is analysed or musical recordings are dynamically modelled, visualised by computing. Both instances are exemplary of certain "categories of thought" that easily mistake the abstract for the concrete (Whitehead [1927-1928] 1985, 7-8)..5 So, what can we do to avoid music falling prey, in Abbatean terms, to the gnostic approach, in which music merely functions as an example within a philosophical architecture?

To answer this question, I turn to Deleuze and Guattari (1994), who in a way address the same problem in their project, which asks what philosophers do. For them, a philosopher creates concepts that are connected to a real world as problems (33). Problems in this context are not (intellectual) “obstacles” to be overcome by reason (Deleuze and Guattari [1980] 2004,

\footnotetext{
${ }^{55}$ Categories of thought are based on reasoning; on how the mind "sees" and conceptualises the world without "concrete appreciation of the individual facts in their full interplay of emergent values" (Whitehead [1925] 1948, 198).
} 
399), but are instead (situated) "question-machines" to be traversed (285). In other words, concepts cannot be isolated from the material reality of "problems without which they would have no meaning and which can themselves only be isolated or understood as their solution emerges" (Deleuze and Guattari 1994, 16). Creating the problem thus supposes that it is carved out of reality through the creation of questions-an act that also implies the creation of solutions and new insights. This suggests that a musicological relation to the insights of a metaphysician supposes a relationality, not to the concept, but to the problem as a "real," material, and discursive problem, according to which the concept makes sense.

In analogy, we may consider the separation between body and mind as a "real" problem, tensioning material-discursive, nature-culture dualisms, and constituting a "real" musicological discipline, from which Abbatean questions and concepts—“Music-Drastic or Gnostic?"- are distilled as the stalemate position of opposed musical doings and musicological observation from a distance. This demonstrates that the problem of dualism is not addressed by using concepts that add movement to an otherwise static representation (in the sense of music as a dynamic occurrence), but rather by traversing underlying dualisms

In the introduction to Thinking with Whitehead: A Free and Wild Creation of Concepts, Stengers (2011) provides yet another perspective on the "fallacy" of isolated reasoning, in the context of its connection to problem and concept. She argues that entering into philosophy as a "thinking with" means entering into contact with all the material and discursive twists and turns of the philosopher's problem, rather than merely (in abstracto) applying his concepts, transmitting them "in the manner of science" - e.g., we are able to use Newton's calculations without knowing his problem (10, emphasis added). To give an example from the fields of music and computing, practicing études (vocalises) and learning a computer programme for music editing involve specific problems and questions, related to, but also isolated from, a concert reality. Whilst the act of practicing and learning may help to technically "master" an instrument, voice, and the use of particular software, it does not necessarily open one up to the emergence of musical values within and through performing music during a concert or whilst editing a recorded performance. Thus, you cannot simply transmit the lessons learnt and the technique mastered to the act of editing and making music at a concert (and vice 
versa). Therefore, practicing, learning techniques and software do not stand on their own, but involve a "thinking with" the qualitative material and discursive twists and turns of the musicality and materiality involved in making and editing music.

I now turn to another specific aspect of Hasty's argument, in which he transforms Abbate's concept of the drastic into Gendlin's concept of experiencing. Together with Small's concept of "musicking" and the Whiteheadian notion of the processual constitution of reality, Hasty seems to opt for a new phenomenology that goes beyond the experiencing human as the original ground for musical reality, and thus also moves beyond the Abbatean phenomenological approach that produces for her the drastic-gnostic divide. In Bergson's ([1912] 2004) terms, a new phenomenology would be an enterprise that "seek[s] experience at its source" (as inseparable part of the material real), beyond the point at which experience becomes stabilised and identified as human experience through the intervention of perception (240-241).

We know from Abbate's (Jankélévitchian) phenomenological approach, discussed in chapter 1, that placing the "experiencing" body centre stage elicits a perspective in which human experience (entangled with sense perception) becomes the standard model for knowing. Thus, in present-day Euro-American strands of thinking, this introduces a representationalist, two-world logic that assumes a predefined distinction between human experience and the outside world. This establishes human experience as the new ground for, and stable location of, knowledge, creating the dualisms (e.g., nature-culture; body-mind; matter-meaning; human-nonhuman) in which music constitutes an "outside" or nonhuman world (including the human body). The challenge facing Hasty is how to cherish the Whiteheadian process and ongoing generation of events, yet not to support a new grounding in the body via Gendlin's concept of "experiencing." In other words, does Hasty succeed in traversing the Abbatean problem of dualism, which he also refers to as "the split of body and mind" (Hasty 2010a, 207)? Below, I unpack Hasty's (2010a) conceptualisation of the "experiencing body" (201) and ascertain whether it succeeds as a new phenomenology that traverses the mind-body, drastic-gnostic dualisms. 


\subsubsection{Experiencing the Drastic}

Hasty (2010a) faces the issue of (Abbatean) gnostic stability, in which thinking and writing immediately betray the adventure of experiencing the dynamics of musical creation. To counter this difficulty, Hasty's methodological intervention seeks to establish a coherence between musical and musicological practices and language. Setting "things" in motion by using Small's concept of "musicking" (read together with the Whiteheadian idea of process) is an example of Hasty's intervention. Another example is Hasty's call on the performative when he says that "activities of theorizing and analyzing are performative," in which "performare is to really, actually (fully) form or shape" (200, emphasis in original). However, considering the fact that Hasty's concept of the performative is not thoroughly elaborated in his article, we nevertheless see a tendency to merely refer to the (one-way) productive nature of the human intellect; a gnostic activity. By etymological reasoning, building on a correspondence between the Greek "dran" (201) and the (related) Latin "per-formare" (200), Hasty considers the "[t]he drastic or performative" (200) to be interchangeable, as both concepts insist that "real music is music that exists in time, the material acoustic phenomenon" (Abbate cited in Hasty 2010a, 200).

However, despite his taking account of the temporal and material, Hasty (2010a) deepens the gap between the gnostic and the drastic because he does not consider a generative-that is, a dynamic and material—relatedness that informs both the productivity of human reasoning, and the "doing" (dran or per-formare) of music. As evidence of the productivity of "the gnostic positing of concepts, forms, structures, or meanings," Hasty considers how the drastic can be theorised and conceptualised "again and again" in many different ways (201). In this case, difference comes into being through the "living, experiencing body," which "open[s] knowing to a complexity that will not rest in a finished known" (201). Hasty rejects an epistemology based on naive representationalism-as a stabilised, given musical reality. He also rejects a fixed ontology, as in Abbate's (2004) idea of the essential and lost original affect as evidence of a lost musical being. However, the difficulty is that movement and change are added to reality through the experiencing body, 
which now-in lieu of the abstracting mind-takes up function as the apparatus that mediates the thing it experiences whilst simultaneously creating a musical real as exteriority.

We can now see that Hasty's (2010a) response to the Abbatean gnostic and drastic involves gnostic and drastic doings, but remains confined to the boundaries of the (mediating) experiencing human body. To establish this, Hasty displaces the Abbatean concept of the drastic by Gendlin's concept of experiencing (201). This entails a slight, yet significant change in how musical energy is negotiated. It is not the Abbatean drastic affect (although phenomenologically explained), but rather a body's "experiencing" that enables the emergence of meaning, concept, and conceptualisation. Hasty argues for a "new language and a sensitivity to the metaphorical character of the language and concepts we have-and a resistance to their constraints" (207) in order to conceptualise the process of experiencing and meaning-making. Hence his interest in Small's and Gendlin's neologisms, "musicking" (198), and "experiencing" (201). However, although successfully introducing a temporality of doing, Hasty fails to include the musical real as a source of experience and remains instead with an explanation of meaning formation through musical, bodily experience, thus considering the body to be a neutral and distinct mediating apparatus, emptied of the material and dynamic doings of musical being.

In addition to this phenomenological take on Abbate's notion of the drastic, her approach shows yet another tendency, expressed through the words "desperation and peril," towards values that are intentionally not taken up by Hasty's concept of experiencing (Abbate cited in Hasty 2010a, 201). Abbate (2004) considers the drastic to connote "physicality, but also desperation and peril, involving a category of knowledge that flows from drastic actions or experiences and not from verbally mediated reasoning" (510, emphasis added). Hasty (2010a) believes these values to be (already) present in the etymological history of experience (201). For Abbate, listening to and making music do not only involve physicality in the sense of bodily awareness (as in Hasty's experiencing body). Rather, they also imply a body being affected by environmental (musical) forces, felt as a change of intensity through heartbeat, sweat, goose bumps, or the desire to move. The physicality involved in "desperation and peril," for Abbate, demonstrates the affected body as the real 
"thing" affected by music and not as Hasty's mediating apparatus-as simply mediating the experienced "thing."

Crucially, feeling a sense of desperation or being in peril are the emotional effects of an affected body. For Abbate (2004), these effects allow for thinking and speaking about the feelings of the affected body. As such, there is knowledge involved that has to do with feelings and sensibilities, "told" by the body when being exposed to music-as-performed. This transmission of affect, via feelings enacted through thinking and words, suggests the

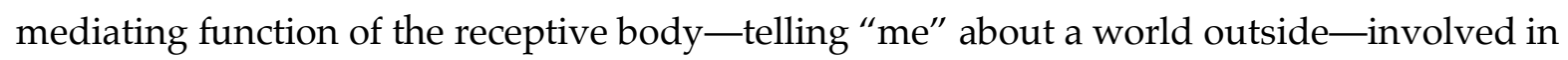
both Abbate's and Hasty's arguments. Abbate's use of these emotions makes sense, as it points to the (Abbatean) drastic relation of inseparability of body and music (affect), and the emotional effect denoting a distinction between music and listener. This distinction is generated within the process of listening and complicates Abbate's concept of the drastic, which implies the affected inseparable body and music and implies the becoming of the listener together with a musical environment. In other words, Abbate's notion of the drastic as involving desperation and peril is of significance, as it demonstrates the gnostic created through, and within, the act and material circumstances of listening. In chapters 3 and 4, we will return to the generative nature of cause-and-effect relations in terms of Barad's (2007) "cutting things together and apart" (394).

Neither Hasty's nor Gendlin's concepts of "experiencing" fully take up the implications of Abbate's concept of the drastic. Hasty (2010a) states that, with regard to the drastic, the connotations of "desperation and peril" do not contribute to "the usefulness of the term," stating further that "[d]espair need not to be at the heart of doing" (201). His worry is that these connotations negate the "doing" captured in the concept of the drastic when, as referred to above, considered from an etymological perspective ("the Greek verb dran - to do, act, make;" 201). However, as demonstrated, there is "doing" involved in Abbate's concept of the drastic, in the affected body and music, and in the distinction produced between the listener and the musical environment. Thus, Hasty turns away from the Abbatean "situated" as the material and discursive concept of the drastic, arriving instead, via an etymological discussion, at Gendlin's concept of experiencing. 
By taking the step explained above, Hasty leaves us with a difficult problem. We have seen in chapter 1 that Abbate positions the body centre stage-as a receptacle. I have demonstrated that her concept of the drastic allows for thinking — through the act of listening to music - the distinction between the affected body and music (drastic) on the one hand, and the musicalised (culturalised) listener (gnostic) on the other. The question is why Hasty considers the relationality between a limited concept of knowing and the experiencing body, but does not consider the Abbatean drastic, involving affect and emotion, as emerging from the relationality between body and music. Hasty introduces a phenomenological dualism of (cultural) body and world, in which the experiencing body mediates music and contributes to the construction of meaning. In other words, his attention goes to the function of the body as mediator, producing knowledge within the domain of meaning-making.

Hasty (2010a) begins by positioning "experiencing" as a concept that denotes process. He accounts for bodies "living, feeling, thinking . . . constantly and newly made and remade in time ... intricately folding and folded into their worldly environment" (200). In my reading, he suggests here a relationship in which an alive, thinking, feeling body interacts with an environment that is (still) considered to be "outside" of the extra-musical and the extra-bodily. As such, Hasty's statement does not involve a uniting of the drastic and the gnostic in a generative sense of "becoming knowledge" and "becoming music."

It is "by and with the living body" that sense is made of things (Hasty 2010a, 201): "You think of, sense, feel, imagine all sorts of things: For instance, you sense your body in all sorts of ways, feel your instrument, value what is happening in light of what has happened and what might" (207). Here Hasty assumes a body and a (musical) thing that are prior to sense-making. That is, although Hasty includes the temporality of process in his argumentspeaking of ongoing experiencing - it is the experiencing body that constructs or represents the multiplicity involved in the ongoing materialisation of novel events, as we can read in the cyclic "again and again" (Hasty 2010a, 201). Echoing Claire Colebrook (2004), this concerns a mode of equivocity; a "distinction between that which signifies [the experiencing, meaning-making body] and that which is signified [the marked musical thing]" (284). This difficulty—the inherent dualist nature of Hasty's (2010a) argument-also follows from 
Gendlin's phenomenology. Citing Gendlin, Hasty proposes that experiencing should “be thought of as that partly unformed stream of feeling that we have any moment" (Gendlin [1962] 1997, 3; cited in Hasty 2010a, 202). That is, Hasty differentiates between experiencing, which "seems to place us 'in' time" (210) and where "meaning [is] an emergent property of all experiencing" (Gendlin cited in Hasty 2010a, 202), and a (musical) world outside. Hasty defines meaning as "a functional relationship between felt sense [experiencing] and signs" or "palpable objects that come to us" (202). This divide, in which the palpable and the feeling body are separated through the representational mediation of meaning, prevents an ontoepistemological reading of Hasty's argument. Furthermore, Gendlin's intervention of a "partly unformed stream" is problematic, as it affirms Hasty's presupposition of an a priori conscious human being, making the distinction between formed and unformed. This suggests a belief in the exceptionalism of human thinking and doing that denies matter (including the human body) its generative nature and considers the (experiencing) human subject as a "given."

In conclusion to this section, Hasty's response to Abbate's question is particularly predicated on conceptualising the processual character of music from the perspective of the human experience of the experienced "thing." Although he considers a relationality between knowing and the human body, his concept of the body tends to instrumentalise it as a mediator, thus implicating a break between a conscious human being and an outside world (including the body). In short, Hasty's "suggestion from the drastic" as an attempt to overcome the Abbatean binary logic, tends instead to repeat this same logic. It is a dualism that re-occurs when adding metaphysical concepts to musical phenomena without engaging with the creation of a problematic of shared situatedness. What we have to explore with care, then, is the relationality involved, namely, the inseparability of the drastic and gnostic. It is musical reality—the inseparable entanglement of matter, the discursive, and musical aesthetics-that demonstrates such a perspective. 


\subsection{Georgina Born: Relational Musicology}

Born is an anthropologist and sociologist of music and culture. In "For a Relational Musicology: Music and Interdisciplinarity, Beyond the Practice Turn," Born (2010a) argues for a shift in how musicologists understand music as an object in the world and as an object of study. In order to meet the challenges of today's widened musicological scope for research and theorising, she proposes a "relational musicology" in the form of an opening up of musicological sub-disciplines to other scholarly and scientific disciplines. In doing so, she envisions an enabling of research on "music of all kinds, historical and contemporary, in ways that can both underpin and help to foster creative developments in musical practices of all kinds" (205). In a footnote, she reminds her readers of Abbate's discussion, calling it a "most theoretically ambitious version" when it comes to the interdisciplinary aspects of musicology's turn to performance and musical practice (219, note 54). As a demonstration of a widened musicological scope, Born endorses Abbate's emphasis on live performance as a "temporal, carnal, and social event" (219). She also affirms Abbate's critique of the accepted study of performance and the practice of music-making; of turning performers and performances "into yet another captured text to be examined ... via a performance science" (Abbate 2004, 509; cited in Born 2010a, 219). Born elaborates on this critique, as she finds the turn to performance and practice flawed because it suggests an interdisciplinarity that is predicated on a conflation of "the historically inclined, humanities model of musicology with the micro-social, musicologically inclined aspects of ethnomusicology" (230). As such Born considers practice and performance studies a welcome attempt to transcend particular boundaries between musicological sub-disciplines. However, she also emphasises the need for further sub-disciplinary introspection as a precondition for opening up to other sources that may enable the renewal of musicological scholarship, like "those deriving from social sciences and history, their methodologies and theoretical resources" (230). For Born, a relational musicology is a better alternative to the practice turn-the theoretical interest in 
the role practices play in human lives-and to musicological performance studies, entailing an "expanded analytics of the social, cultural, material and temporal in music" (243).

Considering Born's engagement with Abbate as outlined above, I want to make the following intervention: As discussed earlier, Abbate (2004) develops her argument through her critique of accepted performance research and a (new musicological) hermeneutic interpretative approach. This critique co-constitutes her rationale for considering the distinction between the drastic and the gnostic as existing in a state of oppositional difference. Like Abbate, Born (2010a) does not agree with accepted performance and practice research, and, citing Abbate, wants to escape hermeneutic models that turn "'performances and performers into yet another captured text to be examined . . via a performance science'" (Abbate cited in Born 2010a, 220). However, Born (2010a) then turns away from Abbate, stating that she misses in Abbate's argument a "clear" alternative (219, note 54)—an alternative that Born proposes through her elaboration of a relational musicology. In the same footnote, Born takes the work of the philosopher and sociologist Theodor W. Adorno as a wedge to emphasise the difference between her argument and Abbate's. Whilst in her portrayal of Adorno, Abbate (2004) considers the hermeneutics in his writings-which she criticises as "allied to the 'musical hermeneutics with laboratory standards'" (527, note 50)_ Born (2010a), first and foremost, follows the sociological argument in Adorno's writings. ${ }^{56}$ Here, I will not go into this distinction and its relation to Adorno's thinking in detail, but explore how this wedge emphasises the Abbatean orientation of music as a drastic occurrence-one that the Adornian analysis is unable to capture. As alluded to before, Abbate (2004) considers Adorno's “technomysticism" (527) to be a demonstration of "clandestine mysticism" (517) with the same result. In this case, "technology, codes, inscription metaphors, and mechanisms" displace "the material and carnal" of real music

\footnotetext{
${ }^{56}$ As mentioned in chapter 1, Abbate (2004) criticises the "clandestine mysticism" in Adorno's ([1928] 2005) hermeneutics and his use of concepts such as "seismographic," through which he clandestinely builds on the affective nature of music-as-performed without really including it in his writings (14). In "Listening, Mediation, Event: Anthropological and Sociological Perspectives," Born (2010c) considers Adorno the sociologist. Whilst considering him helpful to discuss listening from a broader category of experience that includes the "collective and located nature of musical experience" (80), albeit from a critical perspective, she suggests only "to take initial theoretical and conceptual bearings" from Adorno (80).
} 
(527). Of interest is that this Adornian wedge also emphasises Born's (2010a, 232) orientation of music as a cultural form that mediates the social.

Both Abbate's and Born's arguments establish the idea that music implies a gathering together of matter, bodies, activities, and people, prompting the question of how the Abbatean drastic — the "messiness" of a musical occurrence affirmed by Born (2010a, 219, note 54) - enters into Born's account of music both as an object in its own right, and as an object of relational musicological consideration. In other words, does the relational musicology proposed by Born engender a qualitative shift in musicological theory and research that enables responses to "music of all kinds" and music "practices of all kinds" (Born 2010a, 205), by taking up the challenge of the Abbatean problem? Or, in terms of this study, does Born propose a relationality as an intrinsic material and social relatedness from which music, the social, and their relationality are being generated, offering a new perspective on difference beyond a simple opposition of the drastic and the gnostic? In the following section I will unpack Born's argument for a relational musicology.

\subsubsection{The Shackles of Two Conceptual Boundaries}

Born (2010a) predicates her argument on Philip Bohlman's (1993) discussion of a reconfiguration of musicology, in which he formulates an answer to the concern, growing in the early 1990s, towards the untenable scholarly regimes of excluded musical Others, brought about through acts of essentialising and depoliticising the musical phenomenon. Music, as the object of musicological study, had been considered independent from the political, the body, and the "Other" ("Islam or black musics;" Born 2010a, 206). According to Born (2010a), Bohlman emphasises the way in which a depoliticising act in fact makes music more political, for (of course) the drawing of disciplinary and conceptual boundaries is also “immanently political” (207). However, Born does not consider a reconfiguration of musicological sub-disciplines simply by including the excluded (the political, the body, the "Other") through an appeal "to the [changing] politics of the public sphere," as suggested by Bohlman (1993, 208). Rather, what is needed, according to Born (2010a), is a musicological 
introspection that questions "two dominant conceptual boundaries that have underpinned the hegemony of a certain kind of musicology," constraining musicological perspectives that are "relevant to all musics" and musical practices (208). That is, instead of extending the field's objects of research and theorising by inclusion-which would "simply turn on musicology's responsiveness to developments in the public sphere" (208)—Born proposes to revisit musicology's internal structures, allowing for a "redistribution of attention to new objects of [musicological] study" (208).

First, Born (2010a) considers the conceptual boundary between music and the social—which, according to her, concerns the ontological question of "[w]hat music is" (208, emphasis in original)—in the conception of music's ontology within the various musicological sub-disciplines. Here Born touches upon the musicological concept of music as "music itself," which supposedly has an ontologically ambiguous frame of reference all of its own. ${ }^{57}$ According to Born, the conceptual boundary concerns a historically settled differentiation between music and the social that underpins musicological theory and research, and "afford[s] varying degrees of legitimation to the music subdisciplines" (208). I read this as a strong epistemological category that opens up to other subsidiary categories, in which a difference between music and the social is rehearsed again and again as a (de)legitimising opportunity to establish the boundaries of a musicological sub-disciplinealbeit closed off from other scholarly and scientific approaches. Hence the formation of, amongst others, music history, music aesthetics, ethnomusicology, and formal and structural music analysis, which, according to Born, find legitimacy through a "conceptual dualism" considering "the 'social' ... extraneous to 'music'" (208).

Current musicological discourse, according to Born (2010a), affirms Abbate's argument that music cannot be addressed as music itself, since music is shaped "by social and cultural forces" and "music's social contingency and nonautonomous messiness are

\footnotetext{
${ }^{57}$ The concept of "music itself" focuses on the pure sounding gesture that also shines through the idealised "work" concept. This gesture considers, for example, that music (as performed) is kept in a score. See Lydia Goehr (1992) for a history of the "work" concept. In Born's (2010a) argument, the concept of "music itself" is proof of the conceptual dualism in which the social is considered "extraneous to 'music' and equivalent to 'context'" (208).
} 
patent" (Abbate 2004, 514). Born's (2010a) concern, however, rests with the directive force of the conceptual boundary between music and the social. Clearly, she does not include musicology's (and Abbate's) ongoing discussion of how to cope with music's temporal, material, and social being and the problem of representation. ${ }^{58}$ Born states that musicological scholarship assumes the social to be extraneous to music, conceptualising music itself as an independent entity and object to be studied, predicated on autonomy, and represented through musical notation. ${ }^{59}$

As a second conceptual boundary to sub-disciplinary introspection, Born (2010a) asks "what counts as music to be studied" (209, emphasis in original), referring here to the formation of a musicological canon of music considered as worth studying. Born's concern is the established differentiation between music that is included and music that is excluded from musicological theory and research. The proposed conceptual boundaries are obviously related, as they both seem to point to the concept of music itself-that is, assumed as independent of social and material circumstances, and confined to "Western art music" (209). Crucially, Born's elaboration of a relational musicology starts from a point of introspection, which supposedly frees musicology from the shackles of dominant concepts that prescribe what music must be studied and how it must be studied, in order to open it up to other scholarly and scientific insights and thus meet the challenges of a widened scope of musicological theory and research.

\footnotetext{
$58 \mathrm{It}$ is clear that musicologists cannot do without visual and conceptual representations; that they do know that music is a temporal, material, and social occurrence; and that they treat music as if it is static. Music philosopher Stan Godlovitch (1998), in creating a (static) model for studying musical performance, knows that "music typically lives in and for its public sounds which derive from performance," which is a reason to regard "the musical enterprise generally from the performance standpoint" (11). Moreover, as Jankélévich (2003) argues, musicology "is an exponent art" (80). Many musicologists are, or have been, music practitioners (Born was also a performer in a band) and are familiar with the difficulties of representation. However, the problem is that "the fictional character of the model state ... may be forgotten," and that music researchers eventually become the "static onlookers of static [musical] Being" (Barden cited in Mullarkey 1999, 37).

${ }^{59}$ Whilst also considering exclusion, Susanne Cusick (2001) understands "music itself" as a reductive conceptualisation of music, suggesting that "music itself" concerns "an entity that is always present for us to consult, that it is independent of any particular performance or social setting, and that (ideally) communicates its meanings directly to listeners who are properly prepared to interpret them" (492).
} 
However, as mentioned previously, making distinctions between "music itself" and thematising the "social" for scholarly consideration may only serve to shift a conceptual boundary to a conceptual dualism, creating a "social itself," with the effect of remaining within a stationary argument, discussing the terms of the very difference that Born (2010a) wishes to overcome. In other words, Born's "conceptual boundary" evokes a conceptual dualism, inviting musicologists to interrogate a conceptual duality as an incorporated disciplinary difference that needs to be calibrated against a global, musical, and social environment. This suggests that Born's relational musicology builds on establishing these terms and keeps the differences intact, not taking seriously the intrinsic materiality from which music and the social, as defined entities, are generated. In this case, the implicit morality that resides in the warm generosity towards all music and musical practices in the name of the all-encompassing social is of no help, as it does not touch upon the material complexity involved in relation and relatedness, but rather upon a predefined difference to that which is not social and conceptualised by Born as "music itself." It is clear that Born does not consider relationality as a generative value predicated on entanglement. Instead, she cherishes difference between terms and makes distinctions the building blocks for her argument.

\subsubsection{Difference: Preconditions for a Relational Musicology}

For Born (2010a), finding an answer to the issue of constraining conceptual boundaries requires the counterintuitive act of introspection in order to be able to look beyond music's disciplinary formations "to the sciences of the cultural, social, and temporal, which is to say anthropology, sociology, and history" (210). In this sense, a relational musicology would open musicological theory formation and practices of research to "sources of renewal" (230), located outside the familiar music sub-disciplinary network of various musicologies. Born's research at IRCAM — the Paris institute for physical research into music and sound, and into the creation of electro-acoustic sound art-is crucial for her development of a relational 
musicology. ${ }^{60}$ Her aim, as demonstrated in this research, is to establish a macro-social and anthropological orientation in order to "inform critical discourses and processes of judgment-making" and to understand the "institutionalizing of value communities," including "our own contributions and complicity" (218). ${ }^{61}$ In order to do so, a relational musicological methodology requires that insights are borrowed from, in Born's case, sociology, anthropology, and historiography. She narrows this orientation down to prominent scholars, such as the philosopher Michel Foucault, the sociologist Pierre Bourdieu, the philosopher and literary critic Jacques Derrida, and the philosopher and gender theorist Judith Butler (230).

Crucially, Born's (2010a) relational musicology assumes a non-integrative interdisciplinarity. She emphasises the need for an "agonistic-antagonistic mode" (211, emphasis in original); an interdisciplinarity that "springs from a self-conscious dialogue with, criticism of, or opposition to, the intellectual, aesthetic, ethical, or political limits of established disciplines" in order to "contest or transcend the given epistemological and ontological foundations" (211). Although she lessens the agonistic tension of "the doing of critique" —referring instead to the "agonistic pleasure of . . . inter-subdisciplinary dialogue" (206)—she, nevertheless, states that to consider music as "immanently social and cultural" (231) requires a revolution in thought (a "break"(231)) that shifts our ontological and epistemological understanding of all music. It is clear that Born's argument, like Abbate's

\footnotetext{
${ }^{60}$ The Institute for Music/Acoustic Research and Coordination (Institut de Recherche et Coordination Acoustique/Musique, IRCAM) was founded by Pierre Boulez in 1977 (see www.ircam.fr, last accessed September 10, 2019).

${ }^{61}$ Born (2010a) chooses the macro-social as a starting point for research, criticising a "micro-social conception of musical practice" (219). Apart from following Steven Feld's analysis of music's social mediation (Born 201a, 220, 232), which may be considered an attempt to problematise the micro-macro relationship, Born does not explain how the concepts of micro and macro are subject to ongoing debate within the social sciences. Manuel DeLanda (2006), working on a more co-constitutive relationship between the micro and the macro, elaborates upon this debate and its reductionist framing. DeLanda considers how social scientists start from the inherent reduction of a mechanism, of "individual rationality," or "routines and categories that structure individual experience" (4). Following DeLanda, Born's macro position would suggest that music as a "social structure is what really exists" (DeLanda 2006,5 ) and that the micro level of (Abbate's) individual experience, or of accepted performance research, merely involves an epiphenomenon produced by the greater mechanism that involves society as a whole. From this we may infer how difficult it is to see in Born's social scientific take on a relational musicology - which is built on distinctions - a relationality predicated on the generative encounter in which matter meets music and nature meets the social.
} 
and Hasty's, builds on the making of distinctions by separation. In chapter 3, I will shift these binary approaches in their various forms.

Born's (2010a) reference to the philosopher and historian of science Michel Serres is helpful for understanding the rationale of her argument. Serres gives an account of how modern knowledge involves a process of "ever greater specialisation" and disciplinarity, with the growing difficulty of stepping "without interruption" from local knowledge to a global configuration, "implying a homogeneous space of knowledge ruled by a single scientific truth" (cited in Born 2010a, 209). Serres provides a sketch of identity-driven modernism, based on the establishment of a difference between perspectives unified by a single overarching truth. Following Serres, describing the postmodern condition, Born acknowledges that there are now only "regional epistemologies" in which going from one perspective to another "requires an arduous effort," without the comfort of an encompassing truth (Serres cited in Born 2010a, 209). We can now see how Born's move towards a relational musicology involves the overthrow (a modernist act) of the modernist musicological disciplinary focus, in which a "one true music" serves as a unifying principle. As suggested by Born's argument for postmodernist multiple perspectives, this is neither an ideal nor a unifying force at all. Rather, the music she encounters is "immanently social and cultural" (232), which accounts for the "startling diversity of music's existence in the world" (210), thus demanding Serres's "regional epistemologies" to be studied and reconciled. This leads to her proposal for a relational musicology that serves as a postmodernist methodological starting point in order to describe the multiple forms of social and cultural knowledge expression.

However, there is a problem with how Born's (2010a) argument seeks to break with (modernist) disciplinarity bounded by a unifying concept of music itself. The difficulty is that Born's agonistic analytics—considered productive for a new musicological scope and set as an answer to high modernist compartmentalisation-prolongs that same habit by multiplying the same identity-driven exercise. To overcome Serres's "regional epistemologies" of musicology's sub-disciplinary specialisations, Born proposes "to look outside" the musicological disciplines "to anthropology, sociology, and history" (210). 
Supporting her argument, Born borrows from Serres's writing on epistemological change, in which she considers the role of the intellectual as an "attempt to see on a large scale, to be in full possession of a multiple, and ... connected intellection" (Serres cited in Born 2010a, 209). By scaling up, however, Born sticks to a method of compartmentalisation, considering the relation of music against human sociality and against its temporality. That is, her argument relies on the reasoning mind using the reified concepts of music, the social, and time, without considering a generative relationality. However, in Conversations on Science, Culture and Time, Serres argues that "[a]n idea opposed to another idea is always the same idea, albeit affected by a negative sign. The more you oppose one another, the more you remain in the same framework of thought" (Serres and Latour 1995, 81).62 This oppositional stance represents an infinite vice versa between the ideas of postmodernism and modernism.

Related to this dissertation's exploration of immanent ontologies generated through the relationalities of material and discursive entanglements, Born's (2010a) building on difference as the precondition for research and as a negativity between terms presents a real problem in her rationale. She seems to consider difference between music itself and the (under-thematised) social and cultural situatedness of music as a form of imbalance, which she attempts to overcome by emphasising music as a factor in the production of sociality. However, as Serres suggests, this imbricates us within the same dualist discussion in which either the concept of music, or the concept of the social, is dominant (Serres and Latour 1995). Born's (2010a) emphasis on the social, in which music produces socialities and is produced by the social (232), makes it difficult to find references in her argument to that which exceeds the musicological approach—namely, the drastic. Born (2010a) considers the Abbatean problem as a failed attempt at a sociological approach, resting its case based on the micro-sociality of the perspective of individual experience espoused by Abbate.

Although materiality is mentioned as an important factor in the sociality of music, considering the "ontology of the embedded musical or cultural object" (Born 2010a, 210),

\footnotetext{
${ }^{62}$ A revolution or break with the old, in Born's (2010a) terms, rather establishes the new by overthrowing the old and is thus confined to the (conceptual) dualism between old and new it creates. See Dolphijn and Van der Tuin (2011, 2012).
} 
Born's reference to materiality seems to be rather bleak when considering how she salutes Abbate's focus on the drastic as "the temporal, carnal and social event of live performance" (Abbate cited in Born 2010a, 219, note 54). Materiality is only referenced via Born's (2010a) discussion of recording technologies that alert "us to the mediated nature and the materialities of all musical experience“" (236). ${ }^{63}$ In another article, and in concordance with scholars cited below, she addresses the materiality of cultural objects "with reference to their obdurate 'thing-ness,' and to their varying ontological status," noting that objects "construe 'our sense of ourselves as subjects ... how the things that people make, make people'"' (Miller 2005 cited in Born 2010b, 188). This is yet another statement that testifies to the social and anthropological orientation of Born's argument, in which materiality-involved in the production of music and the social—is considered from the enclosure of a (human) social and cultural world. That is to say, materiality is considered by, and positioned against, the human observer, but is not considered to be a generative factor that actively informs a musical sociality.

Considering Born's (2010a) emphasis on conceptual dualities and agonistic analytics, my concern is that the relational musicology that Born proposes seems to be yet another rehearsal of the (Abbatean) gnostic analysis, involving both (a new musicological hermeneutic) recognition and interpretation, and holding the one thing (idea) against the other without considering the material, social, and temporal dynamics of musical creation. As Born (2010a) states, referring to her preference for the antagonistic mode, those which especially qualify for the "agonistics of criticism" (218) are "core problems—such as value, temporality, technology, the social" (242). However, without including generative matter, materialities, and materialisations, these "core problems" are dealt with within stable cultural and social structures. Kirby (2011) aptly points to the problem at hand, stating that, "[i]f the economy of values [culture] can be analyzed, contested, and redistributed" (74)—as demonstrated through Born's (2010a, 231) agonistic analytics, disciplinary categorisations,

\footnotetext{
${ }^{63}$ In chapters 3 and 4, technologies will be discussed as Baradian material-discursive, enfolded practices, challenging the dualism inherent in the familiar concept of mediation (and derivatives). As also suggested by Born's notion of mediation, this concept starts from predefined entities, articulating a (neutral) inbetween that bridges gaps between components or gives a subject access to an object.
} 
and comparative models-materiality is enclosed within a cultural and social frame (Kirby 2011, 74). In other words, music's matter, materiality, and materialisation figure as an outside in Born's argument, emphasising music and musicology as mere social and cultural affairs.

As a conclusion to this discussion, considered from the new materialist perspective of my project, the correction of the conceptual opposition between the music and the social envisaged by Born requires a further step. The aim is not to prove, through critique, an adequacy or, regarding Born's critique on Abbate, an inadequacy of thought (theory or method) to capture a musical, material, and social world, but rather to take into account musicology's knowledge practices as entangled nature-culture practices. Music in all its assumed ephemerality, and the social in all its assumed "culturalness," cannot be dissociated from, in Barad's (2007) terms, matters of "matter" and "meaning." Furthermore, the musical social is neither rescued, nor is Born's music-social dualism resolved, by adding sociological and anthropological knowledge practices to musicology's modernist distillation of "music itself." Correcting conceptual boundaries and considering a linguistic, discursive exercise (re-)affirm the dualism beforehand, as it presupposes both a concept of "music" and a concept of the "social" without taking account of the generativity of matter, materiality, and/or materialisation—a statement to which I will return in the following chapter. Born's theorising of relational musicology concerns a relationality between pre-established terms, addressing the addition of epistemologies, classified according to their (also classified) proximity to (further classified) musicological epistemologies in which the human social, replacing the musical work, is considered the foundational starting point.

2.4. Benjamin Piekut: Gathering Together

Piekut (2014) discusses Bruno Latour's ANT and the benefits (and disadvantages) it is supposed to offer music-historical research. It is a strategy that necessarily shifts a firmly 
established, historical argument, resting on (the search for) fixed origins, "to [the] study [of] different kinds of grouping, the role of non-humans in the creation and extension of those groupings, and the indeterminate shapes that result" (212). This is to question a musicological episteme demonstrated by concepts such as "influence, genre, and context" (191). ${ }^{64}$ Piekut considers these concepts from a Latourian sociality of human and nonhuman elements, suggesting a responsiveness to the contingency of "origin," in which "origins" are the "well-worn tracks laid down by previous accounts" (212); the "worlds imagined by ... researcher and historical actor," subjected to revisions (212). Piekut considers music an "exemplary case for investigating matters of social theory" and serving a historical account (191). Via its "social modes of production and distribution [and] the many allies required by musical sound to exist and endure," music might be considered as enfolded in these socialities (191). Piekut does, however, not consider musicological and other scholarly research into historiography. Instead, he turns primarily to the work of the social scientist and philosopher Bruno Latour, and the musicologist and anthropologist Georgina Born. Piekut bases his argument on his own research on composers, organisations, and pop artists from the late twentieth century (193). In other words, Piekut addresses contemporary music history in terms of the sociality of human and nonhuman factors.

Combining the human and the nonhuman, Piekut's (2014) approach seems promising, serving the well-aimed goal of finding a resolution to the culture-nature dividethe inherent stalemate of the Abbatean, oppositional difference between the drastic and the gnostic. As Piekut states, Abbate's plea is "an exemplary case of this shift [to performance research] in music studies" (202). He argues, however, that this shift requires a more "expansive understanding of performance," not resting its case in "the [Abbatean] isolatibility of the ineffable moment," but addressing the sociality of human and nonhuman factors (202). Nevertheless, accounting for "music's concrete forms" (202) and emphasising the human social as extending beyond "the objects we share" (200) introduces an irresolute

\footnotetext{
${ }^{64}$ The term episteme is used here following Foucault's ([1970] 2002) notion of "the epistemological field," according to which epistemes form the basic concepts "in which knowledge ... grounds its positivity" (xxiii).
} 
friction between the object and the human social that (obviously) disturbs Piekut's wish to operate in "concrete ways" $(200,206,207)$. In my reading, friction is demonstrated by the way in which Piekut does not consider how historical identities (e.g., things, social relationships) are produced as entangled matter and meaning (drastic and gnostic) events that include the historian, as well as how Piekut understands ANT as a research method isolated from a Latourian metaphysics. In other words, placing humans and nonhumans as the (Latourian) "social" centre stage in order to escape Abbate's stalemate and the problem of music-making introduces a tension regarding the pressing question of difference (between the human and the nonhuman; the drastic and the gnostic) and thus of identity formation, relationality, and of how the researcher/musicologist is implicated.

In the following section, I take particular notice of these "tensions," through which I engage with (1) how Piekut follows ANT as a method, taking its metaphysical embeddedness (intentionally) for granted, and (2) how Piekut considers the Abbatean problem solved by extending the concept of performance. Although his study clarifies Latour's ANT as a methodological principle of music-historical interest, I limit my reading to the salient issues concerning metaphysical embeddedness and Piekut's response to the Abbatean plea. I will carefully read Piekut's and Latour's insights, enabling me to point to the intricate difficulties that one encounters when escaping dualism and turning towards material and dynamic being as starting points for research and theorising. I begin with a short introduction into Latourian thinking and research, followed by a reading of Piekut's argument from the two points of view outlined above. In the first, his privileging of ANT as a method is demonstrated. In the second, we see how Piekut cannot escape the confinements of a Latourian metaphysics.

\subsubsection{Latourian Thinking and Piekut's Argument}

Piekut (2014) recognises that, although ANT as a methodology is used by many scholars in various ways and within various kinds of research, it is still strongly identified with the work of Bruno Latour. Demonstrating how Latour's concepts can be of interest, Piekut 
borrows, amongst others, from Latour's well-known research on the sociology of science. In the context of the Pasteurian revolution, Latour (1988) explicates how this was created by innumerable actors, contradicting the familiar linear, historical tale that goes along the lines of genius scientists, technologies, and laboratories, exemplifying scientific progress. ${ }^{65}$ From such a Latourian perspective on research practices, Piekut (2014) distils the task of musicologists to trace the "set" of "associations"- the innumerable actors that are somehow assembled-that traverse the conventional assumptions of the coming into being of historical events (192).

In We Have Never Been Modern, Latour (1993b) connects to wider debates concerning the social sciences. Here, he argues against the (modernist) belief or (unacknowledged) assumption that we (humans) are cut off from the world when doing research and that we are cut off from our past-a stance similarly expressed through the concept of postmodernism. Contrary of this belief, Latour states that the past and the future, the (human) social and the natural, are intimately related, conceptualising the latter as the quasiobject, actor-network; an object in-between the social and the natural (55). This suggests that neither scientific realism, nor social constructivism can be maintained. Scientific data do not offer a transparent view of the world, as realists would insist, nor are they fully constructed through a mediation of a social reality, as would be espoused by social constructivists. For scientific realists, a "real" world is mirrored in representations, whilst for social constructivists, a "real" social domain is mirrored in representations. In short, both worldviews negate the active nature of matter, participating in the ongoing reconfiguration of the world (Latour 1993b). ${ }^{66}$

For Latour (1993b), this debate on scientific realism and social constructivism-both considered realisms that necessarily depend on the truth claims of representations-together with a critique of the "modern constitution" reopens thinking on the social-nature

\footnotetext{
${ }^{65}$ Latour (1988) describes the "chain" through which pasteurisation became the hygiene revolution: "At one end, France; at the other, those who in their laboratories make the microbes visible; in the middle, the hygienists who translate the data from the laboratories into the precepts of hygiene; a little further on, the public authorities who legislate on the basis of advice given by this new profession, scientific hygienism, which must now be taken into account" (56).

${ }^{66}$ For this discussion, see also Barad (2011, 443-454).
} 
relationship when doing scientific research. ${ }^{67}$ Latour goes against the so-called necessary belief in one of the poles (scientific and social realisms) with their implicated dependence on representationalism (as discussed in chapter 1), proposing instead a mix of human social and nonhuman elements. ${ }^{68}$ According to Latour, the actor-network contributes to the coming together of hybrids that "are 'real,' but real quasi-objects [that] do not have the characteristics of being things out there, passive and boring, waiting to be unveiled," but rather "start resembling what our world is made of" (Latour cited in Crawford 1993a, 261); a gathering of the social and the natural, or of humans and nonhumans. ${ }^{69}$

This very short introduction to Latourian thinking, as related to Piekut's argument, serves to demonstrate how ANT as a methodology for empirical research is fully embedded in a metaphysics that considers the world to be constituted by hybrids of actor-network gatherings. However, Piekut (2014) does not want to accept any (Latourian) metaphysics, anxious not to mistake that which has to be explained ( a musical reality) for that which explains (actor-network theory)—that is, to "mistake explananda for explanantia" (193). I recall the ambiguity of the Whitehead citation at the beginning of this chapter. Whereas Whitehead, Bergson, and Barad all seek a metaphysics beyond a detached meta-position of the human intellect, Piekut avoids considering metaphysics, thereby affirming Abbate's $(2004,505)$ notion of "metaphysical mania" as a withdrawal from (drastic) reality. For Piekut (2014), any metaphysics, as articulated by ANT, implicates the framing of empirical research through the power of explication—the meta-position of the human intellect. By arguing that "ANT is not a theory," he expresses his aversion to metaphysics, suggesting his anxiety towards any disturbance of the Latourian quasi-object (hybrid) of the human and nonhuman connection (Piekut 2014, 193). Whilst, also in Latour's thinking the relationship between

\footnotetext{
${ }^{67}$ The Latourian concept of "modern constitution" defines the dualism between the natural and the social as "common understanding that organizes the separation of natural and political [social] powers" (Latour 1993b, 13). It is thought of as written by sociologists and anthropologists. In Latour's example, both are products of the modern constitution, distinguishing and separating "humans and nonhumans, their properties and their relations, their abilities and their groupings" (15).

${ }^{68}$ See Latour (1999). Especially in the first two chapters, Latour critiques the so-called divide between nature and culture. He elaborates here on the Cartesian legacy (1-24) and on how scientific practices translate, step-by-step, the stuff of nature into representations (24-80).

${ }^{69}$ For a discussion on how Latour relates ANT to the scientific realism and social constructivism debates, see T. Hugh Crawford's interview with Latour (1993).
} 
theoretical work and empirical research seems to be of utmost importance. Latour's research into the details of scientific practices—-famously articulated as "how do we pack the world into words?" (Latour, 1999, 24)—seems to be a real opportunity to question Abbate's drasticgnostic dualism in Latourian terms.

The questions with which I want to enter Piekut's (2014) argument concern how Piekut—by emphasising the "common-sense" reality of things, action, and time, based on an accepted difference between method and metaphysics—buys into a dualism predicated on a negativity between terms (202). Consider the Abbatean separation between music-asperformed and the musicological mind, which Piekut supposedly considers resolved by the Latourian nature-social hybrid of ANT. The question then remains whether the positioning of historical things and events, to be enlisted as traces for research, nevertheless has to come to terms with the assumed theoretical intentionality of the (Latourian) historian-as-observer. Finally, how does Piekut's approach, by not thematising Latour's (1999) question of "how ... [to] pack the world into words" (24), work for the Abbatean gnostic and drastic opposition? Before we enter into these questions, I first describe the installed difference in the two readings in which, in my view, his argument is embedded.

\subsubsection{Piekut's Argument: Two Readings}

First, it is clear that Piekut (2014) emphasises ANT as both a useful methodology and an instrument for doing music-historical research that offers "a repertoire of questions and terms" (193). According to Piekut, ANT will provide for "an empirically justified description of historical events, one that highlights controversies, trials, and contingencies of the truth," and will, as such, help "us to attenuate normative assumptions about our object of research" (193). With ANT, his argument seeks to introduce the materialities and actions needed for a "musical sound to exist and endure" (191), which he considers of value to music-historical research. Through a method that deals with things and their effectiveness, a music history is captured in which previously muted things are given voice by the approach of a music historian. Piekut uses (Latourian) methodological concepts of agency, action, ontology, and 
performance in order to examine "three concerns of music-historical interest-influence, genre, and context—with a view to altering how we put them to work" (194). We are encouraged not to focus on, for example, what music is, using influence, genre, and context as reified, neutral entities that direct research and theorising. Rather, Piekut points to how music is "mediated and enacted in the world through specific events and materialities" (202).

Secondly, it is also clear that (with Latour) Piekut's (2014) argument stakes everything on the social, re-enforcing that which Abbate $(2004,514)$ refers to as the familiar truism that music is shaped by social forces. For Piekut (2014), music is an exemplary case for "investigating matters of social theory" (191). As an example, Piekut refers to Born's (2010a) classification, based on her analysis of how music is enfolded in "four orders of social mediation," through which "we relate to each other" (Piekut 2014, 191).70 As such, Piekut distinguishes a musical object as being socially mediated and music as the force that mediates social modes. This brings to mind Born's (2010a) dualism of a social reality and a musical reality, discussed in section 2.3. However, Piekut (2014) nuances Born's categories and brings musical materialities to the stage, emphasising that nonhuman elements are part of the "socialities ... required by musical sound to exist and endure" (191).

In what follows, I turn to how the Latourian empirical metaphysics struggles in terms of the human observer who picks and chooses between human and nonhuman entities. Taken up by Piekut, it suggests—contrary to his aim of bringing things and action centre stage-rehearsing a humanist dualism as a human inscription of materialities, considered as traces of music-historical things and events. This problem of the human registrant does not change when Piekut (2014) says that ANT researchers "follow" networks of actors (199). Another problem is how Piekut's argument considers music a "special, and exemplary case for investigating matters of social theory" (191). As we saw in Born's argument (endorsed by

\footnotetext{
${ }^{70}$ Born's (2010a) four orders of social mediation consist of collaboration and human gatherings, grouped first through the practical exigencies of making music. As an extension, she considers how musical performances aggregate listeners into "imagined communities," the publics "based on musical and other identifications" (232). Widening the circle, she also considers the shaping of "structures of class, race, nation, gender, and sexuality" through music's embodiment (232). As a fourth category, Born distinguishes how, through production and distribution, music contributes to, and is caught up in, "largescale social, cultural, economic and, political forces" (232).
} 
Piekut), the sociological approach—when added to a (predefined) music or musicology as different from the social, and without taking into account the generative nature of matter, materialities, and materialisation-introduces a dualism via which any benefit for musichistorical research (as supposed by Piekut) becomes obscured.

\subsubsection{Method and Metaphysics}

The previous section demonstrates my two readings of Piekut's argument: His account of ANT as a useful methodology to theorise music as historical and social phenomenon; and his(in my view) crucial yet unthematised "bumping into" a metaphysics that inevitably comes with the method. By embracing the Latourian distinction between "weak" and “strong" associations, Piekut's (2014) argument immediately embarks on a Latourian experimental metaphysics that addresses scientific practices as being social practices, involving labour, skills, (the ubiquitous) "things," and practices of translation in which things and actions become incorporated through the act of writing and through scientific symbolisations. Although Piekut does not directly refer to Latour, in my view, his understanding of music as being "weak" or "strong" stems from Latour (1988), who connects weakness and strength to the actant's inability (or ability) to associate (40). In the words of Latour (1988), "[n]o actant is so weak that it cannot enlist another" (159), and "[a]n actant can gain strength only by associating with others" (160). The actant may be human or nonhuman, and emphasis is put on the capability of association as a factor of strength. Thus, Piekut (2014), using the Latourian notion of weak and strong, considers music weak, as it "requires [human and nonhuman] entanglements" (192), through which it speaks (Latour 1988, 160). Think here of the relation, in Abbate's $(2004,505)$ terms, between body and musical affect. Yet music is also strong, in the sense that it associates with many human and nonhuman actors. Piekut (2014) thus reconfigures music as a combined musical-social entity, in which the social concerns an association of interacting groupings of human and nonhuman actors and, at the same time, installs the researcher as the one who observes, describes, and 
registers these interacting objects that make up the musical-social world. ${ }^{71}$ For Piekut, ANT provides a preparation for a research action: a methodology. He does not seem to recognise the implications of Latour's transition of the concept of the "social," which relates the method to a topology of hybrid, natural/social being - that is, to a metaphysics of "associated" human and nonhuman existence. Piekut builds his argument to follow the method, leaving out a discussion of metaphysics by referring to a discussion between Graham Harman and Latour (see Latour and Harman 2011), in which Latour, according to Piekut (2014), "insists that he is interested in methodological claims, not metaphysical ones" (195, note 17).

However, upon reading the discussion between Harman and Latour (and contrary to Piekut's interpretation), I feel that Latour, first and foremost, tries to avoid falling into the trap of what Whitehead (1920) calls "the bifurcation of nature" (38). This refers to the splitting up of reality into two systems, namely: the reality that is perceived through the senses- "the greenness of the trees, the song of the birds, the warmth of the sun, the hardness of the chairs, and the feel of the velvet;" and the reality of "agitated molecules of carbon and oxygen, with the radiant energy from them, and with the various functionings of the material body" (Whitehead 1920, 38-39), thereby suggesting a reality for scientific observation (fact) and a reality for human awareness (value). Considering the extensive citations of Whitehead in Latour's (2008) publication What is the Style of Matters of Concern, it seems that Latour would readily affirm Whitehead's wish for "a metaphysics whose scope transcends" the implicated dualisms of human and nonhuman, subject and object, of culture and nature, in which "[t]he object of such a metaphysical science ... [is to] exhibit in its utmost completeness our concept of reality" (Whitehead 1920, 39).72 In my reading, the

\footnotetext{
${ }^{71}$ For a critique of the tendency to conflate questions of material and nonhuman agency, see Barad $(2007,445$, note 43$)$. Apart from the difficulty of considering human and nonhuman pre-formed, identified entities, the problem is that, without considering materiality, the opposition between the human and the nonhuman suggests that the human is inscribed within a purely cultural domain. 72 In 2005, Latour gave two Spinoza lectures at the department of philosophy at the University of Amsterdam, published as What is the Style of Matters of Concern (2008). The first lecture, "Nature at the Cross-Roads: The Bifurcation of Nature and its End," documents Latour's interest in Whiteheadian metaphysics. In the second lecture, "The Aesthetics of Matters of Concern," Latour deepens his exploration of the (Whiteheadian) concept of reality as the implication of an affective relationship between the two realities, as suggested by Whitehead's (1920) term "the bifurcation of nature" (34).
} 
search for a hybrid conception of reality (that is, a metaphysics) in which the (observed) thing and the human meet, is what Latour is aiming for, and his quest is revealed through his writing-for example in We Have Never Been Modern (Latour 1993b), as referred to above. ${ }^{73}$

Notwithstanding the many instances in which Latour engages with metaphysics, Piekut's marking off of metaphysics from the ANT methodology is understandable, as Latour does not place himself within a history of philosophy (Schinkel 2008, 257). Rather, arguing that "[n]o one can forget Being, since there has never been a modern world," Latour $(1993 b, 67)$ distrusts metaphysics. This demonstrates Latour's often rehearsed critique of using the social (or, for that matter, the musical or the metaphysical) as a framework that explains a world. Indeed, Latours (Whiteheadian) concept of "experimental metaphysics," introduced in Politics of Nature (Latour 2004a, 241-242), reveals his reluctance to think of the (detached) discursive act in metaphysical terms, trying instead "to agree about the furniture of the world" (Latour 2011, 41-46).74

For Latour (1999), questions that concern practices involving the entanglement of nature and the social cannot be settled by metaphysics (in the form of bad practice supporting the modernist divide between nature and the social), but rather have to be empirically disclosed from within a given practice. Latour describes what he had in mind by demonstrating the practice of science in-the-making, as seen in his observation that Amazonian soil is packed with scientific symbolism. Latour accompanies soil scientists on a

\footnotetext{
Whitehead refers to this as the division implied when we think of the world as consisting of two different realities: one of nature (fact), and one of the mind (value). However, Whitehead argues, "the red glow of the sunset should be as much part of nature as are the molecules and electric waves" by which scientists would explain this phenomenon (37). For further discussion on the relationship between the insights of Latour and Whitehead, see the work of the social theorist Willem Schinkel $(2007,713)$.

${ }^{73}$ Latour (1993b) states that we, instead of living in a bifurcated (modernist) world, always attempt to crisscross the divide that separates nature and culture. This back-and-forth movement is "more supple than the notion of system, more historical than the notion of structure, more empirical that the notion of complexity" (3).

${ }^{74}$ Barad (2007) also uses the concept of experimental metaphysics to refer to the "Gedanken, or thought, experiments" (288) of Niels Bohr, Albert Einstein, and Werner Heisenberg. For Barad, it suggests that there is no such thing as a sharp boundary between physics, metaphysics, or philosophy. Contrary to Latour, who places the observer of science-in-the-making at some distance of that making, Barad's ontoepistemological approach suggests that "the study of science and the study of nature go hand in hand" (247); that knowing is in being.
} 
field trip to the Amazon to gather soil samples. In doing so, Latour transforms the Abbatean questioning of the possibility of capturing the drastic into language into a positive question: "how do we pack the world into words?" (24). At the same time, he addresses the constantly recurring negotiation between fact and value in the process of scientific theory formation through the step-by-step description of empirical investigation. In other words, Latour's empirical metaphysics is a situated doing-a question of locality. However, it does not answer the paradoxical problem for Piekut (and for Latour) of how he, as a Latourian historian—the observer present at the scene-avoids becoming merely the voice-over, who enters through the back door. In other words, how is the observer engaged in this actornetwork assemblage?

\subsubsection{Importing Dualisms}

Clearly, Latour's "empirical metaphysics" implies a topology of being and beings through the conceptual hybrid, the actor-network. For Latour such metaphysics concerns "the search for what makes up the common world" (Latour 2004a, 242) as an affair in which "[a]ll of culture and all of nature get churned up" (Latour 1993b, 2). However, this "churning up" of human and nonhuman actors rests on many assumptions and unthematised notions concerning the relationship between matter and the socially constituted (musical) object. This hybrid relationship also assumes a specific implication of the researcher within ANT and a strong anthropocentric tendency which, through materialities and actions, are brought centre stage. The Latourian actor-network relation remains subjected to the cultural inscriptions of the human registrant, or, for that matter, computational registrant. Latour (1993b) starts from gatherings, networks, and "'collective[s]' to describe the association of humans and non-humans," in which he distances himself from the familiar concept of "'society' to designate one part only of our collectives, [establishing] the divide invented by the social sciences" between a human and nonhuman world (4). Conversely, in Piekut's (2014) argument, the relationality suggested by "collectives" remains unthematised.

Furthermore, he does not seem to consider the counterintuitive pre-distinction of human and 
nonhuman entities and actions when making lists of that which is gathered as traces of music history (Piekut 2014, 199-200).

Piekut's concentration on the Latourian method cannot help but buy into the way Latour connects the value of empirical research to the contingency of the social construction of knowledge through "some workable sense of reality" (Kirby 2011, 84)—that is, a metaphysics in which agencies of human and nonhuman actors play an important role. However, citing Kirby (2011), “Latour's insistence that the reader [and describer, registrant] of the world must remain human completely qualifies the meaning of both distribution and agency" (84-85). We see the problem of how this difficulty is (whilst unacknowledged) taken up in Piekut's (2014) statement that "[t]he analyst places all actors on an equal ontological footing" (195, emphasis added).

\subsubsection{Reconceptualising Concepts: The Abbatean Plea}

Piekut (2014) introduces four methodological principles with which music historians can work: agency, action, ontology, and performance (194). These principles are reconceptualised according to the Latourian hybrid actor-network in order to (accordingly) adjust musicological concepts of influence, genre, and context. ${ }^{75} \mathrm{I}$ will only follow here the concept of performance, via which Piekut expands the Abbatean concept of performance as listening and making music within the musical event as a fixed moment that occurs in a fixed place. Following Latour, Piekut demonstrates the Latourian reconceptualisation of the social into (network) association as benefiting music-historical research by focussing on the aforementioned principles. Unfortunately, Piekut's Latourian reconceptualisation implies merely an addition to existing concepts and does not involve a reworking of musicological concepts from within — that is, as a move that unsettles musicology's epistemes. Concepts are

\footnotetext{
75 Latour $(1993 b, 122)$ and Piekut $(2014,191)$ consider agency as distributed amongst an aggregation of things. This raises the question of how this would change the concept of agency as intentionality: Although distributed, it remains part of a (unified) whole. In chapter 3 , I will discuss agency in terms of Baradian intra-activity as ongoing material dynamics. Consequentially, the agency, predefined identity, properties, and boundaries of a given "thing" are indeed challenged (Kirby 2010, 264-265).
} 
thus not re-invented within musicological thinking and do not "[cut] across or [intersect] dual oppositions in an immanent way" (Guattari cited in Dolphijn and Van der Tuin 2012, 100), but address either musicological concerns or Latourian metaphysics. ${ }^{76}$ For instance, Piekut (2014) associates musicology with the concept that "influence" is "[floating] abstractly in musicological scholarship" (202); that "genre" is closed off from change (203-204); and that "context" misleads analysis (204)—all set against a grammar of empirical concreteness afforded by the Latourian concept of the human-nonhuman hybrid. Piekut's Latourian reconceptualisation involves an inherent problem of connectivity. This is due to opposing disciplinary concerns, considering a hierarchy and a moralism in which ANT is the more generous research approach open to the world of things and of benefit to a lesser musicological approach, assumed to be closed off from the world (like in Born's approach). The point is that without really going into the problem of intrinsic relatedness and the generative relationality between the drastic and the gnostic, which is productive for both musical and musicological bodies, the various dualisms (nature-social; nature-culture; nonhuman-human; or drastic-gnostic, all based on a negative relation between the terms) continue to structure Piekut's argument.

Recalling Abbate's discussion of the ineffable (discussed in section 2.4), Piekut (2014), considering his statement about "music's weakness," hastens to add that this does not mean “a trite paean to music's evanescence (it's close!)” (191). Rather, weakness suggests here that music requires collaborators. His argument is that, although "music's drastic qualities lie beyond texts, a more expansive understanding of performance would complicate the isolatibility of the ineffable moment of musical performance" (202). For performance to work as a methodological principle, an expanded concept is needed that takes into account the performance of the human as well as the nonhuman. For Piekut, it is the generosity of a network that recognises the ineffable, and would take up "music's non-discursive effects," as well as the "durative, non-momentary objects and body practices" (202). In other words, he

\footnotetext{
${ }^{76}$ For an elaboration on the difficulty of applying one perspective of thought to explain another, see John Mullarkey and Anthony Paul Smith (2012, 1-18). This same difficulty is discussed by Dolphijn and Van der Tuin (2012) in relation to new materialist theory formation.
} 
affirms a certain musical ineffability, but sees its impact diminishing by pointing to a variety of entities that are required for music to exist in the first place. He thereby does not account for Abbate's and Latour's question of how to negotiate the drastic within scholarly and scientific modes of research; of how to capture the dynamic musical experience by scholarly means of thinking and writing.

Without acknowledging the morality of his own argument, Piekut (2014) considers Abbate's plea first and foremost to be an "argument for a refocusing of musicological inquiry towards the social and ethical dimensions of the performance moment" (201). As referred to above, Abbate's interest is not so much in the social aspect of musical creation ("a truism"). Apart from the Jankélévitchian underpinning of Abbate's argument, to which Piekut does not refer, the ethical moment in Abbate's argument we find expressed via the morality implicit in the statement: "Shouldn't [writing about performed music] be what we do ...," as "real music is music that exists in time, the material acoustic phenomenon" (Abbate 2004, 505)? It is in this sense that her question seems to be Latourian-convinced as she is of the significance of the thing, body, movement, and feeling in musical creation, which is why her plea concerns a serious "wake-up call" for scientists and scholars alike.

Abbate (2001), referring to the ubiquity of research in musical performance, does not deny the co-constitutive factor of the "'performance network' — the paths by which inscription becomes live sound, as well as what is lost or kept in that process" (xiii), which she misses in musicological writings. She discusses the attention to the "dense center" - that is, the musical, and the way in which it is generated and generative through, and within, the human and music-making relationship (Abbate 2004, 508). In conclusion, Piekut (2014) refers to this via a brief excursion into music ecology, tapping into an organismic system that connects music-related things and events. He considers here the possibility for a musicological consideration of "the music itself," of which the "power is distinct but inseparable from other agencies, because it arrives in a tangle" (Piekut 2014, 213). Accordingly, Piekut argues: "Registering the specific effects that musical sound contributes to an ecology is a scholarly endeavour" (Piekut 2014, 213, emphasis added), which he considers quite distinct from the "isolatibility of the ineffable moment" (202) in Abbate's project. Here, 
again, "registering" and "effect" — the Latourian terms that Piekut (2014) uses in his attempt "to grapple with the history of an untidy world" (213)—bring to mind the Abbatean deadlock, residing in the presumed isolatibility and stability of here and there, and of now and then. In other words, Piekut, in his short excursion into music ecology, again-like Born and Hasty before him-attempts to resolve the Abbatean problem by the multiplication of things, humans, and events, but leaves unthematised the serious questions lurking behind Abbate's plea concerning the relationship between the musical drastic and musicological gnostic.

\subsection{Conclusion}

In this chapter, I have shown how the responses of the field (with a focus on Hasty, Born, and Piekut) bring forth the rupture between the drastic and the gnostic suggested by Abbate without being able to address it, and explored the ways in which the three authors call upon metaphysics to support their answers. Hasty, Born, and Piekut, albeit in different ways, all consider metaphysics of process, relationality, and an expanded conceptualisation of performance as necessary steps towards a musicological approach to the dynamics of musical reality. Hasty takes up the creativity of experiencing music, which may allow us to think time and process. Born's argument concerns the overarching field of music studies and its compartmentalisation into musicological sub-disciplines. She considers the predefined disciplinary and conceptual boundaries restrictive to any serious exploration of music and the social as being co-constitutive, proposing a relational musicology in order to accommodate the complexity involved. For Piekut, the complexity of musical reality is addressed by introducing Bruno Latour's ANT, considered here as a methodology that enables the taking up of human and nonhuman entities in scholarly approaches.

The problems raised by these three scholars, and the ways in which they engage with them, have the potential to create a generative material, musical, and social relationality, 
which, as I shall argue in the following chapter, meets the problems raised in Abbate's question. Abbate addresses the dynamics of musical creation in relation to musicological scholarship, but remains stuck within the assumed opposition between the drastic and the gnostic, thus facing the loss of musical dynamics in the musicological gnostic-an issue taken up by Hasty, Born, and Piekut. Hasty responds by introducing process, experience(ing), and change; whereas Born responds by taking active relationality between disciplines as a starting point for an expanded music studies; and Piekut sees a gathering together of human and nonhuman entities as a fruitful musicological starting point. However, in relation to this dissertation's aim to traverse the Abbatean stalemate questionthat is, theorising a music/ology as gnostic in drastic - none of them succeed in establishing a generative drastic-gnostic relationality. They do not reach the "point where individuality is itself undone by the specific entanglements of becoming that transcend the distinction" - in our case, between the drastic and the gnostic (Barad 2007, 362). We have seen that the proposed diagnoses and treatments of Hasty, Born, and Piekut fail to escape an epistemological, humanist perspective. They remain confined to the cultural domain, which continues to be based on a two-world structure of the drastic and the gnostic, or of nature and culture. As such, they rehearse the representationalist two-world logic as articulated by the Abbatean oppositional difference between the human gnostic that cannot cope with the drastic nature of a musical reality of making and listening.

Hasty's response to Abbate's question is particularly invested in conceptualising the processual character of experiencing music. I have demonstrated how Hasty's reading of the Whiteheadian metaphysics of process (in Gendlin's terms) of the experiencing body reduces the body to a (phenomenological) standard of music perception. Although Hasty considers a relationality between knowing and the human body, the body functions as a receptacle-a crucial agent, yet nevertheless implicating a break between a conscious human being and an outside musical world.

The connection between music and the social as a conceptual opposition, envisaged by Born, primarily aims to prove the adequacy or inadequacy (regarding her critique of Abbate) of thought (theory or method) in order to capture a musical and social world. 
However, the musical social is not rescued, nor is the dualism between music and the social resolved by adding sociological and anthropological knowledge practices to musicology's modernist conception of "music itself." In addition, correcting conceptual boundariesconsidered as a linguistic, discursive exercise-affirms the dualism beforehand, as it presupposes a concept of "music" and a concept of "the social" in which materialities are considered passive, predefined "things," and instrumental in the production of the two concepts. In my new materialist reading, Born's theorising of a relational musicology implies a relationship between pre-established terms, thus undermining any generative relationality through which music, musicologies, and the social might come into being.

Piekut questions how Latourian metaphysics (which he considers the hybrid constitution of being and beings) works within the actor-network methodology. Actornetwork concerns an empirical metaphysics that observes and traces the step-by-step transformation of natural entities into symbolical gestures. Piekut's reluctance to deal with metaphysics as such seems to respond to the problem of a "metaphysical mania" (Abbate's term), which concerns the (predefined) framing of that which occurs, affirming the dualism of the gnostic that dominates the drastic. However, the Latourian empirical metaphysics deployed by Piekut has a fundamental flaw regarding the human observer who seems to pick and choose between human and nonhuman entities. It, too, ultimately rehearses a humanist dualism now recast as the human and cultural inscription of materialities, considered as traces of, in Piekut's case, music-historical things and events.

My approach is critical of the pre-identification of "things" and "thoughts" —of making distinctions that determine which connections are built. In other words, when starting from the perspective of a dualism, one becomes "swallowed up" by dualisms. However, as Kirby (2011) argues, the doing of critique, opposing one's position to the other, "already rehearses this difficult question about identity formation and the implications of relationality" of the drastic and the gnostic (83). It is in this sense that my critique of Hasty, Born, and Piekut does not suggest a promise of reference to a greater (Baradian) truth, or to some other foundation, nor does it buy into the indifference of relativism. Rather, following Barad $(2007,88)$, I consider the doing of critique as performative; as being part of-together 
with the aforementioned scholars and their discussions- that musical world that we try to understand.

After considering the field's responses to the Abbatean plea, what remains open for exploration is the relationality involved when properties, identities, temporalities, and localities are generated through material and discursive relatedness. This calls for a different metaphysics, which I will explore through the work of Barad's (2007) notion of an agential real. This exploration, I shall argue, considers the Abbatean drastic and gnostic as materialdiscursive practices through, and within, which music, musicology, and their relationship become constituted. In this regard, the assumed temporal nature of listening to, making, and studying music that so easily lures us into the puzzle of language and of the social—and in doing so, negates materiality—constitutes, for Barad, an Abbatean challenge as much as it constitutes for Abbate a Baradian challenge. 


\section{Chapter 3}

\section{Agential Realism: The Ethicality of "Spacetimemattering"}

Practices of knowing and being are not isolable; they are mutually implicated. We don't obtain knowledge by standing outside the world; we know because we are of the world.

-Karen Barad, Meeting the Universe Halfway $(2007,185)$

My performances ... conveyed the impression that a work was created at that moment. . . Though they were performances of pieces I knew well, the template had been forgotten ... . [T]hey were distinctly, exaggeratedly material, directing attention to the physical reality of the musicians, the sounds ... and one's place as a listener or performer within that sound.

—Carolyn Abbate, In Search of Opera (2001, xv-xvi)

On many occasions, of which the epigraph above is an example, Carolyn Abbate seems to allude to how there must be another metaphysics at work; one that complicates the assumed oppositional difference between the drastic and the gnostic. Karen Barad's (2007) metaphysics of an agential real offers an elaboration of a different metaphysics, providing the option to explore, as I will argue, the inseparability of the drastic and the gnostic as an onto-epistemology—a knowing in being. Barad's metaphysics is detailed and complex. Therefore, this chapter in its entirety is dedicated to an exploration of her insights, forming an introduction to her thinking in the context of musicological scholarship. Moreover, this chapter also serves to illuminate Barad's notion of diffraction as both a methodology and a method. As a methodology, diffraction is respectful to differences and their consequences when thinking with and from within an agential real, whilst as a method, it presents a 
generative research action of reading insights together. I will take up this method in the next chapter when reading the insights of Abbate and Barad together, aiming to generate a reworked concept of music/ology.

By means of a short biography, Karen Barad is a professor at the University of California, Santa Cruz, where she teaches feminist studies, philosophy, and history of consciousness. Her doctoral research was in theoretical particle physics, in particular, quantum field theory. Prior to her move into interdisciplinary academic environments, Barad had a tenured appointment in physics. ${ }^{77}$ Physics plays a prominent role in Barad's elaboration of a metaphysics, methodology, and method. It also plays a significant part in her work on ethics, turning her insights into an ethico-onto-epistemology in which knowing in being becomes infused with a politics of justice.

Physics, in terms of Niels Bohr's (1958) philosophy of physics—a specific philosophical engagement with physics based on experimental research and philosophical analysis—gives Barad a point of entry to think across the disciplinary boundaries of science and the humanities. For Barad (2007), Bohr's thinking and research open up new understandings of physical and philosophical issues, such as the relationship between the knower, the known, and knowledge; the role of measurement; the concept and its relation to the material apparatus; questions of meaning-making; the nature of causality; and the nature of reality. Barad's work on these issues provides an invaluable window through which to understand the rationale of her metaphysics of agential realism.

My specific entrance into Barad's (2007) thinking in particular concerns her reworking of Bohr's (1958) inseparability thesis, which positions humans and their concepts as inseparable parts of the world that they seek to understand. In Barad's (2007) reading, Bohr questions the binary thinking present in the "taken-for-grantedness" of human exceptionalism and, more generally, of a humanist worldview. Barad's reworking of Bohr's thesis problematises the transcendent stance of linguistics and science-a stance that is based on a notion of objectivity that considers the human to be the detached and disinterested

\footnotetext{
${ }^{77}$ For this biographical information, see the website of the University of California in Santa Cruz (UCSC), https://people.ucsc.edu/ kbarad/ (last accessed September 10, 2019).
} 
observer, writing, speaking, and thinking for that which is observed or measured. In other words, Barad's (Bohrian) inseparability thesis involves a radical immanence that does not accept an individuated, isolated body, thing, or thought as the starting point for research and theorising, but rather traverses dualisms, such as the Cartesian mind-body, the scientific object-subject, or the representationalist nature-culture dichotomies.

To meet the consequences of how metaphysics, the inseparability thesis, and the question of methodology relate, Barad elaborates on the physical phenomenon of diffraction. In classical physics, diffraction is observed when light passes through a slit or aperture. In Barad's (2007) work, however, diffraction becomes "an apt (material and semiotic) figuration for the methodological approach" (29), allowing the reading of texts, such as those of Barad and Abbate, through one another. For Barad, diffraction is a tool, a metaphor, but also the ontological condition for mattering. In that sense, diffraction forms an overarching trope for Barad's metaphysics of an agential real, experimenting with, and thinking, the world's differential becoming by "enacting new patterns of engagement" (Barad 2010, 243).

For Barad, physics, in terms of quantum field theory, serves to deepen the notion of the "Other" as an integral part of the world's reconfigurings..$^{78}$ Ethics, in this regard, is not a pre-established judgement about the good, working as "a superimposing of human values onto the ontology of the world" (Barad 2010, 265). Rather, it entails a responsibility that is "an incarnate relation" and part of ongoing differentiations through which things and thoughts come into existence or not (Barad 2012a, 81). After discussing Barad's metaphysics and methodology, this chapter concludes with an elaboration of her particular ethics. Whilst this may initially seem out of place in the context of the Abbatean and musicological starting point of this dissertation, the notion of ethics brings out the politics of valuing as part of an agential real. In the fourth and final chapter, I elaborate on the aspect of valuing as both part of musicality and a creative force; as an inseparable part of music-in-the-making.

\footnotetext{
${ }^{78}$ The dualist notion of the other as a difference is based on the idea that entities, their properties and identities, pre-exist as such the intra-actions that affect them. Barad's metaphysics of an agential real considers difference an entangled relationality. The "Other" is constituted through intra-active "othering," which entails "an indebtedness to the 'Other,' who is irreducibly and materially bound to, threaded through, the 'self'" (Barad 2012d, 47).
} 
This chapter starts with a discussion of Barad's metaphysics of an agential real, followed by sections on methodology and method, and concludes with sections on Barad's elaboration of ethics. First, however, in order to explore the depth of Barad's thinking more fully in the context of this study, I shall discuss the musical and musicological relevance of her work, starting with a discussion of how both Barad's and Abbate's thinking and approach—on the level of studying the dynamism of (musical and musicological) beingdemonstrate shared insights.

\subsection{Abbate and Barad: Shared Insights}

Quantum physics, and the theoretical and experimental work of Niels Bohr to interpret the relationship between quantum (mathematical) formalism and the atomic/subatomic behaviour of matter, define the terrain upon which Barad (2007) elaborates an agential realist understanding of "the nature of the causal relationship between discursive practices and material phenomena" (34). Barad often articulates this as how "matter comes to matter" (152), involving the double meaning of "matter" as both fact and value (in a way similar to the dual meaning of "music" as both fact and value). It is plausible to argue that quantum mechanics - the physics of particle behaviour at the atomic and subatomic level—confronts physicists and philosophers with the same struggle that Abbate formulates for musicology: To capture both fact and value from the dynamics of (musical) matter's ongoing differentiation, whilst also meeting the academic obligation to give an objective, unambiguous account of that fact. Abbate (2004) refers to the "scientism" of musicological scholarship, emphasising how "the universalizing endemic in academic discourse" defies her account of the subjective witness, and instead seeks objectification by analysing music via the score, the social, or the cultural (536). In other words, Abbate addresses the academic imperative to control the unstable materiality and temporality of musical becoming, predefining the object of research as a known structure that appeals to rational concerns 
without recognising the performative and materialising act of musicological knowing and musical becoming.

Although it is not my aim here to discuss the rich, historical formation of musicological epistemes, I nonetheless want to point to the fact that musicology's ingrained difficulty with the dynamics of musical creation (as discussed by Abbate) is a difficulty that was also encountered by physicists who saw themselves confronted with the dynamic character of quantum behaviour in relation to the scientific principle of unambiguous description (a problem taken up by Bohr, as discussed below). As argued by Barad (2007), physicists and philosophers of science consider the question of quantum mechanics a real challenge, shaking the foundations of scientific research and demanding serious attention. ${ }^{79} \mathrm{I}$ see a similarly urgency in Abbate's (2004) argument when she considers the possibility that musicology might "find itself a wallflower at the ball" by not accounting for the dynamic reality of music-as-performed (505).

In physics, the problem lies in the dynamic nature of quantum mechanics, represented by the probability principle of mathematical formalism, which does not allow for a classical epistemology of an objective description of facts, built upon observation, transparent measurement, and the prediction of a "nature" that happens before our eyes (often with the help of visualisation technologies). This apparently implies the outsider status of that which (or the one who) observes or measures a "nature" that follows the "laws of nature." Thus, quantum physics marks a shock in physics, which relied for "hundreds of years" on the successful paradigm of Newtonian physics, often called "classical physics" (Barad 2007, 418, note 18). Barad (2007) refers to quantum physics as a turning point in thinking, not in the sense that Newtonian physics is now overruled, but to recognise the limits of a paradigm based on the "ability to ignore measurement interactions by presuming that they can always be reduced to the point where they are negligible" (108-109). The experiments of quantum physics rather demonstrate how nature's activity may be ignored by

\footnotetext{
${ }^{79}$ That physicists are concerned with philosophical issues considering experimenting and epistemic values of objectivity and observation is unusual. Barad (2007) makes clear that the philosophy-physics of Niels Bohr is surprising in this regard.
} 
measurement or observation, but cannot be removed or reduced-nature is not a passive and willing co-traveller.

Although the dynamics involved in the propagation of sound waves and quantum physics do have overlapping physical concerns, it is not my aim to suggest a direct comparison or analogy between music-as-performed and the performance of particles at the atomic and subatomic level. Nevertheless, it is tempting to consider the complex relationship between, respectively, notation and mathematical formalism, and with that also the knowledge claims of musicology and physics. In this sense, I believe it is helpful to understand that some of the (Bohrian) epistemological difficulties of quantum physics (how to take account of the dynamics of being) that Barad's reworking of Bohr's insights addresses, are articulated in their musicological variation by Abbate's plea to capture musical doing, and thus may as such be considered familiar territory to musicologists.

Another characteristic that demonstrates the shared nature of the Baradian and Abbatean problem, is the particular attention both pay to experimentation. I recall our discussion in chapters 1 and 2 of how Abbate's tests touch upon, and can readily be engaged with, a Bergsonian perspective, supported by Jankélévitch's Bergsonism—as also featured by Abbate $(2004,510)$. To emphasise the importance of the relationship between thinking and playing (or experimenting), I turn again to Bergson ([1889] 1910), who addresses the Abbatean drastic through his concept of duration (durée) and the gnostic, considered here as the human intellect and locus for reasoning. For Bergson, the human intellect always presupposes reality, and as such it keeps reality at a distance, and is thus unable to encompass the dynamics of, in Abbate's case, musical duration. This affirms Abbate's observation of how easily a musicological, analytical approach to a musical performance can become paradoxical. When music has to be brought "to mind" by means of representations, it becomes subjected to the same process described by Bergson ([1889] 1910) concerning the spatialisation of time: “We project time into space, we express duration in terms of extensity, and succession thus takes the form of a continuous line or a chain" (101). In Bergson's ([1934] 1946) terms, musicological analysis would then start from measuring "[t]he line ... [which] is immobile, [whilst conversely,] time is mobility. The line is made, it is complete; time is 
what is happening, and more than that it is what causes everything to happen" (11). ${ }^{80}$ Thus, the spatialisation of time does not do justice to time's dynamic reality, nor to its real-time, material effects.

This friction between the spatialisation effect of thinking on the one hand, and the dynamic temporality of a musical event on the other, is revealed in some of the tests performed by Abbate (2004). In one, she attempts to be gnostic whilst playing: She engages with a Mozart aria from a musicological, analytical point of view whilst accompanying a singer on the piano (510). However, she proved unable to be gnostic (to arrive at some knowledge claim from a musicological point of view) from within the drastic (being engaged in the dynamics of making music). In chapter 1, I argued that, although Abbate may consider that the test failed in the context of the drastic-gnostic dualism (when considered as an oppositional difference), she did nonetheless experience what Bergson ([1934] 1946) suggests by "intuitive[ly]" knowing music, "[following] the undulations of the real" (35). Engaging with music in-the-making provides a means to "restore to movement its mobility, to change its fluidity, to time its duration" (Bergson [1934] 1946, 17). From Abbate's tests, we may conclude that she intuitively knows music, but finds herself, as a musicologist, unable to account for an intuited knowledge of music.

Clearly, Abbate does not want to distance herself from the experiences of making and listening to music when engaged in musicological study. This is a point Barad (2007) also takes up, arguing that she does not "merely reflect on science," but rather engages in the practice of doing physics "while addressing entangled questions about the nature of scientific practice" (248). In this sense, the Abbatean plea for a musicological engagement with "occurring" music and the tests she performed-engaging in the practice of musicology whilst listening to, or making, music—supports Barad's (2007) maxim that "the study of science and the study of nature go hand in hand" (247). In other words, via her experiments, Abbate supports Barad's (2012a) statement that “[t]heorizing, a form of experimenting, is

\footnotetext{
${ }^{80}$ Bergson seems to suggest here that time precedes the generativity of being as causal. Bergson's notion of time is more thorough than suggested here. However, I will not pursue this further. See section 3.6., in which I discuss how, for Barad, time and space do not precede, but rather are inseparable from, the act of mattering.
} 
about being in touch" (207). Nevertheless, the crucial (drastic) dynamics of Abbate's tests, which for her demonstrate a fundamental incommensurability between musicological study and playing, radicalises and troubles Barad's (Bohrian) inseparability thesis: "We are part of that nature that we seek to understand" (Bohr 1958, 1; see also Barad 2007, 26). The term "radicalising" is employed here in the sense that being involved in the dynamics of making music means participating "in a performance of spacetime (re)configurings ... more akin to how electrons experience the world" (Barad 2010, 240). Abbate's test could therefore be said to represent a foray, in a way similar to Barad's electron, into the dynamics of making music that produces intuitive knowledge, enabling one to think with the dis / continuity of musical becoming. This involves many instances of musico-material and discursive "doings" within and through which sounds come together, becoming music (or not) — that is, as dis / continuity. I will come back to this crucial notion when discussing Barad's concept of intra-action.

I hope that recalling the discussion of the Abbatean question and the tests she performed has demonstrated a research interest shared by both Abbate and Barad-an interest that affirms both Barad's thesis of the inseparability of the researcher and the object of research, and Abbate's Bergsonian intuited knowledge as viable starting points for research. Moreover, both are exponents of the discipline under research: Barad does and theorises physics; whilst Abbate makes and theorises music. We discussed the BergsonAbbate relationship through the introduction of Jankélévitch, yet as Van der Tuin (2011) makes clear, Bergson and Barad enrich each other's concepts. Both posit the problem of the (human) relationship with the ongoing dynamics of being as a problem of binarity. Both share a perspective that-by embracing this binarity as a way to stay "with the trouble" (Haraway 2010, 53; Haraway 2016)—contributes positively to scientific research. ${ }^{81}$

\footnotetext{
${ }^{81}$ Barad (2007) is convinced that "agential realism" provides "insights that might help solve some of the unresolved foundational problems" of quantum mechanics (248). Bergson ([1934] 1946) places "metaphysics side by side with science" (47), with the belief "that they are, or that they can become, equally precise and certain" (50). See also, in the same book, Bergson's establishment of "a philosophy which would submit to the control of science and which in turn could enable science to progress" (77).
} 
To grasp the Baradian approach it is helpful to consider how the starting points for thinking reality differ between Abbate and Barad. Although Abbate starts from the position of listening and playing within the dynamics of musical performance, her starting point is the phenomenological, normative subject that invents the "given," leaving unexplored the workings of musical and bodily materialities. Conversely, Barad starts from the entangled nature of matter and meaning, before the "thing" (human or nonhuman) is defined, with the crucial question of how matter comes to matter, with its inherent double meaning.

What I hope to have established in the previous discussion is that, although Barad's (2007) Bohrian inspired "philosophy-physics" (352) may seem far removed from the musicological issues raised by Abbate, their shared perspectives on the relation between the observer and the observed demonstrate an (unwitting) proximity that is quite independent of disciplinary distance. It is this nearness on which I base my reading of Barad's theoretical framework—namely, her concept of agential realism.

In the following, I explore Niels Bohr's contribution to the interpretational problem of quantum physics - a contribution that provided the inspiration for Barad's transdisciplinary engagement, as she defends and works through her objection to, and the limitations of, Bohr's philosophy-physics. Barad's (2007) objections mainly involve the epistemological and humanist tendencies of Bohr's approach. Barad elaborates on the inherent ontological orientation of Bohr's thinking, thus opening it up to a posthumanist account of technoscientific and other nature-culture practices. However, the overall challenge of my discussion is musicological, following the Baradian thesis of the inseparability of matter and meaning — a challenge that goes beyond Barad's thinking per se..$^{82}$

\footnotetext{
82 I refer here to Barad's careful explanations regarding the nature of quantum physics. Although detailed and graspable-also for a non-specialist-they still include, for me, non-intuitive territory. I miss the feeling of thinking with a mathematical formalism and doing physics, however, I cannot entirely escape referring to it either. In view of this, and because I do not expect that it will impede my argument, I do not include Barad's (2007) detailed discussion on how agential realism may particularly contribute to "a more coherent and robust interpretation of quantum theory" (332). Nor do I give an account of Bohr's thinking in terms of its history or place in physics, but instead consider it in the context of being a generative source for Barad's agential realism.
} 
3.2. Agential Realism: The Bohrian Fold

[T] he real reward for the "labour of careful measurement" was not greater accuracy but the "discovery of new fields of research" and the "development of new scientific ideas."

—James Clerk Maxwell (cited in Kumar 2008, xvi)

Niels Bohr's contribution to the debate of quantum mechanics forms a thread that strongly resonates with agential realism—Barad's theory of the generative dynamics of the world's becoming. Bohr's $(1950,1958,1961)$ take on this debate is first and foremost epistemological, oriented towards the need for an unambiguous relationship between what can be accounted for in research and its subsequent communication. Familiar issues of conceptualising physical phenomena acquired a new urgency through early- and mid-twentieth-century research into atomic physics, which confronted physicists with an increasing number of unknown experiences, suggesting a probability state of nature. According to Bohr (1958), this demanded the "examination and refinement of ... conceptual tools" (1) in order to save physics from inconsistencies and ambiguous descriptions. This concerns, not least, the specific features and scale of quantum phenomena that "[transcend] the scope of classical physical explanation, [given that] the account of all evidence must be expressed in classical terms" (Bohr 1958, 39, emphasis removed). With this, Bohr refers to the fact that the explanation of quantum physics was constrained by the language of classical physics, oriented towards a "common-sense" understanding of particular properties, such as their position, momentum, and character-as either wave, or particle. For Bohr (1958), such properties are unambiguous only when one is able to account for their material configuration in terms of their position (the specific location of a thing), and momentum (the quantity of a body's motion, measured as the product of its mass and velocity). This leads to a definition of a wave as "an organized travelling disturbance in a medium" (Loy 2006, 3), and of a particle (as a thing that occupies a particular position). 
Bohr's purpose is clear: to retain the unambiguous descriptions and comprehension levels familiar to traditional physics within the physics of atomic processes-their measurement and observation—in an attempt to establish a direct link between the proper use of (classical) concepts and the most recent material, experimental setups. In other words, in order to measure position, the measurement apparatus needs to materially embody the notion of position through parts that are fixed and stable, whereas for measuring momentum, an apparatus with moving parts (the material embodiment of the concept momentum) is needed. For Barad (2007), Bohr's philosophy-physics of embodied concepts, in which linguistic and material doings become inseparably related, forms a crucial source of inspiration (26), suggesting an apt starting point from which to think "the natural and social worlds together" (67). In other words, Bohr's philosophy-physics opens up the possibility to think about the inseparability of knowing and being, considering meaning and matter as entangled within the dynamics of becoming. In short, it enables us to consider the entanglement of the agencies of observation and the object of observation.

According to Barad (2007), Bohr's thinking offers "a proto-performative account of scientific practices" (31). Likewise, she argues that for Bohr, knowledge-making practices are "material enactments that contribute to, and are part of, the phenomena we describe" (32, emphasis added). Bohr's insights imply that the use of language necessarily involves a material configuration: Particular material arrangements give definition to particular concepts and produce particular objects with particular physical properties. We see here the emphasis on relationality, which—articulated as inseparability-is present in all of Barad's work and interwoven with her (Bohr-inspired) thesis that we are part of the nature that we seek to understand (Bohr 1958, 1; see also Barad 2007, 26). Thus, resolving semantic and the ontic inevitably involves the inseparability of the agencies of observation (including the material arrangement) and the object of observation. In the following, I examine in greater detail the intricacies of Bohr's take on the wave-particle discussion, which has perplexed physicists throughout the twentieth century. I consider some of the concepts that form the nodes in Barad's metaphysics of an agential real, related to Bohr's $(1958,71)$ central notion of 
"wholeness" in atomic processes, i.e., the inseparability of agencies of observation and the object of observation.

In quantum mechanics, engaging with the behaviour of nature on the atomic and subatomic level, the equation of Erwin Schrödinger (a physicist and peer of Bohr) "supplants the laws of classical mechanics, formalized as Newton's equations" (Barad 2007, 249). Schrödinger's equation adheres to the wavelike behaviour of matter. Given the wave function of a particular quantum state, which is, for instance, a function of the position of particles at a particular time, the equation enables one to calculate wave functions for all other moments in time (Barad 2007, 251). This means that physical quantities do not have determined values. Rather, like the wave function, they have the character of a regulation from which to calculate the probability of measurement results (the probable position of a particle). Paraphrasing Barad (2007) on the effectiveness of Schrödinger's equation, this accepted quantum formalism allows one to calculate all that is possible to know about a given physical situation (based on a particular wave function). This does not involve a precise trajectory, as in Newtonian physics (based on the predetermination of the physical quantities involved), but a specification of the probability that a particle will be found at some position $x$ when it is measured at some time $t$ (Barad 2007, 251). Quantum physics leans on two pillars—-theorising and experimentation—and mainly involves the collection of data to calculate probability factors. This, nevertheless, involves real experimental circumstances for obtaining measurement results (data) for calculation.

Bohr (1961) does not address Schrödinger's quantum formalism (the mathematics) as such, but rather highlights how it leaves unresolved interpretational issues (73). For Bohr, the role of quantum formalism must be restricted "to its role of computing device, of foreteller of probabilities" (Omnès 1999, 155). Crucial is that the formalism does not give an account of atomic processes in classical terms (it does not say what happens during the experiment), nor does it include the material setup of the measuring apparatus. However, as Bohr (1958) points out, when physicists conduct experiments, they have to make clear what they did and learnt. Therefore, "the account of the experimental arrangement and of the results of the observations must be expressed in unambiguous language with suitable 
application of the terminology of classical physics" (Bohr 1958, 39), not least because the variables—wave, particle, position, and momentum —used in quantum mechanics concern real properties in a real world and are familiar concepts of classical or Newtonian mechanics. ${ }^{83}$

Bohr (1961) states—in addition to the materially embodied concept referred to above- that unlike classical (Newtonian) mechanics, which thrives on knowledge claims about the future and past behaviour of objects as derived from the calculation of initial (predetermined) values, the study of quantum mechanics is bound to the quantum postulate. Following Bohr, the quantum postulate entails that "any observation regarding the behaviour of the electron in the atom will be accompanied by a change in the state of the atom" (78). He argues that "an independent reality in the ordinary physical sense can neither be ascribed to the phenomenon nor to the agencies of observation" (54). In other words, the postulate precludes (Newtonian) calculations based on initial values, thus prohibiting knowledge claims based on past and future states. Due to the postulate's inherent disturbance of measurement interaction, causality based on a fixed time-space relationality cannot serve as the foundation for calculation. As a consequence, according to Bohr, the postulate obstructs the possibility of defining the state of a physical system, commonly understood as independent of the agencies of observation, in which the "elimination of all external disturbances" is accounted for (54). Bohr's conclusion is that for an unambiguous description of atomic phenomena, the quantum postulate therefore demands the development of a concept of complementarity that secures the consistency between possible definitions and observation (55).

The notion of complementarity was already brought out by questions on the nature of light. Both light and matter can exhibit wave and particle behaviour-a duality that plays

\footnotetext{
${ }^{83}$ Note that classical mechanics is not made redundant by quantum mechanics (numerous technologies work with classical mathematics and classical experiential circumstances), but is rather caught up by it. This is an important point that could lead us to understanding Barad's use of the physical model of quantum behaviour in philosophical questions as an unacknowledged mashing up of scales. This is, however, not the case. For Barad, as I will discuss below, scale does not pre-exist theorising or experimenting, but is co-constituted with it. Further, although quantum behaviour can be ignored by classical (i.e., observational) measurements, it cannot be undone.
} 
an important role in Bohr's (1961) elaboration of complementarity as a concept in response to the epistemological problems raised by quantum physics. At the end of the nineteenth century, the heated debate of light as a particle versus light as a wave seemed to be settled once and for all: “Light is a wave” (Barad 2007, 99). However, the experiments of atomic physicists during the first quarter of the twentieth century produced puzzling results: "Light manifests particle-like characteristics under one set of conditions and wavelike characteristics under other circumstances" (Barad 2007, 100). Following a disturbance, such as spreading out in all directions when passing an obstruction, waves become entangled and a diffraction pattern is generated. A diffraction pattern consists of alternating light and dark spots when produced by electromagnetic waves (light), and alternating crests and troughs when produced in air or water. Waves reinforce one another when waves that meet are in phase (moving in the same direction), and neutralise each other when the waves that meet are out of phase.

Considering Bohr's (1961) account of quantum physics, he refers to the electromagnetic system of light when speaking of diffraction and when considering the distinction between wave and particle behaviour. Contrary to waves, which propagate through space, overlapping, and combining their amplitudes, particles "are material entities, and each particle occupies a point in space at a given moment" (Barad 2007, 76). That is, it was assumed that particles cannot entangle and do not spread out, occupying instead a locally defined (if probable) position. A first remarkable experiential result is that light exhibits, depending on specific circumstances, wave or particle (photon) behaviour. Even more remarkable is the fact that matter-for instance, an electron-exhibits wave and particle behaviour under "complementing circumstances," meaning that light (as electromagnetic waves) and matter (for instance photons or electrons) may exhibit either wave or particle behaviour, but not both simultaneously (Barad 2007, 100). Thus, light and matter cannot be described as simultaneously being composed of photons (i.e., particles) and being an electromagnetic wave. In short, the puzzling problem of the duality of light as either wave or matter made clear that, in a theoretical sense, a conceptualisation that encompassed both possible behaviours of light (as particles and waves) was lacking. Thus, the dual character of 
light could not be reconciled by a single overarching theory as demanded by the classical ideal.

For a "classical" physicist, who considers matter and light to be fundamental objective entities, this duality highlights a theoretical insufficiency—one that demands an effort to find a new theory that can reconcile wave and particle realities. For this reason, the dual character of light and matter confronted physicists with the need to take a new step in the analysis and synthesis of physical phenomena (Bohr 1958, 33). According to Bohr (1961), the question of duality does not, however, confront us with a contradiction or a (temporary) theoretical failure, but rather "with complementary pictures of the phenomena" (56). Wave and particle behaviours can thus be determined under mutually exclusive conceptual and experimental circumstances, implying that the concepts of wave and particle, and the experimental observation of wave and particle behaviours, are considered inseparable, but mutually exclusive. With this Bohr also argues that the notions of "wave" and "particle" are abstractions that do not stand on their own, but rather are only "definable and observable through their interaction with other systems"-for example, via a specific material measurement apparatus (Bohr cited in Barad 2007, 296, emphasis removed).

Returning to Bohr's (1961) quandary of the impossibility to define space and time simultaneously, I hope to bring across the ontological consequences (elaborated by Barad) that underline Bohr's concept of complementarity by introducing the physicist Werner Heisenberg's concept of uncertainty. Both Bohr and Heisenberg were involved in the measurement problem generated by the inevitable disturbance effect caused by the quantum postulate during (experimental) interaction. As Bohr (1961) notes, Heisenberg elaborated on a concept of "reciprocal uncertainty" that affects measurement values of atomic quantities: Defining the momentum of a particle accurately makes "the determination of the space coordinates of the particle correspondingly less accurate," and vice versa (63). However, Bohr argues, Heisenberg's emphasis on uncertainty regarding the possibilities of measurement leaves unimpeded the necessity to acknowledge "the complementary nature of the quantum-theoretical description" (73). Heisenberg's approach fails to take account of this description in which the nature of matter, as either particle or wave, is considered in terms of 
the specific relatedness of agencies of observation (experimental circumstances) and the object of observation to the measurement of matter as being in either state. Simply put, under quantum circumstances (when the effect of the quantum postulate applies) one apparatus is needed when measuring momentum and another when measuring position.

Following Barad (1995), Heisenberg's uncertainty principle thus recognises an epistemological limit in our interaction with reality due to the quantum hypothesis. ${ }^{84}$ This limit entails that, through the interaction of measurement, the position of an object is disturbed. As an example, Barad (1995) considers what happens when the lights are suddenly turned on in a room: The chairs are struck by photons, which, however small, disturbs their positions (50). Classical physics resolves this by adjusting the measurement calculations. Quantum physics, however, does not allow for adjustments to reduce the disturbing effect of measurement interaction. Heisenberg made the point that the "knowledge obtainable of the state of an atomic system will always involve a peculiar 'indeterminacy'" (cited in Bohr 1958, 38-39) due to a disturbance of the object of observation caused by measurement when particles interact. This has the effect that the more we know of a particle's position, the less we know of its momentum and vice versa. Crucial for Bohr (and Barad) is that Heisenberg's uncertainty principle foregrounds the assumption that "the very act of observation disturbs the way the object would have been had it not been observed" (Barad 1995, 47).

\footnotetext{
${ }^{84}$ Heisenberg's theory of uncertainty intrigued many scholars and artists. To give an example from performance studies, see Peggy Phelan (2005). With reference to Heisenberg (Phelan 2005, 114) and Bohr (Phelan 2005, 115), she discusses how quantum mechanics marks "the transition from 'objective' measurement to 'uncertainty,' from deterministic rules to probability and chance" (116). From understanding quantum mechanics as an uncertainty problem, transposed to performance study's theoretical concerns, Phelan concludes that quantum mechanics demands that we account "for the power of perception itself to transform the measure of matter" (116). This suggests that things change by being observed, with the certainty that we will never be able to know the real world. Barad (2007), however, does not follow this neo-Kantian reading. Elaborating on Bohr's concept of complementarity, she argues that it is not the case that things change properties, but that through the relating apparatus of observation and object of observation, semantic and ontic indeterminacies are resolved. Thus, quantummechanical concerns are ontological rather than epistemological. Further, as to Phelan's remark about the artist's "power of perception" (above), with Barad's terms, I would argue against the unilateral notion of perception: matter too observes, "feels, converses, suffers, desires, yearns and remembers" (Barad 2012c, 48).
} 
According to Barad (2007), Bohr's critique of Heisenberg follows his principle of complementarity - a principle that hinges on a different notion of indeterminacy. For Bohr, the uncertainty principle is not a question of not being able to know a particle's position and momentum simultaneously, but that properties, like position and momentum, do not preexist measurement interaction (Barad 2007, 300). Bohr distances himself from measurement disturbance as a given principle, "since the term disturbance connotes the existence of some undisturbed, well-defined, observer-independent classical state" (cited in Barad 1995, 53). Bohr's complementarity principle emphasises wholeness as the principle that defines the inseparability of agencies of observation and objects of observation. Complementarity thus precludes any independent analysis of the two components (time and frequency; particle and wave; time/space and dynamic [energy/momentum] concepts) as combined, and instead suggests that the inseparability of agencies of observation and objects of observation enables "the very possibilities for definition of the concepts and the determinateness of the properties and boundaries of the 'object'" (Barad 2007, 302).

In “Appendix B," Barad (2007) speaks of the importance of Bohr's discussions with Albert Einstein, practicing the famous Gedanken or thought experiments, accompanied by detailed drawings of experimental setups, in which Bohr theoretically tested the principle of complementarity (399). ${ }^{85}$ For example, one of these drawings figured an apparatus with two slits through which, when light was shone or particles were fired, a diffraction pattern consistent with wave behaviour resulted. ${ }^{86}$ Another "which-slit" apparatus was modified in order to trace the particle's path through one of the slits. This apparatus showed that, when light was shone or particles were fired at the slits, a scatter pattern consistent with particle behaviour resulted. For Bohr, the thought experiments demonstrated that whether light or matter were observed as waves or as particles was related to the very concept that gave

\footnotetext{
${ }^{85}$ Thought experiments are pedagogical tools to test the consistency of physical theory, providing the gound for Bohr's debates with Einstein (Barad 2007, 101; Kumar 2008, 253-299).

${ }^{86}$ The two-slit apparatus gives an account of the diffraction pattern when light propagates from the source to a (light-sensitive) screen through the two slits-that is to say, along two different paths. This diffraction pattern of alternating dark and light spots is consistent with the effect of enforcement, when two waves coincide, going in the same direction; and of weakening or neutralising, when two waves have opposite directions or are "out of phase with one another" (Bohr 1958, 4).
} 
meaning to the apparatus used. In that sense, there was no contradiction, as the experiment was reproducible and consistent; “[o]ne apparatus consistently manifested one kind of behavior, and a mutually exclusive apparatus consistently exhibited another" (Barad 2007, 106). According to Bohr (1950), the experiments point to a "novel type of relationship ... termed complementarity," which, at the same time, implies a principle of limitation (52) _ although not as in Heisenberg's uncertainty principle as a limitation to human knowledge, but rather, as quantum "wholeness." 87 In quantum circumstances, an "object" is thus indeterminate (scare quotes are needed here, because we cannot even speak of, or suggest the existence of, a pre-given object) outside the material and conceptual circumstances and embodied concept of measurement or observation.

As such, wholeness suggests the inseparability of "description" (what we understand by "wave" or "particle"); the "material set up" for measurement or observation; and the “object of observation" (Barad 2007, 118). In other words, inseparability concerns the entanglement of agencies of observation (the materialisation of the concept) and the object of observation, which Barad (2007) elaborates as the entanglement of matter and meaningmaking practices. Or, as Barad suggests, wholeness means the "lack of an inherent/Cartesian distinction between the 'object' and the 'agencies of observation'” (118). Unlike classical conditions-where the state of an object is determined by the combination of dynamic (momentum) and space-time (position) properties, which are thus predeterminedin quantum situations, complementarity implies a mutual exclusion of these concepts. This introduces an ontological indeterminism that can only be resolved through "the interaction between the objects and the measuring instruments ... [,] form[ing] an integral part of the phenomenon" (Bohr 1958, 72), thus connoting the inseparability of the concept, the measurement apparatus, and the object being observed.

Of crucial importance in order to accommodate Bohr's insights within Barad's theory of an agential realist ontology is the epistemological and ontological shift that Barad

\footnotetext{
${ }^{87}$ These Gedanken experiments were realised in the 1990s. According to Barad (2007), the results were consistent with Bohr's interpretation that measurement devices do not give pre-existing values, "but rather that it is the specific material configuration that gives definition to the notion of the property in question" (264).
} 
recognises in Bohr's philosophy-physics—even though Bohr's aim was to solve epistemological problems, including "unambiguous communication" (Bohr 1958, 67). ${ }^{88}$ In Bohr's account of the complementarity principle, Barad (2007) emphasises that quantum indeterminacies are semantic (without the material arrangement, which is the embodied concept, position or momentum are qua meaning indeterminate) and ontic (through the inseparability of a specific apparatus and object of observation, the properties and boundaries of the object emerge). In short, the inseparability of the embodied apparatus (agencies of observation) and the object of observation implies the possibility (and specific determination) of existence. Barad's concludes that "[f]or Bohr, things do not have inherently determinate boundaries or properties, and words do not have inherently determinate meanings" (138). The consequences of Bohr's insights as recognised by Barad's new metaphysics of an agential real (as discussed in section 3.3.) are far-reaching. For Barad, Bohr paved the way for a consideration of the world's indeterminacy (classically resolved by measurement or observation) as a meeting of the natural (matter) and the social (concept/meaning): "Meeting the universe halfway," whilst recognising that "each meeting matters" (353). Furthermore, what Bohr establishes goes against the entrenched beliefs of representationalism - the idea that words and the things they purport to represent are independently determined. Thus, representing does not involve mediating access to an observed nature, but rather, representing is an enactment, producing both matter and meaning. For Barad, Bohr's insights shift dualisms and go against a metaphysics of individualism that otherwise suggests that things, subjects, and events exist and come into being in isolation.

Following Barad (2007), Bohr thus uproots the (classical) idea that is based on individual existing entities. Instead, Barad continues, his principle of complementarity

\footnotetext{
${ }^{88}$ This is not the place for an in-depth review of the rich legacy of the objectivity of the epistemic. For a general account of the history of objective knowledge, see Lorraine Daston and Peter Galison (2010). See in particular their account of how, for physicists at the beginning of the twentieth century, the objectivity episteme demonstrated a slight shift from suppressing the subjective experience of a world to communicating that world. For, as we encountered in a similar way in Bohr's argumentation, if "knowledge of the nature of things failed the test of communicability, it could not be science" (Daston and Galison 2010, 301).
} 
suggests that entities—-both "object and measuring agencies"—emerge from their "intraaction" (128). Barad's neologism "intra-action" is relevant here, as it suggests "ontological inseparability," whereas the usual "interaction" assumes an action between independent and predefined entities (128). Furthermore, Bohr (1950) makes clear that the notion of a determinist causality "has deep roots in our conscious endeavours to utilize experience for practical adjustment to our environments" (51). Causality in such terms is a binary affair in which independent entities have a strict cause-and-effect relationship unless one observes “no causal determination" as a "state of freedom" (Barad 2007, 131). However, in both situations one assumes dependence on a pre-given subject and object. Thus, causality explained as deterministic or as absolute freedom cannot be reconciled with the experimental circumstances of quantum mechanics. This is because the intra-action through which entities emerge does not allow for complete determinism, nor for absolute freedom. In order to resolve ontic and semantic indeterminism, entities are bound to their relationality within the specific phenomenon, again demonstrating the inseparability of agencies of observation and the object of observation. However, for science to be reproducible, a causal structure is needed. In the following section, I explicate how Barad elaborates this as in/ separability, which entails the local subject-and-object relatum-the relation defined through and within the phenomenon, and constituting the possibility for objectivity and causal relationships.

What begins for Bohr as an epistemological problem of crucial scientific concern is shifted by Barad to become a problem of ontological significance, further elaborated as an agential realism, which is a performative account of the in/separability of nature-culture practices. For Barad (2007), Bohr's insights urge us to rework familiar concepts such as "space, time, matter, dynamics, agency, structure, subjectivity, objectivity, knowing, intentionality, discursivity, performativity, entanglement, and ethical engagement" (33). In the following section, I will discuss the ramifications of this Bohrian proto-performative fold in Barad's account of agential realism, emphasising the aspects of in/separability of object and subject. Proceeding, we will then examine diffraction as both a methodology (i.e., as a 
statement of onto-epistemological engagement) and a method (i.e., the actions to take and efforts to make) for a kind of research and theorising that is attuned to an agential real.

\subsection{Agential Realist Reconfigurings of Objectivity and Subjectivity}

Barad's reworking of the notions of subject, object, subjectivity, and objectivity resonates with Bohr's conceptualisation of quantum wholeness as articulated by the inseparability thesis. To recap, for Bohr, quantum wholeness entails that the phenomenon acts as referent for ontic and semantic resolution, providing the condition for the unambiguous communication of measurement results. This conceptualisation of the phenomenon refers to entangled being and not to the colloquial (dualist) notion of the phenomenon as a physical entity with determinate properties to be unveiled by measurement. Rather, it involves the (non-dualist) inseparability of agencies of observation and the object of observation. The agencies of observation consist of the going together of the concept embodied in the apparatus that measures "position," necessarily conditioned by the notion of "position" as representing a fixed location. Agential separability—a separability within the phenomenon via the enacted cut between the apparatus and the object, constituting the resolution of ontological indeterminacy — forms the non-dualist condition for objectivity (Barad 2007, 175). Phenomenal intra-action between the observation and the object of observation "cut[s] things together and apart" — that is, separability always involves in/separability and emerges within, and through, phenomena (381). For Barad, phenomena are not "laboratory creation," but "the ontological inseparability or agentially intra-acting components" (33). As such, in agential realist terms, phenomena involve ontological resolution and constitute "the basic units of reality" (33).

According to Barad (2007), in Bohr's terms objectivity entails the "unambiguous communication of the results of reproducible experiments" (174). Bohr reformulates the 
objective matter of fact as "permanent marks—such as a spot on a photographic plate, caused by the impact of an electron-left on the bodies which define the experimental conditions" (cited in Barad 1998, 96). In quantum research, multiple experiments-resulting in multiple positions of spots on a photographic plate-constitute the data for probability calculations. In other words, objectivity for Bohr does not refer to the inherent properties of an object, to pre-existing measurement procedures, or to neutral experimental conditions. Rather, objective results refer to the phenomenon-that is, to the experimental circumstances, which include the embodied concept, i.e. position or momentum, materialised through (and with) the apparatus. The "Bohrian cut" (in/separability or exteriority within) between the agencies of observation and the object of observation thus concerns a non-Cartesian subject-object distinction (Barad 2007, 174).

Both Bohr's (1958) notion of quantum wholeness and Barad's (2007) reworking of it as phenomenal intra-activity implicate complementarity, suggesting the impossibility of a situation in which all quantities (position or momentum) become determinate, or have definite values (197). The subject and the object are not determined in advance, nor is one of them fixed and used as a referent with which to understand the other. It is clear that phenomena (in the Baradian sense) provide an alternative to the representationalist dichotomy between word and world, or between symbolic presentation and reality. For Barad (2007), a concept is not a transparent medium "that transmits a homologous picture of reality to the knowing mind" (97). Instead, concepts and material setups are mutually defined and question "materiality and signification," as well as "the relationship between them" (Barad 2007, 132). The Baradian metaphysics of entangled being thus undermines representationalism. The belief in the separability of the knower, the known, and knowledge shifts "the focus from questions of correspondence between descriptions and reality (e.g., do they mirror nature or culture?) to matters of practices/doings/actions" (Barad 2003, 802).

Barad's (2007) ontological reworking understands the Bohrian phenomenon as the epistemological in/separability of the agencies of observation and the object of observation in their plural form as the primary ontological units, being "the ontological inseparability of objects and apparatuses" (128, emphasis in original). For Barad, phenomena concern entangled 
being, not things in themselves. An entangled state, also across epistemology and ontology, "cannot properly be understood as a composite system" in the sense of a mixture, which would allow one to observe the different elements of the mixing (271). Rather, an "entangled state ... must be understood as a single entity" (271, emphasis in original). In other words, object and subject emerge through, and within, the entangled being of intra-activity.

The starting point for Bohr was an epistemological one, with a focus on Gedanken experiments of theoretical physics embedded in laboratory practices (Bohr 1950). Barad (2007) reworks this epistemological focus, involving "human concepts, human practices, [and] human knowledge" with Bohr's assumption of a predetermined concept of what the human is (334). Although Bohr (1950) affirms the co-constitutive role of the human when measuring quantum behaviour, the assumption of the human as pre-existing interaction nevertheless creates doubt concerning the inseparability thesis in the form of an exterior distinction between the human (thinking) subject on the one hand, and a phenomenal quantum entanglement on the other. The problem then arises of how objectivity might be secured. Barad's (2007) reading takes up the potential of Bohrian agential separability, which secures objectivity, considering that "part of the world becomes determinately bounded and propertied in its emergent intelligibility to another part of the world," including the human as an intra-actively emergent factor (149). Objectivity is secured by the "accountability to marks on bodies, and responsibility to the entanglements of which we are part" (Barad 2012c, 53, emphasis added). In other words, objectivity does not aim to correctly determine what scientific and scholarly research and theorising report about a reality that is supposedly passively awaiting measurement. Agential reality does not recognise representations of an (objectified) independent reality, but rather highlights how differences that matter (in its duplicity) concern "real consequences" - that is, how differences effect change (identities and boundaries) and therefore demand our accountability and responsibility (Barad 2007, 37).

Turning now to Barad's conceptualisation of subjectivity, we will see that, as with the concepts of "object" and "subject," objectivity and subjectivity are also related to Barad's notion of difference. From the previous discussion, we might infer that, according to Barad, Bohr's non-dualist reformulation of objectivity must implicate a reformulation of 
subjectivity, which is often considered as the counterpart of objectivity in dualist terms. Following this classical interpretation, the objective represents the "universe in general," whereas the subjective account defines the universe "in particular" through human intentionality (Grosz 1994, vii). ${ }^{89}$ Abbate (2004) refers to such a dualism when contrasting "the universalizing endemic in academic discourse" with her subjective engagement with music through listening (536). Here objectivity and subjectivity are considered as two mutually exclusive orders to which music is subjugated and in which the former suggests a musical world independent of the latter, suggesting to "[cast] one's lot" with drastic actions and feelings (Abbate 2004, 536). In other words, objectivity and subjectivity define (scientific) distance between terms, and subjectivity repeats such a distinction as a contrast between inside and outside.

Considering scientific distance, we discussed the non-representationalist Baradian take on scientific experiments that produce intra-actively a local and temporal separability within phenomena as a difference within. Objectivity, in the Baradian sense, concerns a practice in which the distinction between object and objectivity is intra-actively determined by the in/ separability of the object and the material setup of the agencies of observation. In the same move, this apparatus delineates a knowing subject such as, for instance, the researcher. However, considering subjectivity as the relationship between inside and outside, Barad (2014) considers the non-binary liveliness of the "borderland," which does not leave behind the outside when inside, and vice versa (168). This suggests that Barad does not place subjectivity in opposition to objectivity—in terms of value, respectively, a weak or a strong scientific approach.

Additionally, Barad (2014) does not suggest a clear-cut separation between the materiality of the object as "objecthood" and the subject as "subjecthood." Instead, she

\footnotetext{
${ }^{89}$ As Barad (2007, 125-126) suggests, Bohr's concept of the phenomenon concerns the epistemological inseparability of the agencies of observation (subject) and the object of observation (the phenomenon produced). For Bohr, the distinction between subject and object is made through intentional human observation, meaning that in the end, Bohr's account establishes an "intersubjective notion of objectivity" in which the sociality of the human knowing subject involves the limit of knowledge (Barad 2007, 153). This suggests that the Bohrian inseparability thesis of embodied concept and of being part of the world we seek to understand, nevertheless, introduces the Cartesian predefined, disengaged "liberal humanist subject" as the ground for knowledge (Barad 2007, 154).
} 
explores this borderland by seeing how "diffraction patterns [illuminate] the indefinite nature of boundaries-displaying shadows in 'light' regions and bright spots in 'dark' regions" - affirming the relation of outside and inside as a relation of "exteriority within" (Barad 2007, 135). This means that, in terms of Abbatean musical subjectivity, subjectivity concerns a relationality between a "musical-material outside" and a "subjective-material inside" through which music and subject come into being, each never leaving the other behind. The listener's subjectivity and the music's musicality are entangled histories, "[e]ach ... diffractively threaded through and enfolded in the other" (Barad 2012a, 207). Again, when considering the intra-active in/separability through which subject and object emerge as exteriority within, subject and object concern both subjectivity and objectivity, in the sense of entangled material histories that shine through one another.

\subsection{Agential Realism: Diffraction as Method and Methodology}

Barad's metaphysics of an agential real, building on the inseparability thesis, and the diffractive methodology she proposes are two sides of the same coin-methodology and metaphysics are intertwined. The method for research and theorising is not an action (at a distance) derived from Barad's metaphysics. Rather, as Barad's general methodology suggests, it is an inherent part of the metaphysics of an agential real. Thus, in a very real sense, metaphysics, methodology, and method are inextricably bound together. Taking into account Barad's metaphysics of an agential real, in this section I explore how diffraction is both a method and a methodology, enabling us to take account of the intra-active productivity of matter-meaning practices, and to affirm the inseparability of agencies of observation and the object of observation—that is, to affirm the entanglement of ontology and epistemology.

Diffraction troubles the familiar notions of epistemology, methodology, and method. Whereas epistemology deals "with criteria for what constitutes scientific and scholarly 
knowledge" (Lykke 2010, 144), methodology is mainly considered a procedure of particular actions, or a template and application of "inquiry through which an alien object might be ciphered" (Kirby 2011, 5). According to these definitions, method entails the actions and tools—derived from epistemological and methodological concerns-for doing research and theorising. However, these familiar epistemological concerns leave us with a problem implicated by the inseparability thesis of knowing in being, namely that, when doing research or theorising, a methodological "in-between" (a template, an application, a theory, a representation) is constituted, which would then mediate a world, establishing a predefined nature-culture dualism. As Barad (2007) states, we are inextricably part of the world's specific materialisations, and this "requires a methodology that is attentive to, and responsive/responsible to, the specific material entanglements in their agential becoming" (91). The crucial role of diffraction as both methodology and method, and even as an "overarching trope" of knowing in being, is to help unravel entangled being, of which one is inseparably part, and to "illuminate the nature of nature" (Barad 2007, 29).

For Barad, diffraction underlines how paradigm changes, as famously theorised by the philosopher of science Thomas S. Kuhn ([1962] 2012), are rather a cause of concern. In Kuhnian terms, shifting the Newtonian paradigm as guidance for "normal science" to the quantum paradigm as (new) guidance for "normal science" constitutes a revolutionary change. However, Barad (1995) states that, nonetheless, "after the revolution ... 'normal science' resumes" (70).90 In both paradigms normal science endorses a "culture of extreme objectivity," according to Barad $(1995,70)$, and it is in relation to this that she values the

\footnotetext{
${ }^{90}$ Kuhn ([1962] 2012) describes "normal science" as the research practice that is "firmly based upon ... scientific achievements that some particular scientific community acknowledges for a time as supplying the foundation for its further practice" (10). Kuhn theorises the structure of scientific revolutions in which "normal science" encounters anomalies "that subvert the existing tradition of scientific practices" (6), leading to a crisis and the emergence of new theories, followed by a resolution in the form of a new paradigm. For Kuhn, paradigm (change) means a new "normal science" capable of attracting "an enduring group of adherents away from competing modes of scientific activity ... sufficiently open-ended to leave all sorts of problems for the redefined group of practitioners to resolve" (11). Gender studies scholar Nina Lykke (2010) argues that Kuhn proposes "science and knowledge-producing practices to be part of society and not as something that simply follows its own internal logic of development" (128). For Barad, the social embeddedness of scientific practices is evident, but there is more to it: Material doing and the human are inseparably part of generative intra-activity.
} 
radical nature of Bohr's notion of complementarity and unambiguous description of quantum behaviour. For Barad, Bohr's contribution nuances the Kuhnian paradigm crisis now considered a crisis of science itself. The focus is not on the (Kuhnian) incompatibility of old and new theories, but on the nature of scientific concerns as an effect and part of a nature (either Newtonian or quantum) that is not a given ("anymore") thus rejecting an objective view from a distance..$^{91}$ Recall here Bohr's notion of how the observation/measurement of quantum behaviour "orders" that a concept (position/momentum) is embodied in the material apparatus of observation and therefore intra-actively entangled with the object of observation. This might be considered as defining the very diffraction apparatus that plays such a prominent role in Barad's methodological elaboration.

Diffraction as a physical phenomenon is the coming together of waves, resulting in a diffraction pattern, consisting of waves that are enhanced or cancelled out through their meeting. That which generates diffraction and the subsequent diffraction pattern is called the diffraction apparatus or diffraction grating (Barad 2007, 71 ff.). Quantum physical research into the nature of light, using diffraction apparatuses, demonstrates how a diffraction pattern is a remarkable, heterogeneous effect of light and dark, with dark spots in light regions and light spots in dark regions, "illuminating the indefinite nature of boundaries" (Barad 2007, 93). The entanglement of the apparatus, waves meeting, and a diffraction pattern as the effect of difference, provides insights into the "entangled structure of the changing and contingent world, including the ontology of knowing" (Barad 2007, 73). Knowing is knowing in being; it is an entangled affair in which different waves meet. It is a relationality that is generative of new differences, and diffraction patterns emerge as the heterogeneous effects of differences.

For Barad (2007), diffraction is both an optical phenomenon and an inspiration to elaborate a methodology and a method. In this regard, it stands in a long tradition of "using visual metaphors as a thinking tool” (88). However, as discussed previously, concepts are embodied and material-discursive doings. Therefore, we may not interpret her use of

\footnotetext{
${ }^{91}$ Barad's concern regarding the objective mode in relation to nature's liveliness we also see articulated in Abbate's (2004) critique of new musicological performance research, noting that "the objective mode [of normal science] protests too much, bypassing the uncanny qualities ... in trying to domesticate what remains nonetheless wild" (508).
} 
diffraction as metaphor in referential terms that would enable for us the analogical view from which to understand the (Other) world; a world in which things and thoughts are emergent differentiations (diffraction patterns)—the effects of a (matter-meaning) engagement. Rather, diffraction as metaphor articulates a methodology as materialdiscursive practice; as a doing that makes us "pay attention to the kinds of differences that different understandings of diffraction evoke" (419, note 25$)$. Diffraction as a methodology is consistent with the inseparability thesis, inviting us to understand the world from within, being part of it, paying attention to differences that matter. As a method and analytical tool, diffraction may be considered in analogy with the physical phenomenon, even though it "does not imply that the method itself is analogical" (88, emphasis in original). A diffractive method of reading insights together-that is, reading insights through a diffraction grating and being attentive to differences that emerge therefrom-is at odds with a reflective reading against a "fixed target/mirror" that looks for difference as "different from," or for origins and authenticity (90). Diffraction as a method concerns a grating through which research and reading insights meet, enabling us to study what the effect (the diffraction pattern) of diffraction is, and how this relates to the grating as the tool employed. Further, diffraction articulates-consistent with Barad's metaphysics of agential realism—the ongoing "new" of enfolded generativity. In other words, by building on the inseparability of agencies and objects of observation, and on the temporality involved in matters of materialisation, diffraction undermines methodologies that build on reflection, featuring stability and the centrality of the subject as set against, or in opposition to, the object.

\subsubsection{Diffraction as Implicated in Practices of Research and Theorising}

Barad's insistence on the inseparability of matter and meaning (or of object and subject) takes her philosophical practice beyond the familiar predetermination of object (of research) and subject (who/ what performs research or who/what observes). The act of diffractive reading confronts one with the (considerable) difficulty that one must shift familiar reading practices that interpret and localise, and that would objectify Barad's thinking against the fields of 
physics, feminist studies, philosophy of science, or, indeed, musicology. The problem is that such a practice would assume Barad's work to be an identifiable achievement brought to a state of completion-an independent entity and fixed fact of the past. The point is not that she is alive-meaning that her insights may change and more writings may follow-but that considering her work as an artefact waiting to be analysed contradicts the very notion of agential realism. Agential realism's focus is on the inseparability of matter and meaning, and the intra-active relationality between enfolding practices generative of new things and thoughts. Bohr's insights do not oppose Barad's insights, but are enfolded as diffractive patterns in agential realism—that is, thoughts overlap, enhancing particular ideas and diminishing others. Thus, for Barad, matter and meaning (in experiential research and theorising) do not precede the act of analysis as propertied and identified things and thoughts. Rather, it is precisely in their meeting, through their "intra-action that the boundaries and properties become determinate and that particular concepts ... become meaningful"' (Barad 2007, 139). In their inseparable togetherness, the knower, knowledge, and the object of knowledge become locally and intra-actively determinate, whilst always remaining open to future intra-active enfoldments. The same goes for humanities research and theorising.

Nevertheless, in the sense of time's irreversibility, Barad's articles and books-those already written and published-are indeed events of the past. However, including (although certainly not limited to) musical events, time's irreversibility does not impede retrospection, rehearsal, reconstruction, or, for that matter, any other "retro-" or "re-" prefixed possibilities that might modify the assumed and already given, enfolded in and productive of new intraactive relationalities. In this sense, Bohr's thinking as reworked through Barad's articles and books is a rich, generative source for my own thinking towards a revaluation and reconceptualisation of the (Abbatean) musical drastic and musicological gnostic, and their entanglement. As we know from our engagement with music, the "re-" of rehearsing or replaying cannot undo time, but states the "again" as a difference-a reworking—in which past and future intra-act (in the practical sense of making music, relating that which can be made better to the expectations of a coming event). This suggests that Baradian, agential 
realist performativity embraces a past that can "never [be] left behind, [and that is] never finished once and for all" (Barad 2007, 181); indeed, "the past and the future are enfolded participants" of matter's iterative materialisations (181).

Taking diffractive reading (and research) as a starting point from which to engage with Barad's work has an powerful impact on the strategies of thinking, writing, reading, and analysing, necessitating a shift in existing strategies that "capture, explain, organize, and categorize" — the familiar epistemological modes, focusing on the predefined, "already contained ... in the fabric of the known" (Grosz 1999, 16). This suggests that for Barad, as well as for those who explore her thinking, so-called origins, sources, things, and ideas, as the usual foundational entities of analysis, are not the preeminent elements for interpretation and (re)arranging, but rather have to be considered productive generators of the "new" in a concrete material and discursive way. ${ }^{92}$ In other words, Barad invites us to reconsider how research is done, albeit not by making adequate that which was considered inadequate thinking, but to consider an infinite productivity of research, involving discursive, musical, and material doings..$^{93}$

To include the diffractive, intra-active generativity of matter and meaning, Barad must continuously resist the stabilisation and spatialisation of time, which accompanies the use of language and writing. Language is understood here as referred to earlier, discussing how the Abbatean plea obstructs the expression of that which is changing and caught up by the dynamics of materialisation. The dynamics involved in the determination of properties and meanings—so aptly demonstrated by music's insistence on temporality and materialisation—are difficult to express through language and thinking.

Contrary to the Baradian argument, we are confronted with a linguistic practice of representationalism that assumes a divide by building a stable connectivity between "words and things" (Foucault cited in Barad 2003, 811). For example, consider the musical world and

\footnotetext{
${ }^{92}$ For an (Baradian) understanding of the "illusion of retrospection," see Alexandre Lefebvre in the introduction to Jankélévitch's (2015, xix, xx) Henri Bergson.

${ }_{93}$ For example, in "Quantum Entanglements and Hauntological Relations of Inheritance," Barad (2010) refers to the very article she is writing. Reading texts and space-time coordinates through one another, she deepens the notion of intra-active doing as the disruption of (historical) continuity.
} 
how a stable continuity between the note $G$ (when written or spoken) and the sound heard seems self-evident: “I hear a G!” However, according to the Baradian notion of an agential real, a representation such as the $\mathrm{G}$ is not mediating access to a tone that is heard, but involves a particular material and discursive practice, namely, the engagement with the materiality involved when considering notated music and the specific cultural practice requiring a G. Framed in this way, a G relates to a specific material-discursive practice of representation, which diffracts with a material-discursive practice of singing, resulting in a G sung in a specific way. In short, representations (note, timbre, duration, musician, and voice) involve the same Bohrian notion of the inseparability of the agencies of observation (the material arrangement embodying the concept of $\mathrm{G}$ or any other note) and the object of observation (the sound made and listened to) as a material-discursive practice that may be diffracted with other practices.

Thus, considering representation as material-discursive practices generated by, and generative of, new things and thoughts, Barad traverses the Bergsonian problem of language (which stabilises that which is dynamic) by starting from the (non-dualist) inseparability of matter and meaning. As previously discussed, Barad $(2007,26)$ specifically complicates this question of the relational as inseparability, stating her Bohrian thesis that we are part of the nature that we seek to understand. Clearly, this implies a hermeneutics from within, explicating the generated and the generative whilst being inseparably involved in the very processes of distinction and becoming.

The ramifications of Barad's inseparability thesis and the performative account of material-discursive practices move us towards diffraction as both a method and a methodology that is attuned to the inseparability and the dynamics of material-discursive generativity. A shift to diffraction as a tool for research and theorising not only affects analysis, but is also agential towards the structure of Barad's argument. This becomes visible in her use of the visual aspects of writing. Through the frequent use of scare quotes, hyphens, slashes, brackets, neologisms, and by linking words without spaces, she emphasises an inherent, dynamic connectivity between words and things, and of being on the cusp of "in-" and "-determinacy;" of "re-" and "-configuration;" and of "dis-" and "- 
continuity," all caught up (or not) in intra-actions. For Barad (2010), these are necessary interventions that articulate how coming into being involves in/separability, in which "object" and "subject," indeed, need scare quotes because entities do not pre-exist their intraaction.

From the way in which Barad elaborates Bohr's insights, it is clear that she does not aim for an analogy between a microscopic and macroscopic world by using diffraction as a tool, a metaphor, and an overarching concept. That is, the dynamics of quantum behaviour, if observed by using diffraction as a tool, do not necessarily reveal any self-evident truths about the world in which we live. Additionally, Barad does not aim for a dialectics, a rational weighing of pros and cons, progressively developing a definitive standpoint. Rather, she questions precisely the fixation of any difference between terms, implicated by drawing analogies or when considering dialectics. We might say that diffraction supersedes the familiar concept and method of discursive analysis, otherwise known as reflection. Before gaining a more detailed understanding of diffractive research practices, we first consider the concept of reflection.

\subsubsection{Diffraction Supersedes Reflection}

When considering Barad's elaboration on diffraction as a methodology, Donna Haraway's research into visualisation technologies must be brought into play. Haraway (1997) uses the concept of diffraction as a metaphor for certain knowledge practices, enabling her to take account of the "material-semiotic" practices of technoscience (16). ${ }^{94}$ Haraway (1988) argues for "situated knowledges" — knowledge produced from a located and embodied perspective- as opposed to a system of knowledge production based on "transcendence and splitting of subject and object" and metaphorically expressed by the mirror of reflection

\footnotetext{
${ }^{94}$ Barad (2014) refers to Trinh T. Minh-ha's 1988 paper "Not You/Like You," in which she explores the notion of diffraction without exactly referring to the term. As Minh-ha argues: "difference as understood in many feminist and non-Western contexts ... is not opposed to sameness, nor synonymous with separateness. ... There are differences as well as similarities within the concept of difference" (cited in Barad 2014, 169, emphasis in original).
} 
(583). For Haraway, the ontological aspects of diffraction promise to exceed representationalism as a common critical practice incorporated in reflexivity. Here, we might ask why reflection—such a common optical metaphor for knowledge practices—is a problem at all. ${ }^{95}$ Barad (2007) elaborates Haraway's suspicion that reflection and reflexivity-as a method for investigating the self and for accounting for the self in research and theory formation-can rather lead one astray when used as common critical practices. The reason is that, as epistemological practices, reflection and reflexivity conform to the binary logic of representationalism.

As Haraway (1997) states, reflection and reflexivity constitute the representationalist cut between the observer and the real, "only displac[ing] ... the same elsewhere, setting up the worries about copy and original and the search for the authentic and really real" (16). Haraway responds in particular to how reflexivity has been taken up and discussed by philosophers of science as both a methodology and a critical practice at a time in which they seemed to be summoned to choose between realism (i.e., reflection mirroring the real as it really is) or relativism (i.e., reflection mirroring the one who gives meaning to an untouched reality). According to Haraway, this is a "false choice" (16)—or rather a non-choice—because it obscures the real problem, namely, the scholar's search to segregate him- or herself from the object of research, leading either to a transcendent and clean object of research (realism), or to the disinterested interpreter (relativism). ${ }^{96}$ Both modes hinge on reflection as a method by which to engage with reality by placing a mirror, separating researcher and reality. This is a narrative we recognise in Abbate's critique of the academic gnostic as an attitude of scientific observation, conflated with the objectivity episteme in order to account for the scholarly knowledge claim—that is, non-corporeal and transcendent.

Whether in a realist or a relativist mode, either way reflection and reflexivity presume access to representations, here considered as reflections of a pre-existing nature (realism) or

\footnotetext{
${ }^{95}$ For the deployment of diffraction as a methodology as opposed to the work on reflexivity and critical reflection that dominates contemporary educational literature and practices, see Vivienne Bozalek and Michalinos Zembylas (2016).

${ }^{96}$ Latour (2004b) makes the same point as to the non-choice between realism and relativism, stating that a thing "is ... a gathering ... [designating] matters of fact and matters of concern" (233, emphasis added).
} 
culture (relativism and social constructivism). This easily leads to representationalism, in which it is assumed that representations mediate a reality, or are seen in terms of a one-toone correspondence with reality and as such would give a full explanation of reality. For Barad (2003), however, representations are material-discursive practices that intra-actively produce reality. Representations are made through and within (entangled) materialdiscursive practices. Emphasis is thus put on "matters of practices/doings/actions" and not on mediating or reflective modes, suggesting that language and other symbolic means mirror or communicate nature or culture (802). Representations as a matter of materialdiscursive practices become diffractive doings, "illuminating the indefinite nature of boundaries" (803). This suggests, for example, that the relation between composing and performing is a "relation of 'exteriority within'" (803). The relation between composing and performing is a temporal relationality and a doing, entangled with specific materialdiscursive practices of theorising, researching, composing, or performing. As a singer who starts working on a score, instead of asking what "this" composer means, one might ask how performance is incorporated in "this" composition. The latter question, starting from the indefinite nature of boundaries, mobilises intra-activity and therewith all kinds of connectivity (and possible actions). Conversely, asking for a composer's meaning presumes the stability of musical representations and a structural foundation that pre-exist the (double) relation between a composer/composing and performer/performing.

An agential realist approach does not want to undo representations and also respects the social and cultural means involved, but considers them intra-actively constituted. They are enfolded material-discursive practices that do not neutrally mirror or mediate a given reality, nor can the presence of the mirror be negated. ${ }^{97}$ For Haraway, as well as for Barad, in order to make a difference, "one must be in the action, be finite and dirty, not transcendent and clean" (Haraway 1997, 36). In Barad's (2007) terms: “To theorize is not to leave the material world behind and enter the domain of pure ideas where the lofty space of the mind

\footnotetext{
${ }^{97}$ René Magritte's famous painting Ceci n'est pas une pipe articulates this very point; what we see is a representation of a pipe, not a pipe. Moreover, it demonstrates that representations are made and "do not simply refer in ways that we have come to expect" (Barad 2007, 360).
} 
makes objective reflection possible. Theorizing, like experimenting, is a material practice" (55, emphasis in original). In the words of Pierre Boulez ([1986] 1990)—who is often called an intellectual confined by the dialectics of composition-a composer's concern for performance goes hand in hand with "summon[ing] up the courage to take the plunge himself" (32), for "music has no real existence except in direct communication" (33). Affirming Boulez's statement, we might say that reflection and reflexivity as epistemologies subscribe to the binary logic of representationalism and do not recognise the ongoing differencing of matter, space, time, and value, from which bodies and thoughts cannot be withdrawn in isolation. ${ }^{98}$

Like Haraway, Barad (2011) is not against the use of metaphors per se, but rather considers the setting up of the mirror metaphor of reflexivity—that is, thinking analogically, and finding "the same things / relations / patters everywhere" (445)—to be a flaw that obstructs any rigorous engagement with the heterogeneous histories of scientific and scholarly practices. We can say that Barad's use of difference, as that which comes into being differentially, necessitates a methodology that enables us to take account of processes of differencing as diffractive processes. Barad's (2007) concept of diffraction as a "methodological approach ... of reading insights through one another in attending to and responding to the details and specificities of relations of difference and how they matter" (71, emphasis added) is, in a quantum-mechanical sense, in-formed (intra-actively generated) by Barad's understanding of diffraction as a physical phenomenon. In section 3.2. on Bohr, I discussed how, in an experimental setup of a two-slit apparatus (also called a diffraction grating), light, beamed through the two slits, results in a diffraction pattern on a photosensitive screen. This diffraction pattern serves as evidence for the wave behaviour of light, showing alternating dark and light spots corresponding to the effects of waves meeting in phase (light) and out of phase (dark). That is to say, diffraction patterns are used to study

\footnotetext{
${ }^{98}$ I. C. Jarvie explains the inescapable conundrum when knowing and being are (un)acknowledged and opposed: "before we can answer the question of what exists, we have to solve the problem of what we know," and vice versa (cited in Mullarkey 2010, 14). According to Jarvie, solving the problem of what we know does not solve the problem of what exists, "and how we can assess the problem of what exists and hence can adjudicate our claims to know that it does" (14). In short, when knowing and being are placed in opposition in a representationalist manner, they implicate each other in every move of the argument, installing a circular logic.
} 
the nature of light, in which "light is not merely a tool but an object of inquiry as well" (Barad 2007, 85). That is, whereas classical physics uses reflection as an epistemological tool for studying lenses and mirrors based on rays of light, diffraction is used to do quantummechanical research into the very ontology of light itself.

We also know the notion of light as a refracted ray (which gives us the colours produced as a prism, or, when light shines through water) seems to intersect and displace the legs of the heron standing in the pond. In these situations, too, light is considered, in terms of geometrical optics, a ray with a particular direction, intersected or not-based on refraction and reflection as revealed when looking in a (distorting) mirror. For Barad (2007), the methodological point is that refraction (52) and "reflection [have] an asymmetrical focus that fixes one as standard against which the other is read" (418, note 17). Using the ray of light as a heuristic instrument with a particular trajectory (for example, bouncing off a surface), the mirror is the standard from which a particular (refractive) reflection as distorted result is derived. Instead, research into diffraction does not reduce light to a ray, but studies the nature of light by using a diffraction grating (the instrument). This grating, consisting of an obstacle for light's trajectory, "produces patterns that mark differences in the relative characters (i.e. amplitude and phase) of individual waves as they combine" (81). As argued above, Barad does not consider light simply as a tool for demonstrating reflection (light rays bouncing off a mirror), nor is she interested in the effect of waves colliding with an obstacle. Instead, she turns to quantum-mechanical and physical optics questions of diffraction, involving experimental approaches to understand the phenomenon of light, "[making] light's wavelike behavior explicit" (81). Diffraction traverses the dualism inherent in reflection and takes into account how agencies of observation (mirror) and the object of observation (rays of light) build on representationalism, assuming a "preexisting determinate boundary between subject and object" (89).

For Barad (2007), considering diffraction as a methodology with which to read insights through one another is analogous to diffraction in physical optics research, although this "does not imply that the method itself is analogical" (88, emphasis in original). A diffractive analysis concerns a performative reading or research in which differencing is 
productive of differences that matter. Exploring diffraction as methodology and method, Barad's (2003) aim is thus to "sharpen the theoretical tool of performativity for science studies and feminist studies and queer theory," considering their mutual concern (803). As such, a diffractive analysis disrupts common research paradigms-both in the sciences and the humanities, and in predetermined interdisciplinary engagements. Such common paradigms rely on reflection as a setup that starts with the difference between fixed entities, seeking "homologies and analogies," observing the world from a distance, and deepening the nature-culture binary (Barad 2007, 88).

Barad reworks the Bohrian notion of how the entanglement of the diffraction apparatus (the agencies of observation) and the objects of observation (e.g., light) produce new phenomena. Considering musical and musicological matters, this explains how differences come to matter, and how sedimented (propertied and identified) music and musicology can become productive of new intra-activities- that is, when taken up by the ongoing matter of differencing. Therefore, what matters is not so much the fact that differences are observed as marked properties and boundaries between entities, identities, or essences (e.g., different timbres, harmonies, and melodies, as well as different music/ologies), but rather, how these differences are diffractively (re-)produced through and within intra-active in/separability (Barad 2007, 73). Therefore, a diffractive methodology builds on scholarly and scientific research and theorising practices that are taken up in ongoing, temporal sedimentations of enfolded intra-activities-enfolded in the sense that musical and musicological practices do not stand on their own, but are intra-actively entangled with "other" material-discursive practices. Intra-active in/separability, then, involves the non-Cartesian "exteriority within" through which both the subject of observation and the object of observation emerge as differences, yet without undoing the relationality of their entangled or phenomenal being. Musicology, re-conceived as music/ology—the study of musically entangled being — escapes the dualisms foregrounded in chapters 1 and 2. In the following section, I demonstrate how an intra-active, diffractive approach enables different approaches to research and theorising, whilst simultaneously 
discussing the difficulties involved when exploring entanglements and the differences produced.

\subsection{Studying Entangled Being Diffractively}

An Abbatean/Baradian shift, affirming the materiality and dynamics of musical and musicological coming-into-existence, does not start from any predefined notion of music, representation, or category, but rather encounters musical mattering by listening or "looking/thinking" inside the complexity of entangled musical being. That is, rather than studying predefined entities—“differences that are already in place" (Barad 2007, 232)—we study how differences (things, thoughts, and representations) are produced and contribute to musical and musicological reconfigurations. The (re)configurations effected concern partial matterings—-taking into account material constraints and discursive boundaries—that are intra-actively generated and part of all that music and musicology can be. This suggests that the music/ological encounter through playing, listening, research, and theorising is a case-by-case specific practice, generating a partial account of all that such an encounter might generate. Crucial then is the specific intra-active relationality within and through which a music/ological account of music emerges.

Relationality here concerns a relating through "intra-active and topological dynamics" through and within which a specific musicological knowing is generated for (and generative of) further intra-actions (Barad 2001, 103). ${ }^{99}$ In other words, being involved as a musicologist (or a musician) within entangled musical "being" suggests that "the very ontology of the entities"-in this case, musical and musicological—“emerges through

\footnotetext{
${ }^{99}$ Topological questions concern boundaries and connectivities. Geometry investigates shapes and sizes as flat planes (Euclidian) and curved surfaces and spheres (non-Euclidian). According to geometry, spaces are considered in terms of "the characteristics of enclosure," whereas topology investigates connectivities and boundaries that do not start from predefined (geometrical) relationships between space and the object of research, but consider relationality and boundedness as dynamic reconfigurings that matter (Barad 2007, 436, note 78). We only have to think of how musical recording technologies provide for a new understanding of spacetime as a dynamic changing topology, reconfiguring the notions of location, proximity, and time, which matters musically.
} 
relationality" (Kirby 2011, 76, emphasis in original). Based on the inseparability thesis, musical materialities, musicians, knowledge, and musicologists do not pre-exist their involvement. Rather, it is through intra-action that entities, the ability to act (agency), its very nature (valuing/touching music), and musicological knowing (objects and subjects) come into existence, although crucially without being able to claim permanence and strict determination. These practices remain open-ended.

Musical and musicological properties (material and theoretical characteristics) as well as musicians and musicologists are not isolable, as the term inter-action-as action between distinguished modes (object and subject) —might suggest. Therefore, it is not necessary to make a distinction between the musical and the musicological, as both practices are music/ologically entangled in performance research. Studying music from an Abbatean/Baradian perspective concerns the study of intra-actions through and within differences (things, thoughts, identities) that variously stabilise and destabilise the materials. Discourses, aesthetics, ethics, subject and object positions (configuring and reconfiguring the musical phenomenon) come to matter in the double sense of materialising and meaningmaking.

Both Barad and Abbate prove that it is crucial to start from and within practices, which for Barad means diffractively "reading" them together and being open to the results as differences that matter. This requires that one does not impose any predefined theories, categories, or other epistemic tools for analysis on music/ological practices. Whilst common practice, such an approach would bypass the dynamics of music/ological properties and boundaries as emergent differences. Barad's methodology of diffraction, apart from serving as a methodology for reading insights through one another, also serves as a tool to study entangled musical being, which is the study of differences / entities that materialise intraactively. In what follows, I propose to distinguish a few orientations for diffractively studying the complexity of musically entangled being.

We already discussed the practice of diffractively reading insights through one another. This entails a reading practice that concerns a particular engagement in a specific locality; a specific space, time, culture, nature, and history. In Barad's (2003) own terms, 
reading practices operate as diffraction gratings or apparatuses. The implications of this approach reach beyond the specific nature of scientific practices. Instead, they "[offer] an understanding of the nature of material-discursive practices," and produce differences that matter (Barad 2003, 816). Thus, apparatuses / practices / gratings are not simply instrumental as "inscription devices, scientific instruments set in place before the action happens" (Barad $2007,169)$, but also have a prominent role in the production of music/ological entities. As Barad (2003) argues, "apparatuses are dynamic (re)configurings of the world, specific agential practices / intra-actions/performances through which specific exclusionary boundaries are enacted" (816, emphasis removed, underscore in original). At any time, some things are included, whilst others are excluded from research and theorising. As such, my Abbatean/Baradian reading apparatus, as well as musicology as a specific discipline and a specific musical performance setup, function as diffraction gratings (apparatuses/musicomaterial-discursive practices) within which music/ologists are phenomenally entangled. For musical and musicological aesthetic, semantic, theoretical, material resolution, the particular practice is the referent.

For Barad (2007), there are in principle two orientations to study entangled being: first, in being part of the entangled phenomenon (a musician making music, a musicologist doing research); and secondly, when enlisting a "further auxiliary apparatus that can be used to [investigate] the 'original' phenomenon in question," such as an academic discipline (345). The scare quotes are necessary, as Barad's agential realism does not consider original and static being, but emphasises practices of differencing. This means that, for instance, studying musical performance from the perspective of music/ology as a phenomenal practice means that a music/ologist is an inseparable part of an extended practice of studying musical performance.

In the former orientation, emphasis is on that which is generated and how this generates further intra-activity, like when we explore this music and how it generates particular dance patterns. In the latter, we work "backwards," with emphasis on the musicomaterial-discursive practice / diffraction apparatus that performs the agential "cut" - that is, the musicological and musical threshold through which musical or musicological entities are 
included and excluded from mattering. Emphasis in this case is on the diffraction apparatus or material-discursive practice itself, suggesting a new phenomenon from which to act. In this case research involves, for instance, the philosophy of scholarly research and theorising that scrutinises musicological research into the relationship between music and dance patterns.

The difference between both forms of analysis is merely one of emphasis. In one situation, that which is generated is investigated, for instance, as to how it is taken up in new intra-activity. Whilst in the other, the focus is on that which is generative, for instance, as to how this musicology as a material-discursive practice is itself produced, or how this performance setup as a material-discursive arrangement is produced. Yet both are entangled practices of musical or musicological production. The Abbatean plea for taking up the material dynamics of musical performance for musicological investigation is also a plea to study the relationship between music and musicology. In short, it is a call to place the agential "cut" for inquiry neither into musical observation, nor into the apparatus with which music is observed, but rather as a "cut" that enables the observation of music, musicology, and their relationship.

Imagine the difficulty of carefully attending to how and where the "cut" between the object and agency of observation, as the in/separability within, is enacted-to take account of the specificity of a material-discursive practice as to how the specific "cut" is implicated. What is the object and what is the subject? What is the object of observation and what are the agencies of observation? This may appear to be less of a problem for laboratory research (with an assumed clear and predefined distinction between object and subject) than it is for research and theorising within the humanities (where the subject and object of research evolve through an interpretative act). However, for both, a diffractive analysis proposes a non-reductive approach to difference, in the sense that differentiations depend for their definition on the inseparability of matter (the research setup) and meaning (the agencies of observation). This suggests a need to be partial in what can be known and what can be done, nevertheless demanding careful analysis of what actually is at stake, especially concerning inclusions and exclusions. 
Let me give an example that explains the complexity involved in studying entangled musical being, issuing the "proper accounting of the agential cuts within the specific phenomenon in question" (Barad 2007, 345). The enfolding of a musico-material and music/ology practice within a material-discursive practice must not be underestimated, as it performs the "cut" from which the musico-material and music/ological practice of making, researching, and theorising materially and meaningfully emerge. My example pertains to the work of musicologist Nicholas Cook.

\subsubsection{Diffraction: The Intricacies of Studying Phenomenal Being}

Nicholas Cook (2004, 2007, 2013) makes a strong case for studying music as performance via empirical and computational means, making use of recordings. For example, Cook (2013) argues that his study of Frédéric Chopin's Mazurkas is motivated by “a traditional musicological question-how music relates to culture more generally-[and benefits] from the study of performance and in particular from the use of quantitative approaches" (326). In 2006, I attended a seminar at the University of Amsterdam in which Cook presented the results of his research on the aspect of timing in Chopin's Mazurka op. 17, no. 4. Cook (2007) discussed how he and his team had developed software able to capture timing and dynamic information. "[B]oth down to single-note level" (Cook 2007, 185), the software enables him to distinguish the loudness of distinct tones and the time characteristics of rallentando and rubato passages that connect the "disjunct series of phrases of which the Mazurka consists" (187). The software, in combination with visualisation technologies, provides a means to "stabilize ... perceptions" and enables "communicating them to others" (Cook 2007, 194). Of interest for exploring the difficulties of studying entangled music/ological being is how Cook installs a measuring apparatus that allows him to examine recorded interpretations by measuring particular dynamics and timings. For Cook, this enables a "rehabilitation" of comparative musicology by means of comparing data, obtained through computing, of recordings of the same performer and those of various performers, all playing the same 
Mazurka (185). ${ }^{100}$ Note how comparative musicology needs a concept of sameness as a standard for establishing its knowledge claims. Seen from Barad's agential realist framework and from Abbate's phenomenological notion of engaging with musical performance, this highlights a problem, as it reduces the intra-active dynamics of differencing-within and through which both the performer and the Mazurka come into existence-to stabilisations and category formations that constitute a "neutral" outside of the specific musico-materialdiscursive practice of playing Mazurkas, or a particular Mazurka. However, it also demonstrates perfectly the intricacies involved if one is to tune in to the specificity of the entanglement inquiry. Let us see how this works for Cook.

The key point for studying entangled being is that the researcher/theorist is an inseparable part of a phenomenon's material-discursive arrangement, producing the separability of the agencies of observation and the object of observation. As Barad (2007) argues, "agential separability [enabling object and subject to differ] is enacted only within a particular phenomenon" (345). As discussed above, we are all part of phenomenal being and cannot really look or listen inside another phenomenon, as this suggests another agential "cut" that separates the object of observation and the agencies of observation. A performer/listener thus becomes part of a different phenomenon than a musicologists / listener. It also suggests a particular material-discursive apparatus through and within which the phenomenon is produced. The point that Barad (2007) makes is that, in this situation, the software that captures timing and dynamics performs a measurement, "['peeks'] inside a phenomenon," indicating a "specific definite value of the property being measured" (345, emphasis in original). The phenomenon is constituted by the agencies of observation (the measuring apparatus, software, and researcher) and the object of observation (the replayed recorded musical object). The difficulty encountered in Cook's (2007 and 2013) analysis, is that the software (the measuring agency) cannot "peek" inside the musical phenomenon and have "an 'outside' view of the phenomenon itself," which is

\footnotetext{
${ }^{100}$ Of importance for Cook (2007) was that a comparison based on the computed results focuses "analysis on the network of relationships between different performances and not-or at least not just-on the relationship of each performance to the score" (185).
} 
needed to observe the entanglement (Barad 2007, 345). That is, in order to be able to observe the entanglement- the phenomenon as the material-discursive research apparatus that produces the agential cut-another apparatus/material-discursive practice is needed. This means that the measured value is specifically and meaningfully related to the referent-that is, the phenomenon (measuring apparatus and recorded musical object to be measured). It is therefore crucial that an acknowledgement of the agential cut in question-the threshold that delineates the object and the observation-occurs.

Just how crucial that acknowledgement is, became clear when, both during the seminar and in his written works (Cook 2004, 2013), Cook demonstrated his findings by presenting the visualised data and by playing the recordings of various performers of the specific fragment of Chopin's Mazurka op. 17, no. 4. Of course, in musicological courses this is a common practice, presenting a score, graphics, or an analysis and then demonstrating this by playing a recording of the piece in question. However, during Cook's presentation, it became clear that listening to the Mazurka fragments, after analysis in terms of computational data, concerned a completely different phenomenon and musico-materialdiscursive practice with another agential cut than reviewing the graphs. This second agential cut (the act of listening) delineated other means, and another subject and object of observation, and in doing so, effected other (qualitative) outcomes, which in turn affected the audience musically in a different way than when examining graphs. Remarkably, the change of observational mode (and thus, the change of entangled musical being) caught the audience by surprise, prompting a confused (Abbatean) discussion that questioned whether Cook's presentation actually did concern research into the dynamics of musical performance, or into a musicological representation (thereof). Of interest for this dissertation is that the audience's confusion demonstrated the importance of acknowledging the specific materialdiscursive practice and with that the agential cut made, especially its consequences for cause-and-effect relations, and for positioning the object and the subject. That is, measurement values and the concept of timing were materially and meaningfully determined and entangled with the specific material setup of Cook's research. 
This demonstration does not question Cook's findings, but rather brings to the fore a different understanding of research and theorising, emphasising how such practices are onto-epistemologically entangled as specific material-discursive practices to the exclusion of others-in this case, concerning the performances listened to by the audience. What could be questioned then, from a music/ological perspective, is whether Cook's (2013) intervention in performance research in Beyond the Score does not simply reinstall a "score," in which, through computing, indications of speed are added to an otherwise predefined form and norm. Cook's research helps to explicate how research within an agential realist framework concerns an entangled music/ology. From this viewpoint, his research into the rallentando and rubato aspects of Chopin's Mazurka as established by various recorded performances indicates a correlation between the behaviour (timing) of a particular sound phenomenon and a measuring apparatus that defines frames of time and loudness. Following this line of thought, Cook's research produces ontic and epistemic resolution: A tone's time and loudness properties are defined and are meaningful within and through the entanglement of the measurement apparatus and the object of observation. In other words, a tone's matter and meaning do not pre-exist measurement or observation. Furthermore, a tone's matter and meaning are established within and through a particular entangled practice.

From a music/ological perspective, rallentendo and rubato passages are effects of particular musico-material-discursive intra-activities that constitute the interpretative and ontic frame from which these passages materialise as meaningful. Also, the question of time involves an entangled musico-material act of timing, which cannot be abstracted through a framework in which $t$ serves as the standard from which to compute rallentendo and rubato, which are considered as consisting of positions (notes) in space that diverge from $t$. The musico-materiality and time of these passages are generated together without a foundational notion of time as abstracted, spatial linearity (the clock, the metronome). Rather, during rallentendo and rubato passages, musicians wilfully undo the constituted regularity of a musico-material timing. Without being able to elaborate on this question further, I hope to make clear that music/ological research on matters of rallentendo and rubato would pose this as a question of a generative act of entangled musico-material timing. 
By referring to Cook's research, I hope to have demonstrated how an Abbatean/Baradian diffractive approach implies a music/ology that stays with the practices of "doing" and "making" in all their specificities, taking care of the specific materialdiscursive practice and how the "cuts" of in/separability are made. Baradian diffractive research and theorising thus implicates the non-linear and emergent aspects of cause-andeffect relations: Agency is not a singular act, but rather involves an enactment within and through a phenomenon. Moreover, the subject/object dichotomy is not absolute, but part of agential in/separability. In short, music/ology does not involve a (totalising) theory through which musical performance can be explained, or for which musical performance serves as exemplification.

I discussed Barad's metaphysics of an agential real at work as a diffraction grating, demonstrating how this is productive of differences (things and thoughts as temporal matter-meaning sedimentations). I also pointed to the difficulties of diffractive analysis and research. Although many concepts are already introduced, in the next section, I demonstrate the materialising effects of an agential real in the case of people meeting and in the case of singing.

\subsection{The Metaphysics of an Agential Real}

Barad's notion of agential realism as a new metaphysics is a response to the question of how to grasp a world, thinking through the fundamental awareness that we are entangled with the world's ongoing (re)configurings. Within this metaphysics, there is no foundational and reassuring background of fixed time and space, and change does not involve an unfolding of matter and meaning as developmental processes in any particular direction. From our discussion so far, we might infer a few anchors that structure Barad's metaphysics. Barad's (2007) notion that the "world's radial aliveness" (33) is a source of creativity that "can never 'run out'” (177), and stabilises and destabilises, implicates both agency (the real is an agential 
real) and the inseparability thesis (we are part of the world that we attempt to understand). It also obstructs the possibility for a complete cartography. That which occurs and stabilises does so intra-actively by configuring the entities involved in this relationality: "no-thing" pre-exists the intra-active meeting; the quantum leap (i.e., a change of energy level) produces a fundamental dis / continuity. Considering the radical aliveness of being as an intra-active relationality, Barad asks how differences (identities, properties, boundaries-in short, matter and meaning sedimentations) come to matter.

Considering “[m]atter [as] . . substance in its iterative intra-active becoming-not a thing, but a doing, a congealing of agency" (Barad 2012b, 34)—-there is no outside of being. Through and within intra-active relationality, the world configures and reconfigures. This unceasing materialising is imbued with a fundamental dis/continuity. Taking this into account, Barad's emphasis is on the question of how things and thoughts come into existence and how they, as sedimentations, become generative of new things and thoughts. Barad's insights thus modify Abbate's epistemological emphasis on the impossibility to know a music that is not there. With Barad, we might ask what materialises when the reality of thinking meets the musical reality: What role is played by musico-reality (the dynamics of musical sound) and the "marks on bodies" (a Bohrian/Baradian concept, suggesting the effect of a causal relation)? In short, how does a music/ology, as knowing in being, materialise? How is it generated, and how is it generative of further intra-actions?

Barad $(2007,2010)$ is keen to question causality, temporality, and entanglement. The causal relation involves (due to the inherent dis / continuity threaded through the world's materialisation) a certain strangeness. This concerns the enactment of "spacetimemattering," in which time, space, and mattering become determined as temporal sedimentations that are always caught up in the world's ongoing (re)configurations. Entanglement suggests that matter and meaning do not involve mixing, much like Abbate's notion of the drastic and the gnostic, in which the terms-although operating together-can still be distinguished from each other. Conversely, entanglement involves how an agential real involves mattermeaning practices, and entities (stabilised sedimentation) are also considered doings. In this framework, materialising involves meaning-making, and the discursive and the material 
cannot be separated. As the how of an agential real does not lie in a general answer, but "is precisely in the specificity of the particular practices" (Barad 2012c, 54), I now provide two accounts of how matter comes to matter.

To demonstrate the materialising effect of intra-active relationality, let us imagine humans meeting each other (although this could just as easily involve electrons or sound waves) and how, by entering the "meeting zone," many possibilities arise. Imagine how the actual meeting might take place; how possible materialisations, meanings, and agencies build up. Then, at some point, a cut is made; we know what is meant, and intra-activity enacts a specific agency, making us, for instance, shake hands (rather than kissing, or hugging, or bowing). ${ }^{101}$ Whilst this may seem to be an oversimplification of such a meeting, in terms of Barad's thinking, its complexity is not demonstrated by confining the territory to the specific social, cultural, and (human) material circumstances-in short, by reduction. Rather, the complexity of this meeting resides in how intra-actions, moments of touch, and materialisation are enfolded practices in which every intra-action generates new intra-active possibilities (and impossibilities) for further actions. The doubt whether to shake hands, kiss, hug, or bow already presupposes intra-active cuts of a material-social nature within which the actual meeting is enfolded. Following Barad, to encounter suggests agential intra-action, thriving on "response-ability" as the ability to respond and to be responsive, concerning an

${ }^{101}$ Agency is also a familiar concept in Latour's (1993b, 1999) writings. However, Baradian agency does not concern the notion of agent, actor, or actant, as Latour does, nor does it concern the notion of agency as owned by a human agent. Considering Latour, in order to escape "any trace of anthropomorphism," he uses the terms "actants" or "acting agents" to refer to "doings" (Latour 2004a, 75), by which things change by going "from one actant to the next" (Latour 2008, 17). However, attempting to escape anthropomorphism, Latour, nevertheless, starts from predetermined (human and nonhuman) entities, considering change as a difference from an earlier state, rather than a differencing. Conversely, Barad (2010) complicates difference as differencing, considered as "ongoing differentiating patterns of worlding," in which differences become manifest through intra-action (265). In other words, Latour sees his use of the words "agent" and "actant" (rather than "actor;" Latour 2004a, 75) as a means to escape anthropomorphist connotations, whilst leaving the human as a predefined unity of intentional doing (and anthropomorphic acting) intact. Richard Taruskin's (2005) argument about music historiography was musicology's encounter with a Latourian leaning towards agency. Taruskin speaks about "statements and actions" as "an endless chain of agency" constituting human history (XXVI). Furthermore, and also with some dissonances regarding Latour's work (Latour includes human and nonhuman agency), Taruskin argues that agents have to be specified, "and agents can only be people" (XXVI, emphasis in original). I mention these examples in order to underline how entrenched the notion of the human agent is, and how common it is to start thinking from an isolated individual entity that has agency and, through its intentional or non-intentional doing, evokes change. 
intra-active touching of the other within agential in/ separability (Barad 2012a, 208). For Barad (2012a), materialisation involves a "condensation of response-ability;" atoms and molecules sediment into further materialisation through intra-active responsiveness (215).

To give a second example in terms of singing, when intra-acting with a score, response-ability is not about finding the right response. In a Baradian sense, the score is an entanglement of intra-acting stories and materialities; "[e]ach is diffractively threaded through and enfolded in the other" (Barad 2012a, 207). After years of training, seeing the note $\mathrm{G}$ means that my singer's body already reaches out towards it, affirming this as an agential intra-active meeting effecting the sung note G. Touch, response-ability, intra-action, and agential in/separability demand that we are attentive to the material, politically, culturally, and historically loaded meetings through which properties, identities, and boundaries are constituted. In Barad's (2010) terms, singing the prescribed G is an "enabling of responsiveness," involving an inhalation and "(re)opening up to" the mind/body that jointly configure the vowel of the rehearsed note, whilst feeling with anticipation what might come into being (265). At the same time, it involves opening up to the environment as an acoustic co-constituent (Barad 2010, 165). This means that agency involves response-ability, through which singing the note $G$ is not a matter of realising or actualising a rehearsed and known possibility, but of being in touch as a musical relating that endures. The memory and anticipation of the mind/body is reconfigured in the flesh, and therewith opens up to new possibilities and impossibilities—-that is, to the dynamics of mattering. ${ }^{102}$ Therefore, it literally matters whether one is singing a $G$ in order to see, for example, if it matches the prescribed frequencies of the digital tuning apparatus, or singing a $G$ as part of a specific song.

My example also makes clear how Barad's notion of the intra-active, relational constitution of things, identities, and boundaries forecloses the idea of intentionality as connected to agency-either to the wilful action of the human subject, or related to human

\footnotetext{
102 Milla Tiainen and Jussi Parikka (2013) make a similar argument regarding the "imperceptible but ontological crucial moments of transition that (all) moving, receptive, interactive bodies undergo" (213, emphasis in original).
} 
subjectivity (Barad 2007, 407, note 22). Intentionality is troubled by an ontological relationality articulated as intra-action and diffraction. The human-commonly considered the beholder of intentional action as an independent, free individual-does not pre-exist intra-action. "My" intentionality of doing "this" rather than "that" as a pre-existing state of mind, in Baradian terms, involves intra-action within the phenomenal; as an entangled being through which a particular state of mind comes into existence. For Barad, intention and agency are not external factors possessed by an individual. This means that a relational ontology demands a reconsidering of common notions involving causal connections.

3.7. Material-discursive Practices: Traversing Disciplinary Thresholds

Barad's agential realist reworking of Bohr's phenomenon-the inseparability of the agencies of observation and the object of observation-might also be described as a diffractive reading of the sciences and the humanities, affirming the relational nature of meaning-making within the sciences, as well as the question of materiality within the humanities. Note that for Barad (2007), this reworking always involves specific practices. When she argues that phenomena, as the primary ontological units, "are the ontological inseparability/entanglement of intraacting 'agencies'" that constitute reality, it is not to suggest a generalisation of the Bohrian apparatus ready to be installed in the humanities (Barad 2007, 139, emphasis removed). Instead, it suggests that matter is an intra-active doing-one that is neither confined by Bohr's epistemological concerns, nor by the humanities' concern for (human) meaning formation. For Barad (2010), agential realism concerns a dynamic of material doing "unto 'itself' as it were, without the need for some supplement like culture or history to motor it" (268, note 11). This notion of material doing as a dynamic of ongoing differentiation (which includes both the human body and the mind) is crucial for understanding Barad's conceptualisation of intra-action. 
Agential realism's emphasis on the world's intra-active generativity may remind us of other philosophies concerned with the processual, differential, and non-teleological constitution of reality. As Deleuze and Guattari ([1980] 2004) state, using a musical example: "All of music is pervaded by bird songs, in a thousand different ways, from Jannequin to Messiaen. Frr, frr" (330). Here, "Frr, frr" may be the sound of a small bird's rapid movements, flying hither and thither, whereas the number 1,000 is used to express the limitless number of movements (in terms of Baradian enfolded intra-actions). The point I wish to make is that an agential realist ontology does not concern the generality of a thousand tiny and different movements that constitute reality, but rather emphasises the specificity and precision of local material-discursive practices through which, in this case, music is diffracted with bird song, or with a bird's rapid movements via (and within) specific material-discursive practices. In other words, agential realism is neither a generalised Bohrian apparatus, nor a relativist indifference of possibilities and impossibilities. Instead, it concerns a specific, generative local effect of intra-active relating. Hence the terminology that Barad (2007) uses to articulate precision and specificity as a matter of intra-acting agencies in the following quotation: "It is through specific agential intra-actions that the boundaries and properties of the components of phenomena become determinate and that particular concepts (that is, particular material articulations of the world) become meaningful" (139, emphasis added). ${ }^{103}$

As discussed above, Barad (2007) traverses the Bohrian apparatus as an embodiment of human concepts, shifting linguistic representations to discursive practices which, like apparatuses, "are material reconfigurings through which 'objects' and 'subjects' are produced" (148). Barad speaks of material-discursive practices, which traverse common notions of discursivity and discourse. She establishes these practices as material-discursive doings by using the concept of performativity as a diffraction grating. ${ }^{104}$ Performativity as a

\footnotetext{
${ }^{103}$ Deleuze and Guattari ([1980] 2004) are famous for their use of the number thousand to express, beyond number or quantity, the infinite ways of becoming. I used their example to demonstrate how Barad, whilst also using the notion of an ongoing worlding in general terms, emphasises instead the enfolded material-discursive specificity of how "things" come to matter.

104 John Langshaw Austin introduced the concept performativity in a series of lectures at Harvard University in 1955, entitled How to Do Things with Words. Austin's merit was that he distinguished words
} 
diffractive apparatus allows for the negotiation of changing relationships between different insights, bringing into play both Michel Foucault's (1972) concept of discourse, and Judith Butler's ([1993] 2011) concept of performativity. ${ }^{105}$ Both concepts are traversed by Foucault's ([1978] 1998) notion of power, which contradicts familiar understandings of power as located in a unique source of sovereignty from which secondary and descendent forms [of power] would emanate... [Instead, power] is the moving substrate of force relations ... produced ... in every relation from one point to another. (93) 106

Foucault and Butler question representationalism and the humanist idea of individualism, which assumes reality to exist and to be comprised of separate and distinct beings. However, through a diffractive reading. Barad (2007) finds Foucault's and Butler's insights flawed

that perform - the performatives - and words that describe - the constatives. By using very common examples, such as "I name this ship the Queen Elizabeth," or "I do," as uttered in the course of a marriage ceremony, Austin (1975) explains first, that performatives are self-referential (they enact in the moment of utterance); and second, that they actually constitute a social reality (5-7). Austin's theory provided fertile ground for many scholars of culture, language, and identity. According to Professor of early modern literature James Loxley (2007), Austin's theory of speech acts was at the same time convincing and striking (2). As Loxley argues, this was demonstrated by the debate between John Searle and Jacques Derrida, in which Derrida "deconstructed [Searle's attempt] to demarcate a strict boundary between 'real' and 'fictional' utterances" (3). In this section, I am interested first and foremost in Barad's discussion of Butler's contribution to the performativity debate, specifically concerning a certain lack of rigour in Butler's work when it comes to the "doing" of matter.

${ }^{105}$ Foucault (1972) argues that discourse does not concern "a group of signs (signifying elements referring to contents or representations) but practices that systematically form the objects of which they speak" (49). For Butler ([1993] 2011), the practice of discourse as performativity is not "a singular or deliberate act," but must be understood "as the reiterative and citational practice by which discourse produces the effects that it names" (xii).

${ }^{106}$ In section 2.3.2., we briefly encountered the philosopher and gender theorist Judith Butler and the philosopher Michel Foucault in context of Born's elaboration of a relational musicology. Now I remain with Barad's work, introducing the insights of Butler and Foucault only in terms of those issues that are taken up by Barad in a rather critical way, to illuminate the intricacies of entangled, non-anthropocentric matter-meaning practices. Sociologist Thomas Lemke's (2015) inquiry, concerning a diffractive reading of Foucault and Barad, is of interest here. He emphasises that Foucault's notion of the "government of things" provides an opening to materialism and non-anthropocentrism. Lemke demonstrates how Foucault's thinking does not enforce the supposedly clear limit of a social and anthropocentric focus. However, in my reading, Lemke does not sufficiently account for the complexity of Barad's notion of the performative nature of intra-action and entangled, matter-meaning practices. He too easily places Barad's thinking with a general new materialist scholarship that tries to combine the human and the nonhuman, ignoring the agential realist notion that "humans" and "nonhumans" do not precede intra-action, but are generated material-discursive differences as effects of differences. 
when used to negotiate the material dynamism of bodies that matter and the limiting insights of, respectively, the social domain and the human body. According to Barad, Foucault affirms the relevance of the physical body and does not see the body in terms of "a 'history of mentalities'... [that would picture] bodies through the manner in which they have been perceived and given meaning and value" (Foucault cited in Barad 2003, 809). What Foucault does not offer, Barad (2003) argues, is "an account of the body's historicity in which its very materiality plays an active role in the workings of power" (809). This means that an agential realist exploration of, say, a singer's body, demands trans-disciplinary research and theorising that does not only consider the body's contours (e.g., the soprano's head, the length of her vocal chords), but also includes a detailed account of "how matter makes itself felt" (810). To a certain extent, Barad's critique of Foucault (and Butler) involves Foucault's concentration (except excursions into anatomy, physiology, and clinical medicine) on the humanities in terms of "psychology, sociology, pedagogy and other 'human sciences'" (Lemke 2015, 8). In the following, I explicate how Barad, as both a physicist and a philosopher, treasures trans-disciplinary research and theorising, establishing an ontoepistemology as a material-discursive practice of bodily production that traverses the sciences and the humanities.

As stated before, Barad (2007) uses the concept of performativity as a diffraction grating. She does not, however, consider performativity "a form of linguistic monism that takes language to be the stuff of reality," whilst simultaneously determining what is real (133). Here we might recognise Abbate's (2004) critique of new musicology's emphasis on the dynamism involved in meaning formation without considering the material production of music and meaning (506). The performativity of language might be explained via the famous speech acts of John Austin (1975), in which, in a marriage ceremony, the "I do" is considered a performative utterance-as a "doing" that culturally and socially inscribes the involved bodies as married. For Barad (2007), the difficulty is that this notion of performativity only operates one way: the becoming of the world is dictated by language and meaning, yet matter, materiality, and materialisation are excluded. 
Conversely, when deployed as a diffraction grating, performativity possesses multiple slits that entangle Bohr's proto-performative account of scientific practice, Butler's concept of performativity, Foucault's notion of discourse, feminist theory, and a posthumanist metaphysics that questions modernist humanism, dualism, and anthropocentrism. As such, reading these insights diffractively through one another via a confrontation with the notion of performativity produces a material-discursive reality as the effect of differences that matter. It is not that, through the use of the notion of performativity as a diffraction grating, differences appear-in the sense of insights being classified by their difference against the notion of performativity. Rather, a diffractive reading is a local doing "where the effects of difference appear" (Haraway cited in Barad 2014, 172, emphasis in original). For Barad, taking performativity as a diffraction grating produces agential realism's cartography as a posthumanist performative account of material-discursive practices that is not limited to either the social or the discursive as the usual habitat of humanism. The inseparability thesis implicates that which is labelled human, woman, man, queer, or animal and emerges performatively as an effect of material-discursive practices. In other words, agential realism is not a conceptual and closed framework-the conventional definition of a framework of thought. Instead, it refers to phenomena; to the entangled concerns of material-discursive intra-acting agencies of the world's ongoing performativity.

It is clear that Bohr's proto-performative and philosophical account of scientific practices relates the discursive to materialities. The same tendency to traverse boundaries between matter and meaning formation we find in Foucault's argument-namely, that discursive practices do not describe a world, but rather produce "the subjects and objects of knowledge practices" (Barad 2007, 147). This argument points to a performative account that can also be found in Butler's work. Barad's interest in the scholarship of Butler and Foucault is already enfolded in the agential realist account of the Bohrian inseparability thesis. By diffractively reading Bohr, Foucault, and Butler through one another, Barad (2007) establishes a means by which to free "Bohr's account from its reliance on human concepts and the static nature of apparatuses" and to reconceptualise "the notion of discursive practices ... [in order to] to take account of their intrinsically material nature" (147-148). 
Foucault's ([1975] 1991, [1978] 1998) analyses of the workings of power link discursive practices to the materiality of the body. ${ }^{107}$ For Foucault, power is not an external force enacted upon a subject. Rather, power "is an immanent set of force relations that constitutes (but does not fully determine) the subject" (Barad 2007, 63). Power, in Foucault's ([1975] 1991) terms, has performative aspects as the "meticulous control of the operations of the body" (137) and is not instigated by a reigning ethics, nor by the dictate of institutions. Thus, Foucault eschews theories of linguistic representation, critiquing representationalism via the "constitutive aspects of discursive practices in their materiality" (Barad 2007, 57).

Foucault ([1975] 1991) is famous for his work on the genealogy of the modern concept of the body, discussing how a body is not forced into submission through physical violence, but by controlling its behaviour, and by making sure it acts in accordance with the ways in which it is controlled. Foucault illustrated this new concept of the human body via the detailed descriptions of practices of control in hospitals, prisons, schools, armies, and workshops, all of which had one thing in common, namely, that the body was no longer seen as the signifier of the prisoner, patient, student, etc., but rather as the object of control. That is, control did not address the "signifying elements of behaviour or the language of the body" (137). Instead, in the institutions included in Foucault's research, control was oriented towards efficiency, the economy of movements, and its internal organisation. Here the body was not considered as a whole, but for its parts, which could be controlled and made useful (Foucault [1975] 1991). In my view, the crucial aspect in this for Barad, discussing the link between discursive practices and the materiality of the body, is the way in which Foucault talks about constraints-how they "bear upon the forces rather than upon the signs," and that "the only truly important ceremony is that of exercise" (Foucault [1975] 1991, 137). "Discourses" in this instance are those practices that systematically and through exercise "form the objects of which they speak" (Foucault cited in Barad 2007, 204).

\footnotetext{
${ }^{107}$ Foucault ([1978] 1998) argues that "power must be understood . . . as the multiplicity of force relations immanent in the sphere in which they operate and which constitute their own organization" (92). In Foucault's ([1975] 1991) work, the "multiplicity of force relations" are conceptualised as "disciplines," meaning "methods, which make possible the meticulous control of the operations of the body, which assured the constant subjection of its forces and imposed upon them a relation of docility-utility" (137).
} 
Butler ([1990] 2006), expanding Foucault's work on discursive practices in their materiality, theorises how the gendered subject is constituted through performativity. Butler argues that "there is no gender identity behind the expressions of gender; that identity is performatively constituted by the very 'expressions' that are said to be its results" (34). Gender is an iterative doing through which gendered subjects come into being, meaning that a subject does not pre-exist this doing or its "expressions." From this we might suggest that Butler's emphasis on the non-representationalist, performative constitution of the gendered subject might be affirmed by Barad. Conversely, however, Butler's theory of performativity in Gender Trouble ([1990] 2006) and Bodies that Matter ([1993] 2011; which especially addresses materialisation), considers the materialisation of human bodies as the effect of the power of regulative norms (Butler [1993] 2011, xii). According to agential realist insights, her theory thus misses a thorough understanding of how matter materialises. This is why Butler's theory of performativity is questioned by recent feminist scholarship—specifically, how her notion of materialisation takes into account matter's generativity in relation to the human body. ${ }^{108}$ Barad (2007) further extends this question, also doubting whether Butler's theory might be strong enough to enable "considerations beyond the realm of the human body" (207).

Diffractively reading agential realism and Butler's theory of performativity through one another, Barad (2007) achieves a more thorough understanding of materiality and agency by reworking performativity from iterative citationality (Butler's notion) to iterative intra-activity. Butler ([1993] 2011) reconsiders the materialisation of bodily matter as a performative force which, like gender, comes into being through the iterative citation of previous acts ("an echo or citational chain;" 214, note 5) that are governed by regulatory norms. Barad (2007) does not question that the workings of social norms do have an effect on a human being, but equally does not recognise how Butler accounts for discourse (209). Barad's question concerns Butler's notion of citationality as the citation of previous acts, whereas agential realism considers the iterativity of intra-actions in the constantly emergent

\footnotetext{
${ }^{108}$ See Kirby (2011) for a thorough discussion of how Butler's take on materiality is flawed, considering the body's materiality as mere cultural inscription (72-75).
} 
present. Through iterativity, entities emerge, affirming the entanglement of natureculture and suggesting that the body's materiality has "a say" within and through entangled material-discursive intra-activity. In Barad's (2007) terms, “bodies are material-discursive phenomena that materialize ... with ... the particular apparatuses of bodily production through which they come to matter (in both senses of the word)" (209).

Regarding Butler's use of different domains (acts of culture and acts of nature), starting from the dynamism of intra-acting agencies, agential realism does not consider different domains that operate in isolation. Rather, they are considered as enfolded materialdiscursive practices. Nor does agential realism presuppose different kinds of materiality as a precondition for either research, or theorising. Crucial here is how the causal linkage between discursive and material practices emerges through intra-action, thus producing phenomena. Thinking of the notorious gesture-sign-grunt system (also from my experience as a singer) through which music is communicated during rehearsals, gestures, signs, and grunts assume a different, highly specific material-discursive instantiation in order to communicate a "wished for" quality of sound or musical phrase. Music "matters, and so the nature of the specific embodiment matters" (Barad 2007, 210). ${ }^{109}$ Barad explicates that Butler's account of the materialisation of bodies considers materialisation to be an effect of citational repetition-as the power of discourse, or (if considered active) as a support for communication. As demonstrated by the example of the gesture-sign-grunt system as a form of communication in intra-action, the particular materiality of gesture, sign, and grunt matters, in the double, material-discursive sense, acquiring specific meaning only through and within the act of materialising. For Barad, performativity-as in the example-therefore suggests an iterative intra-activity, involving material and discursive aliveness as enfolded material-discursive practices of cutting together/apart in which causality emerges from the specific intra-action. Butler's notion of performativity (as citationality), as discussed by Barad (2007), seems to uphold a predefined difference between nature and culture in which the

\footnotetext{
109 Joseph Kerman (1985) discusses, following Abbate's drastic-gnostic dualism, how musicians demonstrate through their "arcane sign-gesture-and-grunt systems" that there is a great deal of thought about performance, but of a kind that cannot be "articulated in words" (196).
} 
capacity (as agency) of citation supposes a human subject (culture) that pre-exists his / her body (nature). Despite the dynamic repetition involved in Butler's notion of citationality, it still leads Barad to argue that "questions about the material nature of discursive practices seem to hang in the air" (64).

As a summary of my discussion of Barad's apparatus of diffraction-and inspired by Butler's work on performativity, Foucault's work on the human body and discourse, and Bohr's work on the epistemological difficulties of quantum mechanics-I wish to stress diffraction's multiple effects. Based on the in/separability thesis—“cutting together/ apart"—agential realism and intra-active relationality reconfigure objectivity, subjectivity, causality, and agency as entangled affairs within, and as part of, the world. Using performativity as a diffraction grating, Barad (2007) demonstrates how the effect of differences (as the marks left on bodies) define the "experimental conditions, [serving] as both the endpoint and the starting point for meaningful and objective scientific practice" (120). This clearly underlines the non-dualist foundation of both difference (not as opposing entities) and differencing (not change as a differing from) - a point to which I return in section 3.8 .

Discussing the Bohrian fold in Barad's insights and the implicated diffractive methodology, followed by an engagement with the conceptualisation of an agential real, I concluded by looking at how Barad traverses disciplinary thresholds or, in other words, how the Baradian approach entails a plea for transdisciplinary research and theorising. Starting research and theorising from phenomenal being (the inseparability of matter and meaning) means, in music/ological terms, that musical and music-related entities are seen as musicomaterial occurrences. Whether it be "stable" musical objects (scores, documents, and inscriptions into the digital mode) or music-as-performed, in all cases it concerns occurrences: Effects (the diffraction patterns) of musico-material-discursive practices, which have to be studied as entangled phenomena, require knowledge and experimental expertise across the domains of the sciences, the humanities, and musical practices, depending on the particular research question. In the remainder of this chapter, I explore Barad's account of ethics, demonstrating how her notion of ethics engenders a more thorough account of 
relationality as intra-active engagement. In particular, Barad's $(2007,380)$ approach to ethics offers a possibility to consider normativity as an inherent part of material intra-actions. In music/ological terms, her work helps me to consider how different musico-materialdiscursive intra-actions produce different musico-materialisations in and of the world, suggesting the crucial quality of relationality as enacted responsiveness. I will elaborate further on a musico/logical account of musical normativity in chapter 4 .

\subsection{Onto-epistemology: The Ethical Call}

Agential realism ... is a call, a plea, a provocation, a cry, a passionate yearning for an appreciation of, [and] attention to the tissue of ethicality that runs through the world.

In the previous sections, we discussed how Barad's metaphysics of radical immanence works, shifting a classical (Cartesian, Newtonian) worldview that hinges on the individual and on the isolation of the ontic and the epistemic. As Barad (2007) argues, "[k]nowing is ... a practice of intra-acting with the world as part of the world in ... its ongoing articulation" (379, emphasis added). I have argued that, for Barad (2010), metaphysics (agential realism), methodology (diffraction), and the in/separability thesis ("cutting together/apart") unconditionally implicate each other (244). Put another way (and consequentially), the very concepts of agential realism, diffraction, and "cutting together/apart" trouble the transcendent mark of common understandings of metaphysics. Clearly, Barad (2014) shifts any common notion of difference and in doing so, opens inquiry into how "to differ" (as a doing) effects differences, involving a complexity that she attempts to capture with the concept of differencing, understood as "differences-in-the-(re)making" (168).

Now, to introduce Barad's take on ethics, I must pause for a moment to consider the depth of Barad's concept of differencing. Difference is commonly referred to as identity and 
boundary, with a negative connotation ("this" is not "that"), or in a pejorative and hierarchical sense ("this" is better than "that"). Barad (2007, 2010), however, takes up the notion of difference as caught up in the ongoing intra-active relationality of worlding. She suggests instead that difference (e.g., between subject and object) concerns a temporal state of matter-meaning formation within the bounds of their entangled (phenomenal) state, which is neither originary, nor final, nor a clear-cut opposition between subject and object. For Barad $(2007,2010)$, differencing relates to in/determinacy and ethos, in the sense that it concerns intra-active mattering caught up in a dynamic of ontic and epistemic resolution, putting coming-into-existence (or not) to the test.

Further, materialisations as "[s]pace, time, and matter [or 'spacetimematterings'] are intra-actively produced in the ongoing differential articulation of the world" (including ourselves) and do not involve a smooth, continuous transformation in space or through time (Barad 2007, 234). As discussed, classical thinking and the humanist point of view holds matter to be discrete, with time having its place, whilst recognising place as the stability of a thing that has its specific position in a container called space. A demonstration of this formulation as an entrenched worldview can been seen in countless scholarly practices of which musicology is no exception. Notwithstanding the difficulty of having to cope with the temporal dynamics of the musical object of research, its methods of analysis consistently inhabit the classical Newtonian worldview, considering the discreteness and predictability of both past and future. As Suzanne Cusick (2001) argues, musicology, as found in the United States of America after World War II, was modelled on other academic disciplines. In order to be considered "scientific, objective, and serious, it was to be clearly differentiated from its object of study" (Cusick 2001, 473). At the same time, as we habitually act "on" things and follow clock time in linear space, we inhabit the discreteness of classical thinking's notions of matter, time, and space, and the continuity of an unfolding existence. Either through academic emphasis on a Newtonian informed scientism, or through our habit of seeing ourselves detached from the object of our attention, we exclude the possibility to account for music's temporal and dynamic being and, as I will argue, also exclude a Baradian notion of ethics. 
Clearly, Abbate's question, the reactions discussed in chapters 1 and 2, as well as many other musicologists who protested and still protest against musicological analyses based on stability and (scientific, objective) distance, provide evidence that this matter is a concern shared by a significant portion of the community. I think here of the musicologists that contributed to Rethinking Music, edited by Nicholas Cook and Mark Everist (2001). These musicologists rethink the musicological discipline (traversing Kerman's and Kramer's new musicology) as a body of explication that has lost its consistency. In their introductory remarks, Cook and Everist speak in terms of a Kuhnian paradigm change, asking anew the foundational question of the "relationship between musicology and the rest of the world" (vii), and thus considering musicology part of the world. ${ }^{110}$ The question posed by Cook, Everist, and the other contributors to their book, is taken up by Barad as a question of generative and intra-active relationality. In a similar way, Barad's notion of relationality challenges a simple replacement, as for example suggested by "the before Kerman/after Kerman paradigm" (Cook and Everist 2001, viii), which holds that new musicology would simply be the dis- or replacement of musicology. Rather than asking the question of where to position musicological scholarship in the context of a changing world, with Barad, we may pause to consider the consequential question of relationality, suggesting that musicological knowing is in being as a music/ology, and thus affirming radical immanence. We are part of the (musical) world we seek to research and theorise. This suggests aliveness and a dynamic relationality of musicologists to music, in which the natures of that relation, musicologists, and music do not pre-exist their intra-action.

For Barad $(2007,2010)$, the unpredictable aliveness of dynamic relationality is encapsulated in the quantum leap: Whereas classical physics is based on a continuity of energy levels, quantum mechanics demonstrates that an electron jumps from one energy state to another, infusing reality with a foundational unpredictability and discontinuity (Barad 2007, 113, 423, note 22). However small the electron may be, it effects an inescapable

\footnotetext{
${ }^{110}$ Cook and Everist (2001) take into account the effects of globalisation ("the near collapse of classical music"), neo-colonialism, anthropocentrism, the ethical consequences of musicologists' "actions as teachers, researchers and ... members of the human race," and the effects, in gendered terms, of "the [participation] of women in the discipline" (vii).
} 
dis/continuity that troubles all notions of discreteness and linear cause-and-effect relations. Further, it troubles the common idea of "our" existence as a pre-existing whole, unfolding through time and in space as a smooth material extension. As Barad (2010) states, it is not "that something is here-now and there-then without every [sic] having been elsewhere inbetween, it's that here-now, there-then have become unmoored-there's no given place or time for them to be" (247-248). Thus, Barad (2010) first invites us to think the almost unthinkable, namely, that space, time, and matter are intra-actively materialised; cause and effect, before and after, come into being intra-actively as a "cutting together/apart" which, without the intra-active notions of time, space, and matter, do not make any sense (244). With the quantum leap Barad again complicates the notion of relationality, suggesting a discontinuity effected by the leap; something that occurs without movement and that is without "spacetimemattering" in-between. However, the terms that frame the "before" and "after" of the leap "are not separate coordinates, but entangled reconfigurings of spacetimemattering" (Barad 2012d, 19). Thus, the leap involves a dis/continuity that is "neither continuous with discontinuity nor discontinuous with continuity," troubling the "cutting into two" on which a classical and Newtonian worldview is premised (Barad 2012d, 19). Hence Barad's (2010) notion of agential in/separability as a matter of "cutting together/apart" (244).

In other words, matter and materialisation — the identity of what, where, and whenis un/done by quantum dis / continuity. This is counterintuitive to our notion of relating to one another, in which "you are you" and "I am I," and "[m]atter is discrete, time is continuous" (Barad 2010, 249). Barad thus invites us to be responsive to this foundational dis/ continuity, if only to recognise how discreteness is untenable in the sense that music and musicology are not discrete units, but rather inhabit enfolded practices. That is, music and musicology reach out to each other and/ or are attracted by traversing disciplinary bordersthat is, "no unity can hold, not from within or without" (Barad 2010, 250).

We might imagine now how the entangled state of a dynamics of enfolded differencing concerns an inherent dis/ continuity, suggesting an inherent speculation or open-endedness in all materialisations. Intra-active "spacetimemattering" thus entails the 
new at every cut as the "ongoing rematerialisings of relationalities, not among pre-existing bits of matter in a pre-existing space and time, but in the ongoing reworkings of 'moments,' places,' and 'things,'” threaded through one another (Barad 2010, 268, note 9).

Following Barad's (2010) concept of radical immanence, the intra-active encounter, mapped as an agential "cutting together/apart," thus opens up space for the new and the unpredictable. As such, now introducing matters of value into the heart of intra-action, Barad's notion of onto-epistemology acknowledges an inherent ethical call. The difference between "something" materialising (included), or not-materialising (excluded), effects the (im)possibility of further materialisations, and must thus be (ethically) accounted for. In short, Barad's plea (see the epigraph at the beginning of this section) to pay serious attention to ethicality as an inseparable part of intra-action concerns intra-action's agential cut, which both closes off and opens up. Note that exclusions are the effects of intra-active engagements with the world, always involving a Baradian "cutting together/apart," meaning that the closed-off never gets to leave the stage. Following this line of thought, Abbate's (2004) question "Music—Drastic or Gnostic?" might be considered a demonstration of how the ethical call is threaded throughout musicology. In this regard, musicology, as a materialdiscursive practice, is haunted by the excluded music-as-performed (and all that is related to the dynamics of musical performance). This haunting quality is an enduring factor of a musicological struggle (as discussed in chapters 1 and 2) that testifies to the destabilising effect of the excluded-albeit one that can open up to musicological re-configurations. In the following section, I discuss how Barad's notion of an ethos at the heart of mattering emphasises relationality as responsiveness.

\subsubsection{The Intra-active Relationality of Barad's Ethics of Mattering}

Clearly, the Baradian notion of enfolded intra-activity questions an ethics founded on a binary reasoning devoid of materiality and based on the predefined status of individual beings and their relationships. Does Barad establish a concept of ethics that traverses the human locale? I will argue that, by infusing matter and meaning with the ethical beyond 
human exceptionalism, Barad's thinking bears on intra-active relationality when considered as a general term. A way to approach Baradian ethics is to zoom in on how it troubles all ontological "preexistence" and the epistemological "preexistent," presupposing that ethicality is not about human individuals meeting each other (or their institutions), nor, as with Baradian agency, is the ethical a preformed notion of the good or justice owned by humans (Barad 2007, 361). Instead, the ethical emerges from the intra-active encounter. ${ }^{111}$ Initially, Barad (2007) emphasises the non-individual emergence of ethics, reminding us of Emmanuel Levinas's notion of "being in one's skin;" an account of subjectivity not founded on individuality, but on "a relation of responsibility to the other" (391). ${ }^{112}$ Barad shares the ontology of Levinas, in which relatedness within a phenomenon, the entangled "me," and the Other, are the primary units through which any difference comes to matter. However, Barad challenges the limitation of Levinas's humanist focus, whilst simultaneously elaborating his concept of responsibility as a mode of intra-active relating:

\begin{abstract}
Responsibility - the ability to respond to the other-cannot be restricted to humanhuman encounters when the very boundaries and constitutions of the "human" are continually being reconfigured and "our" role in these and other reconfigurings is
\end{abstract}

\footnotetext{
${ }^{111}$ Coming back to the notion that a Baradian ethics goes in all directions, bleeding through all matters of intra-action, this suggests we may consider it as a generalised "valuing;" as an operative force that is intra-actively threaded through and reconfiguring a world. This valuing also includes matters of aesthetics and truth. We might at first consider how ethics (already) thrives on the question of (social, cultural) relationships, forming a shared node with Baradian intra-active relationality. Although truth and beauty are thought of as values localised in the thing-as truth in the object and the beauty of the musical object (of art) - a Baradian ethics is nonetheless an invitation to explore value (or more specifically, valuing) as a particular force in every direction that thrives on relational being, infused with intra-active mattering. In the same way that Barad's metaphysics of an agential real does not consider ethics as the limit of the good, nor does it consider aesthetics as the limit of beauty or truth, nor as the limit of knowing the world. In chapter 4, I will attempt to explore musicality as such a value that blooms through and within relationality as an emergent intra-active force of a music-to-come.

112 Levinas ([1974] 2006) speaks here of an inverted identity as "being-in-one's-skin, having-the-other-inone's-skin" (115). Barad follows Ewa Plonowska Ziarek's (2001) study on Levinas, in which Ziarek understands his approach to embodiment as a question of "ethical experience," preceding the distinction, thought, and carnality of conscious being (49-50). For a discussion on Levinas and the ethical turn in Continental philosophy, and an insight in the reception of Levinas's writings, see Robert Eagleston (2010). Eagleston considers how Levinas's account of ethics tries to understand "how our obligations to others arise" (210); a question that must be seen in connection to twentieth-century European atrocities, which confronted philosophers with the "exclusion or (often murderous) transformation of otherness" (217).
} 
precisely what "we" have to face. A humanist ethics won't suffice when the "face" of the other that is "looking" back at me is all eyes, or has no eyes, or is otherwise unrecognizable in human terms. (392)

To traverse the ethical as a uniquely human endeavour, Barad (2007) demonstrates how both particles and brittle stars (a sort of starfish) are complex phenomena, the intelligibility of which is not a "mind-based capacit[y, but concerns] marked historialities ingrained in the body's becoming" (393). For particles and brittle stars, knowing the Other is not a matter of cognisance, but of "differential responsiveness (as performatively articulated and accountable) to what matters" (380). Particles and brittle stars-the so-called inanimate and animate- "disrupt humanist and antihumanist assumptions about the nature of identity, performativity, agency and ethical practice" (Barad 2008, 335, emphasis added). The animateinanimate distinction is an ingrained dualism, denying matter (particles, rocks, trumpets) its aliveness and keeping it farthest removed from humans. The idea is that, through human intentionality, the inanimate can be animated - an idea that also extends to the world of musical practices, as will be discussed in chapter 4 . What Barad means here is that practices of intra-active mattering, when considering particles or brittle stars, demonstrate how identity formation is phenomenal.

I recall Barad's notion of performativity: Rather than Butler's notion of citationality, which suggests repetition at the surface (as some point of reference at which identity stays the same) without taking into account the material-discursive differentiality involved, Barad's (2007) concept of iterability suggests mattering "all the way down" (362). ${ }^{13}$ Subject and object emerge (materially and meaningfully) within and through the in/separability of intra-action. Additionally, the Other "is irreducibly and materially bound to, threaded through, the 'self'” (Barad 2010, 265). That is to say, "'Otherness' is an entangled relation of

\footnotetext{
${ }^{113}$ For Barad (2007), the notion of "all the way down" means materialising "to the very atoms of existence, and beyond, to a point where individuality is itself undone by the specific entanglements of becoming that transcend the distinctions between bios and technics, organic and inorganic, artificial and natural, mind and body" (362). In a similar way, Haraway argues: "There is no border where evolution ends and history begins, where genes stop and environment takes up, where culture rules and nature submits, or vice versa" (cited in Dolphijn and Van der Tuin 2016, n.p.).
} 
difference" (Barad 2007, 236), suggesting that ethicality resides in the relationship of what Barad (2010), in her reworking of Levinas's notion of responsibility, calls "response-ability" (251) — that is, a readiness to respond whilst being caught up in the dis/continuous process of mattering $(268$, note 10$)$.

In this sense, in Barad's (2007) work, studying the brittle star contributes to deepening the notion of ethical relationality beyond the human. The brittle star, a close relative of the starfish, might be considered a complex eye. The limbs and central body are covered with "spherically domed calcite crystals" that function as microlenses, collecting and focusing light "directly onto nerve bundles that are part of the brittlestar's diffuse nervous system" (370). It can change "its geometry and its topology-autonomizing and regenerating its optics in an ongoing reworking of its bodily boundaries" (375). The brittle star recognises its predators via a process in which "recognisability" involves it making sense of its environment through its ongoing responsiveness, which is ethical in the sense of a "normative differential responsiveness" (380). Importantly, how this responsiveness is enacted matters to both the brittle star and its environment: something is at stake. Crucially, we may see here how ethical value, localised in the encounter between the brittle star and its environment (the Other), is wrought out of an emergent agency as the "how" and the "why" of responsiveness. A brittle star's differential responsiveness within and through its intraactive engagement with the world thus demonstrates that, also for humans, "ethics is about mattering, about entangled materialisations [that] we help enact and are a part of bringing about, including new configurations, new subjectivities, new possibilities"' (Barad 2008, 336). In other words, Barad shifts the common ethical notions of a "good" relationship and of responsibility (which suggests that one individual is, or feels, responsible for another). Again, such concepts of responsibility suggest a stable, identified world with the assumption that the "good" or "correct" response is known, can be judged from a distance, or is calculable through observation. For Barad (2012b), responsibility concerns an unceasing and movable responsiveness and an intra-active "matter of welcoming, ... enabling the response of the Other" (81). 
To understand how the ethical occurs, I wish to argue that the ethical call, as an inherent part of Barad's agential realism, emphasises an intra-active "procedure" of differencing that lies at the heart of mattering; at issue is "response-ability" as the ability to respond and to be responsive. Thus, response-ability suggests a practice of engagement that is attentive to a possible response that quite literally "matters." ${ }^{114}$ This process concerns Barad's (2007) attentiveness, being prepared for that which might be on the other side, suggested by responsiveness and response-ability. Through this attentiveness, an ethical moment is constituted before the emergent agential enactment, which is then established, bringing the intra-active encounter to a closure, with something coming to matter (or not).

Considering how specific intra-actions come to matter, one might imagine a threefold movement in one move of ethico-onto-epistemological entanglement. We recognise this in Barad's (2007) argument regarding the importance of including ethicality in practices of mattering, since

the possibilities for what the world may become call out in the pause that precedes each breath before a moment comes into being and the world is remade again, because the becoming of the world is a deeply ethical matter. (185)

The pause is the moment of responsiveness and response-ability; an attentiveness towards the world, followed by the breath of agency and the specific enactment, marking both time and matter.

\footnotetext{
${ }^{114}$ For an understanding of responsiveness and response-ability, see Kirby's $(2011,10-12)$ discussion of the strange behaviour of lightning. The way in which a lighting strike discharges involves a strange form of responsiveness and ability to respond between ground and thunderstorm. Barad (2012e) citing Kirby, discusses lightning's queer communication between sky and ground, in which electrical discharge happens before "sender" sky and "recipient" ground emerge (33-35). Deleuze (2004), also referring to how thunderbolts explode between different entities, calls such strange responsiveness that ensures communication the "invisible, imperceptible dark precursor" (145, emphasis in original). Kirby, Barad, and Deleuze refer to how identity or difference emerge from, in Barad's terms, intra-activity, without the need for another identity to perform the task of bringing differences together. The notions of "queer communication" and "dark precursor" explicate that which Barad (2015) terms ontological indeterminacy and the radical openness of spacetimemattering.
} 
To give an example from the musicological field, the working of acoustic ethicality involves a responsiveness in which something is at stake; vibrations die, vibrations are enforced. Vibrations, perceived as sound, emerge from enfolded intra-actions, involving the entanglement of sound waves that intra-act with an acoustic historiality, including all the vibrations that define a given concert space. As Aden Evens (2005) argues, the concert space is full of vibrations "to be modulated to the point of audibility by a suitable sound" (7, emphasis added). From a Baradian point of view, the notion of suitability may refer to normative responsiveness; i.e., a specific ethicality in the attentiveness of waves meeting. This suggests that not every encounter matters: Waves that meet, do not necessarily respond in ways that effect new wave configurings. Waves cancel each other out when out of phase, or enforce each other when in phase. This suggests that intra-actively waves are included and excluded from mattering or vibrating, which matters to the timbre and the loudness of sounds as the temporal effects of the causal intra-activity of both the concert hall acoustics and the musician. Following Barad (2007), this example also demonstrates how "the larger material conditions are integral to what a phenomenon is" (472, note 53). The notion of "suitable" sound troubles the idea of inanimate beings, in this case waves. The "suitable" sound, inseparable from the larger musico-material apparatus (including the concert space), then concerns a normative responsiveness, in which waves are taken up in normative practices of suitability; they are not isolated abstractions.

To conclude this section, I have discussed how Barad's argument on ethicality shifts the familiar idea of the ethical as the limit of "the good" and a purely human endeavour. This is an argument established from the Baradian notion of enfolded intra-activity, which concerns how entangled practices of knowing and being undermine not only any stable identity or limit, but also the assumed isolated free will of human intentionality or agency. Considering entangled being, "me" and the "Other" are implicated in a relationality of "cutting together/apart" — that is, in/separability. Moreover, the Baradian inseparability thesis brings into play radical immanence from which even a human mind, intellectually reasoning (about ethics), cannot escape; the world is not merely an idea, existing in the human mind. Barad's (2007) example of the brittle star illustrates that intelligibility may be a 
concern of "differential responsiveness to what matters," rather than a matter of understanding (470, note 43). As Barad states, “[t]o the contrary 'mind' is a specific material configuration of the world" (379). This suggests that holding memories, responding to stimuli, and thinking thoughts "are intra-active engagements with [and part] of specific configurations of the world" (472, note 52). Clearly, Barad's approach to ethics is not informed by a common notion of human judgement based on a transcendental knowledge of "the good." Instead, Barad extends the notion of human ethicality of "the good" into how particles and brittle stars maintain an intra-active relationality with the entangled Other (their environment), in which something is at stake; things either come to matter, or they do not.

By addressing ethicality as involving both particles and brittle stars, Barad deepens the notion of relationality as ethical mattering through responsiveness and touch. Within this framework, ethicality dramatises responsiveness and materialisation-or, to put it another way, gives mattering a procedure of movements in one move. For Barad (2012a), ethicality urges us to rethink relationality, which she elaborates as touch in its many forms; a matter of responsiveness and response-ability—-to fathom how the "nature of matter entails an exposure to the Other" (217, emphasis added). Touch and responsiveness involve a mattermatter relationality that precedes the moment of in/separability-that is, the moment of exteriority within, when agency enacts separability as mattering. Barad elaborates the matter-matter relationality as a matter of the inhuman-something to which I turn in the following section. Barad's notion of the inhuman focuses on the dynamics of spacetimemattering itself, which, in my view, will be helpful to rethink musicology as music/ology, traversing entrenched notions of music and musical performance in terms of human sociality, intentionality, and subjectivity. 
3.9. The Inhuman: The Ethics of Entanglement

In the previous section, we established that Baradian ethics are inseparable from the mattermeaning intra-activity of the ongoing articulation of the world. We have pointed to how a Baradian ethics takes notice of surfing on the cusp, at the edge of indeterminacy, and "before the binary of inside/outside, inclusion/ exclusion, mattering/not-mattering" (as exteriority within) becomes defined (Barad 2012a, 81). Here, Barad (2012e) uses the concept of the inhuman to think how the material "liveliness of indeterminacies . . . bleed[s] through the cuts and inhabit[s] the between of particular entanglements" (222, note 19) —in other words, bleeding through matter-meaning practices that establish the human and nonhuman.

Alternatively, the inhuman is the intimate matter-matter relationality we may not notice, yet may nevertheless call upon us at any moment as a determinate part of the world's (re)configurings. The inhuman surfaces via "events that appear to us as random," yet may nevertheless matter, as they are intra-actively related to events elsewhere (Greenstein and Zajonc cited in Barad 2012e, 215). Expecting the unexpected of the inhuman, Barad (2012e) once more reminds us of how "an ethics committed to the rupture of indifference may arise" through responsiveness as touching towards, being full of expectation, sensing "the indeterminate" (216). Such responsibility is not based on human intentionality, judgement, and calculation. Rather, it is a relation in which matter senses matter, full of anticipation. In other words, Barad invites us to experiment and go beyond Levinas's ethics of responsibility (infused with obligation), involving both the human and the human Other, thus extending response-ability to the inhuman, the insensible, and the indeterminate. Barad introduces here a sociality based on openness and responsiveness on the level of touch as matter's selftouching, "involving every possible kind of intra-action with every possible kind of virtual particle it can interact with" (212).

Barad's (2012e) ethicality as sociality is informed by the inhuman without the urge for complete understanding, making us sense "the infinitude of the other;" the not-propertied or bounded, but dynamic im/ possible Other (219). Thus, via the notion of the inhuman, Barad 
complicates the relational as a response-able touching that reaches out and also complicates the Other beyond the defined being on the other side of the agential cut. Rather, the Other is the "stranger that never leaves me," energising my reaching out and my "longing for justiceto-come" (219).

Here, Barad's (2012c) ethicality takes a leap, encountering Derrida's notion of a dynamics of justice that precedes (or goes against) conventional ethical judgement, in which the Other is an epistemological object for judgement as "justice [that we know] in advance" (67). From the Baradian agential realist point of view, this notion of justice can be considered a material-discursively sedimented justice, which is a notion of justice that we commonly work with (which is both political and social). However, also a material-discursively sedimented justice is not forever fixed, material-discursive practices are enfolded intraactions that undergo forces from within and without that reconfigure such practices.

Barad's notion of ethics is informed by inhuman aliveness and by Derrida's (1994) notions of respectively ghosts / spectres, genealogy / inheritance, and différance. With Derrida, Barad (2010) strengthens her concept of ethics, whilst simultaneously deepening the concept of the ethical human, which is not so much informed by material-discursive, agential cuts (seemingly of human control), but rather materially informed beyond (or, rather, before) human consciousness. With her notion of ethicality, Barad subscribes even more clearly to the speculative nature of the probabilistic aspects of agential realism's quantum leap, exploring how ethicality inhabits the cusp of dis/continuity, where mattering as intra-active relationality emerges (or not).

Barad's (2010) notion of the inhuman materialises Derrida's understanding of how ghosts and spectres inform a strange inheritance and in doing so, inform a genealogy with inherent instability. Derrida (1994) invites us not to focus on events, but rather on how they are preceded and accompanied by "the nocturnal noise of its concatenation, the rumbling sound of ghosts chained to ghosts" (5). ${ }^{115}$ That is to say, Derrida speaks of spectres and

\footnotetext{
${ }^{115}$ Derrida (1994) aptly relates spirits, spectres, and ghosts, reading together Shakespeare's Hamlet ("[e]nter the ghost, exit the ghost, re-enter the ghost" [xx]), with the first lines of Marx's Manifesto ("[a] spectre is haunting Europe-the spectre of communism" [4]). For Derrida, this strange connection opens up to questions of inheritance and genealogy; a Baradian take on how events come into being and to
} 
ghosts as addresses for us to consult in the name of justice for those who are excluded, those not present, not yet born, or long dead. Barad (2010) diffracts Derrida's ghost or spectre with the notion of the aliveness of the inhuman as the void that is full of insensible life. It is a plea to inform ethics with those inhuman aspects of human life that touch the insensible Other. In short, "it is about being in touch ... [and] being responsible and responsive to the world's patternings and murmurings" (Barad 2012a, 207).

For Derrida, the appearance and reappearance of ghosts have an inevitable ethical connotation that resonates with Barad's (2010) ethical notion of response-ability as a material touching that "precedes the intentionality of consciousness" (265). This touch constitutes a "before" of mattering (in one move), in that it goes beyond responsibility as obligation in common human-human interaction. Derrida's (1994) ethical connotation considers the coming into existence of events and how there is something that goes on between them that "can only maintain itself with some ghosts" (xviii, emphasis in original). ${ }^{116}$ Barad (2007, 2010, 2012a) understands Derrida's notion of the ethical as a material dynamic that is inherently ethical. Derrida (1994) suggests this by the expression "[t]o learn to live" (xvii), evoking the difficulty that life is not something that teaches us to live otherwise: Even when attempting to change life, you "just" live, suggesting that one learns to live "without tutelary present"a learning alone, "from oneself, with ghosts" (xvii-xviii). In other words, there is no preexisting concept or referent for justice helping us to act in a just way. Counterintuitively, we learn with "certain others who are not present, nor presently living, either to us, in us, or outside us" (Derrida 1994, xix). We recognise here Barad's (2010) notion of response-ability as reaching out, full of expectation, beyond the determined thing or notion of justice, enjoying "a performance of spacetime (re)configurings" (240). For Derrida (1994), justice is a justice-to-come as disjunction (différance) that

\footnotetext{
which diffraction apparatus their becoming is related. However, the strange appearance and reappearance of ghosts (like quantum leaps) are an inseparable part of the ongoing articulation of the world. For Barad and Derrida, ghosts and quantum leaps demand a speculative approach to how the ethical is entangled with ghosts that are part of how and what things are coming into being. ${ }^{116}$ The philosopher Simon Critchley (2009) points to how Derrida's notion of maintaining relates to the French maintenant, suggesting maintaining is an "act of presencing irreducible to the present" (153, emphasis in original).
} 
(without debt and without duty) [renders] to the singularity of the other to his or her absolute precedence or to his or her absolute previousness, to the heterogeneity of a pre- which ... means what comes before me, before any present, thus before any past present, but also what, for that very reason, comes from the future or as future: as the very coming of the event. (28, emphasis in original)

In my reading of Derrida, he articulates here how justice-to-come relates with, or is even conditioned by, différance. For Derrida (1982), différance is "neither a word nor a concept" (3), but rather a "strategic doing" "between the active and the passive .. . without finality" (7, emphasis in original). Through and within such strategic doings, "the here-now unfurls" (Derrida 1994, 31). Similarly, in Barad's (2010) terms, justice-to-come involves unfurling differencing and the non-coincidentiality of self and Other: Ethicality involves "'Otherness' as an entangled relation of difference" - that is, diffraction (265). Derrida's ideas speak to the Baradian notion of how self and Other, past and future, are dis/continuously reworked, suggesting that causality is an intra-actively emergent factor, and that mattering is "mattering-to-come," just (precisely) as justice is "justice-to-come," involving enticement and reaching towards.

Barad's (2010) notion of dis/continuity as time and space being dis/jointed is a differencing that speaks to Derrida's concept of différance. Both concepts suggest the noncontemporaneity of the present with itself (and of "me" with myself), reaching out to those no longer there, or yet to come. Ethical mattering then involves a justice-to-come-that is, a diffracted responsiveness towards the inhuman and the Derridian ghosts of past, present, and future, which "inhabit" indeterminacy; the edge of non/materialisation. Barad (2010) diffracts Derrida's insights on ghosts that haunt the materialisation of events with her own insights on quantum field theory, concerning entanglements and involving relations of responsiveness towards the ghosts in the void. She explicates that the separability-within holds together (articulated by scare quotes) "'self' and 'other,' 'past' and 'present' and 'future,' 'here' and 'now,' 'cause and effect'”' (265). 
Barad's (2010) notion of the working through of the inhuman aliveness of quantum leaps also shows how the world's genealogy escapes any suggestion of smooth unfolding or of justice as the lawful construction of harmony. Indeed, it affirms an open-ended worlding, throwing new light on questions of genealogy, inheritance, and ethics, and of how past, present, and future are related to, and inseparable from, ethicality. A genealogy of mattering, for Barad (2010), concerns being entangled;

threaded through with anticipation of where it is going but will never simply reach and of a past that has yet to come. It is not merely that the future and the past are not there and never sit still, but that the present is not simply here-now. (244)

The political desire to repair injustice in the sense of including the excluded, or doing justice to that/ those what/who have been wronged, or attempting to change the past via iconoclasm, will only repeat injustice elsewhere. In all cases, actions are built on leaving the past behind, changing, or undoing it. For Barad, doing justice cannot be performed by the act of erasure, as being entangled implicates that past and future are never closed, but always open to change. However, the marks on bodies, the "sedimenting effects [of the past], its trace, cannot be erased. The memory of its materializing effects is written into the world" (Barad 2012c, 67). The notion of the inhuman helps Barad to consider the heterogeneity of material intra-activity traversing and destabilising material-discursive practices. Inhuman doing, diffracted with Derridian ghosts and spectres, establishes a concept of justice (and ethical materialisation) through and within touching as reaching out with expectation to the "Other" on the cusp of possibility and impossibility, beyond the material-discursive sedimentation of a notion of justice as either law or morality.

Barad's notion of ethics demonstrates the inseparability of knowing, being and ethics as an ethico-onto-epistemology in which knowing in being is threaded through with the Other. It is in these Baradian terms that I will consider a music/ological approach affirming the inseparability of epistemology, ontology and valuing through and within the inhuman aliveness of musico-mattering. 


\subsection{Conclusion}

I conclude this chapter with a summary of the issues discussed, considered as an introduction of Barad's thinking to the musicological realm and to the following chapter's diffractive reading of the insights of Barad and Abbate. Barad's reading together of quantum physics, Bohr's attempt to give an unambiguous account of quantum measurement, and posthumanist and feminist scholarship, establishes her metaphysics of an agential real. Here she builds on a reworking of the Bohrian inseparability thesis, arguing that we are part of the world that we seek to understand and help to create. Although the concept of metaphysics might be misleading with regard to the sedimented transcendence it radiates, Barad's is a "new" metaphysics with a "new" starting point for research and theorising. The scare quotes point here towards the entangled, agential, and intra-active relationality of how things come to matter and are generative of other matterings. For Barad, mattering includes both "new" and "old." Nothing starts from scratch: past, future, old, and new are entangled within and through the intra-activity of material-discursive practices.

Considering Barad's understanding of mattering with its double meaning, it would be unjust to figure agential realism simply as a material turn. Barad shifts the inherent dualism and reductive take of both realism (matter as passive background) and social constructivism (matter is meaningfully formed by humans). Instead, Barad's inseparability thesis concerns intra-active, phenomenal being through which subject and object come into being as an "exteriority within," constituting a temporal non-Cartesian separability that enables ontic and epistemic local resolution.

I consider in/separability — that is, studying and coping with the world whilst being part of it-an important element of Barad's thinking. Here, Barad's concept of diffraction is crucial, as a metaphor, a physical phenomenon, and a method of research and theorising into the relational nature of how things come into existence. Diffraction enables one to think, not 
only beyond the human point of view, but also matter-matter or inhuman relations, which, nevertheless (and beyond anthropomorphism) involve intra-active matter-meaning configurations. With the notion of intra-active in/separability-the non-Cartesian exteriority within-Barad shifts any binary notion of difference predicated on individual, isolated things that are different from each other. Difference and the world's specificity, including our participation in it, are vital to Barad's metaphysics as questions of differencing and response-ability. That is to say, difference is considered an effect of iterative intra-active materialisation, and concerns a temporal sedimentation of matter-meaning formation.

Although initially counterintuitive, the inseparability thesis triggers in Barad's thinking a deep engagement with the relational, which we find in the notions of agency, causality, relating, enforcing, and cancelling intra-activities, and reaching towards the unexpected. All these relations mentioned are caught up in generative matter-meaning practices. In other words, relations neither involve connections linking the terms, nor does a familiar concept like co-constitution-involving the terms without the relationalities—work for Barad. Rather, the Baradian notions of relational being materialise intra-actively in a single move a specificity of all that is involved in this material-discursive practice, or, in our case in this music/ology.

Barad's (2007) diffractive readings of Foucault, Butler, Derrida, and Levinas contribute to what Mullarkey (2006) calls the "[p]ost-Continental . . intervention into the contemporary reception of European thought in the Anglophone world" (1). In the feminist philosopher Rosi Braidotti's Deleuzian terms, Barad's diffractive readings invest in the "[deterritorialization] of French theory" a new tendency in Continental thought that traverses "the analytic versus Continental divide in philosophy" (Braidotti 2012, 28). Barad's (2010) embrace of the radical immanence of mattering as differencing implicates and complicates ethics as an ongoing valuing ("care") and an exploration of "justice-to-come." This ethicality does not start from predefined differences, such as human versus nonhuman, but instead traverses sedimented material-discursive practices, such as the scholarly and scientific disciplines. Barad's (2015) ethico-onto-epistemology, valuing and knowing at the heart of mattering as a radical un/grounding of ontology, thus undermines predefined 
differences of all sorts through its "undoing of universality [and emphasises the] importance of the radical specificity of materiality as iterative materialization" (413). In Mullarkey's (2006) terms, this suggest a philosophical return "to earth from the inconsequential heavens of transcendence" (3). However, in Baradian agential realist terms, the suggested linear notion of "consequences" is reworked, in which consequences are real differences and the effect of intra-actions, which are "specific material engagements that participate in (re)configuring the world" (Barad 2007, 91).

This agential realist (and diffractive) notion of intra-action as generated and generating structures the following chapter's encounter with Abbate's insights into the necessity of musicology's "fall to earth" (2001, vii). Unravelling and complicating the notion of transcendence in opera studies, she argues that "her" performances (the ones she attended as a listener) "never produced the sinking feeling that one was in the presence of Werktreue [a faithful representation of the score; translation mine] that 'this is a good performance of that.' . . the template had been forgotten" (xvi). In Abbate 2016 and 2017 the notion of musicology's "fall to earth" (2001, vii) is elaborated into a material turn, in what follows I will include this move in Abbate's musicological thinking.

By reading Abbate's and Barad's insights together-thus traversing the gnosticdrastic dualism-I will turn to the problem of music/ology. This concerns a relationality of the musico-material-discursive encounter within and through the dynamics of worlding, affirming knowing and valuing in being. Further, my hope is that the chapter's exploration of an embodied concept of musicality emphasises, in Abbate's notion of the drastic, the inherent touch of the musico-material encounter, thereby emphasising musicality in Barad's understanding of material-discursive phenomena. 


\section{Chapter 4}

\section{Musicality: An Intra-active Musico-material Encounter}

Following up on the previous chapter's discussion of Barad's agential realism, our discussion of Abbate's (2004) question “Music—Drastic or Gnostic?" in chapter 1, and the field's responses to it in chapter 2, the current and final chapter tackles the principle objective of this dissertation: mapping a music/ology (a musical knowing in being) that conceptualises a musico-material dynamics as intra-actively generated by and generating new intra-actions. Such a music/ology traverses inherent dualisms of representationalism, as well as the inherent prioritisation of human sociality and subjectivity, thus suggesting a significant shift in common methods of research and theorising. To explicate this shift, I start this chapter with a summary of what has been established thus far. Simultaneously, I define the path ahead, which will include a diffractive reading of the insights of Abbate and Barad, reworking the concept of musicality into a question of difference, which, in my reading, constitutes the nodal point where their arguments meet. I read together, on the one hand, Abbate's (2004) provocative question, which "embraces" difference as a human limit (drastic or gnostic); and, on the other, Barad's (2007) concept of difference, which affirms intra-active relationality, according to which coming to matter (that is, generating both materiality and meaning) is the effect of differing. 


\subsection{Abbate's and Barad's Arguments: The Limits of Diffractive Reading}

Abbate's (2004) plea puts forward the supposition that drastic musical reality and gnostic musicological representation exist in a state of oppositional difference, presenting both a moral and a musicological concern. Abbate's plea urges musicologists to take account of what she perceives as their acknowledged (but often neglected or overlooked) raison d'être: to perform music as a dynamic occurrence-one with real (drastic) effects on listeners and performers alike. Abbate questions the assumption that knowledge grows from the accumulation of human reasoning and symbolic representations, unmarked by the nature of music and by scholarly practices - an assumption that, according to Abbate, is implicated in the "universalizing endemic in academic discourse" (536). Her plea thus calls into question musicological research, theorising, and representation of such musical dynamism.

However, as a rhetorical question with a metaphysical connotation, "Music—Drastic or Gnostic?" creates a stalemate that effectively obstructs any resolution, or even curious exploration, of the representational problem. Drastic musical reality insists on "presentness," whereas, according to Abbate (2004), the act of thinking and scholarly writing thrives on the "present pastness" (536). In this way, Abbate suggests that, in a metaphysical sense, musical reality is cordoned off by the gnostic or cognitive aspect of a musicological approach. In a practical sense, Abbate indicates the fate of musicologists: They have to wait until the music has passed, suggesting that the search for the "real" musical object will always be smothered by bad timing — either too late, or too early.

Abbate thus suggests a metaphysical foundation, supporting a binary opposition between the drastic and the gnostic, which are distinguished by their respective relations to time, space, and matter. Drastic musical dynamism suggests an enmeshment of materiality, time, and space, framing an absolute musico-material "real" as a paradoxical, ongoing "here and now" (paradoxical, because multiplying the present suggests an ahistorical "real"). For the gnostic to be productive, Abbate envisages a necessary retreat into reasoning as a gnostic positioning in space and in time, considered as coordinates of overarching absolute values 
and separating an immaterial world of human intellect from the material world of a musical reality. Abbate's drastic-gnostic dualism therefore suggests a musicological approach capitalised on an overarching, stabilised notion of space and time. Therefore, her approach ultimately remains limited to experimental and interpretational means, based on a priori categorisations, connecting the physical, social, cultural, political, and historical with that which is known as (sounding) music.

Regarding matter and materiality, let us recall how binary thinking, inherent in Abbate's question, is linked to Jankélévitchian metaphysics, in which phenomenologicallived bodily experience is set against both a musical outside and idealist traits, and in which music is considered inaccessible to language and thinking. This results in the inescapable knot of a Cartesian binary—one predicated on human thinking and a unified subjectbetween body (as matter) and mind (as meaning), separating a musical, material, dynamic world (nature) from a reasoning mind in the interest of human perception (culture). As previously discussed, for Abbate, both body and music are of an inaccessible material outside, represented and made knowable through the phenomenological body. This suggests that the affected body and the musical on the one hand, and the human intellect and human perception on the other, belong to two different ontologies: one in which the body and music are caught up in the dynamics of nature; and one in which the body and music are seen in the context of (human) culture. ${ }^{117}$ In my reading, Abbate's plea demonstrates three lines of thought: one of morality (the plea itself); one that brings fundamental questions to the fore regarding a musicological engagement with musico-material dynamics; and one founded on a metaphysics articulated by the two-world logic of inescapable representationalism.

Following Barad's research method of diffractively reading insights together, the first two lines of thought mentioned may contribute to the productive nature of a direct, joint

\footnotetext{
${ }^{117}$ Bergson ([1912] 2004) makes this point, suggesting that "to ask whether the universe [music, body, nature] exists only in our thought, or outside of our thought [human cognition, culture], is to put the problem in terms that are insoluble, even if we suppose them to be intelligible; it is to condemn ourselves to a barren discussion, in which the terms thought, being, universe will always be taken on either hand in entirely different senses" (13, emphasis in original). Bergson seeks a "common ground on which combatants meet" in terms of the image, a union of body and mind (13) - or, in Abbatean/Jankélévitchian terms, drastic and gnostic. As discussed in chapter 3, Barad (2007) suggests the notion of intra-active inseparability, addressing the problem of materiality and intelligibility beyond human exceptionalism.
} 
engagement with Abbate's and Barad's arguments. I suggest that such a diffractive reading may be productive in the sense of affirming Abbate's plea as a concern to include the drastic in musicological research and theorising, whilst simultaneously complicating Barad's plea of an agential real, demanding a concern for both the included and excluded of research and theorising. Additionally, both arguments constitute an invitation to think with (musico-) material dynamics. Indeed, the question of concern and a musico-material reworking of musicological matters lie at the heart of my notion of music/ology. As an entangled material-discursive practice of knowing-in-being, music/ology proposes a thesis of radical immanence; a non-dualist metaphysics of (musical) worlding. These aforementioned issues or lines of thought structure both Abbate's and Barad's arguments, addressing the inseparability of metaphysics, methodology, and value (ethics and musical aesthetics).

Regarding diffraction as a method, we may recall that it is both a physical phenomenon and a metaphor for Barad's (2007) methodological approach of "reading insights through one another in attending to and responding to the details and specificities of relations of difference and how they matter" (71). ${ }^{118}$ Diffraction works constructively with differences and allows them to find resolution (matter), thus shifting the predefined difference on which reflection and critique are predicated. As discussed in chapter 3 , a diffractive reading supposes a starting point of radical immanence for research and theorising: It implies starting neither from the individual thing (for example, musicological thinking as a set of predefined, sedimented ideas), nor from the musical event as a unified performance. Rather, it takes as its starting point the ways in which things and thoughts come into phenomenal existence; how matter (boundaries and properties) and meaning are intra-actively established; and how phenomena are generative of new things and thoughts. From this we may infer that a critical and dialectical treatment-starting from the entity and presuming an outside—of Abbate's and Barad's insights can be foreclosed by a generative

\footnotetext{
${ }^{118}$ For further reading on diffraction as both a method and a methodology, see Kaiser and Thiele (2014) in Parallax. In that same journal, see Van der Tuin's (2014) contribution on Chantal Chawaf and posthuman interpellation.
} 
and diffractive approach, which includes the thesis that the researcher is part of the world that she seeks to understand.

Another point is that Barad's and Abbate's insights, for different reasons, do not demand to be aligned (as sedimented ideas in space and in time) in a given philosophical discussion. Indeed, Abbate (2004) regards metaphysics as a "mania" to be avoided because it emphasises the gnostic and is unable to relate to music's material and dynamic existence (505). As for Barad (2007), she does not address philosophical subject matter-ontology, epistemology, ethics-as categories to think with, but rather, as material-discursive practices that are both generated and generative, and open to reworking. As such, she questions structural (dialectical) rigidity as the "framework" of thinking (Barad 2007, 448, note 5). ${ }^{119}$ Similarly, Abbate and Barad are involved as practitioners in a musical and physical world; making music (Abbate) and doing physics (Barad) marries them both to material and discursive practices of music/ological and scientific research and theorising.

Reading Abbate and Barad in terms of a critical stance, valuing their insights against a philosophical domain or against each other according to a "practice of negativity" (Barad 2012c), would deny both phenomenal being and how diffraction enables new things and thoughts. In this regard, Barad's insights are as valid as Abbate's. Such an approach would simply repeat the same dualist problem of positioning knowing against being, thereby mobilising all of the derivative dualisms, such as nature versus culture, nonhuman versus human, unanimated versus animated, and so forth (Barad 2012c, 49). Nevertheless, the responses to Abbate's plea discussed in chapter 2 testify to the tempting lure of the critical approach—one that simply repeats oppositional differences. Also, when considering, in a more foundational sense, Abbate's question “Music—Drastic or Gnostic?" not just as a

\footnotetext{
${ }^{119}$ For a demonstration of how concepts and insights gleaned through the critical method of reflection are reduced to questions of sameness, see Slavoj Žižek's (2012, 931-950) account of "agential realism." For Žižek, Hegelian thinking provided a point of measurement against which Barad's insights and concepts are mainly assessed as not up to the set standard. Yet, through his critical, oppositional stance, Žižek misses the notion of diffractive reading (and of agential realism) as generative and a mode through which issues can emerge via this approach. Ironically, the question that might be considered a good starting point for reading Hegel and Barad together, is articulated as Žižek's negative sigh of impatient disbelief: "Why does Barad not make this point?" (947). For more on Žižek's critical discussion of agential realism and for an in-depth discussion of Barad's methodology of diffraction as an intra-active reading practice, see Geerts and Van der Tuin (2016).
} 
question to be answered by repudiation, but as an articulation of a dualist metaphysics that concerns the very setting, we can see how this might urge Barad (2007) to her non-dualist reading of Bohr's insights, and to her work on the inherent ethicality of "spacetimemattering." "Spacetimemattering" articulates the entanglement of space, time, and matter, which intra-actively and iteratively differentiate within and through phenomenal being. Material change is not a continuous unfolding or transformation in time, in space, but rather involves a dis / continuous differentiation, creating spacetimematter in one movement (Barad 2007, 179).

However, thinking the insights of Abbate as setting the scene for Barad's work again risks a critical and hierarchically informed approach, in which Barad's insights would simply be imposed on Abbate's insights. A diffractive approach, reading one through another horizontally, is of great benefit here, as it respects how musicology's legacy, as demonstrated in Abbate's work, is vital to a Baradian agential realist approach of entangled practices. Thus, reading insights together, and being attentive to what emerges within such a setting, does not "work as [following the] scripture nor to somehow be the 'undutiful daughter"' (Barad (2012c, 58).120 Again, scripture, dutifulness, and undutifulness are all concepts that suggest predefined categorisations from which one takes a position either to agree or to disagreethat is, for dialectical reasoning as a standpoint outside of any actual involvement in research and theorising.

Notwithstanding her firm drastic-gnostic dualism, considered by her as the foundation of musicological scholarship, an inspiration for diffractively reading Abbate's and Barad's insights involves how the political thrust of Abbate's plea subscribes to the untenability of separating musicological research and theorising from a dynamic musical reality. This structures her argument and opens it up for revaluing and reworking. In this sense, Abbate's plea also "interpellates" me and my intuited (materialised) knowledge as a

\footnotetext{
${ }^{120}$ As a response to a question posed by Rick Dolphijn and Iris van der Tuin (2012), Barad (2012c) refers to Rosi Braidotti's (2000) concept of the dutiful and undutiful daughter, expressing the methodological danger of feminist scholarship becoming "loyal to her master" by dutifully following the scripture, pronouncing the master's status. Dolphijn and Van der Tuin (2012) propose that Barad's diffractive methodology does not issue such a relationship, as it concentrates on "reading various insights through one another [, hence producing] something new" (58).
} 
(former) singer into the discussion, demonstrating diffraction at work, interrupting Abbate's argument, and bringing to life "[my] call from elsewhere" (Van der Tuin 2014, 240). ${ }^{121}$ In Baradian terms, Abbate's plea-in paying serious attention to musicology's neglect of studying musico-material dynamics—demonstrates a sensibility to "the constitutive exclusions of those ideas we cannot do without" (Barad 2012c, 49).122 In this (political) sense, my call affirms that which the Abbatean constitutive outside excludes: the drastic character of live performed music, considered here as the musico-material dynamics through, and within which, reality "in-the-making" becomes determined. This new concept takes up Abbate's notion of live performance as a material-discursive enfolded practice, traversing the Baradian notion of aliveness as intra-active dynamism and agency, which Abbate relates to a happening between the contours of a musical event that takes place "then and there." ${ }^{123}$ Attention to the political aspect of Abbate's plea, emphasising music-in-the-making as musicology's excluded, thus confirms the impossibility of separating "matters of fact from matters of concern (Bruno Latour) and matters of care (María Puig de la Bellacasa)" (Barad

\footnotetext{
${ }^{121}$ For a reworking of Althusser's concept of interpellation, see Van der Tuin (2014).

122 Abbate's (2004) concept of the drastic is similar to Judith Butler's ([1993] 2011) famous concept of the "constitutive outside" (x), in that both concepts denote "the very limit to intelligibility" (x). In this regard, Barad (2007) would consider both Abbate's concept of the drastic and Butler's concept of the constitutive outside as "exclusions [that] are a constitutive element of boundary-drawing practices" (439, note 86$)$. ${ }^{123}$ For a discussion of how the concept of performance has been "radically re-inscribed, reinstalled, and redeployed," see Jon McKenzie $(2001,13)$. McKenzie discusses how performance is the key term of our century through the accumulation of organisational, technological, and cultural performance. For a discussion of the inherent, distinct nature of performance, see Erika Fischer-Lichte (2004). Fischer-Lichte uses the distinction between aufführen and ausführen, apparent in the German language, to differentiate between the "Aufführung eines sozialen Aktes" [enactment in relation to a public] and the "Ausführung" [the material execution] of that act (32, translation mine). In the Dutch language this distinction is also apparent as, respectively, opvoeren [the social act in relation to a public] and uitvoeren [the material execution of that act]. However, in my argument, I do not maintain this distinction. Following Barad, I consider the material and the social to be entangled in every act as (musico-) material-discursive intraactivity. The notion of live performance as unrepeatable is discussed by Peggy Phelan (1993). Phelan suggests that "[p]erformance occurs over a time which will not be repeated. It can be performed again, but this repetition itself marks it as 'different.' The document of a performance then is only a spur to memory, an encouragement of memory to become present" (146). I want to point here to different tendencies: Whilst Jankélévitch (2003) and Abbate (2004) propose the unrepeatability of performance in relation to the phenomenological experience of a human (body) present in the moment of the event, Phelan (1993) discusses the unrepeatability of performance in relation to the emphasis on replay and remake of performances based on their economic value, which goes against the ontology of performance as that which "becomes itself through disappearance" (146). As such, performance cannot participate in the circulation of reproductions. However, thinking with Barad and Abbate, reading diffractively, emphasis is put on how music matters and cannot be erased, and how the (creative) music industry prompts questions as to what is excluded from mattering.
} 
2012c, 50). ${ }^{124}$ In other words, Abbate's sensibility towards musicology's constitutive outside energises her, my own, and Barad's arguments and their relationality, traversing any dualism as a fait accompli, and affirming the political and ethical traction of facts and values that cannot be separated.

In this political sense, Abbate's plea opens the way to think how the science-versushumanities schism of the academic world is most explosive in music (as well as in the inseparability of code and electromagnetism in music computing), obstructing (feminist, new) materialist research and theorising. Clearly, for music studies-and in a broader sense, music-related studies—retreating into a material world of facts (acoustics, instruments, bodies, technology) and a cultural world of values (meanings, histories, representations) upholds an impossible separation between the instruments and forces used to create vibrations, the vibrations themselves, sound, and music—or in a general sense, between a world of substance and a world of interpretation or meaning formation. In Barad's (1995, 2000) terms, this involves an unacceptable separation between what we know as the humanities (matters of concern) and the sciences (matters of fact), as if there were the humanities on the one hand, and the sciences on the other, emerging from different worldsa proposition for which the analogy of the inseparability of sound waves and musical value works well. Likewise, the drastic-gnostic dualism concerns a fundamental but unjustifiable

\footnotetext{
124 The musicologist Emily I. Dolan (2015) discusses Latour's (2004b) suggestion, as referenced by Barad (2012c), to consider in the "thing ... matters of fact and matters of concern" (Latour 2004b, 233, emphasis removed). For Dolan (2015), the turn to materiality via Latour's work offers musicology "one path back to Adler's garden, whereby we can recast the loving adoration of musical culture as a new kind of worthy intellectual engagement" (91). Dolan sees Latour's notion of "concern" as (merely) a reminder of "the role aesthetics [played] in the birth of musicology" and the richness of "the discipline's foundational principles" as articulated by Guido Adler in the late 1800s (88). The premise is that we, as musicologists, "have it all" - we simply have to look towards our own discipline. Barad (2012c), citing Latour and Puig de la Bellacasa, argues that "[m]atters of fact, matters of concern, and matters of care" are entangled in the same way as ontology, epistemology, and ethics are inseparable (69). Thus, it is not a matter of affirming the richness (all the things in the garden of Adler for a musicologist to pick and choose) of musicology's object of research; rather, the point is an intra-active engagement of in/separability and the music/ological task of studying and unravelling the musico-material enfolded entanglements of which we are part. We see Barad's insights affirmed by Puig de la Bellacasa (2011), who explores the ethico-political relationality of (Latour's) "concern" through her notion of "care." Puig de la Bellacasa considers how concern "denotes worry and thoughtfulness about an issue," whereas care concerns a stronger affective and ethical presence as a material doing that involves touch (89-90). More than how matters of concern infuse matters of fact with attention and respect, matters of care "engage with their becoming" as a "transformative ethos" that traverses any pre-existing morality (100).
} 
break within musicological scholarship between that which is of the mind on the one hand, and a dynamic musical reality "out there" on the other. Within this framework, musical reality is posited as unreachable yet, nevertheless, remains musicology's matter of concern, and is productive of intuitive knowledge of the musical, affective, dynamic, and material/ physical world.

As discussed in chapter 3, Bohr inspired Barad to think how the agencies of observation (the material apparatus and the observer) and the object of observation are ontologically and epistemologically inseparable: There is no apparatus that acts as a neutral mediator, giving us a view into the world "out there." There is no predefined difference between subject and object, or between cause and effect-in a similar way care and fact are intra-actively entangled. Barad's insights regarding entanglement also suggest that representations are made through material-discursive practices, thus offering a different understanding of the interpretative model through, and within which, the musicological object of research and theorising emerges. This model is common for the humanities, and we encountered it most specifically in chapter 1 as new musicological hermeneutics, then the subject of Abbate's critique. A Baradian understanding of a hermeneutic approach employs a diffraction apparatus as a method of research and theorising that is both structuring and generative. As with experimental research, it is through and through material-discursive and of the musico-material world. In this way, a Baradian approach already traverses and complicates Abbate's notion of an either/or (drastic/gnostic) engagement with music. Rather, engagements with music are specific musico-onto-epistemological practices of performing, listening, thinking, researching, and theorising. That is to say, diffraction entails that theories and practices do not pre-exist specific research or theorising. Research issues, method, and so forth, are not simply starting points, but effects (diffraction patterns) of diffraction apparatuses (enfolded material-discursive practices).

My argument thus considers how Barad's inseparability thesis of radical immanence affirms the generativity of enfolded intra-active being, supporting Abbate's doubt as to the presumed (academic) clarity of classificatory distinctions, negating the complexity and dynamics of ongoing musico-material intra-activity. In the previous chapter, we established 
that if research and theorising start from the identified, the categorised, the object, or the subject—in other words, from the division—things cannot be brought together "again." We cannot add the drastic to the gnostic like movement to the score, effect to a cause, matter to meaning, music to its vibrating substance, the social to the musical, or vice versa. In short, as we have seen in the responses to Abbate's plea as presented in chapter 2, splicing the drastic and the gnostic together, or in general starting from a difference, poses the very real danger of repeating the dualism as a classificatory strategy elsewhere. ${ }^{125}$

However, reading their insights together, in political terms or in affirmative terms of shared lines of thought opening up to a different metaphysics and methodology, I stumbled upon a difficulty of competing interests and parting ways, which, again, emphasises the complexity of "diffraction as an object [physical phenomenon] and method of study" (Van der Tuin 2014, 234, emphasis removed). In this case, diffraction suddenly appeared as an unforeseen responsiveness, "[generating] an interference pattern" that illuminates differences and how they emerge (Van der Tuin 2014, 231-232). The difficulty I encountered is that, for me, this sudden responsiveness immediately turned into a felt "no," taking a distance from Abbate's position whilst recognising the musico-material-discursive complexity of my close encounters with her intellectual commitment. It made me literally feel how the question of boundary (identity) formation is an implication of a diffractive relationality (Kirby 2011, 83). Moreover, in Van der Tuin's (2014) terms, this sudden responsivity "demonstrates how diffraction is always / already at work when one reads,

\footnotetext{
${ }^{125}$ See also Taruskin's (2005) critique of Carl Dahlhaus's famous question: "Is art history the history of art or is it the history of art?" (Dahlhaus cited in Taruskin 2005, xxvii, emphasis in original). Taruskin explains Dahlhaus's problem as part of the "[g]reat Either/Or" dialectical questions that "cast all thought in rigidly . . . binarized terms" (xxvii). His answer is to consider the interdependence of musical production and reception, leading to the presumption that "mutually exclusive 'internal' and 'external' categories can and must function symbiotically" (xxvii). Taruskin's approach in writing The Oxford History of Western Music is thus to refuse "to choose between this and that ... to embrace this, that, and the other" (xxvii, emphasis in original). However, exchanging exclusion for inclusion leaves untouched the problem of how difference (the duality between identities) between "this," "that," and the other comes into being. This also leaves untouched not only the duality between Taruskin as the qualifier of a particular "this," "that," etc., but also the duality between nature and culture, which Taruskin does not consider. In other words, inclusion of the otherwise excluded does not tackle dualisms, but merely displaces them elsewhere. One way of engaging with Barad's work, as discussed in chapter 3 , is to see how difference is an emergent effect of intra-action's exteriority within.
} 
writes and converses, in a scholarly manner and otherwise" (242). In other words, the difficulty upon which I stumbled demonstrates how Barad's question of ethicality is a valuing and inseparable part of mattering, threaded through the configuration of my position towards Abbate and Barad. Diffraction as attuned to the entanglement of matter, meaning, and value involves "how differences get made, what gets excluded, and how those exclusions matter" (Barad 2007, 30). Reading Barad together with my (interpellated) intuited knowledge of being a singer gradually overpowered any attempt to read Barad and Abbate together.

The reason for this, as I will argue, is that Abbate's (2016, 2017), as yet undiscussed, material turn to the shop floor of making sound for film and of "doing" musicology denies the constitutive effect of intra-active material doing. Instead, she installs predefined things in the form of an assemblage, either by putting forward the ingredients, or in the form of a phenomenological take on the effect that a distinct world of new technologies has on the act of making. With this turn, Abbate joins the different materialisms (discussed in section 4.2.) as an intervention against the dominance of culture, language, the discursive, and meaning formation (discussed in chapter 1 in the context of new musicology). Yet, although assembled under the label of "materialisms," these approaches miss a crucial consideration (see also section 2.4.) regarding material doing, human intentionality, and how subject and object, culture and nature, mind and body, are thought as mixed entities-an inter-activity of entities. This suggests a predefined divide between, for instance, music and its material substrates, whilst, in my view, Barad's (2007) notion of entangled being as "ontological[ly] indeterminate" allows one to think of the dynamics of musico-materialisation as intraactively defined (265). In other words, following Abbate's line of thought in her recent articles, by reading her arguments together with Barad, will simply trap me in the same dichotomous discussion of the drastic (matter) set against the gnostic (meaning). Such as approach would foreclose the possibility of music/ological questions and my musician's call from elsewhere, which consider the leap into the dynamic intra-activity of musico-material worlding. Therefore, before I am able to make this leap, I must first engage with the metaquestions that shine through both Abbate's and Barad's pleas, restricting Abbate to a frame 
of binary thinking and offering Barad to think matter's experiential nature. Only then can I take an excursion into Barad's notion of causality and agency. I conclude with a reworking of the concept of musicality as an enacted responsiveness, which will, in my view, allow for a music/ology that thinks with/in musico-material dynamics.

4.2. Questions that Permeate Barad's and Abbate's Insights

We see the question that seems to inspire Barad's thinking and that is at work within all her writings articulated in the title of her essay What is the Measure of Nothingness? Infinity, Virtuality, Justice (Barad 2012f), written to address artists and art lovers at documenta 13, the annual edition of the five-yearly art exhibition in Kassel, Germany. Barad's question (and her answer), although addressing the arts, does not exactly position the object(art) and the human subject (artist) as cultural articulations in need of exploration. Rather, it highlights the complexity of ontological indeterminacy, of bringing together science and the arts, gathered around the broader question of "how things come to matter" in both senses of the term. In a specific way, her question suggests nothingness as "the infinite plenitude of openness," in which infinities are "incarnate marks of in/ determinacy" (16).

Barad's (2015) concept of nothingness hinges on the quantum principle "of ontological indeterminacy [calling] the existence of . . . a zero-energy, zero-matter state [as argued by classical physics] into question" (394). Additionally, if there is no such zero state, nothingness is not determinately nothing, but rather, "may . . be the source of all that is, a womb that births existence" (Barad 2015, 394). Barad's (2012f) article thus explores the in/determinacy of no/matter. These are indeed matters of interest for those who create/ play / reason with (ac)knowledged things, ideas, and/or their values, and how these enable a human lifeworld. From an agential realist point of view, measuring (observing) nothingness is an intra-active occurrence and already implicates the nature of matter "and its agential capacities for imaginative, desiring and affectively charged forms of bodily 
engagement" (Barad 2015, 388). In other words, through the notion of nothingness, art is addressed in terms of the world's intra-active and ongoing creativity, which traverses any normativity of the natural (or of art), building instead on differing and therewith unsettling "the very foundations of non/being" $(2015,401)$.

To underline the importance of exploring nothingness, Barad (2012f) considers how it concerns the entangled in / finity of mattering, including the in / finite mattering of "us." She considers how "we" are an inseparable part of nothingness, containing one another with the consequential message that justice-to-come (or, mutatis mutandis, art/music as beauty-tocome) resides in every tiny bit of mattering, and not in ethical or aesthetic judgements that precede intra-actions. Consequently, she conceives of an ethico/aesthetico-ontoepistemology (Barad 2012f, 17). Barad (2015) further explicates how nothingness involves virtual intra-activity (performing measurements as relatings) as the "ongoing thought experiments the world performs with itself" (396), suggesting the radical openness of which artists have intuited knowledge: "Matter is never a settled matter" (401).

Barad's (2012f) profound essay on the creative intricacies of nothingness gives rise to notions of infinity, virtuality, and justice. It enacts a speculative engagement, a reaching towards the un/expected in which something is always at stake. Combining ethics with aesthetics, Barad suggests that valuing lies at the heart of mattering, which traverses the morality of good taste. For Barad (2015), the question of nothingness affirms ontological indeterminacy: every finite being is always already imbued with "infinite alterity diffracted through being and time" (401, emphasis removed). Barad's (2015) elaboration of the physical problem, conceptualised as vacuum, void, and nothingness, provides an inspiration for artists and art lovers alike, as it does for "marginalized people" who suffer under the regime of "collective assumptions" of normality as that which is natural (412). Turning now to questions that underpin and structure Abbate's thinking, we will explore how the latter notion of normality, which is based on culture as nature's scribe, is central to Abbate's material turn as articulated in her most recent articles.

Many years after "Music-Drastic or Gnostic?," Abbate revisits and re-configures the ontological and epistemological issues addressed in her 2004 article. Abbate (2016) turns to 
the question of causality, articulated as musicological enchainment, challenging the ease with which music and sound are "connected to the cultures in which they originated" (793). Abbate (2017) enacts "history at work" (98) when she unexpectedly comes across a film still of a "moving" hand, suggesting movement in the "wrong medium" (88-89); the hand moved at the moment the photograph was made, leaving "a trace in the image" (76). In terms of Barad's metaphysics of an agential real, the film still operates in an agentive manner, shifting the direction of Abbate's planned musicological historical research and theorising towards the observation of musical imprints on actors' gestures in silent films.

At first sight, her recent publications (Abbate 2016, 2017) might be considered responses to her earlier plea (Abbate 2004), resolving the drastic-gnostic dichotomy by sustaining a "material turn" in musicology. Abbate (2016) marks this material turn as "a move away from aesthetics commentary, from works-as-texts, away from the top of the food chain, the famous artists, composers and great theories" (820-821). In other words, for Abbate, the articles of 2016 and 2017 demonstrate a turn to the dynamics and materialities involved in musical and musicological work. This apparently constitutes a different move in her thinking, in which she traverses new musicology's emphasis on culture and texts, searching for a way out of cultural and social representationalisms. Instead, she draws attention to the speculative mode of doing musicology (due to unexpectedly coming across a photo) and to the complex causality involved in making sound objects. Nevertheless, Abbate leaves the main problem of the drastic-gnostic dichotomy untouched. As I will argue, Abbate eventually subscribes to a nature-culture divide in which cultural and social forces invest in, and are subjected to, material constraint.

In both of her recent articles, Abbate's overarching argument is primarily structured by a material approach, respectively paying attention to the shop floor of sound design (Abbate 2016), and to the effect of sudden material intervention (Abbate 2017). This approach is held against the academic mind and considered to demonstrate its failure, thus eventually repeating the same dualism as addressed in “Music—Drastic or Gnostic?" (Abbate 2004). Abbate attempts to find new ways to conduct musicological research and theorising, stressing the causal intricacies demonstrated by the making of sound objects for film (Abbate 
2016), and the speculative moment involved in history-in-the-making (Abbate 2017). The belief that underpins her arguments turns this tendency towards the material aspects of producing music and musicology, effecting a critical reconstruction that serves, and is about, the binary of "vernacular" and "high" philosophies (Abbate 2016, 822), as well as about the academic habit of "decoding," set against attention to the matter at hand (Abbate 2017, 100). Abbate is still not theorising knowing in being.

Abbate (2016) underpins her dualist approach by considering artisanal "ordinary, mundane objects" that "give voice to a vernacular philosophy" (823), set against musicology's "high philosophies of music," read as a gnostic approach, clarifying a material world from a distance (822). Abbate $(2017,100)$ argues how her material approach (the encounter with the film still) becomes overruled by the academic preference for texts and decoding signs, neglecting careful study of material detail. In other words, both arguments, fed by the critiqued academic frame of high- and low-order musical and musicological engagements, hold us captive in the dualist and representationalist refrain of the $\mathrm{drastic} /$ material/low versus the gnostic/meaning/high, representing a reality "out there" and thus foreclosing the generativity of material-discursive intra-activity. For Abbate, the drastic-gnostic opposition is much more than a catchy article heading, implicating an entrenched nature-culture divide. In my reading, this divide is not resolved, but repeated in her recent articles, notwithstanding the fact that Abbate's argument is nuanced and complicated, with many keywords and concepts that attest to materialities and to the relationality of gathering and making things.

Thinking with Abbate and Barad diffractively, it is clear that the material turn in Abbate's later work continues, and builds upon, the critical stance articulated in her earlier article. ${ }^{126}$ Abbate upholds the dualist position, bypassing feminist (new) materialisms, and

\footnotetext{
${ }^{126}$ Framing her analysis by comparing thoughts lures Abbate $(2016,2017)$ into a critical, dualist (natureculture) approach, which also keeps me captive here in my attempt to come to grips with the dynamics of matter and how I am an inseparable part of this doing. Kirby (2011) articulates this difficulty as follows: "If we want to address the question of Nature or materiality in a way that does not presume that materiality can be either added to, or subtracted from, something that it isn't (Culture, ideation), then how we identify our own position vis-à-vis another's, how we configure this relationship, will anticipate and rehearse this same difficulty" (83).
} 
scientific and scholarly approaches to research and theorising that are materially in-formed (i.e., mattering as both forming and informing). ${ }^{127}$ Without any specific interest in, or comment on, the theoretical implications of their very different legacies, Abbate (2016) enunciates her approach, namely, to stand on musicology's “old foundational focus on materialities," or to be "nourished by the material turn in other disciplines" (821). The point that grounds Abbate's material turn is that its focus becomes drawn to "historical conditions of production and experience," in which the "[e]vent character-ontology—is critical" (821). This suggests an emphasis on making and doing with a performative motive, in the sense that "musical sound has ... efficacy" (823, emphasis in original). I read Abbate's plea for a material approach together with Barad's insights on how things and thoughts are phenomenal, pointing towards matter-meaning entanglements in which efficacy is an agential enactment that is intra-actively engendered, and not something that a thing, sound, or thought "has." This reading lays bare the inherent difficulty with Abbate's point of departure (material properties), identifying the things and the thoughts that condition the becoming of music and musicology. At issue is that, whereas her earlier argument (Abbate 2004) at least addresses the drastic as a dynamic, material reality (albeit one inaccessible to the gnostic mind), the arguments articulated in Abbate's $(2016,2017)$ later articles propose a material turn that considers "stable" musical (related) entities as accessible ingredients with which to think, and to which musicologists might return again and again. ${ }^{128}$ Thus, Abbate's approach recognises material significance, but stages the human gnostic as an a priori capacity to act.

\footnotetext{
${ }^{127}$ For research and theorising into new and feminist materialisms, see Stacy Alaimo and Susan Hekman (2008); Rick Dolphijn and Iris van der Tuin (2012); and Vicki Kirby (2011). For a more object-oriented take on new materialism, see Levi Brant, Nick Srnicek, and Graham Harman (2011). See also the works of musicologists Sally Macarthur (2010), Freya de Mink (2013), and Milla Tiainen (2017; see also Tiainen and Parikka 2013), building on feminist materialisms.

${ }^{128}$ See Erika Fischer-Lichte $(2004,281-284)$ for a distinction between performance as event, artefact, and "work" (to which one may return again and again). Fischer-Lichte uses this distinction to explicate how subject and object become conflated in performance art. However, an agential realist notion does not recognise a simple return, implicating one stable side, often considered to be "the thing" or "nature." For Barad (2010), it is a question of differencing, meaning that the "re" of "re-turn" also implicates the dynamics of intra-active generativity.
} 
In many (new) materialist approaches, the difference between thing and thought, or nonhuman and human, is a confusing riddle. ${ }^{129}$ However, Abbate seems to establish an epistemological intervention (against the new musicological emphasis on meaning and culture) as a way by which to address the material aspects that are part of the production of music and musicology. Piekut's (2014) Latourian approach into hybrid human-nonhuman entities (as discussed in section 2.4.) follows this same lead. The focus is on identified materials, thoughts, and doings, obscuring how, in Baradian terms, the distinctions of, and between, human and nonhuman, and the nature of agency are effects of differences or diffraction apparatuses. The problem Barad (2008) poses-which, in my view, is also the question that underlies Abbate's question of "Music—Drastic or Gnostic?" - is how not to position difference as a consequence of human interactions with the musico-material world; as an effect that follows a cause "in a linear chain" (336). Rather, difference concerns "the entangled materialisations we help enact and are part of bringing about, including new configurations, new subjectivities, new possibilities" (Barad 2008, 336). In other words, Abbate's material turn bypasses the onto-epistemological intricacies addressed specifically by feminist materialisms.

From Dolphijn and Van der Tuin (2012), we learn that the "material turn . . in other disciplines," as referred to by Abbate $(2016,821)$, demonstrates many discordant arguments. Cecilia Åsberg, Kathrin Thiele, and Iris van der Tuin (2015) discuss how new materialisms prioritise "ontologies of immanence," suggesting "a horizontal plane on which, or from which, differences are made" (145). These scholars suggest how, within the gamut of materialisms, object-oriented ontologies (OOO) and speculative realism wrestle with the relationship between the object (the independent thing) and the subject (the unified substance that observes), summoning once more, transcendence. ${ }^{130}$ Feminist materialisms, like Barad's metaphysics of an agential real, here take a different stance, considering the

\footnotetext{
${ }^{129}$ See Kirby's $(2017,14)$ work on how many new materialisms and speculative realisms struggle with how to take up materiality in thinking without leaving anthropocentrism, as a pre-existent difference, intact. 130 Åsberg, Thiele, and Van der Tuin (2015) share their worries about how 000 and speculative realism (again) turn to the thing, installing a transcendence and thus missing the mark set by feminist materialisms. Moreover, they suggest these frameworks miss, or even negate, the well-established materialism of feminist scholarship.
} 
in/ separability of object and subject that do not precede, but rather emerge through and within intra-action. Again, Barad's metaphysics of an agential real recognises neither the isolated entity, nor the liberal, individual human being. Her metaphysics rejects the notion of agency as human intentionality or the ability to intervene in material and cultural processes, supporting and affirming the ruling concept of what human life is. This is precisely what Abbate leaves untouched, thus installing a sharp dualism and anthropocentrism. Following Kirby $(2017,9)$, we might say that Abbate considers the human mind as the capacity of doing "materialist philosophy," and thus assumes a pre-existing difference between the human and the nonhuman, culture and nature, stability and instability, or gnostic and drastic.

Revaluing and reworking issues that Abbate's (2016, 2017) articles bring to the fore thus demands that we first revisit Abbate's 2004 question of "Music_-Drastic or Gnostic?," for this meta-question still haunts these recent texts. To understand how the humanist project underpins and captures Abbate's drastic-gnostic dichotomy, I turn, again, to the famous discussion concerning Judith Butler's notion of matter and the discursive (see also section 3.7.). In this case, the discussion concentrates on the assumptions built on the ([un]acknowledged) belief in human exceptionalism, meaning that eventually, the gnostic (culture) replaces the drastic (nature), in which case reality becomes an inaccessible outside to the hermetic gnostic position (Barad 2007, 63-66; Kirby 2011, 2017).

The musicology referred to and critiqued by Abbate acknowledges the dynamics and materiality of musical performance, although these are negated by musicologists for practical (serving academic standards) and ideological reasons (see the "work" problem; Goehr 1992). Hence, musicology's commitment to "stable" musical objects, such as scores, recordings, software, and so forth, builds on the assumed promise (at which point the ideology of representationalism enters) that stable musical objects allow for a returning to, again and again, as a fulfilment of scholarly work, sharpening theories and interpretations.

The example of how the scare quotes are used in Butler's ([1993] 2011) title Bodies That Matter: On the Discursive Limits of "Sex" illustrates the troublesome relation between nature and culture sketched above, which also underpins Abbate's notion of the drastic and the 
gnostic. ${ }^{131}$ Butler articulates how sex (as act, occurrence, and identity) is not a stable object to which one may return, involved as it is in an ongoing process of materialising, instigated by "regulatory [cultural] practices" (xi). Without suggesting any analogy, bypassing Butler's emphasis on questions of identity formation, imagine how also music (act, occurrence, and identity) is, in Abbate's terms, drastic and not a stable object to which one may return. Like sex, music is non-contemporaneous with "itself," provoking the familiar argument that neither sex nor music can be grasped by the stability of representations.

Notably, the scare quotes used by Butler are of a different nature than those used by Barad in order to articulate ontological indeterminacy: "We" do not precede the specific (enfolded) intra-action that defines "us" as "we." Here I follow Kirby $(2011,2017)$ who, deepening her insights in an entangled natureculture, has frequently challenged Butler's material reading of the discursive and the cultural whilst sharpening her own argument (for example, see Kirby 1997, 101-128). Similarly, Kirby (2017) argues how the scare quotes used by Butler effectively displace a dynamic real as a "pre-cultural, or extra-linguistic appeal to . . . the reality of sex" (5). Such reasoning would support Abbate's (2004) argument of how a musical pre-cultural real is impossible to grasp. In Kirby's (2017) terms, Butler's scare quotes articulate how the reality of sex (or in our case, music) "is rendered unthinkable because it is only with/in language and discourse that the [musical] world appears sensible" (5). With Butler, Kirby describes how the humanities adhere to a nature-culture dichotomy, where the object of research thus emerges within the confines of language and signs-in sum, representations.

Music, for Abbate, and sex, for Butler, thus become specific social and historical artefacts. Like Butler ([1993] 2011), Abbate (2004) discusses how the constituting effect of (social and historical) regulatory practices is unquestionable, in the sense "[t]hat high classical music was shaped by social and cultural forces, by national ethoses, and that musical works were molded by their maker's psychic individuality" (514). In short, without referring to Foucauldian regulatory practices, yet in a similar way to Butler's notion of the

\footnotetext{
${ }^{131}$ See Barad (2007) and Kirby (2017) for this discussion on Butler (following Foucault).
} 
materiality of sex, the materiality of music is for Abbate the drastic outside, which is nonrepresentational and presents a discursive limit. Nevertheless, musical materiality is perceived and responded to by the (phenomenological) body. Abbate is tireless in convincing her readers of the affect felt when experiencing music, yet all the time, music and the body remain exterior to her language. In other words, the (Jankélévitchian) phenomenological body, crucial to Abbate's argument as receptive to musical impact, produces music as lived experience. The phenomenological body is thus part of a social and cultural force field that produces "the most intimate sense of self" (Kirby 2015, 6) that "[loves] music for its reality" (Abbate 2004, 505). However, experience as expressing the unsayable, ephemeral, and unthinkable - that is, non-representational-is itself part of the productive power of such social and cultural representational processes.

The difficulty Abbate embraces is thus not that she fails to recognise musico-material efficacy, but rather that, similar to Butler's argument on sex, thinking and language impose a limit for musical matter. In Barad's (2007) terms, this creates an outside of the "really real," introducing a two-world metaphysics. In other words, accounting for how musical matter matters to an experiencing body, Abbate's argument suggests that the discursive- or, more generally, the representation—excludes dynamic musical reality. As a consequence, any musicological, interpretative approach towards musical performance displaces that reality as cultural and subjective production. In this way, Abbate and Butler succumb to a general problem for the humanities, namely, the interpretative model through which the object of research and theorising is discovered within "the productive force of the presentation process itself," and which "gathers its legibility, or meaningfulness, through webs of subjective and cultural significance" (Kirby 2015, 5). Although Abbate does not want to displace dynamic musical reality by the caprice of social and cultural mobility, she (like Butler) nevertheless subscribes to the dichotomous idea that social and cultural force fields make a musical world sensible.

Even though Abbate has good reason to account for the musical "real" with which she engages in later articles, like Butler, her argument leaves questions in limbo about how matter comes to matter, as well as "[q]uestions about the material nature of discursive 
practices" (Barad 2007, 64, emphasis added). For a better understanding of the drastic as framed by Abbate, let us now move to the question of causality, first in terms of Barad's metaphysics of an agential real, followed by a section on Abbate's challenge of enchainment as a causal relationship.

\subsubsection{Causality: Causal Intra-actions}

Both Barad (throughout her oeuvre), and Abbate, particularly in "Sound Object Lessons" (2016), explore the causal relationship. Abbate (2016) challenges the ease with which "musicological enchainment" is revered as the conventional narrative of historical and cultural continuity of cause and effect (793). Barad's metaphysics of an agential real challenges the linear causal relationship of a mechanistic or Newtonian worldview. As discussed in previous sections, there are crucial differences between the insights and subject matters of Abbate and Barad, however, I do not pursue these specifically. Rather, in this section, I grasp the notion of how Abbate's argument troubles, whilst Barad's fully shifts, any concept of linear and mechanistic causal relationships.

Both authors consider such reductive causality as based on an inherent separation between cause and effect as predefined terms and as a predefined relationality articulated as stimulus and response-in other words, if A, then B. Crucially, what both make clear is that exploring causality comes down to exploring a particular relationality involving material change, in which one term is considered the cause, and another the effect. For Barad (2010), this implies exploring material doing "unto 'itself' as it were, without the need for some supplement like culture or history to motor it" (268, note 11). For Abbate (2016), this means exploring the shop floor of "sound technology during the machine age, roughly 1870 to the early 1930s" (793). Abbate faces the complex relationality between the material setup for making sound and music for film, and human cognisance as artistic imagination and musicology, observing their generative relationality. Thus, by taking seriously Barad's focus on material dynamics and Abbate's focus on the complex relationalities involved in audio production for the moving image, in this section my hope is that exploring the question of 
causality as a notion that structures both Abbate's and Barad's arguments will inspire thinking the intricacies of non-linear causality involved in musico-materialisations, explored thereafter.

In any volume on (the history of) philosophy, the concept of causality takes a prominent place and it is clear that the concept has an extended bibliography. However, although the following bears witness to this extensive bibliography, a discussion on causality in the light of the history of thought that accompanies it is beyond the scope of this dissertation. Here, the focus of interest is how Barad's notion of intra-activity can prompt causality as an emergent factor with the potential to challenge Abbate's material turnconsidered here as a musicological approach that localises a particular sound object for film as the result of a causal relationality between particular components.

Barad's (2007) notion of emergent causality concerns a relationality of materialisation, producing "marks on bodies," as the traces or differential responses of enfolded processes of materialisation $(472$, note 53). Causality is phenomenal: The specific cause-and-effect relation and the produced materialisation are inseparable from the material-discursive practice or material arrangement (as embodied concept) involved. Causality in this sense does not entail common questions of causation (in which causes could also be effects), or of acausality (in which case it is assumed that things and thoughts happen by chance and do not have a causal history). Nor does it concern questions of causal relations (in which effected things and thoughts have more than one cause), or indeed, of as yet unknown causal relationships. Rather, at issue here is that, in all the aforementioned cases, the starting point is to put the terms in place and in time, separating cause and effect as existing against a world "out there." ${ }^{132}$ Contrary to Barad's understanding, this suggests inherent difference and a

\footnotetext{
132 The Marxist philosopher Alexander Spirkin (1990) outlines the principles of causality, making clear his preference for dialectical reasoning, considered as "the doctrine of historical development through contradictions," delineating and opposing components of a causal relationality as entities for reasoning, and using this as a "guide to action" (63). Although referring to a (dialectical) dynamics, according to Spirkin, causality ultimately concerns the activity of the reasoning mind, starting from the stability of categorisations and producing a link that is "in harmony with actuality and experience" (17). Conversely, Barad emphasises inseparability as an ethico-onto-epistemology in which agential intra-actions matter, producing causation and resolving inherent indeterminacy without any pre-distinction of value/meaning, world and mind.
} 
predefined distinction of categories such as identity (epistemology) and entity (ontology). Such an approach would ask what can be done to that entity and how it reacts (human intervention, value, cause and effect), and what can be known or said about it (epistemology and discourse). Instead, Baradian intra-active, non-linear causality emphasises phenomenal being, considering cause and effect to be enacted components that are ontically and semantically dependent on the intra-active material-discursive setup from which they emerge (the phenomenon). Barad thus brings together ontological, epistemological, and ethical concerns in one move as an ethico-onto-epistemology.

Intra-action's non-dualist and non-anthropocentric engagement is foundational to Barad's understanding of causality, thus traversing common notions in musical practice. Think of how easily one speaks of the intentional doing of the performer, animating the instrument or voice, and how marks are left on instruments and performers' bodies caused by repeated contact. Animation and marks are then understood as discursive effects, and matter is valued as something to reckon with and to be mastered. Whilst such notions may simply be modes of speaking, they nevertheless underpin the idea of music as a social and cultural practice that (re-)constitutes the power structures that materialise the regulatory norms. These allow for a music to come into existence or not, in which the practice of making music is set against materiality, thus mediating between matter and discourse. For example, when the vocal apparatus (musical instrument) is considered the (neutral) mediator, or perhaps the mode of inscription between a vocal discourse, (re)producing regulatory musical norms, and the musical sounds produced, I see how Baradian discourse is nonanthropocentric and material. It is a reworking of Foucauldian discourse, taken from its human foundation, now considered a material-discursive practice entailing a phenomenal entangled being in which matter is considered a doing in itself (Barad 2010, 268, note 11). After all, in Discipline and Punish, Foucault ([1975] 1991) establishes punishment as a regulative discursive practice, thinking together the norms involved in delinquency, the notion of the prisoner (specifically, the prisoner's body) to be regulated, and the specific material (panoptical) conditions of the prison. In a similar (Baradian) way, musical norms, 
the vocal apparatus as the musical regulated body, and the material conditions of a body or a concert hall cannot be torn apart as separated musical/meaning and material practices.

Take a sung musical tone, considered here as a Baradian phenomenon; an entanglement of musico-material-discursive "components" (between scare quotes here, as they do not pre-exist intra-action as such). The tone produced is not one and does not stand on its own, now and here, but is enfolded in the world's ongoing intra-activity. That is, the tone is a configuring of a "differential pattern of mattering ... produced through complex agential intra-actions of multiple material-discursive practices . . . of bodily production" (Barad 2007, 140, emphasis removed). In other words, the tone could be termed an aural "diffraction" pattern, defined through and within intra-actions. ${ }^{133}$ Like any specific measurement, observation, or other (material-discursively) enfolded practices, listening, performing, knowing, theorising, and researching perform material-discursive cuts that include and exclude. Within and through these enfolded intra-actions (agential cuts), a causal structure is enacted in which one component part entails the object of observation (cause), and the other the observational agency (effect; Barad 2007, 337). Thus, enfolded intra-activities are materialised in the sung tone-for example, the intra-action between tone (cause) marks my hard palate in a felt sense (effect)—and are generative of other intraactions. Thus, all forms of observation are "causal intra-actions, [and] physical processes," and part of the contingent nature of multiple enfolded intra-actions configuring the phenomenon of, for example, a sung tone (Barad 2007, 337). It can therefore be seen that it is not self-evident, when singing a tone, that I am the cause and the tone the effect of my effort. In order to determine this specific non-linear cause-and-effect relationship, we have to

\footnotetext{
${ }^{133}$ In the field of machine (robotic) hearing, the study of visualised, acoustic diffraction patterns is used to support research into the active binaural localisation of sound sources. Its aim is to develop auditory space perception for robots, serving missions of search and rescue (Zhong, Sun, and Yost 2016). John McGowan, Grégory Leplâtre, and lain McGregor (2017) of the Institute for Informatics and Digital Innovation at Edinburgh Napier University are conducting research into how music appears visually. They work with visualisations (cymatics) based on "physical impressions of sound created in mediums such as water ... or through particular material on a brass plate" (n.p.). The impressions or (diffraction) patterns are the effects of diffracted sound waves. In the case of a sung tone, when considered as a diffraction pattern, the tone is the effect of differences that all contribute to (and are inseparably entangled with) the specific, heterogeneous constitution of the tone.
} 
analyse the phenomenon of tone as inseparable from a specific musico-material-discursive apparatus (producing the cut).

I use Barad's (2012d, 2015) insights to account for circumstances as materialdiscursive diffraction apparatuses, occurring at all levels, from the micro to the macro. In musical terms, I consider the physical constitution of sound waves and its effects on the social and cultural manifestations of music-all involving intra-active matter-meaning configurations. Barad $(2007,108)$ gives the example that, strictly speaking, the furniture is being rearranged through the bombardment of photons when we turn the light on in a dark room. Barad (2012d, 2015) considers the evidence of quantum effects at the molecular and biological levels to be of a larger magnitude than the so-called subatomic, micro-scale. Barad (2012d) finds evidence for this in how the entangled state of dis/continuity and in / determinacy works through in, for instance, the "everyday macroscopic phenomenon" of lightning, which is only partly explained by classical physics (45). The stepped leader is, however, an effect of a "nonlocal communication" between cloud and ground, in which "the existence of sender and receiver follows from this nonlocal relating rather than preceding it" (Barad 2012d, 35). Further, the notion of level is an inherent part of material-discursive materialisations through, and within, level becomes intra-actively defined (Barad 2015, 421, note 60$).{ }^{134}$ This suggests, taking the example of singing a musical tone, that sound waves and a singer's hard palate are not of different worlds or ontologies, but are intra-actively related in producing a tone. However, in Baradian terms, intra-active effects on the level of sound waves are an inherent part of the musico-material-discursive dynamics of producing a tone (Barad 2012b, 10-25). In other words, Barad's (2007, 140) emphasis on material doing, in which the discursive is also considered to be a material and boundary-drawing practice,

\footnotetext{
${ }^{134}$ See the website of the American National Weather Service (NWS), https://www.weather.gov/safety/lightning-science-initiation-stepped-leader (last accessed September $10,2019)$. The website offers a description of the initiation of the stepped leader and its connection to the ground. The point that Barad (2012b) wants to make also concerns the kind of questions prompted by the nature of lightning. Accepted scientific knowledge, as displayed on the website mentioned above, follows a narrative of linear causation between negative and positive charges. Barad, affirming Kirby (2011, 138-139), is concerned that installing a division between negative and positive charges "[shuts] down the discussion," whilst many puzzles remain about "the nature of the electric field," how it is animated, and how "receiver" and "sender" come into being (Barad 2012b, 50, note 38).
} 
affirms the performativity of matter and the nonlocality of a music (and musicology) in-themaking. Furthermore, it affirms the notion of matter's in/determinate causal relating.

When singing a tone, pursuing an aesthetics of continuity and flowing quality follows a "rule" for the "classical" singing style, here considered an enfolded material-discursive and boundary-drawing practice. This requires an effort that necessarily demands diving into the agential dynamics of multiple enacted and enfolded causal relationships, causing the nature and specificity of "this" singing as both an effect and an inseparable part of a differential pattern of inclusion and exclusion. As such, "this" singing creates specific matter-meaning, marking musical agency, musical time, and musical space, and does not follow a predefined continuous course in space and in time. Barad's notion of causal intra-activity challenges common understandings of musical dynamics as a tonal flow and musical structure in time and acoustic space. Rather, such "components" undergo changes through the use of musical parameters, or are programmed by rhythm, beat, melody, harmony, dynamic, texture, and so forth, assumed as social and cultural inscriptions. Barad (2007, 2010, 2012c) gives us a view of the dynamics of (musico)spacetimematterings as enfolded material-discursive practices in which continuity and discontinuity, the material and the social, are not a priori categories, but rather are intra-actively defined "topological shifts (e.g. changes in continuity, boundedness, etc.) [which] may be of great significance" (Barad 2007, 430, note 19). Think of singing into a microphone, transducing the sound, re-enforcing or recording it, completely reconfiguring the notion of location and nearness, of musical time and space, in which the loudspeakers might be considered the markers of this topological shift.

It is thus not sufficient to approach singing a tone (or making music in general) through and within the idea of the inter-active emergence of causal in/separability, delineating cause-and-effect relationship as that which cuts together the separated. This would suggest that causality is understood in either determinist terms (mechanism), or in terms of free will (agency; Barad 2007, 24). ${ }^{135}$ Conversely, the notion of intra-active aliveness

\footnotetext{
135 Determinism is related to a Newtonian worldview, finding evidence in Newtonian mechanisms and their strict determinism, which suggests that "given the 'initial conditions' (i.e., the position and momentum of a particle at anyone instant in time) and the full set of forces acting on a particle, the particle's entire trajectory (i.e., its entire past and future) is determined" (Barad 2007, 107). The
} 
does not consider reality as constituted through predetermined causality, and Barad's thesis of immanence and enfolded being forecloses an absolute free will. ${ }^{136}$ In short, Barad's reworking of causality thus emphasises the in/determinacy and dis/continuity of intraactive in/separability. This suggests that material-discursive practices as sedimented mattermeaning practices are permeated with in/ determinacy, providing for "a radical open relatingness of the world worlding itself" (Barad 2012d, 46).

Building on this Baradian understanding of causality, I argue that Abbate $(2016,2017)$ seeks to re-appreciate and revalue causality as inseparable from material doing. Also, for Abbate, music does not exist in cultural and social isolation, but rather needs materialities for its production and specificity. I consider her argument as an attempt, after her earlier plea (Abbate 2004), to get in touch with the experiment of a musico-material-discursive world via observation of the shop floor. I argue, however, that Abbate's insights, with regard to the processes of making, differ from Barad's: Whilst for Barad, one is always already part of the shop floor, giving prominence to questions of response-ability and account-ability, Abbate remains at a distance, adhering to a dualist framework of thinking.

Following this discussion, we will need to pause for a moment in order to explore how Barad introduces the notion of the void as a means by which to consider how intraactive causality as a physical process is haunted by virtual matter. This then leads into a discussion of how the indeterminacy of the non/materialised or the no/thing and

\footnotetext{
worldview or explanatory framework based on Newton's calculations, as threaded through (amongst others) all levels of personal, societal, political, artistic, and scientific thinking and doing, we see articulated in 1814 by the philosopher and mathematician Pierre-Simon Laplace-known as Laplace's demon. Diffracting Laplace with Newton, Barad (2010) positions Laplace's demon as "the hero of a thought experiment, a clever chap who stops time, gathers information about the whereabouts and instantaneous movements of every particle, making for a complete data set which when plugged into Newton's equation gives Man his ultimate wish of complete knowability" (248). In a contemporary sense, it could be suggested that Laplace's demon is evident in the way data industries attempt to use information to predict the future.

${ }^{136}$ For Barad (2007), "causality is neither a matter of strict determinism nor one of free will" (234). As previously discussed, exclusions are implicated in every intra-active doing, foreclosing both strict determinism and the idea that everything is possible at any moment. Bergson ([1934] 1946) supplements this argument-thus further complicating the notion of the possible-by showing how free will is related to the given: Often (and unacknowledged), the notion of "free will is reduced ... to a simple 'choice' between two or more alternatives, as if these alternatives were 'possibles' outlined beforehand, and as if the will was limited to 'bringing about' ('realiser') one of them. They therefore still admit even if they do not realize it, that everything is given" (17-18).
} 
no/meaning are, as previously discussed, entangled with intra-active causality in a felt sense. Or, put another way, it is the new as an entangled im/possibility that tensions intraactive causality. For a music/ological approach, fathoming the nature of the new as entangled non/musico-mattering, and the relationship between the new in music-in-themaking on the one hand, and the musical field on the other, is central to the present argument.

\subsubsection{The Silence of the Cabinet}

Abbate (2016) addresses the problem of causality via the relational complexity involved in the making of sound objects, challenging conventional narratives of (historical and cultural) continuity. She cites "the ease with which we [musicologists] practice musicological enchainment," here considered as "the assertion that sound phenomenon or object $\mathrm{x}$ has become cultural phenomenon y (or y has become x)" (793). Abbate suggests a musicological trope to connect sound objects and music in a cause-and-effect relationality "to the cultures in which they originate" (793). To support her critique of "easy" musicological enchainment, Abbate considers connections made between science, technology, and the production of music and sound as "early methodological models for enchainment arguments" (794). She especially cites the way in which Adorno (2005) links "magic lantern technology" to effects in Wagner's music, and how Wagner's acoustic effects are embodiments of "the machine [lantern] and its tricks" (Abbate 2016, 794).

Abbate, famous for her research on Wagner's operas, has also discussed Adorno's arguments on Wagner in her earlier work (see Abbate 1996, 13-14, 2001, 107-145). She explicates Adorno's notion of Wagner's phantasmagoria as "musical or acoustic illusions" beyond their material means of production — the voices, the instruments, but also the musical structures (Abbate 2001, 107-108). However, Abbate critiques Adorno's analysis of Wagner's music as an "easy" enchainment argument: The "optical illusions" produced by the magic lantern (an early technology and apparatus of image projection) are posited as the direct cause for Wagner's composing, in turn producing "magic" acoustic effects on listeners as the 
lantern's "sonic embodiment" (Abbate 2016, 794). Although Adorno's work is of interest to the field of musicology and widely discussed, any deeper discussion lies beyond the scope of this dissertation. However, it is important to note how Abbate, critiquing Adorno's "easy" enchainment, considers her approach of consulting the shop floor to be the better option.

Nevertheless, in terms of this dissertation's music/ological approach of radical immanence, both Abbate and Adorno share in their arguments the same issue of representationalism, based on a predefined binary between the discursive and the material as divided components of human concern. In Baradian terms, Abbate overlooks how any act of making is a material-discursive practice, involving matter-meaning materialisations. Additionally, she does not take into account how musicological work itself is a materialdiscursive practice, and thus forecloses a music/ological material-discursive setup for thinking through/with/in music. Thus, Abbate's turn to the shop floor is an "easy" solution that ultimately fails because it is based on the same (unspoken) premises as Adorno's "easy" enchainment. Nevertheless, although missing the intra-active shift, Abbate's exploration is nuanced and speaks to many materialist approaches. Therefore, I now present a short summary of Abbate's analysis, specifically examining how she uses a cabinet of curiosities as a strange assemblage connecting sound objects to the material and discursive practices from which they are produced.

Abbate's (2016) argument explores the connection between the objects contained in a proposed "cabinet of curiosities," assembled and curated by her. In her cabinet, she brings together the things and thoughts that play a role in sound technology during the machine age, "roughly 1870 to the early 1930s" (793). It is tempting to see Abbate's cabinet of curiosities as a Baradian lively material-discursive palette for musicological engagement. However, Barad's notions of entanglement and intra-action-implicated as researcher and material doing-are missing in the research apparatus. Therefore, Abbate's notion of the proposed cabinet refers to the stillness of specific things on a shelf as ingredients with which to think, eventually suggesting that the sound object is a consequence of multiple causes. ${ }^{137}$

\footnotetext{
${ }^{137}$ See the work of education scholar Maggie MacLure (2013), for an account of how cabinets of curiosities figure as an "alternative logic of qualitative research" (229). MacLure argues how curiosity and
} 
As Abbate argues, the cabinet of curiosities is an assemblage that tries "to make sense of the objects" — a reminder of the musicological difficulty ("easy" enchainment) of making sense through multiple yet linear connections that "shape our histories of technological artifacts and sound objects" (793). The cabinet contains a quotation from George Eliot's Middlemarch, two sound objects designed for early sound films, and the last item is a microphone. ${ }^{138}$ One of the sound objects is the music/sound that accompanies a pamphlet blowing down a street, and the other accompanies a candle that is passed along a table. Sound objects can be considered objects in the sense that they are worked and reworked by sound designers who are able to return again and again to their object of making; an iterative process made possible by (new) recording and replaying technologies for sound and film. Abbate's understanding of a material turn brings her to observe the practice of making, directing her interest towards the striking strangeness of the sound objects: "it is not the real noise made by [the pamphlet's and the candle's movements], but some heightened translation of what that sound could be" (797). As a result, the sound falls somewhere between a musical accompaniment and a sound that seems to emerge from the moving prop. For Abbate, this is due to the relationality between new technological possibilities and the implicated freedom of imagination engendered by an unknown aesthetic territory. ${ }^{139}$

Abbate (2016) thus closes in on the practice of recording and replaying technologies, involving the specific workings of the microphone. The microphone, although often neglected as mere "[c]og and servant" (811), is a transducer, converting acoustic vibrations

wonder implicate the researcher as part of the assemblage, as well as relationalities [I suggest] that can be "thought of as [Baradian] entanglement or 'intra-action"” (229).

${ }^{138}$ Eliot's text reads as follows: "The element of tragedy which lies in the very fact of frequency, has not yet wrought itself into the coarse emotion of mankind; and perhaps our frames could hardly bear much of it. If we had a keen vision and feeling of all ordinary human life, it would be like hearing the grass grow and the squirrel's heartbeat, and we should die of that roar which lies at the other side of silence" (cited in Abbate 2016, 793). Eliot articulates here how a human is (luckily) not capable of taking in all the sorrows of everyday life and how this human "incapability" causes such sorrows to be overlooked. Abbate refers here to how the microphone, hearing "everything," challenges audio artisans to reconsider which sounds are overlooked and which sounds should be overlooked for listeners to make sense of a film image. ${ }^{139}$ Abbate emphasises the unknown territory of making sounds and points towards the common practice referred to by Michel Chion (2009) as "rendering." Chion refers to the way in which sounds are made "truthful, effective, and fitting," based on the audience's association of a sound with a situation, rather than necessarily using the "real" sound (488). 
into a varying electrical potentials. It is praised for its creative participation in sound production, but also criticised for its "lack of discrimination" by virtue of its "hearing" everything without (human) prejudice (816). ${ }^{140}$ Evoking Eliot's text, written between 1871 and 1872, Abbate points to how both text and microphone question "that roar which lies at the other side of silence" (807). The (early) microphone bears the promise to reveal the unheard, like the microscope reveals the unseen, engendering questions (and audio imaginations) of what lies at the other side of the hearing threshold, and what it would mean if humans could hear it all. For Abbate, human imagination, perception, and touch were triggered to the extreme, as in the period between 1870 and the early 1930s, things and technologies were new and not (yet) settled or controlled within practical regulations of sound production for film, nor was there an aesthetics "in place" that could function as reference.

Abbate (2016) thus appraises a sound designer's onto-epistemology-a knowing in (musical and sonic) being - by investigating the habitat of early twentieth-century sound designers through the study of recordings and documentations. For Abbate, this turn to materialities is needed to overcome the musicological gnostic or compulsion for transcendence as a point from which to explain the musical world. ${ }^{141}$ It is in this sense that I consider Abbate's problematisation of enchainment and causality to be of interest to a

\footnotetext{
${ }^{140}$ Regarding microphone technology, there is the problem of a normative practice concerning what the microphone must "hear" and what not; there are numerous sorts of microphones oriented towards the circumstances of use and desired results. An important technological component of microphones and speakers are the transducers: Like a musical instrument or a voice, they transduce force (acoustic vibration) into electronic vibration. The electronic vibration is subsequently manipulated by the Public Address System (PA), and back again to the acoustic vibration of a speaker, perceptible to the listener's ear (another transduction level into the binary of digital representation of today's PAs might be added). Transducing as an operation and a concept works well for those involved in writing about processes, events, and actions. Sound studies theorist Jonathan Sterne $(2003,22)$ takes the concept as his starting point for writing "The Audible Past," whilst Julian Henriques, Milla Tiainen, and Pasi Väliaho (2014) use the notion of transduction to express how rhythm as vibration "elicits transmissions or transductions of affect across multiple participating 'media'" (20, emphasis in original). Barad (1998) sees a piezoelectric crystal (an observation apparatus that receives and transmits ultrasound vibrations used to form fetal ultrasound images) as a transduction apparatus "for making and bridging boundaries" (100); that is, to question the intra-action between the discursive and the material (89).

${ }^{141}$ See Estelle Barrett and Barbara Bolt (2013) for research into the arts. Their work can simultaneously be seen as an exploration of a new materialist practice that considers the materiality involved in discursive formations. As such, methods of writing about art that were only concerned with meaning, the social, and the cultural, are shifted.
} 
music/ological material turn. After all, with Abbate, the dilemma we face is how to bring the material back into the equation "without losing the insights of the linguistic [cultural or new musicological] turn that characterized the last decades of the twentieth century" (Hekman cited in Barrett and Bolt 2013, 7). This suggests that Abbate's material turn and Barad's agential realism do not want to displace the human, meaning, and/or musical aesthetics, or recognise matter as their sole ground. Rather, the difficulty is onto-epistemological in nature, affirming the entanglement of knowing and being, and not, as suggested by Abbate (2016, 793), the quality of the assemblage as a chosen mixture of ingredients with which to think and attribute meaning. Following Barad, we must instead traverse the drastic and the gnostic, accepting that music/ology as onto-epistemology is always already a material-discursive enfolded practice. This necessitates a concept of causality that is understood as entangled with a specific material practice through which one component temporally emerges as cause and another as effect.

Reading Barad's and Abbate's insights on the issue of causality together, there remain problems that need attention, as they hinder Abbate's material turn. That is, they hinder her work as a music/ologist, whether it concerns theorising or the researcher's direct observation of making sound or music. I presume that the eventual purpose of Abbate's analysis is to enable an exploration of both angles of engagement with music. However, her desired understanding of causal relationality - that is, the establishment of a cause-and-effect relationality beyond linearity—is obstructed by the argument's reliance on predetermined ingredients that humans (musicians, music scholars, theorists) act upon. Thus, in order to enable Abbate's argument to open up to a (new) materialist turn, there are two more issues that need exploration.

First, Abbate (2016) adheres to a metaphysics of two separate worlds: a (material) world that gives expression to vernacular thinking, which in its turn feeds "high" philosophical thinking with the ethical suggestion of an "elsewhere." As Abbate suggests, this metaphysics is "attentive to mundane objects that have been disdained and overlooked" (829). Abbate refers here to the value-laden difference between "vernacular" thinking, which follows from materials at hand, and "high" thinking as reasoning about "technological 
artifacts," which would embody "epistemologies of sound, or lessons on listening" (798). We encountered a similar distinction between thinking and objects of thought as the common separation between the sciences and the humanities. According to this logic, scientific thinking is dependent on experiential research for its object, whereas scholarly thinking is dependent on the scholarly object as (co-)created by the active mind through the processes of thinking and interpreting. For Barad, all thinking involves a material-discursive practice, which does not assume that we must all do our own experimental musicology (something that Abbate might seem to, but does not propose). As an excursion to the shop floor, Abbate's material turn rather questions if there is such a sharp boundary between music/sound making and music/ology.

Rather than following Abbate's distinction between frames of thinking (vernacular and high philosophy), I would instead emphasise how she also makes the case for a music/ology conducted via thought experiments, which is a material-discursive matter (Barad 2014, 154). Abbate (2016) suggests an interrogation of technological objects and how they are part of making sound. In doing so, she turns to "the complexities in interactions between humans, instruments, and technologies" (829). However, the problem is that Abbate's material turn does not go into the matter of the suggested "complexity in interactions," but is yet again caught up in a struggle with a predefined difference between the drastic and the gnostic-in Baradian terms, between matter and meaning. Abbate "suggests some enchainment [herself]" (794) as to how artisanal doing enchains with "music's efficacy" (829) and "gives voice to a vernacular philosophy" (823, emphasis added). The problem is that this does not foreclose a musicological "easy" enchainment, now shifted to the concept of "giving voice to." Following Van der Tuin's (2011) work on Bergson ([1889] 1910), the mechanism of language or thinking as actively "giving voice to" assumes a mute world, suggesting a one-way direction, nourished by human reasoning. This is true for both Abbatean concepts of "vernacular" and "high" philosophies. In this sense, enchainment as "giving voice to" rather "prescribes or describes ..., control[ling]" the very thing that affords philosophical expression in the first place (Bergson cited in Van der Tuin 2011, 24). In Barad's terms, "giving voice to" involves a similar move as suggested by inter-action: 
Through a process of rationalisation, a cause-and-effect relation is imposed upon dynamic being, producing a connection that is based on human interest in a muted world. In short, reading Abbate and Barad together, the point is that, although Abbate proposes a material turn for musicology, she overlooks the possibilities inherent in an investment in material doing and in the intra-active entanglement of music, matter, and the discursive.

The second issue concerns Abbate's attempts to pursue a causality through which matter and meaning are both considered “doings." Here she follows Jankélévitch's $(2003,27)$ remarks on encountering material objects. Abbate (2016) considers "how encounters with material objects, such as tools, or observed physical gestures, or heard sounds, engender complex feedback loops" (804). This assumes, in terms of musical performance, that through feedback loops, a circuit of communication between hand and instrument is instigated, readjusting sound or music-in-the-making, and readjusting and reshaping the hand (Abbate 2016, 803). This suggests that hand, instrument, and the communication between them share the same problem - that is, the music to be made. This is summarised as a feedback filter, which functions as the operational limit of the feedback (Faucher 2013, 47). ${ }^{142}$ Here the idea of the filter thus concerns knowledge of the music or sound to be made, and how this knowledge informs the actions required to achieve the desired result. ${ }^{143}$

Abbate's notion of a feedback loop and implicated filter as a cause-and-effect relation is a familiar image with which to think the processual side of musical materialisations. However, the difficulty inherent in Abbate's (Jankélévichean inspired) argument is the assumption of a predefined problem, which determines the music to be made and is shared by all the components involved. I am aware that Abbate speaks of "complex" feedback loops

\footnotetext{
${ }^{142}$ To think music-in-the-making, Étienne Souriau's (2015) concept of instauration is of interest. Souriau conceptualises the making of the work-to-be-made (oeuvre à faire) as an instaurative act. This act takes place within the tension between the work already made and the "work in limbo," also referred to as the "spiritual form," or "the Angel of the work" (230). With these notions Souriau attempts to articulate how every doing concerns a "progressive coming together of [the work's] two existential aspects, the to-bemade and the made" (236). Abbate (2001) refers to such notions of music-as-performed by considering "a master voice" calling (18). In Souriau, however, it is a call that accompanies and changes with every act of the maker, who becomes increasingly attuned to the work made.

${ }^{143}$ Abbate does not further theorise her notion of the feedback loop. Kane X. Faucher's (2013) chapter on the ontological status of information from a Deleuzian perspective, specifically considering the concept of the feedback loop, is helpful in this respect.
} 
and therefore my argument on the predictive nature of feedback—through the implicated filter or limit as the music to be made-may seem far-fetched. Abbate's notion of feedback may be her way of addressing the intense and complex causality involved in making music. However, the underlying universalising assumption of knowing the musical result to be achieved, and that all musical, sonic, material, and discursive components involved share this knowledge in the same human manner, is common in musical (and musicological) environments. In these environments, materiality is considered (human) mind/meaningdependent, serving as sub-stance for cultural inscription.

Missing here is Barad's (2007) notion of the in/separability of phenomenal being: Cause, effect, and agency are material-discursive and intra-actively related-that is, cut together-apart. In other words, materialisation and the material dimension (constraints, one has to practice; exclusions, one's voice does not have the just disposition to perform particular music) of discursive regulatory practices "[entail] matter as [an] active 'agent' in its ongoing materialization" (Barad 2003, 822, emphasis in original). To explore matter as active agency, in the following section I turn to Barad's notion of ghostly causality and to Abbate's notion of improvisation as that which complicates causal connectivity.

\subsubsection{Intra-Actions: Ghostly Causality}

Thinking of performance as music-in-the-making brings to the fore how Baradian (musical) phenomena are not simply "little chunks" of spacetimemattering in a sea of nothingness. ${ }^{144}$ Similarly, intra-actions are not gatherings that draw upon a complete set of all possible forms of existence, also localised in what is called nothingness or "the void" as a chaotic space from which "our" world emerges (Barad 2007, 150, 2015, 393-394). In this notion, the void is the unspeakable home of the mysteries of life and of the cycle of birth, life, and death. In these terms, it is also the home from which music comes and to which it goes when it is, in

\footnotetext{
${ }^{144}$ In Baradian terms, through and within agential intra-activity meaning and matter become determinate. This process is conceptualised as spacetimemattering, in which "mattering" is understood as the marking of time, space, matter, and meaning. That is to say, music-making does not happen in time and in space, but is part of a "dynamic field of matterings" (Barad 2012e, 221, note 16).
} 
Abbate's (2004) terms, “passed present." In a classical (pre-quantum) paradigm, however, researching the void and the unspeakable prompts transcendence through questions of origin; of who or what motivates and organises music, life or, more generally, materialisations; and of who or what brings forth the new. With the findings of quantum physics (and the derivative techno-scientific products all around us), encountering nothingness as the "living breathing indeterminacy of non/being" (Barad 2015, 396) does not so much prompt a caution towards letting transcendence in through the "back door," for instance by installing the uncaused as nature's ability to spontaneously create ex nihilo, or as Aristotle's concept of the "unmoved mover." ${ }^{145}$ Rather, following Barad's (2015) understanding of ghostly and queer causality, nothingness entails "an endless exploration" of matter onto "itself," involving the edge of non/existence, im/possibility, dis/continuity, and in/determinacy (396, emphasis removed). ${ }^{146}$ This suggests that the Baradian (quantumphysical) notion of exploring nothingness addresses the entangled ontology of phenomena as "building blocks" that configure the world, in which phenomena are understood as "relations without [predefined] relata" (Barad 2007, 444, note 33). Phenomena are relational practices and doings rather than things, and with the notion of nothingness, Barad zooms in on the edge of non/ existence where phenomena come to matter (or not).

Turning to Abbate's (2016, 2017) notions of improvisation, Abbate considers here the bringing in of the new and discontinuity in terms of leaving a predicted path. Clearly, this point of view assumes the existence of given things, relations, and structures. She argues how sound objects are produced through "playful actions . . . as artisanal improvisations in the moment, demanding ingenuity on the spot" (Abbate 2016, 821-822). This is an argument that sees the new and the disruption caused by human intervention in the midst of confusing

\footnotetext{
${ }^{145}$ Based on the principle of motion, Aristotle (1984) discusses the impossibility of the uncaused motion, exploring the notion of the "first unmoved mover [that] cannot have any magnitude," as magnitude suggests finite being; the unmoved mover "causes a motion that is eternal" (446).

${ }^{146}$ The terms punctuated with a slash are used to indicate a superposition, a term borrowed from physics, denoting how, through a disturbance, waves combine. The resultant wave is a sum of the relative differences (Barad 2007, 76). Here, "superpositions represent ontologically indeterminate states;" components cannot be identified, as would be the case in a mixture (Barad 2007, 265, emphasis removed). Crucial for Barad (2010) is that superpositions involve the indeterminacy at the heart of spacetimemattering and "undo classical notions of identity and being" (251).
} 
times and places: The human takes up a (sound) object and relates it to another object, subsequently judging the result for further actions. Abbate's phenomenological stance thus introduces a dualism with the human as ground, initiator, knower, and inventor of music or sound. The human actor starts with, and returns to, the thing (sound object), adding a relation (tool or imagination), and judging the new in opposition to the old.

Abbate (2017) further explores the understanding of improvisation and "insouciance" (85). For Abbate, insouciance is how performers accept that their performance will not last and make "peace with the ephemeral," upholding a certain carelessness that frees "them to return the next day, and the next, with something even better" (85, emphasis added). In Baradian terms, Abbate emphasises how musicians conveniently "forget" the past in order to get over the not fully realised musical responsiveness of last night's concert, although the past as "marks on bodies" cannot be erased (Barad 2007, 316). For Abbate (2017), insouciance thus suggests a certain indifference, whereas improvisation related to music-in-the-making has a moral aspect: Provisional actions are judged necessary to secure continuity when "outcomes are uncertain" (the show must go on), or to achieve a better result, assuming a clear notion of the end product (85).

For Abbate (2017), goal-orientated insouciance and provisional action is set against Jankélévitch's adage to waste time and follow in music the "detour" that music-making is; an aimless track (101, note 10). ${ }^{147}$ Following Jankélévitch's notion of musical improvisation as an aimless detour and "model for continuing when outcomes are uncertain," Abbate explores how the new as discontinuity is brought about through such free action and through the action determined by usefulness, as the show must go on (85). Considering the sudden encounter with an unidentified photograph, Abbate replicates Jankélévitch's account of improvisation as an aimless track (84). In Baradian terms, however, Abbate's approach is based on an additive logic, in which an improvisatory outside is analysed against the

\footnotetext{
${ }^{147}$ Abbate (2017) cites Jankélévitch, who argues: "Le détour est le chemin lui-même . . . la musique est tout entière cette circonvolution sans but" [The detour is the way itself . . music fully is this winding movement without aim] (101, note 10, translation mine).
} 
stability of a text or a planning. ${ }^{148}$ Abbate's encounter with the photograph, which was not intended for her, transformed her planned research into an essay on starting research from the encounter with a material object. This she defines as a new event, generating an unforeseen detour from the defined, foreseen, "old" plan. In other words, Abbate's phenomenology upholds the human as the standard for observation, pushing our discussion on causality back to the given, into the binary world of choices between the determinism of human musical and musicological doing (the provision involved in improvisation, as the show must go on) on the one hand, and the free play of the human as a deviation from the given on the other. A Baradian approach considers Abbate's notion of improvisation and "provisations" as doings in (predetermined) time and in (predetermined) space (cf. Barad 2010, 254). ${ }^{149}$ The difficulty is that, in considering both the contemporary material setup for sound design and the sudden encounter with the photograph, Abbate $(2016,2017)$ still follows an additive approach. That is, she sees the causal complexity and change involved in musical and musicological mattering (i.e., in the human relationship) as set against a musical and musicological world of things. From a Baradian perspective, Abbate does not push her materialism far enough, which would mean starting with intra-active doing as an iterative practice through and within which phenomena are constituted. Additionally, it would mean being attentive to how causal complexity involves multiple enfolded material-discursive practices of bodily production (music, musicology, researcher, things, thoughts).

The difference between the approaches of Abbate and Barad, in the context of causal complexity, is that Barad's thesis of radical immanence leaves no "back door" for binary

\footnotetext{
148 In his historical and ethnographic study of the Dutch orchestra Instant Composers Pool (ICP), the musicologist Floris Schuiling (2018) cuts across the assumed separated categories of written and improvised music. Schuiling argues that in the performance practice of the ICP, creativity in performance works in relationship with "the interpenetration of composed and improvised material" (n.p.). ${ }^{149}$ Eventually, for Abbate, improvisation and the unforeseen do not disrupt linear causality as the predefined order of time and necessity of things to happen. Of interest here is the concept of "preposterous events," used by the English and comparative literature scholar Patricia Parker (1992) to demonstrate how "the presentation of an order authorized as 'natural" rather demonstrates the workings of discourse, involving "the histories it forges and the authority it creates" (213). This notion thus supports Barad's notion of material-discursive practices through and within which time, position, and sequence are intra-actively produced. We also recognise the order of "before" and "after" as an unsettled matter in the terms of cultural analyst Mieke Bal (2006), who argues that "the anachronistic approach ['preposterous history'] is nevertheless self-consciously historical" (xx).
} 
thinking, neither in terms of allowing transcendence to "sneak in," nor in terms of an overarching and settled notion of time and space. Barad (2010) uses the term "ghostly causality" to articulate how intra-active causality is shifted from within through that which is excluded from mattering, but also through the ongoing matter-to-matter intra-actions as differences that "percolate through every 'thing'" (268, note 9). Whilst in her earlier work, as previously referenced in this dissertation, Barad referred (with Butler) to the "doings" of constitutive exclusions, in her more recent work, she signals the crucial nature of "constitutive inclusions" as "the in/determinacy, the virtuality that is a constitutive part of all finitude" (Barad 2012e, 215-216). In terms of Abbate's exploration of improvisation and how to handle the unexpected, Barad would instead emphasise how "we" are part of the dynamism of "mattering and not-mattering," which is irreducibly left open because of constitutive exclusions and inclusions. I argue that this dynamism of mattering and notmattering does not negate, but rather traverses, the common notion of improvisation as a wilful and useful action combined with a free (specifically aimless) detour. ${ }^{150}$ This suggests precisely the confusion inherent in Abbate's material turn: We observe from a distance improvisation as a recognised material doing and a recognised playing (wilful, useful, aimless, including their respective negations) with, for instance, a particular chord or rhythm. At the same time, this improvisation is bound by a musician's collaboration with other musicians, the sounding gestures, the acoustic environment, the audience, and the fact that an improvisation is a finite occurrence. As such, the improvisation is part of a musical performance, which is an enfolded, sedimented, material-discursive event bound by time and location. However, Barad (2012e) takes issue with what it means to originate

\footnotetext{
${ }^{150}$ George E. Lewis and Benjamin Piekut (2016) demonstrate the many approaches to improvisation studies in a two-volume publication. Of interest to our discussion is the contribution of the cultural theorist Michael Gallope. Gallope (2016) distinguishes in Jankélévitch's thinking on complex temporality an opening to think musical improvisation as a matter of "real-time," suggesting to make music without criteria (152). Real-time is the lived instant that can only become known to experience as the interval between the "just before" and the "just after" (146). Unfortunately, according to Gallope, Jankélévitch's account of improvisation turns away from the topic of real-time and instead discusses musical improvisation as a philosophical explanation of Franz Liszt's Rhapsodie, thus remaining within the duality between improvisation and notated composition-hence the notion of detour as different from the notated 'route' (152). Abbate's (2017, 101, note 10) discussion on improvisation also refers to this study of Jankélévitch on Liszt.
} 
(materialise) in the dynamics of musico-material-discursive intra-activity, in which (musical and musicological) improvisation as a sedimented (recognised) musico-material practice is continuously disrupted and opened up by the "doings" of that which is excluded (e.g., the Other chords and rhythms) and of the included instability effected by material aliveness. This conception demands responsiveness to an emergent musicality, upon which I elaborate further below..$^{151}$

For Barad, the dynamism of which "we" and "our" music-making are part, opens up towards the unforeseen and the unheard, evoking expectation and exploring the unexpected. She widens the aspect of constitutive inclusion to the virtuality or superposition of indeterminacy and determinacy, of existence and non-existence, and virtuality as of materialisations, considered as "the ongoing thought experiment the world performs with itself" (Barad 2015, 396). Using assertions from quantum field theory, Barad (2015) attempts to express and imagine how questions of the void, the nothing of nothingness, are questions of virtual doing, of which "we" are part. She asserts that the source-creatio ex nihilo—of the new is not an outside, and that the void or nothingness is neither a thing with nothing in it, nor a thing with virtual particles moving in it. Rather, it concerns the liveliness of in/ determinacy in terms of "quantum fluctuations of the quantum vacuum" (Barad 2012f, 9, emphasis in original), threaded through the world.

Although upholding the classical and "literary" concepts of vacuum, void, and nothingness, quantum field theory, to which Barad (2012f, 2015) refers, traverses the common idea of nothingness (the void or infinity) as the passive outside of that which is propertied, limited, and lacking infinity (Spirkin 1990, 90-98). ${ }^{152}$ Combining quantum field

\footnotetext{
${ }^{151}$ See the work of the musicologist Ingrid Monson (1996) on jazz interaction and improvisation. Monson builds her research on discussions with musicians. Drummer Ralph Peterson, for instance, speaks of improvisation as happening "in fragments and [coming] from different parts, different voices" (cited in Monson 1996, 78). In my view, as a singer who worked with composers and their scores, as well as with improvisers and their musical "baggage," Barad's notion of how the excluded and the included open up sedimented intra-active matter-meaning practices is an apt exploration of how improvisation as the speculative and unforeseen materialises through every musical action.

${ }^{152}$ Spirkin (1990) considers a dialectics of the finite and infinite, discussing the ongoing diversity of existence as testifying to the infinity of being. However, he nevertheless starts the discussion with finite and infinite as opposing differences. Despite this, Spirkin's argument is elaborate and helpful in seeing
} 
theory with quantum physics, Barad (2012f) argues that, "[s]ince vibrations of the field carry energy, and only a discrete set of energy states can exist [because of the quantum physics postulate of special relativity], and a mass value can be assigned to each energy state," there must be a correspondence between energy and the mass of matter (13, emphasis added). Barad continues: "A field vibrating at a particular frequency or energy is equivalent to the existence of particles of matter with a particular mass" (14). Matter and field are thus entangled: Referring to Barad's inseparability thesis, matter (also in terms of "our" world) is of the field. Matter emerges within and through the field, and when Barad speaks of "vacuum fluctuations," we may understand this in particle (matter) wave (field) complementary terms "[as] the existence of virtual particles," considered as "quantized indeterminacies-in-action" (14, emphasis in original).

Here, Barad establishes a radical material openness towards infinity. Infinity is not understood in the Newtonian sense, which we recognise in Jankélévitch's adage to waste time (see above). Such a concept would see infinity as the quantification of an infinite series of individual moments-as an endless repetition going in both directions, past and future (Barad 2007, 437, note 82). Nor does it entail the concept we lend to the feeling of awe when beholding the endless space of the cosmos at night. For Barad (2012f), the Other of the finite, opposing endlessness to limited space and time of all that exists- that is, the specificity and temporal limit of intra-active mattering-is not set next to the virtual as infinite source. Rather, her notion of infinity entails an "ongoing material reconfiguring of nothingness" as “infinite richness" (Barad 2012f, 19-20). This infinity and the material "aliveness" of nothingness (vacuum fluctuations that cannot be determined zero) are threaded through one another and through all phenomenal being or finite existence (Barad 2012f, 20). The idea of the material "aliveness" of the void, entangled with existence, emphasises in Barad's thinking how in/determinacy and dis/continuity are at the heart of material-discursive intra-active (phenomenal) being, supporting her argument that intra-actions (as constitutive exclusion and inclusion) reconfigure the possible and thus reconfigure differing itself.

how Barad's argument attempts to traverse dualism in every respect: The void is infinity as marked carnality, entangled with all existence - that is, the finite and the infinite cannot be torn apart. 
The slashed dis / continuity and in/determinacy that articulate entangled states and their collapse into determinate states of discontinuity, continuity, indeterminacy, and determinacy are both contingent and intra-actively enacted (Barad 2007, 424, note 27). In other words, the heart of mattering is speculative and intra-active, refusing the idea that causality is preceded by regulatory systems, or by an overarching notion of space as a container and linear time. Nevertheless, in everyday life, we experience stability in terms of both continuity and discontinuity as causality in a felt sense: Pressing or not pressing the key of the piano with sound or no sound as an effect.

Barad (2010) terms intra-active (non-linear) causal relationships "ghostly entanglement[s]," which are threaded through with past and future matterings (22). Causality, as an iterative intra-active enactment, is "written into the fabric of the world" (Barad 2007, 261), becoming "an inheritance" that temporalises and spatialises non-linear intra-activity in phenomena (Schrader cited in Barad 2012d, 39). ${ }^{153}$ In other words, past and future are reconfigured intra-actively, not by taking the past as present, nor by assuming that the past can be erased, but as a "ghostly" causality "threaded through the spacetimemattering of the universe" (Barad 2010, 22, emphasis removed). Barad's notion of ghostly causality suggests that traces of past differences (the effect of intra-actions as marks on bodies) cannot be erased. Thus, "the past is not closed (it never was)" and "[t]here is no inherently determinate relationship between past and future" (Barad 2010, 22). The ghostliness of intra-active entanglements suggests how mattering diffracts spaces, times, and matter, and how mattering involves "all the traces" of "enfolded" materialisations (Barad $2010,22) \cdot{ }^{154}$

\footnotetext{
153 In chapter 3, the relation between Barad's notion of ghostly causality and Derrida's (1994) notion of ghosts and spectres of the past that haunt our lives was explored. Barad (2010) reworks the concept of haunting as hauntology in order to articulate an in/determinate ontology that is continuously destabilised by haunting intra-activity.

${ }^{154}$ Barad's suggestion of ghostly intra-activity shines a new light on musicological research and the encounter between music of the "past" and "present," or music of "here" and from "there" as an intraactive entanglement through, and within which, past and present, and here and there, become audible reconfigurations. Rather than critiquing authenticity (see Taruskin 1995), research and theorising involve the task of making (ghostly) diffraction patterns (and their musico-material-discursive practices) thinkable, visible, and audible, revealing how "then" and "there" are enfolded differences in the "here" and "now" of musical mattering.
} 
Let us consider Abbate's notion of causality, from a musical and musicological point of view, read through Barad's notion of how causal intra-activity involves the speculative of mattering and not-mattering. This reading introduces the dynamics involved in musical mattering (or not-mattering), and how we are in/separable part of such practices. What Abbate and Barad both make clear is that nothing stands on its own, articulated by the importance of the encounter: Barad (2007) does so through her notion of the intra-active encounter, affirming phenomenal being; Abbate (2016) through the (inter-active) material and discursive encounter of the shop floor and, later, through the sudden encounter with a photograph that she received but was not meant for her, yet changed her research orientation (Abbate 2017). Taking account of Abbate's question of the drastic and the gnostic, in the following, final section, I will explore a concept of music/ology as a matter-meaning encounter in the context of musicological research and theorising. Whilst, at the same time, I will suggest a concept of musicality that is helpful as a means by which to think within the non-dualist (drastic/gnostic) dynamics of musico-mattering.

\subsection{Musicality and the Drastic: Musico-material Agency}

Via its exploration of Barad's concept of agential realism and Abbate's material turn, this dissertation indirectly establishes an answer to Abbate's (2004) question “Music-Drastic or Gnostic?" It shows that music is phenomenal, meaning that, in the Baradian sense, music is an effect of, and entangled with, musico-material-discursive intra-activity, and generative of other intra-actions. From this it follows that matter and meaning involve ontoepistemological practices of knowing-in-being, and are immanently enfolded. This viewpoint shifts the ontological and epistemological divide suggested by the drastic-gnostic opposition. Furthermore, the mattering of sound involves a notion of "reinforcement" (or not), as sound waves enhance or cancel each other out. A scholarly approach to music is always specifically located (and locating): It provides for a specific engagement and not 
simply a gnostic or epistemological view from some location, mediated by "consciousness, experience, language or any other alleged medium," overseeing the musical field (Barad 2007, 409, note 9). Music/ology, as proposed as a result of this study, is an ontoepistemological concern: a specific material engagement, marking the inseparability of ontology, epistemology, and musical value, requiring the researcher or theoretician to be part of the world's (re)configuration. Based on the above statements, I now explore further the Abbatean question of how the musicologist is not able to observe music (the drastic) in a scholarly manner (the gnostic). As a specific engagement, Abbate's question is now rephrased as the Baradian problem of how "we are always looking inside a phenomenon" (Barad 2007, 345), suggesting that to "see" music from a musicological point of view necessitates another extended phenomenon. The preceding suggests the necessity for an intra-active relationality for the observation of, or thinking with, music-in-the-making. Barad's (2012f) states that there are no independent entities: “[a particle does not] stand on its own" (14). This statement includes music and all its derived components, thus affirming an extended phenomenal state of being, in which music-in-the-making is in/separably entangled with music/ological practice.

Citing the work of Niels Bohr, Barad (2007) points to how observation (in the broadest sense) always involves embodied concepts or representations that are inseparable from their specific material arrangements. As Abbate (2004) shows, music, when performed, awakens in musicology a concern (or observational interest) in the drastic as an embodied concept that tunes in to the temporal dynamics of the ongoing material-discursive differentiation of musical bodies. In terms of my argumentation, we may consider Abbate's notion of the drastic as an embodied concept, suggesting a specific material arrangement. This opens up an intra-active musicological relating to the material and dynamic aspects of music. However, as discussed earlier, the Abbatean notion of the drastic is centred around a humanist and phenomenological two-world logic. In order to traverse the dualism that underpins Abbate's argument and forces its heading for a stalemate position, and to achieve a diffractive reading of Abbate's and Barad's insights, I take a leap into a diffractive reading, embracing material-discursive intra-active inventiveness. I shall now consider how both 
Abbate's notion of the drastic and Barad's concept of agency draw on material-discursive doing, and how this structures their respective arguments.

For Barad (2007), agency entails the dynamic process through which causal intraactivity emerges, stabilising (and destabilising) the generativity of worlding. Reading Abbate's and Barad's arguments through one another, both involve relatings, which Abbate conceptualises as musical affect and emotion, whilst Barad elaborates agency as the ongoing dynamics of the world's intra-active relationality. She specifically conceptualises agency as emergent differential responsiveness, in which "different material intra-actions produce different materializations of the world" (Barad 2007, 380). This suggests that both Abbate and Barad consider intra-active doings, such as musical affect and agency, as the origination of mattering respectively.

In order to formulate a concept for music/ology that allows one to think with, or to look inside, the temporal and dynamic musico-material phenomenon, I will explore a notion of musicality as material agency. I consider this material agency as included in the intraactive dynamism of responsiveness, enacting a temporal causality and delineating (the musical) object and (the performing) subject. This notion traverses the idea of musicality as an added talent or personal quality—something learnt or gifted, which someone owns. The notion also traverses the idea of music as a single particular structure and expression. Instead, music is considered an effect or, in Barad's terms, a diffraction pattern, involving "doings" understood as the musicality of the world. Finally, by reading Abbate and Barad together, I traverse the drastic-gnostic dualism. Hence, the problem of music/ology's relationality becomes the problem of the musico-material-discursive encounter within the dynamics of worlding, affirming knowing and valuing in being. My hope is that the exploration of the concept of musicality emphasises in Abbate's notion of the drastic its inherent touch of the musico-material encounter-like in Abbate's $(2004,511,533)$ tests of playing and listening to music. Likewise, I aim to emphasise in Barad's understanding of theorising — a form of experimenting that "is about being in touch" (Barad 2012e, 207)—a valuing as musical concern. Before embarking on a reconceptualising of the concept of 
musicality, let me first explicate how Barad's inclusive concept of agency is of interest for this undertaking.

\subsubsection{Musical Agency: An Enacted Doing of Intra-active Responsivity}

The concept of agency is of considerable importance to Barad's metaphysics of an agential real. It is the nodal point of intra-active dynamics and a difficult concept to grasp. She states: "Agency is 'doing' or 'being' in its intra-activity" (Barad 2007, 178, emphasis removed). The scare quotes indicate this must be an impossible contestation: We do not start from a given or from a general concept of doing or being. Rather, the "how" of doing and the "what" of being are intra-actively determined. What we can glean from Barad's work is that agency, the superposition of in/determinacy (entailing undetermined coexisting possibilities and impossibilities for change), and causal relationships are intra-actively determined in one move, therefore (re)configuring doing and being. Thus, we can say that agency, entangled being, and causal in/separability intra-actively constitute the dynamism of the world's ongoing (re)configuration. We must therefore think of agential "worlding" in terms of differential differing, and not as change in terms of a change agent-a who (or what) that manages change. Nor must we think of it in terms of changing variables or properties against some stability from which change may be derived. Also, we must not conceptualise agential dynamism as an empty process in which processual movement implicates agency. Rather, agential dynamics entail material-discursive "doings" that are performative, suggesting that any mattering matters: New possibilities and impossibilities emerge, (re)configuring the ongoing mattering of the world (Barad 2007, 141). As Barad (2007) argues, "matter is substance in its intra-active becoming — not a thing but a doing, a congealing of agency" $(151,336$, emphasis removed). That is to say, the "congealing of agency" must not be considered in dualist terms as a fixed body, bursting from energy that blasts its influence into a distinct environment. Rather, agency is an enacted dynamism, negotiated specifically within and through intra-active matter-meaning in/separability, inherent in every phenomenal encounter. Speaking of agential realism as the real of which, for instance, "we" 
are in/separable differentiations, we might speak of a dynamic of phenomenal occurrences, involving entangled matter-meaning patterns within and through which agency, causality, and thus the material-discursive effect, are produced. In Barad's (2007) terms, the world is the dynamic "intra-play of indeterminacy and determinacy [that] reconfigures the possibilities and impossibilities" (225) of intra-activities that determine a musical world. Rather than a com-position of things, agency as enacted causal intra-activity coexists with “indeterminacies, contingencies, and ambiguities" (Barad 2007, 225). Thus, for Barad, agency is dynamism intra-actively enacted: It is a reworking of the common inter-active dynamism in which agency is the outgoing active force "possessed" by a thing, animal, or human.

In Barad's (2007) terms, the space of agential dynamism is widened considerably compared to the managerial power of any change agent, which suggests agency to be an outgoing (cultural) power as the impact or influence possessed by a human or nonhuman. Agency is differing through inexhaustible intra-active dynamism and not something that can be possessed by a thing, animal, or human. This begs the question of how agency as a practice of differing becomes precise as intra-active doing. One answer would be that agency becomes precise in the "how" of specific practices as temporal (matter-meaning) manifestations involved in, for instance, singing — as manifestations that must be considered entangled with the intra-actions that caused them to happen. Another engagement with this question, closing in on agential doing, is articulated through Barad's (2015) notion of how matter is inventive "in its agential wanderings" (387). Barad suggests how inventiveness builds on agency as the material nature of imagination, considered as "the material explorations of the mutual indeterminacies of being and time" (Barad 2015, 388). This can be explicated in terms of a "thick" present that embodies many possible "continuations" of music-in-the-making at each intra-active instant, demanding that matter's imagination is attuned to "the condensations of past and future condensed into each moment" (Barad 2015, 388). ${ }^{155}$

\footnotetext{
155 Barad (2015) uses the word "thick" in "the thick now of the present" (388), in which the present entails a condensation of "other beings, places and times" (417, note 2$)$.
} 
Barad (2012c) brings to the fore how material "aliveness" and agency entail each other as an emergent responsiveness in a way that not only the human consciousness feels, yearns for, and remembers, but "matter [also] feels, converses, suffers, desires, yearns and remembers;" in short, reaching towards the un/expected "Other" (59). With her notion of the inhuman, Barad (2012e) articulates how facing the agential working of matter means facing our entangled ontology, marking an indeterminate non/existence that is indifferent to our human concerns. It means facing finitude because, despite "all our concerns with nonhumans as well as humans, there is, nonetheless, always something that drops out" (Barad 2012e, 216). According to Barad (2012e), precisely in accepting the inhuman as producing the liminality inherent in non/mattering might make us aware of "an ethics committed to the rupture of indifference" (216). Counterintuitively, the inhuman, the "indeterminacy at the heart of being calls out to us to respond" (Barad 2012e, 219). With regard to Barad's ethics, this suggests that our "humane" compassion is a doing that is attentive to, and caring for, relatings or intra-active matterings to come. In terms of this dissertation, facing the liminality of musical mattering and not-mattering suggests how a musical compassion concerns a musico-material relating as a call for inventiveness and imagination, involving care and attentiveness to music-to-come. Let me give an example of how the inhuman nature of agential intra-activity calls a musician to respond as part of a musico-material event.

Via my experience as a professional singer-forming in fact the impetus for this dissertation-I can demonstrate intra-active agency and related causality by tuning in to how a singer's engagement involves a "(com-)passionate" responsiveness to the un/ expected, involving relatings as inventiveness and imagination. The act of singing in a concert situation concerns intra-active enactments that traverse the notion of a singer's interactive control over that which has been rehearsed (the present as condensed past/future). Thus, repeating the piece as studied (with optimal musical-bodily coordination), doing what the score says, doing what the composer suggests, the conductor asks, the stage director demands, the producer tells, the public likes, the manager wants, and so forth, is traversed by musico-material intra-activity as agential enactments, involving responsivity and 
inventiveness in the material-discursive encounter. This suggests that the complexity of preparation-the condensation of past and imagined future does not unfold in performance, but that past and future become intra-actively reconfigured as an emergent re-member-ing and a yearning of all bodies, including the re-member-ing and yearning of acoustics, performers' bodies, instruments, and so forth. In other words, performance concerns an intra-active material-discursive dynamism that entails an emergent agency that becomes precise through responsivity, intra-actively negotiating past/future condensations with a new un/expected - the superposition of in/determinacy becomes determined, configuring musico-materiality—-temporal determination of all that is involved in this music-in-themaking. As a personal account (which, I dare say, would be confirmed by other performers), during the musico-material turbulence of a concert, un/exceptional events go by unnoticed, but there are moments of strange intra-active clarity: certainty or uncertainty about the justness of breath, bodily coordination producing a tone, a timing, or an anticipation of the accompaniment. Such moments might be thought of as demonstrating how performing occurs within and through the dynamism of ongoing, enfolded, and dis/continuous intraactions, producing agential cuts that enact a causal structure that temporally delineates subject and musical object. The example also demonstrates how agential intra-activity concerns the intra-active in/separability of matter-meaning constitution. Agencies of observation and the object of observation are agentially cut together-apart; they are a knowing and valuing in being through and within which "things" come to matter, materially and meaningfully. Furthermore, differentiated intra-active (sedimented) levels of musicomaterial-discursive enfoldment, such as timing, harmony, melody, breathing, bodily coordination, memory, the relation with other performers, and the audience, seem to intersect in a "chaotic" manner in which continuity and discontinuity act as agential factors that are determined intra-actively.

Agency, for Barad (2007), thus involves the dynamism of ongoing mattering, considered to be "a vitality to intra-activity, a liveliness, not in the sense of a new form of vitalism, but rather in terms of a new sense of aliveness," and an "agency [that] never ends" (235). A crucial point that follows from Barad's notion of agency as an intra-active material 
"aliveness" is that it is "not something possessed [or driven] by humans, or non-humans for that matter" (Barad 2012c, 55, emphasis added). In this formulation, there is no exterior force that has agency-unlike Abbate, who implicitly considers music to be an exterior force that affects bodies-nor is agency equivalent to human intentionality as a force emanating from a body. In short, agency is intra-active dynamism in one, ongoing motion. It is in these terms that I consider how a music/ological approach to the entangled, musico-material dynamics of music-in-the-making might need a concept that relates to, and embodies, such intra-active dynamism; a concept that embodies the agency of relational (intra-active) doing, through which cause-and-effect relations emerge that are generative of musico-material mattering. Let us therefore turn now to how an embodied concept of musicality might allow for a music/ological approach to the dynamics of musico-material mattering.

4.4. Musicality: The Ethics at the Heart of Musico-mattering

Following Abbate's plea, let us consider music as a problem of the musico-material encounter-an emergent musicality as both agential responsiveness and material inventiveness. Immediately I must add that this is an exploration generated via a diffractive reading of Abbate and Barad. Therefore, this dissertation does not allow me to fully work out a new theory of musicality. It does, however, allow me to conceptualise musico-material spacetimemattering, complicating the assumption that music-related entities pre-exist their relations. This traverses Abbate's (2004) notion of absence or lack, and the gap between musical entities and musicological analysis—a gap Abbate critiques as a "clandestine mysticism," pointing towards the hermeneutic attempt to fill in, or refer to, the liveliness of such an assumed musical in-between (513).

Keeping this in mind, I think it helpful to point out how musicality as both music's and music/ology's problem—as questioning from within "doing" and "being" distinguishes itself from the "refrain" as music's problem, as famously expressed by Deleuze 
and Guattari ([1980] 2004, 332). Deleuze and Guattari find in the musical refrain an inspiration for their elaboration of the ebb and flow of stabilisation and destabilisation inherent in their concept of territory, in which the refrain is denoted as involving a "'holding together' of heterogeneous elements" (357). The scare quotes here refer to the jeopardy of jumping "from chaos to the beginnings of order in chaos" (343). Deleuze and Guattari's notion of the (musical) refrain seems, in Barad's (2010) terms, to suggest a diffraction pattern that "[holds] together the disparate without reducing difference to sameness" (265). Reading Deleuze and Guattari together with Barad, and with my own exploration of a concept of musicality that embodies the intra-active encounter, I take account of how all are interested in the stabilising and destabilising character of the world's ongoing patterning. Further, I want to argue how "holding together" in terms of a refrain on the one hand, and in terms of a diffraction pattern on the other, differ only marginally in their orientation. Whilst Deleuze and Guattari ([1980] 2004) emphasise construction as a creative activity through their concept of the refrain, Barad (2007), through her concept of diffraction, puts greater emphasis on the entangled nature of the intra-active encounter that "[cuts] things together and apart" (381). In Deleuze and Guattari ([1980] 2004), we see their interpretation of the refrain demonstrated in the way in which they use many examples from (Western classical) compositional practices. Hence, it is tempting to consider their elaboration of the refrain as encompassing any rhythmic motif that helps structuring music, explicated as a composer's problem of creating the "refrain" with the territorialising effect of holding the music together (Bogue 2003, 3). However, as Deleuze and Guattari ([1980] 2004) argue, nothing would prevent them from considering the "sonority" of the refrain more then "a privilege to sound" within the sphere of musical composition (356)—i.e., in the broader sense of a metaphysics that affirms becoming in general. ${ }^{156}$ Rather, Deleuze and Guattari pursue the refrain's sonority in a

\footnotetext{
${ }^{156}$ I refer here to Michael Gallope's (2010) analysis of Deleuze and Guattari's move from the broader to the narrower view when considering the refrain's sonority in musical terms and not as "metaphysical orientation to all life" (89, emphasis in original). According to Gallope, it is the close ("narrower") reading of musical composition that allows Deleuze and Guattari an analysis "of how specific music can orient us toward such an affirmation" (89, emphasis in original). In Baradian terms, with the notion of specific music, an ethicality of mattering is introduced: The refrain and its sonority do not demonstrate mattering in general, but the specificity of (all) mattering, thus questioning the "what," the "how," and the "why" of mattering and not-mattering.
} 
"narrow" sense, demonstrating through a close listening how the sonority (the holding together) of the refrain goes together with sound's inherent material-discursive indeterminacy (using Barad's [2007] terms), making sound into a "cutting edge of deterritorialization" (Deleuze and Guattari [1980] 2004, 383). As such, for Deleuze and Guattari ([1980] 2004), the refrain as a pattern of "holding together" includes human and non-human life, but is permeated with sound's "force of deterritorialization [also effecting] the most massive ... reterritorializations" (383). Read together with Barad's notion of the encounter on the edge of non/mattering, we might see in Deleuze and Guattari's ([1980] 2004) refrain an "assemblage [that] is sonorous," yet one that is threaded through with the danger of "mistake[s] in speed, rhythm, or harmony . . . bringing back the forces of chaos" (343). Barad (2010), not considering sound's "valence" per se, would describe this process as how refrains as "[d]ifferences are [inherently agential,] always shifting within" (268, note 9).

In the terms of Deleuze and Guattari ([1980] 2004), my Baradian/ Abbatean reworking of the concept of musicality positions emergent agency as a musico-material responsiveness located on (and also locating) the edge of non/mattering. This concept brings together the notions of "holding together" - through non-linear causal intra-activity, literally threaded through with the heterogeneous musico-material effect (the diffraction pattern)-and the dynamic occurrence of musical differing (in-the-making), involving the excitement and nervousness of "[mis / take] in speed, rhythm, or harmony" (Deleuze and Guattari [1980] 2004, 343). That is, I propose a notion of musicality that emphasises the intra-active encounter as an inventiveness through responsiveness, which is productive of difference. It suggests an encounter through and within which something either comes to matter or not, suggesting that musical value is not ordained by reputed powerful subjects at a distance, but is at the heart of (all) musico-material-discursive mattering.

In other words, I propose a concept of musicality attuned to the "edgy flickering" that infuses any musico-material-discursive practice with the speculative of all musico-mattering. As such, musicality does not involve a standard for the judgement of musical taste, nor does it implicate any musical morality, denoting an obligatory practice of striving for "good" and/or "just" music. Such a standard would bring back the Abbatean gnostic as reasoning 
from a distance, whilst morality would bring back culture as a regulative practice with a prominent place for human intentionality. Both positions deny musicality as a concept of entangled musico-material practice, operating on the edge of non/mattering. In a similar nondualist manner, the reworked concept of musicality does not refer to a property added to a tone, an instrument, a dancer, a performer, or a listener. Instead, it takes account of the crucial and dynamic factors at work in the intra-active mattering and non-mattering of music, thus bringing value into the heart of musico-material doing. In one move, it traverses all common notions of musicality as the property of learnt skills and a general human ability or capacity to act musically. Thus, value is not a musical standard to which one can relate, expressed as inherited skills or categories to think with. Rather, value at the heart of mattering is an ongoing valuing as a touching with/in the musico-material dynamics involved.

Musicality is a known concept referring to a set of human talents, skills, and behaviours. As a basic human need or inherent motivation, musicality also refers to a specific quality of a thing, instrument, tone, or movement, or to the musicality of speech. Although the noun "musicality" and the adjective "musical" are ambiguous terms, leaning heavily on some notion of what music is, I would suggest that musicality concerns inherent properties (e.g., the gifted musician), or (learnt) properties that are added to humans and things, both of which are related to, and pre-exist, a general concept of music. This suggests at least a questionable relationship between music and musicality, in which the two phenomena seem to pre-exist each other. ${ }^{157}$ The crux of my argument is that musicality in this sense upholds a duality between qualities that are considered either as natural or as added properties—qualities that are related to the senses, and that are sensitive to music.

\footnotetext{
${ }^{157}$ This confusion demonstrates the problem of a transcendent ontological a priori, which considers processes of becoming to start from a foundational entity: Is music as position and standard a first, or is musical activity the foundational act on which music depends? Considering this dissertation's new (feminist) materialist perspective, the philosopher Brian Massumi's (2002) notion of "ontological priority" is helpful here. His concept emphasises an engagement with the ontogenetic nature of emergent being (traversing the common-sense idea of original entities), which does not involve an "assertion of a time sequence" in which action would have priority over being, or vice versa (8). In this regard, we may consider the relevance of Barad's (2007) term "spacetimemattering." This concept articulates the ontogenetic nature of the world's reconfigurings in one move (of which "we" as emergent effect of differing are an inseparable part).
} 
Moreover, the notion of musicality upholds a more general, yet reified concept of music that serves to understand and interpret musicality as meaningful and appropriate. Again, this implies a relationship that echoes Abbate's drastic-gnostic dualism, and ignores Barad's notion of the inseparability of matter and meaning.

Yet, and without critiquing the scholars and scientists mentioned above, this dualist concept pervades arguments on the subject of musicality (albeit often unnoticed), most commonly referring to the specific qualities that are "owned" by humans, animals, or things, in relation to performing, dancing, and listening, and underpinned by an overarching general notion of a pre-existent music (e.g., de Mink 2013; Théberge 1997, 172). ${ }^{158}$ With critical verve, the musicologist Philip Brett (2006) considers musicality a label and "tool for social control dressed up ... as talent" which, in relation to an ideology, constructs "a concept of 'art' as an elite and segregated human activity" (22). Brett's concern points to Butler and Foucault's shared problems of representationalism and power as structure, asking how a concept of art, distributed as a power structure in a musical world, "[produces] the subjects [it] subsequently [comes] to represent" (Butler cited in Barad 2003, 804). In Brett's argument, the common concept of musicality points towards a talent or added property from which to identify and qualify humans and things, set against a reified notion of a concept of art. Although it is indeed taken up in the generative dynamics of power formation and representationalism, Brett ultimately leaves the concept's definition untouched.

We also find musicality as an object of research in itself in the work of Henkjan Honing, Carel ten Cate, Isabelle Peretz, and Sandra E. Trehub (2015). They define musicality

\footnotetext{
158 Théberge (1997), although not denying the notion of skill, argues how the concept of musicalityreferring to musical skills such as playing an instrument or composing music-underlines a pervasive bias in Western classical music. Negated is how, for instance, African-American music (and its derivatives) never made a complete break with dance. In dance, "the body both responds to the shaping influence of rhythmic sound and makes use of it" whilst shaping an expressive action. This action is related to the music performed, yet also different from it (172). Therefore, according to Théberge, it makes sense to consider musical skills as a more "general ability to listen in a creative and structured manner" (172, emphasis in original). De Mink's (2013) research on musical prodigies considers musicality in terms of how it is commonly spoken about as possessing a special talent, demonstrated by the comments that inform De Mink's argument. These comments consist of audience responses to (internet) videos of prodigy performances, uploaded between 2007 and 2012 (52). In line with the respondents' concept of musicality, according to De Mink, musicality is giftedness, also defined as the skill and ability that one has (10).
} 
and its relationship to music as a "natural, spontaneously developing trait based on and sustained by biology and cognition" (1). Music, according to them, "can be defined as a social and cultural construct based on that very musicality" (1). Their argument considers musicality a "phenotype;" a specific "innate" aptitude of humans and animals acquired through relating to an environment (3). These musicologists, with a general interest in the evolution of music, are seeking to identify the biological and cognitive components of which musicality is presumed to consist (3). This approach guides their intellectual intervention, privileging questions on the biological and cognitive constitution of musicality. Musicality here tends to be considered an a priori biological capacity to "act musical" in terms of cognition-that is, knowing, perceiving, and appreciating music. Thus, their research follows an approach that separates matters of ontology and epistemology, leaving musical value as an uncontested cultural and social construct-a rather bleak and passive background. It is clear that this research acknowledges a fundamental relationship between music and musicality, however, it is grounded in binarity. Musicality is appreciated as an innate complexity of humans and animals, emphasising the dualism as pre-existing research and analysis, and denying complexity to a musico-musicality relationship that is already social, cultural, material, alive, and sensible. In short, the previous examples, each in their own way, consider musicality as the ability to engage with music, upholding two domains in which music is a (reified) standard and an environment to turn to, or connect with, in a (preexisting) musical manner.

Following Barad (2012d), cuts that separate the human from the animal, the immaterial from the material, or culture from nature, are made as a matter of human practices of differentiation-that is to say, "as cultural distinctions" (31). The problem is that, by starting research and analysis after cuts or distinctions are already in place, one is not able to account for the materialising effects produced by these cuts. What fact/values are included and what facts/values are excluded from consideration have crucial materialising effects. Consider, as Abbate has told us in all registers, how music involves a musicomaterial occurrence, situated in-the-making (that is, in musicality). This means that music and musicality—musical "doing" and "being"—cannot be torn apart. With Barad (2012d) we 
might argue, "if differentiating doesn't happen in space and time but in the making of spacetimemattering" (32), it suggests that the materialising, entangled, and dynamic nature of music and musicality must be accounted for.

I thus explore an embodied concept of musicality that is attuned to the dynamism of music-in-the-making and traverses the inherent duality of the common concept, which refers to property, identity, or an ability possessed, and is related to a general concept of music. Read through one another, Abbate's (2004) concept of the drastic and Barad's concept of agency suggest that musicality should involve a relational dynamic; a "'doing' and 'being' in its intra-activity" (Barad 2007, 178). Musicality then becomes an enactment that intra-actively emerges (not authored by human or nonhuman intentions), threaded through musicomaterial-discursive practices, through which all actions (material and discursive) become determined. This reworked concept of musicality and the concept of music are mutually constituted in dynamic intra-action, suggesting that music is an entangled doing; "a stabilizing and destabilizing process of iterative intra-activity" (Barad 2003, 822). In this sense, music is "a congealing of agency" (Barad 2003, 822). In other words, music might be conceived as a temporal and dynamic thickening of musicality, considered a "doing" or a "being" in its intra-activity. This notion of musicality emphasises the intra-active encounter through which musico-material differences come to matter (in both senses) or not.

Considering music-as-performed a problem of musicality is a "statement of ontological priority," and an attempt to relate thinking and imagining with the dynamic, agential, and heterogeneous nature of musical being in a scholarly manner (Massumi 2002, 8). Whether it concerns the matter-meaning practices in which the strings of an Aeolian harp intra-actively engage with, and are responsive to, differences in air pressure (wind), a blackbird's singing as effect of responsiveness to the Other (bird), or the specific musicomaterial entanglements suggested by a human singing a song, a lullaby, an aria, a track, and so on, in all cases, the sounds produced involve musicality as an agential, enacted musicomaterial responsiveness or intra-activity. In this sense, music concerns the differential constitution of heterogeneous elements (diffraction pattern) or the temporal thickening of musicality. 


\subsubsection{Musicality: Responsivity, the Speculative, and Material Aliveness}

The foregoing explored a reworking of the common concepts of musicality and music in terms of a music/ological concern. These concepts clearly build on Barad's notion of agential "aliveness" as emergent intra-active responsivity, affirming an ontology of radical immanence and (Baradian) phenomenal mattering. At the same time, music/ology takes up Abbate's plea for a serious account of musical performance, not as a bounded and closed event, but as the intra-activity of "multispecies" touched by the dynamism of musicality and threaded through the world's mattering. The notion of multispecies provides an apt means via which to conceptualise specific agential "doing" and "being" as musicality.

Multispecies is a term used by Donna Haraway (2016), pointing towards companion players as "the mortal critters entwined in myriad unfinished configurations of places, times, matters, [and] meanings" (2). This is Haraway's way of "staying with the trouble," as a stirring up of the muddy waters of materialisation (Haraway 2016, 2). ${ }^{159}$ Haraway's argument concurs with Barad's (2012c) affirmation of how life is lived as how matter matters across the in/ separability of intra-active differences (10). Both their arguments are attuned to think, whilst not capturing in thought, the heterogeneous constitution of mattering, involving a dynamic of inherent differences that might explore different materialisations, driven by feeling, conversing, suffering, desiring, yearning, and remembering (Barad 2012c, 48).

My interest in Haraway's argument is how she articulates, in an Abbatean (drastic) way, the enmeshment of multiple intra-actions, not neatly lined up (as musicians on stage, suggesting a performance to take place in time and in space), nor as neatly fulfilled musicomaterial matterings (as the execution of planned actions), but as a touching and testing, involving the speculative of unforeseen music- and music/ology-in-the-making. Although the critters of music-making are not exactly Harawayan "mortal critters" of living and dying (Haraway 2016, 1-2), nevertheless, musico-material critters are involved in the "aliveness"

\footnotetext{
${ }^{159}$ Haraway (2016) makes clear that the word "trouble" does not mean difficulty or problem, but goes back to the (old) French verb trubler, meaning "to make cloudy, to disturb" (2). The meaning of the Dutch adjective "troebel" can also be traced back to this French verb and its meaning (Etymologisch Woordenboek van het Nederlands, www.etymologie.nl, last accessed September 10, 2019).
} 
and dying away of sounding matter. Here we may consider the intra-active liveliness of acoustics and instruments, involving Harawayan critters implicated in bones, conch shells, strings, drumheads, and so forth, as bodies that affect and are affected. However, teaching at a school for music and technology, it is clear that algorithms for composition, editing, recording, and production constitute a new material-discursive "line-up" for musical and sonic mattering. This suggests not only the exploration of new notions of responsiveness and inventiveness, but also to be attentive to what is included and excluded from mattering. By bringing value to the heart of mattering - now recognising the digital as a new "species"musicality is at once musical and ethical as an enfolded material-discursive practice.

With Barad and Abbate, we are thus able to take a music/ological leap into music-inthe-making through the invention of an extended phenomenon for scholarly observation. In this context, the reworked concept of musicality serves as a means by which to grasp how music's (re)configuration is of matter's agential "doing" and "being." We might unravel this intra-active enfolded musico-material dynamism as a tripartite movement in one move: The ongoing intra-active dynamism of musicality as an agential responsiveness implicated in the world's material "aliveness" involves matter-meaning engagements of causal intra-activity and materialisations as produced effects or musical differences. In other words, we might distinguish a radical aliveness within which in/ determinacy becomes determined through and within intra-actions, causing a specific materialisation and a specific intelligibility. In a wider sense, musicality is implicated in the vibrations of the world's intra-active dynamism. As such, it involves an ongoing material touch causing a disturbance (for example in air or water), producing rhythms and melodies through tapping, rubbing, striking, and so forthyou only have to listen or join in. Clearly, it is through and within enfolded musico-material intra-activity, the enfolded agential cuts, the "we" and the " $\mathrm{I}$ " of listeners and performers, that the responsiveness through listening together with acoustic vibrations becomes specifically defined as specific properties and boundaries; as felt musicality in a real sense, generative of new intra-actions.

Any music/ological observation of musico-mattering thus necessitates another phenomenon, following the pleas of Barad and Abbate, with the implication that it matters 
how we conceptualise such an extended phenomenon, not least as "different cuts enact different materializations" (Barad 2007, 361). Therefore, to consider musicality, skill, or talent as an added or gifted quality of human intentionality immobilises and "culturalises" the musico-material dynamics of music-in-the-making. Exploring musicality instead as a material responsiveness that emerges within and through musico-material intra-activity allows one to think that something is at stake-it matters which differences are produced for whom, how, and why. In my view, musicality as musico-material responsiveness affirms the necessity to think (contemporary) music-in-the-making beyond ethics and musical aesthetics as both an ideal and as normative, commonly implicated in music and musicality. Thus, when starting from a non-dualist concept of in-the-making, we are urged to include global, local, glocal, and techno-scientific musico-material manifestations.

For me, engaging with a musico-material and performative account of music-in-themaking means to seriously affirm the complexity involved in how performers (or any researcher or musicologist in relation to theory and research methods)—even when playing from a Western classical score, when trained in a specific musical tradition, or when following a conductor-do not exactly follow a model, according to which their training and musical capabilities would make them fit for the task. This is interesting because (I take for my convenience this example of performers), when considering their training, cultural background, or their physical capabilities, one could state that performers variously do, or deviate from, what they are "supposed" to do. However, whilst playing, performers do things that they never did before during their training, rehearsals, or concerts, suggesting that the musico-material dynamics of musicality must evoke "doings" that are situated, material, meaningful and speculative, and unforeseen. In short, it is through and within the dynamism of intra-activity that musicality is evoked in one move, in response to (and a reaching out for) the un/ expected "Other." This brings into play a musico-material testing and touching, producing tones-in-the-making.

Considering musicality as inseparable from the ongoing dynamics of worlding introduces the notion of how "the unknown, the insensible, new realms of in/determinacy" have materialising (musical) effects (Barad 2012e, 214). The intra-active dynamism of 
musicality does not stop when the music is over, or when a performer/listener sleeps and the music-machine is unplugged. For Barad (2012e), the "inhuman" entails "the indeterminate non/being non/ becoming of mattering and not-mattering"' (216, emphasis added). Barad's notion of the inhuman is thus indifferent to (musical) anthropocentrism and takes issue with the way in which intra-activity concerns a "thickness" by touching on the "liminality of no/thingness" (216). To recap, Barad's use of slashes refers to the superposition of related concepts and conceptualises how states cannot be divided into a dialectical "either this or that," but rather coexist and are reconfigured through and within intra-action. Barad elaborates the radical nature of her thesis, namely, that we are part of the world that we try to understand. Now, in terms of the case at hand, "we" are mattermeaning and, as part of materialisation and non-materialisation, we are involved in superpositions of matter-meaning indeterminacies, employing a crucial responsiveness towards music/non-music, and towards what comes to matter musically and what does not. The dynamism of intra-active musicality evokes a lure of responsivity (“...oops! ...no! ...yes! ...") and reaches out with expectation ("...yes!... there's my timing!”). As mentioned earlier, Abbate's (2004) account of what she was able to think when taking the leap into the intraactive dynamism of musicality as material responsiveness, can be articulated as "doing this really fast is fun...here comes a big jump" (511, emphasis in original). What these moments tell us is that musico-material intra-actions involve musicality as an agential responsivity-as a coping with the speculative of intra-active generativity. Musico-material identities that are temporally stabilised are bound up with responsibility and speculation, in the sense that it matters how one reaches out for the Other's un/ expected response, and how one enables the Other to respond or not. Barad's notion of the inhuman helps us to think musico-mattering beyond the human and the musical Other-that is, beyond the predefined standards against which measurements and observations are evaluated.

Musicality as facing the inhuman—touching on "the liminality of no/thingness" demonstrates Barad's (2012e, 216) radical ontological immanence. In terms of musicomaterial mattering, it articulates the need to take a leap into the dynamism of musicality, suggesting non-coincidence with myself, with music, with my instrument, with my singing; 
in short, non-coincidence with being and doing itself. We might say, recalling Abbate's plea to consider music-as-performed, that being with the dynamics of musicality-i.e., facing the inhuman—entails being/life-as-performed. The leap into the dynamism of musicality now involves facing "the indeterminate non/being non/becoming of mattering and notmattering" (Barad 2012e, 216, emphasis removed). To account for the material dynamism of the inhuman, rather than widening the scope of musicology (our material-discursive and bounded practices) to be more inclusive, I opt instead for a notion of musico-material touching that is "committed to the rupture of indifference" (Barad 2012e, 216). In our terms, indifference has many articulations: as lacking compassion, not caring, not of my concern, overlooking. As such, indifference is ultimately based on negating ontological immanence, suggesting the impossibility of touch, or the inability to account for that which comes to matter or not. This suggests that to explore intra-active musicality does not involve exploring the encounter as a collision between components or opponents, but entails seeking how a musical and musicological commitment to the rupture of indifference involves a responsive engagement at the heart of mattering — an engagement attuned to the un/expected and (inhuman) insensible, both threaded and lived through us (Barad 2012e, 219). In other words, my exploration of a concept of musicality seeks a non-anthropocentric and performative notion of musico-material intra-activity through and within which music and music/ology come to matter. Rather than fighting the collision between the drastic and the gnostic, I wish to start by trying with scholarly inventiveness and imagination to "sing" the present as a congealing of musicality, unravelling how musico-material practices come to matter and are generative of new matterings.

Concluding this chapter, discussing the strong opposition between the drastic and the gnostic in Abbate (2004), repeated in modified form in her later articles of 2016 and 2017, emphasis is given to her entrenched dualist framework of thought. However, the aim is not to overcome Abbate's analysis, but to take issue with how a dualist approach creates a negative (a danger to the field and something unruly) that is kept passive; be it musical matter as the unsayable musical given, or as a musician's labour. With Barad, Abbate's material turn, which focuses on pre-existing components, is traversed, radically shifting her 
analysis of predefined things and thoughts towards a diffractive analysis that starts from an intra-active generativity of (Baradian) phenomenal being.

Intra-active generativity implicates non-linear causality as an emergent feature, suggesting in a single move, the enfoldment of past and future in a present, without needing a trajectory of becoming (if $\mathrm{x}$ then $\mathrm{y}$, and $\mathrm{x}$ becomes $\mathrm{y}$ ), taking place in space and in time. For musicologists to unravel intra-active causality and to imagine musico-matterings involved, I argue for a reworked concept of musicality that springs from the nature of musicomateriality, building on Barad's notion of agency and Abbate's notion of the drastic. I argue not for musicality as the capacity to act musical or as a label for a talented musician, but for musicality as a dynamism of musico-material-discursive intra-activity through and within which music, and all those involved, come to matter. Musicality then becomes an enactment from within heterogeneous musico-material; a "doing" that is responsive and enables responsivity towards the material exploration of the indeterminacies of enfolded musicomaterial. This understanding of musicality traverses notions that build on musicality as a driving human intention. In a diffractive way, this reworked concept implicates Abbate's and Barad's insights, and my own experience as a singer. Although musico-matter entails an enfolded material-discursive practice, nothing (neither ethics, nor aesthetics) pre-exists musicality as intra-active dynamism. Music is a temporal and specific "thickening;" a diffraction pattern, inseparable from musicality as emergent and material responsivity. 


\section{Conclusion}

In agential realist terms, a conclusion, summing up a given argument, is an intra-actively generated difference that is itself generative of new differences. This means that, although an incarnate and finite mark, a conclusion is never a settled matter. Its nature is unsettled, not in a representationalist sense-in which the argument becomes an object of reflection, to be overturned by critique, or by the better, stronger (or louder) voice-but rather, unsettled because the argument is structured by the indeterminacy of in / finite possibilities that are nevertheless constitutive of a specific finitude, to be caught up in new intra-activity: the argument's conclusion as temporal punctum.

Starting my conclusion in this way demonstrates Barad's metaphysics of an agential real as a different metaphysics. It is a working metaphysics that does not so much measure a truth about reality, in which the act of measuring/observation/interpretation moves from a human to (a musical) reality, but rather concerns material-discursive intra-activity in which research and theorising are not exclusively human activities. Musical matters (bodies, sound waves, instruments for sound production, acoustic environments) are also engaged in the relationality of intra-active mattering and not-mattering (in its double meaning).

Music/ology and music as enfolded material-discursive practices produce researcher/performer, music/ological, musical truth and musical reality, as a temporal matter-meaning inseparability, implicating an agential cut-a threshold of that which is included and excluded from mattering. Barad marks this as an ethico-onto-epistemology: a framework of thought that "orders" a methodology, enabling the study of a dynamic (musical) world whilst also being part of it as an observational agency (researcher/listener/performer).

Diffraction is the method and methodology proposed by Barad, which engages with the heterogeneous and intra-active nature of mattering in which difference-like this conclusion as a diffraction pattern-is the temporally defined effect of differing. It is 
inseparably related to the involved material-discursive practice of research and theorising, or the diffraction apparatus. In the same manner as Barad's metaphysics orders a methodology, a serious exploration of her work summons a diffractive, non-binary approach. This means, for example, not reading Barad's work as against Abbate's, which would simply propagate the binary and the same difficulty of predefined differences. Barad's conceptualisation of an agential real and a diffractive method does not provide any immunity against Abbate's argument. It does not suggest that representing musical engagement as drastic or gnostic is wrong. Rather, it suggests that representations are constructed, and an inseparable part of a musical and musicological world, involving constitutive inclusions and exclusions. This implicates a politics of valuing and with it our responsibility and accountability for musical and music/ological practices. Again, it is in this sense that we might say that Barad's metaphysics of an agential real "orders" a methodology that enables the study of a musical world as a generative relationality of which the researcher/listener/performer is an inseparable part. This means that reading Abbate and Barad diffractively already suggests a traversing of musicological scholarship as the transcendental illusion questioned by Abbate. That is, a diffractive reading challenges the deceptive assumption that the gnostic and the drastic are fundamentally different in nature, in which the human gnostic would offer an overview of the drastic world.

Reading Barad's and Abbate's insights together means, for the researcher, to be inseparably entwined with the performative practice and exercise that transforms both Barad's agential real, and Abbate's questioning of musicology's transcendental illusion into a problem of political intensity. Diffractively read, the question can be considered the human dilemma of choosing between (gnostic) freedom, enabling the (musicological) flight from one's own finitude, and the (drastic) musical downfall to the material temporality of earthly circumstances. In other words, something is at stake in which Abbate's concern is relevant to both musicology and humans (as musicologists) when turning to the material and temporal nature of music-as-performed. Barad makes a similar point, albeit one that is not articulated in dualist terms of an impossible choice, but rather as the complexity involved when shifting from classical or Newtonian physics to quantum physics. Classical physics features the 
human perspective as the universal viewpoint, estimating the past and predicting the future by calculation, but excluding both material aliveness and those that are identified as nonhuman. Conversely, quantum physics features material doing as entangled im/possible intra-active mattering caught up in speculation and probability, thus confusing classical calculations of past and future. It announces the "downfall" (to earth) of the human, rendering humans not as pre-existing, but as an inseparable part of the world's matteringthat is, as of an agential real. In other words, shifting the musicological transcendental illusion towards a non-dualist music/ology as knowing and valuing in musical being does not concern a limited effect on a scholarly discipline, but rather constitutes a performative ripple engendering social, cultural, and material effects due to constitutive inclusions and exclusions in all (so-called human, nonhuman, and material) research and theorising. However, this dissertation's scope is necessarily limited-a material-discursive cut-and concerns the inquiry into Barad's agential realism as ontological immanence whilst traversing the Abbatean binary. Further, it questions what this traversal means in terms of music/ological research and theorising.

The pitfalls of the musicological transcendental illusion are challenged by a thorough reading of entrenched dualisms, taking into account responses to, and comments regarding, Abbate's article from 2004 and her later articles from 2016 and 2017, considering a material turn. These responses and comments concern propositions of how to overcome Abbatean binary thinking. These propositions nevertheless start with the oppositional terms (drastic and gnostic) intact, thus initially repeating Abbate's inconvenient truth of a drastic that escapes gnostic reasoning and, therefore, keeping the musicological transcendental illusion intact. Traversing Abbate's (2004) question via encounters with comments from the musicological field, it appeared that experience and phenomenology (Hasty 2010a), despite the suggested interaction between human perception and the world, also fail to bring the two together. Further, Latour's ANT promises a gathering together of human and nonhuman components (Piekut 2014), but struggles with the human as the main conductor - the one who is entitled to link the human and nonhuman hybrid. By widening the "arsenal" and borrowing methods from other disciplines that supposedly enable the 
inclusion of cultural and material diversity in musicological research and theorising (Born 2010a; Cook 2013), the drastic-gnostic dualism is not addressed and thus remains active. Additionally, the aforementioned comments and Abbate's (2016, 2017) material turn leave untouched how one might engage with a material world (beyond visiting the "shop floor") and thus find an answer to human exceptionalism, humanist individualism, objectivism, and transcendence.

A turn to matter and to the pragmatics of making as a way of closing in on material doing bypasses the intricacies of Barad's notion of the in/ separability and intra-activity of phenomenal being. To underline this, the tenor of my argument is that acknowledging the gnostic as unable to stand on its own as a form of human, detached, immaterial reasoning, and thus in need of a material world and differences to support it, only deepens the gap between a predefined material and an immaterial world, leaving the position of the human as sole author unresolved. At the same time, reading Abbate's binary thinking and Barad's thesis of radical immanence diffractively, taking into account the latter's notion of the inseparability of matter and meaning, and how the discursive is material and the material discursive, opens up the complexity involved in musical and musicological mattering. Music and musicology are "doings" that matter, including matters of significance and substance that cannot be torn apart, affirming the absence of any qualitative difference between a material (drastic) real and a symbolic (gnostic) real.

Following the human need to spatialise that which is temporal, as Bergson tells us, Abbate's stalemate position affirms the musicological transcendental illusion and thus prevents access to the study of music-in-the-making. Nonetheless, her plea speaks to musicologists as well as to musicians, both affirming the alleged impossibility of representational access to music. Musicians often find the musicological tone alienating and unable to address that which matters to them-one might use a thousand words, but in the end, it simply comes down to whether you feel the music or not. Similarly, for musicologists, turning to the Abbatean drastic might mean a degradation— to a simple and ordinary craft of making, and of unsayable bodily sensations — which neither explains music nor critiques other thoughts, and thus not interpellating musicology "itself" as a recognised act of 
consistent reasoning. In this sense, a diffractive approach that is responsive to how difference is an effect of differing — not leaving disciplinary musicological groundings untouchedmeans a real shift to a practice of intra-action that does not seek to make music and musicology perfect, but rather opens up to, and is generative of, other intra-actions.

Like this dissertation, I consider Abbate's plea for serious musicological attention to be paid to music-in-the-making as part of a broader movement that envisages both the human position and material dynamism as pressing matters. Due to technological innovations that directly interfere with the very matter of (music and musical) life, demanding reliance on the very technologies used touches on musicology, musical practices, and musical education. As an effect of reading Barad and Abbate diffractively, and also attempting to address such complexity for musicological concerns, I proposed a reconceptualisation of musicality, emphasising the Abbatean inherent touch of the musicomaterial encounter, and the agency and politics of ethicality in Barad's understanding of an ethico-onto-epistemological approach to material-discursive phenomena. I propose that musicality is an embodied concept attuned to the heterogeneous matterings involved in music/ology and music-in-the-making. This reconceptualisation traverses the inherent duality of the common concept in terms of which music is evaluated, implicating a morality of taste or a property, identity, or ability possessed, as well as a general concept of music. To explore intra-active musicality does not involve exploring the encounter as a collision between components and opponents, but entails seeking how a musical and musicological commitment to the rupture of indifference involves a responsive engagement at the heart of mattering. It demands being attuned to the un/ expected and the insensible (here understood as Baradian inhuman matter-meaning relationality), threaded and lived through "us." In other words, my exploration of a concept of musicality seeks a non-anthropocentric and performative notion of musico-material intra-activity through and within which music and music/ology come to matter. Recalling the personal note at the beginning of this dissertation, this reworking of musicality concerns a music/ological approach into musicomaterial mattering, taking account of the so-called provisional and speculative aspects of mattering and not-mattering. Rather than fighting the collision between the drastic and the 
gnostic, it wishes to start by trying, with scholarly inventiveness and imagination, to take a leap into musical "spacetimemattering" and "sing" the present as a congealing of musicality, thus studying how musico-material practices come to matter and are generative of new matterings.

For further research, in the vein of Abbate's and Barad's pleas, I would recommend for today's heated discussions on identity, difference, and inclusiveness—which also play a role in musicological circles-to acknowledge the force that Abbate's extreme dualist proposition based on human exceptionalism continues to have, as demonstrated by her later articles and the aforementioned responses to her plea from 2004. Reading Abbate and Barad together makes Barad's understandings of how difference is an effect of differing and of how ethics is shaped at the heart of mattering even more vital, suggesting how mattering concerns practices of in- and exclusion. Marks on bodies do not disappear; one cannot undo a wrong past, nor heal an anticipated future. Keeping these notions in mind as related to my experience of working with students of music and technology at HKU University of the Arts Utrecht, my recommendations for further research go especially to the effects of and consequences for the algorithmic condition (Colman, Bühlmann, O'Donnell, and Van der Tuin 2018) on music/ology and musico-material mattering-a condition within which musico-material mattering is negotiated through a global, economic networked environment. This suggests that, although the principle of audio technology-recording, back-up, manipulation, (re)play, distribution-has existed for more than a century, the power of computing now heralds new thresholds and new topological concerns. Here I think specifically of how the role of musical practicing and craft has changed, as have the roles of listeners, performers, composers, and producers, and how the algorithmic condition now has an effect on musico-mattering and musical education. My hope is that my reconceptualisation of musicality as a music/ological approach of knowing and valuing in being, contributes to analysing such new musico-material practices, also enabling "us" to be responsive to, and account for, that which is included and excluded from musico-mattering and musico/logical mattering. 


\section{Bibliography}

Abbate, Carolyn. 1996. Unsung Voices. Princeton: Princeton University Press.

Abbate, Carolyn. 2001. In Search of Opera. Princeton: Princeton University Press.

Abbate, Carolyn. 2004. “Music_-Drastic or Gnostic?” Critical Inquiry 30, no. 3: 505-536.

Abbate, Carolyn. 2016. "Sound Object Lessons." Journal of the American Musicological Society 69, no. 3: 793-829.

Abbate, Carolyn. 2017. “Overlooking the Ephemeral.” New Literary History 48, no. 1: 75-102.

Adler, Guido. [1885] 1981. “The Scope, Method, and Aim of Musicology." In Yearbook for Traditional Music, no. 13. Translation and introduction by Erica Mugglestone, 1-21.

Adorno, Theodor W. [1928] 2005. “Schubert." Translated by Jonathan Dunsby and Beate Perry. 19th-Century Music 29, no. 1: 3-14.

Adorno, Theodor W. 2005. In Search of Wagner. Translated by Rodney Livingstone. London: Verso.

Alaimo, Stacy, and Susan Hekman, eds. 2008. Material Feminisms. Bloomington: Indiana University Press.

Aristotle. 1984. "Physics." Translated by J. I. Beare. In The Complete Works of Aristotle: The Revised Oxford Translation, Vol. I, edited by Jonathan Barnes, 315-447. Princeton NJ: Princeton University Press.

Åsberg, Cecilia, Kathrin Thiele, and Iris van der Tuin. 2015. “Speculative Before the Turn: Reintroducing Feminist Materialist Performativity. Cultural Studies Review 21, no. 2: 145-172.

Attali, Jacques. 2006. Noise: The Political Economy of Music. Translated by Brian Massumi. Minneapolis: University of Minnesota Press.

Austin, John Langshaw. 1975. How to Do Things with Words. Edited by J. O. Urmson and Marina Sbisà. Cambridge, MA: Harvard University Press. 
Bal, Mieke. 2006. A Mieke Bal Reader. Chicago: The University of Chicago Press.

Barad, Karen. 1995. “A Feminist Approach to Teaching Quantum Physics.” In Teaching the Majority: Breaking the Gender Barrier in Science, Mathematics, and Engineering, edited by Sue V. Rosser, 43-75. New York: Teachers College Press, Columbia University.

Barad, Karen. 1998. "Getting Real: Technoscientific Practices and Materialization of Reality." Differences: A Journal of Feminist Cultural Studies 10, no. 2: 87-128.

Barad, Karen. 2000. “Reconceiving Scientific Literacy as Agential Literacy.” In Doing Science + Culture, edited by Rodney Reid and Sharon Traweek, 221-258. New York: Routledge.

Barad, Karen. 2001. "Re(con)figuring Space, Time, and Matter." In Feminist Locations: Global and Local, Theory and Practice, edited by M. DeKoven, 75-109. New Brunswick: Rutgers University Press.

Barad, Karen. 2003. "Posthumanist Performativity: Toward an Understanding of How Matter Comes to Matter." Signs: Journal of Woman in Culture and Society 28, no. 3: 801-831.

Barad, Karen. 2007. Meeting the Universe Halfway: Quantum Physics and the Entanglement of Matter and Meaning. Durham, NC: Duke University Press.

Barad, Karen. 2008. "Queer Causation and the Ethics of Mattering." In Queering the Non/Human 2008, edited by Noreen Giffney and Myra J. Hird, 311-338. Aldershot, Hampshire (England): Ashgate Publishing Company.

Barad, Karen. 2010. “Quantum Entanglements and Hauntological Relations of Inheritance: Dis/Continuities, SpaceTime Enfoldings, and Justice-to-Come." Derrida Today 3, no. 2: 240268.

Barad, Karen. 2011. “Erasers and Erasures: Pinch's Unfortunate 'Uncertainty Principle.'” Social Studies of Science 41, no. 3: 443-454.

Barad, Karen. 2012a. “Intra-Actions.” Interview with Karen Barad by Adam Klein. Mousse Magazine and Publishing, no. 34: 76-81.

Barad, Karen. 2012b. "Intra-active Entanglements." Interview with Karen Barad by Malou Juelskjær and Nete Schwennesen. Kvinder, Køn \& Forskning, no. 1-2: 10-25. 
Barad, Karen. 2012c. “Matter Feels, Converses, Suffers, Desires, Yearns and Remembers." Interview with Karen Barad by Rick Dolphijn and Iris van der Tuin. In New Materialism: Interviews and Cartographies, edited by Rick Dolphijn and Iris van der Tuin, 48-71. London: Open Humanities Press.

Barad, Karen. 2012d. “Nature's Queer Performativity.” Kvinder, Køn E Forskning, no. 1-2: 2553.

Barad, Karen. 2012e. “On Touching: The Inhuman that Therefore I Am.” Differences: A Journal of Feminist Cultural Studies 23, no. 3: 206-223.

Barad, Karen. 2012f. What is the Measure of Nothingness? Infinity, Virtuality, Justice. Kassel: Hatje Cantz.

Barad, Karen. 2014. “Diffracting Diffraction: Cutting Together-Apart.” Parallax 20, no. 3: 168187.

Barad, Karen. 2015. “Transmaterialities: Trans / Matter/Realities and Queer Political Imaginings." GLQ: A Journal of Lesbian and Gay Studies 21, no. 2-3: 387-422.

Barrett, Estelle, and Barbare Bolt, eds. 2013. Carnal Knowledge: Towards a "New Materialism" Through the Arts. London: I.B. Tauris \& Co Ltd.

Berger, Karol. 2005. “Musicology According to Don Giovanni, or: Should We Get Drastic?” The Journal of Musicology 22, no. 3: 490-501.

Bergson, Henri. [1889] 1910. Time and Free Will: An Essay on the Immediate Data of Consciousness. Translated by F. L. Pogson. Open Library: Nabu Public Domain Reprints.

Bergson, Henri. [1934] 1946. The Creative Mind. Translated by Mabelle L. Andison. New York: Kessinger Publishing.

Bergson, Henri. [1911] 1998. Creative Evolution. Translated by Arthur Mitchell. New York: Dover Publications.

Bergson, Henri. [1912] 2004. Matter and Memory. Translated by Nancy Margaret Paul and W. Scott Palmer. New York: Dover Publications. 
Bogue, Ronald. 2003. Deleuze on Music, Painting and the Arts. New York: Routledge.

Bohlman, Philip V. 1993. "Musicology as a Political Act.” The Journal of Musicology 11, no. 4: 411-436.

Bohlman, Philip V. 2001. “Ontologies of Music.” In Rethinking Music, edited by Nicholas Cook and Mark Everist, 17-35. Oxford, UK: Oxford University Press.

Bohr, Niels. 1950. "On the Notions of Causality and Complementarity." Science (New Series) 111, no. 2873 (January 20): 51-54.

Bohr, Niels. 1958. Atomic Physics and Human Knowledge. New York: John Whiley \& Sons, Inc.

Bohr, Niels. 1961. "The Quantum Postulate and the Recent Development of Atomic Theory." In Atomic Theory and the Description of Nature, 53-91. Cambridge: Cambridge University Press.

Born, Georgina. 2010a. "For a Relational Musicology: Music and Interdisciplinarity, Beyond the Practice Turn." Journal of the Royal Musical Association 135, no. 2: 205-243.

Born, Georgina. 2010b. “Listening, Mediation, Event: Anthropological and Sociological Perspectives." Journal of the Royal Musical Association 135, no. 1: 79-89.

Born, Georgina. 2010c. “The Social and the Aesthetic: For a Post-Bourdieuian Theory of Cultural Production." Cultural Sociology 4, no. 2: 171-208.

Boulez, Pierre. [1986] 1990. Orientations: Collected Writings. Edited by Jean-Jacques Nattiez. Translated by Martin Cooper. London: Faber and Faber.

Bozalek, Vivienne and Michalinos Zembylas. 2016. “Diffraction or Reflection? Sketching the Contours of Two Methodologies in Educational Research." International Journal of Qualitative Studies in Education 30, no. 2: 111-127.

Braidotti, Rosi. 2000. “The Way We Were: Some Post-Structuralist Memoirs.” Women's Studies International Forum 23, no. 6: 717-728. 
Braidotti, Rosi. 2012. “The Notion of the Univocity of Being of Single Matter Positions

Difference as a Verb or Process of Becoming at the Heart of the Matter." Interview with Rosi Braidotti by Rick Dolphijn and Iris van der Tuin. In New Materialism: Interviews and Cartographies, edited by Rick Dolphijn and Iris van der Tuin, 19-38. London: Open Humanities Press.

Brant Levi, Nick Srnicek, and Graham Harman, eds. 2011. The Speculative Turn: Continental Materialism and Realism. Melbourne: re.press.

Brett, Philip. 2006. "Musicality, Essentialism, and the Closet. In Queering the Pitch: The New Gay and Lesbian Musicology, 2 ${ }^{\text {nd }}$ ed., edited by Philip Brett, Elizabeth Wood and Gary C. Thomas, 9-27. New York: Routledge.

Bühlmann, Vera, Felicity Colman, and Iris van der Tuin. 2017. "Introduction to New Materialist Genealogies: New Materialisms, Novel mentalities, Quantum Literacy." Minnesota Review 88: 47-58.

Butler, Judith. [1990] 2006. Gender Trouble. New York: Routledge.

Butler, Judith. [1993] 2011. Bodies That Matter: On the Discursive Limits of "Sex." New York: Routledge.

Chion, Michel. 2009. Film, a Sound Art. Translated by Claudia Gorbman. New York: Columbia University Press.

Cimini, Amy. 2012. “Vibrating Colors and Silent Bodies: Music, Sound and Silence in Maurice Merleau-Ponty's Critique of Dualism." Contemporary Music Review, no. 31: 353-370. DOI: $10.1080 / 07494467.2012 .759411$

Colebrook, Claire. 2002. Gilles Deleuze. New York: Routledge.

Colebrook, Claire. 2004. "Postmodernism is a Humanism: Deleuze and Equivocity." Women: A Cultural Review 15, no. 3: 283-307.

Colman, Felicity, Vera Bühlmann, Aislinn O'Donnell, and Iris van der Tuin. 2018. Ethics of Coding: A report on the Algorithmic Condition. Brussels: European Commission. 732407, https:/ / cordis.europa.eu/project/rcn/207025 en.html. pp.1-54. Last accessed September 10, 2019. 
Cone, Edward T. 1968. Musical Form and Musical Performance. New York: W.W. Norton and Company.

Cook, Nicholas. 1998. Music: A Very Short Introduction. Oxford, UK: Oxford University Press.

Cook, Nicholas. 2001. “Theorizing Musical Meaning.” Music Theory Spectrum 23, no. 2: 170195.

Cook, Nicholas. 2004. "Computational and Comparative Musicology." In Empirical Musicology" Aims, Methods, Prospects, edited by Eric Clarke and Nicholas Cook, 103-127. Oxford, UK: Oxford University Press.

Cook, Nicholas. 2007. "Performance Analysis and Chopin's Mazurkas." Musicae Scientiae XI, no. 2: 183-207.

Cook, Nicholas. 2012. "Anatomy of the Encounter: Intercultural Analysis as Relational Musicology." In Critical Musicological Reflections: Essays in Honour of Derek B. Scott, edited by Stan Hawkins, 193-209. United Kingdom: Ashgate Publishing Company.

Cook, Nicholas. 2013. Beyond the Score: Music as Performance. Oxford, UK: Oxford University Press.

Cook Nicholas. 2018. Music as Creative Practice: Studies in Musical Performance as Creative Practice. Oxford, UK: Oxford University Press.

Cook, Nicholas and Mark Everist, eds. 2001. Rethinking Music. Oxford, UK: Oxford University Press.

Coole, Diana and Samantha Frost, eds. 2010. New Materialisms: Ontology, Agency, and Politics. Durham, NC: Duke University Press.

Crawford, Hugh T. 1993. "An Interview with Bruno Latour." Configurations 1, no. 2: 247-267.

Critchley, Simon. 2009. Ethics-Politics-Subjectivity. London: Verso.

Cusick, Susanne G. 2001. “Gender, Musicology, and Feminism.” In Rethinking Music, edited by Nicholas Cook and Mark Everist, 471-499. Oxford, UK: Oxford University Press. 
Dahlhaus, Carl. 1983. Foundations of Music History. Translated by J. Bradford Robinson. Cambridge, UK: Cambridge University Press.

Dahlhaus, Carl. 1991. The Idea of Absolute Music. Translated by Roger Lustig. Chicago: The University of Chicago Press.

Dahlhaus, Carl. 2000. “Was ist und wozu studiert man Musikgeschichte?” In Gesammelte Schriften I. Allgemeine Theorie der Musik I. Historik-Grundlagen der Musik-Ästhetik., ["What is and Why do you Study Music History?" In Collected Writings I. General Theory of Music I. History-Foundations of Music_-Aesthetics], edited by Hermann Danuser, Hans-Joachim Hinrichsen and Tobias Piebuch, 196-209. Laaber: Laaber-Verlag.

Daston, Lorraine, and Peter Gallison. 2010. Objectivity. New York: Zone Books.

DeLanda, Manual. 2006. A New Philosophy of Society: Assemblage Theory and Social Complexity. London: Continuum.

Deleuze, Gilles. [1990] 1995. Negotiations. Translated by Martin Joughin. New York: Columbia University Press.

Deleuze, Gilles. 2004. Difference and Repetition. Translated by Paul Patton. New York: Continuum.

Deleuze, Gilles, and Félix Guattari. 1994. What is Philosophy? Translated by Graham Burchell and Hugh Tomlinson. New York: Verso.

Deleuze, Gilles, and Félix Guattari. [1980] 2004. A Thousand Plateaux: Capitalism and Schizophrenia. Translated by Brian Massumi. London: Continuum.

Derrida, Jacques. 1982. Margins of Philosophy. Translated by Alan Bass. Brighton, Sussex: The Harvester Press.

Derrida, Jacques. 1994. Specters of Marx: The State of the Dept, the Work of Mourning, and the New International. Translated by Peggy Kamuf. New York: Routledge. 
Descartes, René. [1641] 1996. Meditations on First Philosophy: With Selections from the Objections and Replies. Translated and edited by John Cottingham. Cambridge, UK: Cambridge University Press.

Dolan, Emily I. 2015. “Musicology in the Garden.” Representation 132: 88-94.

Dolphijn, Rick, and Iris van der Tuin. 2011. “Pushing Dualism to an Extreme: On the Philosophical Impetus of a New Materialism." Continental Philosophical Review 44: 383-400.

Dolphijn, Rick, and Iris van der Tuin. 2012. New Materialism: Interviews and Cartographies. London: Open Humanities Press.

Dolphijn, Rick, and Iris van der Tuin. 2016. “Critical Naturalism: A Quantum Mechanical Ethics." Rhizomes: Cultural Studies in Emerging Knowledge 30: n.p.

https: / / doi.org/10.20415/rhiz/030.e12

Dunsby, Jonathan. 1995. Performing Music: Shared Concerns. Oxford: Oxford University Press.

Eagleston, Robert. 2010. “The 'Ethical Turn' in Continental Philosophy in the 1980s.” In The History of Continental Philosophy, Vol. 7, After Poststructuralism: Transitions and Transformations, edited by Rosi Braidotti, 203-220. Durham, NC: Acumen Publishing Limited.

Evens, Aden. 2005. Sound Ideas: Music, Machines, and Experience. Minneapolis: University of Minnesota Press.

Faucher, Kane X. 2013. Metastasis and Metastability: A Deleuzian Approach to Information. Rotterdam, the Netherlands: Sense Publishers.

Fischer-Lichte, Erika. 2004. Ästhetik des Performativen. Frankfurt am Main: Suhrkamp.

Foucault, Michel. 1972. The Archaeology of Knowledge and the Discourse on Language. Translated by A. M. Sheridan Smith. New York: Pantheon Books.

Foucault, Michel. [1975] 1991. Discipline and Punish: The Birth of the Prison. Translated by Alan Sheridan. London: Penguin Books. 
Foucault, Michel. [1978] 1998. The Will to Knowledge: The History of Sexuality, Vol. 1. Translated by Robert Hurley. London: Penguin Books.

Foucault, Michel. [1970] 2002. The Order of Things: An Archaeology of the Human Sciences. London and New York: Routledge.

Gallope, Michael. 2010. “The Sound of Repeating Life: Ethics and Metaphysics in Deleuze's Philosophy of Music." In Sounding the Virtual: Gilles Deleuze and the Theory and Philosophy of Music, edited by Bryan Hulse and Nick Nesbitt, 1-23. Farnham, UK: Ashgate Publishing limited.

Gallope, Michael. (2016). “Is Improvisation Present?" In The Oxford Handbook of Critical Improvisation Studies, Vol. 1., edited by George E Lewis and Benjamin Piekut, 143-160. Oxford, UK: Oxford University Press.

Gallope, Michael, and Brian Kane, eds. 2012. “Colloquy: Vladimir Jankélévitch's Philosophy of Music." In Journal of the American Musicological Society 65, no. 1: 215-256.

Geerts, Evelien, and Iris van der Tuin. 2016. “The Feminist Futures of Reading Diffractively: How Barad's Methodology Replaces Conflict-Based Readings of Beauvoir and Irigaray." Rhizomes: Cultural Studies in Emerging Knowledge, 30: n.p.

Gendlin, Eugene. 1962. Experiencing and the Creation of Meaning: A Philosophical and Psychological Approach to the Subjective. Evenston: Northwestern University Press.

Godlovitch, Stan. 1998. Musical Performance: A Philosophical Study. New York: Routledge.

Goehr, Lydia. 1992. The Imaginary Museum of Musical Works: An Essay in the Philosophy of Music. Oxford: Oxford University Press.

Grosz, Elizabeth. 1994. Volatile Bodies: Toward a Corporeal Feminism. Indianapolis: Indiana University Press.

Grosz, Elizabeth. 1999. “Thinking the New: Of Futures Yet Unthought.” In Becomings: Explorations in Time, Memory, and Futures, edited by Elizabeth Grosz, 15-29. Ithaca, NY: Cornell University Press. 
Gumbrecht, Hans Ulrich. 2004. Production of Presence: What Meaning Cannot Convey. Palo Alto, CA: Stanford University Press.

Haraway, Donna. 1988. “The Science Question in Feminism and the Privilege of Partial Perspective." Feminist Studies 14, no. 3: 575-599.

Haraway, Donna. 1997.

Modest_Witness@Second_Millennium.FemaleMan@_Meets_OncoMouseTM: Feminism and Technoscience. New York: Routledge.

Haraway, Donna. 2010. “When Species Meet: Staying with the Trouble.” Environment and Planning D: Society and Space 28, no. 1: 53-55.

Haraway, Donna. 2016. Staying with the Trouble: Making Kin in the Chthulucene. Durham, NC: Duke University Press.

Hasty, Christopher F. 1997. Meter as Rhytm. New York: Oxford University Press.

Hasty, Christopher F. 2003. “Hasty Connects Intellectual, Spontaneity: Unabashed, Scholar Brings Intellectual Curiosity to Music's Mystery." Interview with Beth Potier. In The Harvard Gazette, March 13: n.p. https: / / news.harvard.edu/gazette/story/2003/03/hasty-connectsintellect-spontaneity. Last accessed September 10, 2019.

Hasty, Christopher F. 2010a. "If Music is Ongoing Experience, What Might Music Theory Be? A Suggestion from the Drastic." Zeitschrift der Gesellschaft für Musiktheorie (Sonderausgabe): 197-216.

Hasty, Christopher F. 2010b. “The Image of Thought and Ideas of Music." In Sounding the Virtual: Gilles Deleuze and the Theory and Philosophy of Music, edited by Bryan Hulse and Nick Nesbitt, 1-23. Farnham, UK: Ashgate Publishing limited.

Henriques, Julian, Milla Tiainen, and Pasi Väliaho. 2014. “Rhythm Returns: Movement and Cultural Theory." Body \& Society 20, no. 3-4: 3-29.

Hepokoski, James. 1991. “The Dahlhaus Project and Its Extra: Musicological Sources.” Nineteenth-Century Music 14, no. 3: 221-246. 
Hill Collins, Patricia. 2002. Black Feminist Thought: Knowledge, Consciousness, and the Power of Empowerment, $2^{\text {nd }}$ ed. New York: Routledge.

Honing Henkjan, Carel ten Cate, Isabelle Peretz, and Sandra E. Trehub. 2015. “Without It No Music: Cognition, Biology and Evolution of Musicality." Philosophical Transactions B. Royal Society, 370: 1-8. http: / / dx.doi.org/10.1098/rstb.2014.0088

Jankélévitch, Vladimir. 1996. "Do Not Listen to What They Say, Look at What They Do." Translated by Ann Hobart. Critical Inquiry 22, no. 3: 549-551.

Jankélévitch, Vladimir. 2003. Music and the Ineffable. Translated by Carolyn Abbate. Princeton: Princeton University Press.

Jankélévitch, Vladimir. 2008. Henri Bergson. Paris: Presses Universitaires de France.

Jankélévitch, Vladimir. 2015. Henri Bergson. Edited by Alexandre Levebvre and Nils F. Schott. Translated by Nils F. Schott. Durham, NC: Duke University Press.

Kaiser, Birgit Mara, and Kathrin Thiele, eds. 2014. "Diffraction: Onto-Epistemology, Quantum Physics and the Critical Humanities." Parallax 20, no. 3: 165-167.

Kane, Brian. 2012. “The Introduction to 'Vladimir Jankélévitch's Philosophy of Music.'” Journal of the American Musicological Society, 65, no. 1: 215-218.

Kania, Andrew. 2014 (Spring). “The Philosophy of Music.” In The Stanford Encyclopedia of Philosophy, edited by Edward N. Zalta. Palo Alto, CA: Stanford University.

http:/ / plato.stanford.edu/archives/spr2014/entries/music/. Last accessed September 10, 2019.

Kerman, Joseph. 1985. Contemplating Music: Challenges to Musicology. Cambridge, MA: Harvard University Press.

Kirby, Vicki. 2010. “Anthropomorphism, Again.” The New Centennial Review 10, no. 3: 251268.

Kirby, Vicki. 2011. Quantum Anthropologies: Life at Large. Durham, NC: Duke University Press. 
Kirby, Vicki. 2015. “Transgression: Normativity's Self-Inversion.” Differences: A Journal of Feminist Cultural Studies 26, no. 1: 96-116.

Kirby, Vicki. 2017. “Matter out of Place: 'New Materialism' in Review.” In What If Culture Was Nature All Along?, edited by Vicki Kirby, 1-26. Edinburgh: Edinburgh University Press.

Kramer, Lawrence. 1993. "Music Criticism and the Postmodernism Turn: In Contrary Motion with Gary Tomlinson." Current Musicology 53, no. 1: 25-35.

Kramer, Lawrence. 2003. “Musicology and Meaning.” The Musical Times 144, no. 1883: 6-12.

Kramer, Lawrence. 2004. "Music, Metaphor and Metaphysics." The Musical Times 145, no. 1888: 5-18.

Kuhn, Thomas S. [1962] 2012. The Structure of Scientific Revolutions. Chicago: The University of Chicago Press.

Kumar, Manjit. 2008. Quantum: Einstein, Bohr, and the Great Debate about the Nature of Reality. London: Icon Books.

Langer, Susanne K. [1953] 1976. Feeling and Form: A Theory of Art developed from Philosophy in a New Key. London: Routledge \& Kegan Paul Limited.

Latour, Bruno. 1988. The Pasteurization of France. Translated by Alan Sheridan and John Law. Cambridge, MA: Harvard University Press.

Latour, Bruno. 1993a. "Interview with Bruno Latour." Interview by T. Hugh Crawford. Configurations 1, no. 2: 247-267.

Latour, Bruno. 1993b. We Have Never Been Modern. Translated by Catherine Porter. Cambridge, MA: Harvard University Press.

Latour, Bruno. 1999. Pandora's Hope: Essays on the Reality of Science Studies. Cambridge, MA: Harvard University Press.

Latour, Bruno. 2004a. Politics of Nature: How to Bring the Sciences into Democracy. Translated by Catherine Porter. Cambridge, MA: Harvard University Press. 
Latour, Bruno. 2004b. “Why Has Critique Run out of Steam? From Matters of Fact to Matters of Concern." Critical Inquiry 30: 225-248.

Latour, Bruno. 2008. What is the Style of Matters of Concern? Assen, the Netherlands: Royal van Gorkum.

Latour, Bruno. 2011. "Reflections on Étienne Souriau's Les différents modes d'existence." Translated by Stephen Muecke. In The Speculative Turn: Continental Materialism and Realism, edited by Levi Bryant, Nick Srnicek and Graham Harman, 304-333. Melbourne: re.press.

Latour, Bruno and Graham Harman. 2011. The Prince and the Wolf: Latour and Harman at the LSE. Edited by Peter Erdelyi. Alresford, UK: Zero Books.

Leech-Wilkinson, Daniel. 2012. “Compositions, Scores, Performances, Meanings.” Music Theory Online: A Journal of the Society for Music Theory 18, no. 1: 1-17.

Lemke, Thomas. 2015. “New Materialisms: Foucault and the 'Government of Things.'” Theory, Culture and Society 32, no. 4: 3-25.

Levinas, Emmanuel. [1974] 2006. Otherwise than Being or Beyond Essence. Translated by Alphonso Lingis. Pittsburgh, PA: Duquesne University Press.

Loxley, James. 2007. Performativity: The New Critical Idiom. London: Routledge.

Loy, Gareth. 2006. Musimathics: The Mathematical Foundations of Music, Vol. 1. Cambridge, MA: The MIT Press.

Lykke, Nina. 2010. Feminist Studies: A Guide to Intersectional Theory, Methodology and Writing. London: Routledge.

Macarthur, Sally. 2010. Towards a Twenty-First-Century Feminist Politics of Music. Farnham, UK: Ashgate.

MacLure, Maggie. 2013. “The Wonder of Data." Cultural Studies, Critical Methodologies 13, no. 4: $228-232$. 
Massumi, Brian. 2002. Parables for the Future: Movement, Affect, Sensation. Durham, NC: Duke University Press.

Massumi, Brian. 2011. Semblance and Event. Cambridge, MA: The MIT Press.

McClary, Susan. [1991] 2002. Feminine Endings: Music, Gender and Sexuality. Minneapolis: University of Minnesota Press.

McGowan, John, Grégory Leplâtre, and Iain McGregor. 2017. “CymaSense: A Real Time 3D Cymatics-Based Sound Visualisation Tool." In Proceedings of the 2017 ACM Conference Companion Publication on Designing Interactive Systems, June 10, 2017, 270-274. Edinburgh, UK: Edinburgh Napier University. Doi>10.1145/3064857.3079159

McKenzie, Jon. 2001. Perform or Else: From Discipline to Performance. New York: Routledge.

Merleau-Ponty, Maurice. [1962] 2005. Phenomenology of Perception. Translated by Colin Smith. London: Routledge.

Mink, Freya de. 2013. “Musical Prodigies: Past, Present, and Future Perspectives on Exceptional Performance and Creativity." Research Master Thesis, Utrecht University.

Monson, Ingrid. 1996. Saying Something: Jazz Improvisation and Interaction. Chicago: The University of Chicago Press.

Mullarkey, John. 1999. Bergson and Philosophy. Edinburgh: Edinburgh University Press.

Mullarkey, John. 2006. Post-Continental Philosophy: An Outline. New York: Continuum.

Mullarkey, John. 2010. Philosophy and the Moving Image: Refractions of Reality. Basingstoke, UK: Palgrave and MacMillan.

Mullarkey, John, and Anthony Paul Smith. 2012. “The Non-Philosophical Inversion: Laruelle's Knowledge without Domination." Introduction to Laruelle and Non-Philosophy, edited by John Mullarkey and Anthony Paul Smith, 1-18. Edinburgh: Edinburgh University Press.

Newcomb, Anthony. 1984. "Sound and Feeling." Critical Inquiry 10, no. 4: 614-643. 
Omnès, Roland. 1999. Quantum Philosophy: Understanding and Interpreting Contemporary Physics. Translated by Arturo Sangalli. Princeton: Princeton University Press.

Panurgiá, Neni. 2018. “Anthropism/Immanent Humanism.” In Posthuman Glossary, edited by Rosi Braidotti and Maria Hlavajova, 44-45. London: Bloomsbury Academic, Bloomsbury Publishing Plc.

Parker, Patricia. 1992. “Preposterous Events.” Shakespeare Quarterly 43, no. 2: 186-213.

Phelan, Peggy. 2005. Unmarked: The Politics of Performance. New York: Routledge.

Piekut, Benjamin. 2014. "Actor-Networks in Music History: Clarifications and Critiques." Twentieth-Century Music 11, no. 2: 191-215.

Plonowska Ziarek, Ewa. 2001. An Ethics of Dissensus: Postmodernity, Feminism, and the Politics of Radical Democracy. Palo Alto, CA: Stanford University Press.

Puig de la Bellacasa, María. 2011. "Matters of Care in Technoscience: Assembling Neglected Things." Social Studies of Science 41, no. 1: 85-106.

Quin, Ian. 2006. "Minimal Challenges: Process Music and the Uses of Formalist Analysis." Contemporary Music Review 25, no. 3: 283-294.

Rink, John, ed. 1995. The Practice of Performance: Studies in Musical Interpretation. Cambridge, UK: Cambridge University Press.

Rosen, Charles. 1994. “Music à la Mode." The New York Review of Books, June 23, 1994: 1-11.

Schinkel, Willem. 2007. "Sociological Discourse of the Relational: The Cases of Bourdieu and Latour." The Sociological Review 55, no. 4: 707-729.

Schinkel, Willem. 2008. Denken in een tijd van sociale hypochondrie: Aanzet tot een theorie voorbij de maatschappij. Kampen, the Netherlands: Uitgeverij Klement.

Schrader, Astrid. 2012. “Haunted Measurements: Demonic Work and Time in Experimentation." Differences: A Journal of feminist Cultural Studies 25, no. 3: 119-160. 
Schuiling, Floris. 2018. The Instant Composers Pool and Improvisation Beyond Jazz. New York: Routledge.

Serres, Michel. [1985] 2008. The Five Senses: A Philosophy of Mingled Bodies. Translated by Margaret Sankey and Peter Cowley. London: Continuum.

Serres, Michel, and Bruno Latour. 1995. "Third Conversation Demonstration and Interpretation." In Conversations on Science, Culture and Time, 77-123. Ann Arbor: The University of Michigan Press.

Shreffler, Anne C. 2003. "Berlin Walls: Dahlhaus, Knepler, and Ideologies of Music History." The Journal of Musicology 20, no. 4: 498-525.

Small, Christopher. [1987] 1998. Music of the Common Tongue: Survival and Celebration in African American Music. Middletown, Conn.: Wesleyan University Press.

Small, Christopher. 1998. Musicking: The Meanings of Performing and Listening. Middletown, Conn.: Wesleyan University Press.

Souriau, Étienne. 2015. The Different Modes of Existence. Translated by Erik Beranek and Tim Howles. Minneapolis, MN: Univocal Publishing.

Spirkin, Alexander. 1990. Fundamentals of Philosophy. Translated by Sergei Syrovatkin. Moscow: Progress Publishers.

Stengers, Isabelle. 2011. Thinking with Whitehead: A Free and Wild Creation of Concepts. Translated by Michael Chase. Cambridge, MA: Harvard University Press.

Sterne, Jonathan. 2003. The Audible Past: Cultural Origins of Sound Production. Durham, NC: Duke University Press.

Taruskin, Richard. 1995. Text and Act: Essays on Music and Performance. Oxford: Oxford University Press.

Taruskin, Richard. 2005. The Oxford History of Western Music, Vol. 1. Oxford, UK: Oxford University Press. 
Théberge, Paul. 1997. Any Sound You Can Imagine: Making Music/Consuming Technology. Middletown, Conn.: Wesleyan University Press.

Tiainen, Milla. 2017. “Sonic Technoecology: Voice and Non-anthropocentric Survival in The Algae Opera." Australian Feminist Studies 32, no. 94: 359-376.

Tiainen, Milla, and Jussi Parikka. 2013. “The Primacy of Movement: Variation, Intermediality and Biopolitics in Tero Saarinen's Hunt." In Carnal Knowledge: Towards a "New Materialism" Through the Arts, edited by Estelle Barrett and Barbara Bolt, 205-225. London: I.B. Tauris \& Co LtD.

Tomlinson, Gary. 1993. “Musical Pasts and Postmodern Musicologies: A Response to Lawrence Kramer." Current Musicology 53, no. 1: 18-24.

Tomlinson, Gary. 2015. A Million Years of Music: The Emergence of Human Modernity. New York: Zone Books.

Tuin, Iris van der. 2011. "'A Different Starting Point, a Different Metaphysic': Reading Bergson and Barad Diffractively." Hypatia 26, no. 1: 22-42.

Tuin, Iris van der. 2014. "Diffraction as a Methodology for Feminist Onto-Epistemology: On Encountering Chantal Chawaf and Posthuman Interpellation." Parallax 20, no. 3: 231-244.

Tuin, Iris van der. 2016. “Bergson before Bergsonism: Traversing 'Bergson's Failing' in Susanne K. Langer's Philosophy of Art." Journal of French and Francophone Philosophy - Revue de la philosophie française XXIV, no. 2: 176-202.

Wellek, René. 1973. “Zur methodischen Aporie einer Rezeptionsgeschichte.” In Geschichte: Ereignisse und Erzählung, edited by Reinhart Koselleck and Wolf Dieter Stempel, 515-517. München: Fink.

Whitehead, A. N. 1920. The Concept of Nature. Charlestone, SC: Bibliobazaar.

Whitehead, A. N. [1925] 1948. Science and the Modern World: Lowell Lectures. New York: First Pelican Mentor Books Edition.

Whitehead, A. N. [1927-1928] 1985. Process and Reality: An Essay in Cosmology. Edited by David Ray Griffin and Donald W. Sherburne. New York: The Free Press. 
Williams, James. 2008. Gilles Deleuze's Logic of Sense: A Critical Introduction and Guide.

Edinburgh: Edinburgh University Press.

Woodruff Smith, David. 2013a. Husserl, 2 ${ }^{\text {nd }}$ ed. Abington, UK: Routledge.

Woodruff Smith, David. 2013b (Winter). "Phenomenology." In The Stanford Encyclopedia of Philosophy, edited by Edward N. Zalta.

http:/ / plato.stanford.edu/archives/win2013/entries/phenomenology/. Last accessed September 10, 2019.

Zhong Xuan, Liang Sun, and William Yost. 2016. "Active Binaural Localization of Multiple Sound Sources." Robotics and Autonomous Systems 85: 83-92.

Žižek, Slavoj. 2012. Less Than Nothing: Hegel and the Shadow of Dialectical Materialism. London: Verso. 


\section{Summary}

How can we, as musicologists, know the social, material, and dynamic reality of musical performance? This question recurs throughout this dissertation, both as a musicological and as a philosophical problem, albeit each time in a different form, depending on the emphasis on ontological, epistemological, ethical, or aesthetic aspects of music-as-performed. In order to gain insight into the breadth of this question, I am, first and foremost, led by the problem articulated by the musicologist Carolyn Abbate in her 2004 essay “Music—Drastic or Gnostic?"

Abbate's question closely resembles the epistemological problem posed above and is directed towards knowing the dynamic reality of musical performance. However, Abbate confronts musicological performance research with an oppositional difference between being (that is, drastic and unstable) and knowing (gnostic and stable). She concludes that the musicologist is unable to capture the dynamic reality of performance in either thought or language, because he/she cannot simultaneously be present at the performance and conceptualise the process of performing and everything that accompanies it. Drawing upon the reaction of Karol Berger on Abbate's question and on the work of the philosopher Vladimir Jankélévitch and his emphasis on Bergsonian phenomenology, I deconstruct in chapter 1 Abbate's question and its elaboration. This offers me the possibility to approach this philosophical and musicological problem on my own terms in the chapters that follow.

In chapter 2, I engage with the work of several musicologists who have responded to Abbate's question. The arguments of Christopher Hasty, Georgina Born, and Benjamin Piekut offer me the opportunity to further explore the separation between knowing and being by studying the phenomenological, process-philosophical, sociological, and philosophy-of-science aspects of current musicological studies investigating musical performance. I conclude that, although the aforementioned musicologists theorise the complex relationship between knowing and being, they are unable to traverse the drasticgnostic dichotomy.

In order to explore a possible solution to Abbate's problem, I then read her argumentation together with physicist and feminist theorist Karen Barad's metaphysics of an 
agential real in chapter 3. This metaphysics assumes an ontology of radical immanence, focussing on how matter and meaning are inherently tied together. "Things" and "thoughts" come into being as effects of matter-meaning relations through intra-actions-relatings through and within which all forms of being come into existence in their specificity, including "us." Agential realism implies a radical epistemological and ontological shift towards a non-dualistic and performative approach. This permits a non-reductive study of musical performance that undermines a representationalist two-world logic, but requires a thorough reworking of established scientific ideas of objectivity, subjectivity, and causality.

Finally, in chapter 4, I elaborate on Barad's ethical conception of valuing as an inextricable part of intra-actions in a case study on musicality. I propose a notion of musicality that emphasises the many musico-material encounters (valuing and touching) in the course of the musical event as a form of creativity through responsivity. As such, musicality does not present a standard for assessing values, nor does musicality as morality imply a prescription of "good" or "correct" music. Whilst a complete theory of musicality exceeds the scope of this dissertation, I demonstrate how my reworking of musicality is an effect of diffractively reading the insights of Abbate and Barad together. Rather than unravelling dualisms, this performative, intra-active research practice demonstrates music/ology at work, inviting us to study the musico-onto-epistemological dynamics of matter-meaning relations that produce specific music and knowledge, and to study how music and knowledge are generative of new matter-meaning relations. 


\section{Samenvatting}

Hoe kunnen wij, musicologen, de sociale, materiële en dynamische werkelijkheid van de muziekuitvoering kennen? Deze vraag keert, als musicologisch en filosofisch probleem, bij voortduring terug in deze dissertatie, weliswaar in een steeds andere vorm al naar gelang de nadruk ligt op ontologische, epistemologische, ethische en esthetische aspecten van muziekin-de-uitvoering. Om inzicht te krijgen in de reikwijdte van de vraag laat ik me in de eerste plaats leiden door het probleem dat musicologe Carolyn Abbate in 2004 opwerpt in haar essay “Music-Drastic or Gnostic?”

Abbate's vraag lijkt op de ken-vraag zoals ik hem hierboven stelde en is gericht op het kennen van de dynamische werkelijkheid van de muziekuitvoering. Abbate confronteert het musicologische uitvoeringsonderzoek echter met een breuk tussen zijn (drastisch en instabiel) en kennen (gnostisch en stabiel). Ze concludeert dat de musicoloog de dynamische werkelijkheid van de uitvoering niet in gedachten en taal kan vatten, omdat hij of zij niet tegelijkertijd aanwezig kan zijn bij de uitvoering én het proces van de uitvoering en alles wat daarmee gepaard gaat kan conceptualiseren. Gebruikmakend van de reactie van Karol Berger op de vraag van Abbate en het werk van Vladimir Jankélévitch, met zijn Bergsoniaanse fenomenologische benadering, door Abbate aangehaald, deconstrueer ik in het eerste hoofdstuk Abbate's vraag en haar uiteenzetting.

In hoofdstuk twee ga ik in op het werk van een aantal musicologen die op Abbate's vraag gereageerd hebben. De argumenten van Christopher Hasty, Georgina Born en Benjamin Piekut geven me de gelegenheid om de complexe relatie tussen kennen en zijn verder uit te diepen via fenomenologische, proces-filosofische, sociologische en wetenschapsfilosofische aspecten van het huidige musicologische uitvoeringsonderzoek. Mijn conclusie is dat hoewel de genoemde musicologen de complexe relatie tussen kennen en zijn weliswaar in kaart brengen, ze er niet in slagen de bestaande dichotomie te doorbreken.

Om een mogelijke oplossing voor Abbate's probleem te onderzoeken, lees ik haar argumentatie vervolgens samen met de metafysica van een agentieve werkelijkheid zoals uitgewerkt door natuurkundige en feministisch theoreticus Karen Barad (hoofdstuk drie). 
Deze metafysica gaat uit van een ontologie van radicale immanentie die gericht is op de inherente verbondenheid van materie en betekenis. "Dingen" en "gedachten" ontstaan als effecten van materie-betekenisrelaties door intra-acties - een relateren waardoor en waarbinnen alle zijnsvormen, met inbegrip van "ons," ontstaan met al hun specifieke eigenschappen. Een agentieve werkelijkheid impliceert een radicale epistemologische en ontologische verschuiving naar een non-dualistische en performatieve benadering. Dit laat een niet-reductieve studie van de muziekuitvoering toe die de representationalistische tweewereldenlogica ondermijnt. Daarbij noodzaakt deze benadering een grondige verandering van ingesleten wetenschappelijke ideeën over objectiviteit, subjectiviteit en causaliteit.

Tenslotte werk ik Barads ethische begrip van waarderen als onlosmakelijk deel van intra-acties uit in het specifieke geval van muzikaliteit (hoofdstuk vier). Ik stel een begrip van muzikaliteit voor dat de vele musico-materiële ontmoetingen (waarderingen en aanrakingen) in de muzikale gebeurtenis benadrukt als creativiteit door responsiviteit. Als zodanig houdt muzikaliteit geen norm in voor het beoordelen van waarden, noch impliceert muzikaliteit een moraliteit als voorschrift voor "goede" en "juiste" muziek. Hoewel ik in deze dissertatie geen volledige theorie van muzikaliteit kan presenteren, demonstreer ik hoe deze bewerking van muzikaliteit een effect is van mijn diffractieve lezing van de inzichten van Barad en Abbate. Deze performatieve, intra-actieve onderzoekspraktijk demonstreert music/ologie-aan-het-werk, die ons uitnodigt om, in plaats van het uitpluizen van dualismen, de dynamiek te bestuderen van materie-betekenisrelaties waaruit specifieke muziek en kennis ontstaan en te bestuderen hoe muziek en kennis generatief zijn voor nieuwe materie-betekenisrelaties. 


\section{Curriculum vitae}

Jantje (Jannie) Pranger is a mezzo-soprano who specialises in performing twentieth-century and twenty-first-century music. She began her singing career in 1986. Her farewell concert was in 2012. In 2004, she started studying musicology at Utrecht University and graduated from the Research MA programme in musicology in 2008. In 2010, she began her PhD research at the Institute for Cultural Inquiry (ICON) of Utrecht University. During that time Jannie presented papers at international conferences in Denmark, the Netherlands, and the United States, including a "vocalecture" at the NOISE Summer School at Utrecht University in 2013. Jannie has published in the Tijdschrift van de Koninklijke Vereniging voor Nederlandse Muziekgeschiedenis (2012) and is a contributor to the forthcoming volume Voicing New Materialisms, edited by Elisabeth Belgrano, Magdalena Górska, and Milla Tiainen. She currently works as an independent lecturer and holds a tenured teaching position at the School for Music and Technology at the HKU University of the Arts Utrecht. 